\author{
UNIVERSIDADE DE SÃO PAULO \\ FACULDADE DE FILOSOFIA, LETRAS E CIÊNCIAS HUMANAS \\ DEPARTAMENTO DE LÍNGUA E LITERATURA FRANCESA \\ PROGRAMA DE PÓS-GRADUAÇÃO EM LETRAS (LÍNGUA E LITERATURA FRANCESA)
}

\title{
CONSIDERAÇÕES SOBRE O VALOR RESTRITIVO NO BINÔMIO “NE... QUE” EM FRANCÊS MODERNO
}

Teresa Cristina Silveira Hilst

Dissertação apresentada ao Programa de PósGraduação em Letras (Língua e Literatura Francesa), do Departamento de Língua e Literatura Francesa da Faculdade de Filosofia, Letras e Ciências Humanas da Universidade de São Paulo, para obtenção do título de Mestre em Letras.

Orientadora: Profa. Dra. Tokiko Ishihara

São Paulo

2007 


\section{UNIVERSIDADE DE SÃO PAULO}

FACULDADE DE FILOSOFIA, LETRAS E CIÊNCIAS HUMANAS DEPARTAMENTO DE LÍNGUA E LITERATURA FRANCESA PROGRAMA DE LETRAS (LÍNGUA E LITERATURA FRANCESA)

\section{CONSIDERAÇÕES SOBRE O VALOR RESTRITIVO NO BINÔMIO “NE... QUE” EM FRANCÊS MODERNO}

Teresa Cristina Silveira Hilst 
AUTORIZO A REPRODUÇÃO E DIVULGAÇÃO TOTAL OU PARCIAL DESTE TRABALHO, POR QUALQUER MEIO CONVENCIONAL OU ELETRÔNICO, PARA FINS DE ESTUDO E PESQUISA, DESDE QUE CITADA A FONTE.

\section{Catalogação na Publicação}

Serviço de Documentação

Faculdade de Filosofia, Letras e Ciências Humanas da Universidade de São Paulo

Hilst, Teresa Cristina Silveira

Considerações sobre o valor restritivo no binômio "ne... que" em francês moderno / Teresa Cristina Silveira Hilst; orientadora Tokiko Ishihara - São Paulo, 2007.

214f.

Dissertação (Mestrado - Programa de Pós-Graduação em Língua e Literatura Francesa. Área de concentração: Língua e Literatura Francesa - Faculdade de Filosofia, Letras e Ciências Humanas da Universidade de São Paulo.
1. Gustave Guillaume
2. psicomecânica
3. francês
4. negação
5. restrição 
A todos aqueles que, de uma forma ou de outra, contribuíram para que eu chegasse até aqui. 


\section{Agradecimentos}

A Profa. Dra. Tokiko Ishihara pelo enorme voto de confiança em mim depositado.

A Profa. Dra. Isabel Gretel M. E. Fernández pelo primeiro incentivo para a realização desta pesquisa.

Aos Professores M. Jacques Ouellet, Jean-Guy Lebel, Dr. Louis Jolicoeur, Dr. Patrick Duffley, Dra. Diane Vincent e Dr. Manuel Español-Echevarría da Faculdade de Letras da Universidade Laval, Quebec, Canadá, pelas discussões e orientações dadas.

A Geneviève Boudreau, Valérie Tremblay, Karina Jannini, Marcelo L. Santoro e Aline Lima por suas valiosas contribuições para esta pesquisa.

A Faculdade de Filosofia, Letras e Ciências Humanas, Universidade de São Paulo, pela oportunidade de realização do curso de mestrado.

Ao Departamento de Letras Modernas da FFLCH, Universidade de São Paulo pelo apoio e pela ajuda a mim dados.

A Faculdade de Letras, Universidade Laval, Quebec, Canadá, pela oportunidade de realização de cursos de mestrado.

Ao Departamento de Línguas, Lingüística e Tradução, Faculdade de Letras, Universidade Laval, pelo apoio e pela ajuda a mim dados.

A minha família pelo apoio e pela paciência durante esse período.

A todos os meus amigos por continuarem o sendo. 
"Sou a somatória de todas as pessoas que conheci e de todas as experiências que vivi.” (Autor desconhecido) 


\section{FOLHA DE APROVAÇÃO}

\section{Teresa Cristina Silveira Hilst}

Considerações sobre o valor restritivo no binômio “ne... que” em francês moderno

Dissertação apresentada à Faculdade de Filosofia, Letras e Ciências Humanas da Universidade de São Paulo, para obtenção do título de Mestre.

Área de Concentração: Letras (Língua e Literatura Francesa), do Departamento de Língua e Literatura Francesa

Aprovada em: 03 de agosto de 2007

\section{Banca Examinadora}

Profa. Dra. Vera Lúcia Marinelli

Instituição: Faculdade de Educação da Universidade de São Paulo

Assinatura:

Prof. Dr. Alain Marcel Mouzat

Instituição: Faculdade de Filosofia, Letras e Ciências Humanas da Universidade de São Paulo Assinatura:

Profa. Dra. Tokiko Ishihara

Instituição: Faculdade de Filosofia, Letras e Ciências Humanas da Universidade de São Paulo Assinatura: 


\section{SUMÁRIO}

RESUMO

$\begin{array}{ll}\text { Abstract } & 11\end{array}$

INTRODUÇÃO 12

1. TEMA E JUSTIFICATIVA 13

2. Problematização 16

CAPÍTULO I - REVISÃo DA LITERATURA

1. ETIMOLOGia 18

2. NEGAÇÃO E RESTRIÇÃo

$\begin{array}{ll}\text { 2.1. NEGAÇÃO } & 21\end{array}$

2.2. RESTRIÇÃO

2.2.1. O BINÔMIO “NE... QUE”

SÍNTESE DAS TEORIAS SOBRE ‘NE... QUE” 46

CONCLUSÃO SOBRE O BINÔMIO “NE... QUE” 56

2.2.2. OS BINÔMIOS “SANS QUE”, “RIEN QUE”, “BIEN QUE”,

“AUTRE QUE”, “NUL AUTRE QUE” E “POUR PEU QUE” 57

CAPÍTULO II - QUADRO TEÓRICO 63

1. TeORIA DE Gustave Guillaume 63

2. Estudo de Prof. M. Jacques Ouellet 68

2.1. O CONCEITO E SUAS RELAÇÕES SINTAGMÁTICAS 70

2.2. RELAÇÕES SINTÁTICAS

CAPÍTULO III - ANÁlise DO CORPUS

1. Metodologia 83

2. CORPUS JORNALÍSTICO 83

3. ANÁLISE

3.1. SEgUNDO PAILlaRd (1992) 84

3.2. SEGUNDO OUELLET (2004) 86

$\begin{array}{ll}\text { 3.3. EXEMPLOS } & 87\end{array}$ 
CONSIDERAÇÕES FINAIS 143

BIBLIOGRAFIA

$\begin{array}{ll}\text { ANEXos } & 155\end{array}$

Anexo A - Resultados do QUESTIONÁRIO APLICAdo NO CURSO THÉORIE ET PRATIQUE DE LA TRADUCTION, FACULDADE DE LETRAS,

UNIVERSIDADE LAVAL 156

ANEXo B - CORPUS Do “LE PETIT ROBERT” 160

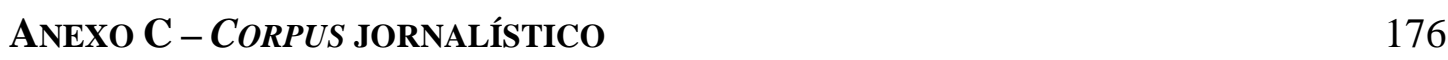

ANEXO D - DEFINIÇÕES DE “APENAS” E “SOMENTE” 270 


\section{RESUMO}

HILST, T. C. S. Considerações sobre o valor restritivo no binômio “ne... que” em francês moderno. 2007. 273f. Dissertação (Mestrado) - Faculdade de Filosofia, Letras e Ciências Humanas, Universidade de São Paulo, São Paulo, 2007.

As gramáticas normativas, as descritivas e as semânticas, assim como outras obras que tratam sobre a negação e sobre a restrição em francês moderno, descrevem as expressões "ne... que”, "sans que”, "rien que”, "bien que”, "autre que”, "nul autre que” e "pour peu que” em diversos quadros teóricos sem descreverem seus valores semânticos, suas naturezas verdadeiras e as funções de "que” distinguindo seu valor dos que a ele estão associados. Este estudo, fundamentado nos princípios da teoria psicomecânica de Gustave Guillaume (1971, 1973), expandido pelas considerações semântico-gramaticais elaboradas pelo Prof. M. Jacques Ouellet (2004) e aplicando as categorias de Paillard (1992) tenta identificar, compreender e explicar o funcionamento do “que” restritivo encontrado nas expressões acima, principalmente na de “ne... que”. Observamos que o movimento de transferência da restrição da expressão "ne... que” para o seu forclusivo verificado pelos autores consultados na negação já foi registrado por Grevisse: “Que puis-je prendre ici QUE l'occasion de la détresse à laquelle je cédai[...] ? (GIDE, Poerte étr., VII).”1 Percebemos que para nós, lusófonos, o termo "somente" em português indica valor concessivo, positivo e os termos “apenas” e "só”, valores restritivos, negativos. Para Boudreau e Tremblay, assim como para nós, houve alto índice de exemplos do tipo B, segundo os critérios de Paillard, onde só um dos termos, "ne... que” ou "seulement”, é possível. Os exemplos analisados parecem indicar uma incidência maior de atributo do suporte passivo do verbo, segundo os critérios de Ouellet, chamado tradicionalmente de objeto direto em relação às outras funções sintáticas.

Palavras-chave: Gustave Guillaume - psicomecânica - francês - negação - restrição

\footnotetext{
${ }^{1}$ GREVISSE, M. Le bon usage. 13e edição, 6 reimpressão. Paris: Duculot, 2006, p. 1455.
} 


\begin{abstract}
HILST, T. C. S. Considerations about the restrictive value of the "ne... que" binomial in modern French. 2007. 273p. Dissertation (Master of Arts) - Faculty of Philosophy, Letters and Human Sciences, University of São Paulo, São Paulo, 2007.

Prescriptive, descriptive and semantic grammars, as well as other works dealing with negation and restrictions in modern French, describe the expressions ne... que, sans que, rien que, bien que, autre que, nul autre que and pour peu que by a variety of theoretical approaches without describing their semantic values, their very nature and the functions of que. Moreover, these works do not distinguish the value of que from those associated with it. This study, founded on the principles of psychomechanic theory elaborated by Gustave Guillaume (1971, 1973) and expanded by grammatical semantic studies made by Prof. Jacques Ouellet, M.A. (2004) and applying Paillard`s categories (1992) tries to identify, understand and explain the functioning of restrictive que, found in the above-mentioned expressions, especially in ne... que. We observed that the transfer movement of the restriction of the expression ne... que for its forclusive verified by the authors consulted in negation was already registered by Grevisse: “Que puis-je prendre ici QUE l'occasion de la détresse à laquelle je cédai[...] ? (GIDE, Poerte étr., VII)." ${ }^{2}$ We realized that for the Lusophones the term somente in Portuguese indicates a concessive positive value and the terms apenas and só indicate restrictives negatives values. Boudreau, Tremblay and us obtained a high number of Paillard's B examples where only one term is possible, ne... que or seulement. The analyzed examples seem indicate more cases of passive support attribute of verb as Ouellet's category, traditionally called direct object instead the other syntactic functions.
\end{abstract}

Keywords: Gustave Guillaume - psychomechanic - french - negation - restriction

\footnotetext{
${ }^{2}$ GREVISSE, M. Le bon usage. $13^{\mathrm{e}}$ edição, $6^{\mathrm{e}}$ reimpressão. Paris: Duculot, 2006, p. 1455.
} 


\section{INTRODUÇÃO}

O interesse pelo tema da pesquisa, o binômio " "ne... que"4, surgiu durante o aprendizado e o ensino da língua francesa moderna. Em primeiro lugar, chamou-nos a atenção o fato de a explicação apresentada nos métodos de ensino de francês ${ }^{5}$ ser tão simplificada e exígua, sendo retomada apenas por Gomes, Gruneber e Job (1995a, p. 90; 1995b, p. 32; 1996, p. 67) ${ }^{6}$ em várias ocasiões. Em segundo, o fato de o binômio começar com uma partícula de negação “ne”, ser apresentado como afirmação restritiva e classificado nos advérbios de negação por vários gramáticos e lingüistas conceituados. Em terceiro, a experiência de ensino a alunos $^{7}$ da área de Humanas, principalmente em Filosofia e Sociologia, mostrou-nos que a partícula "ne” induzia o aluno a erro, na medida em que era lia como negação do complemento, e não como exclusão do complemento da negação.

Alguns passos foram projetados, a longo prazo, para a execução do estudo do tema: (i) verificação da viabilidade da pesquisa (monografia no curso de Metodologia de Ensino de Francês, Faculdade de Educação, Universidade de São Paulo); (ii) pertinência do tema para lusófonos (projeto de ingresso no mestrado, Faculdade de Letras, Universidade de São Paulo); (iii) pertinência do tema para francófonos (projeto apresentado para professores das áreas de Lingüística Gerativista, de Lingüística Semântica e de Tradução da Faculdade de Letras, Universidade Laval); (iv) execução da pesquisa em si, seguindo linhas teóricas aconselhadas

\footnotetext{
${ }^{3}$ Chamaremos “ne... que” de binômio, visto que não há concenso entre os estudiosos sobre ele ser uma locução ou uma expressão, como veremos no capítulo II. O termo "binômio” foi escolhido no intuito de mostrar a existência de uma relação entre as duas partículas que o formam. Os termos “locução” e “expressão” serão usados de acordo com os autores em discussão.

${ }^{4}$ Grifos nossos aparecerão em negrito e do(s) autor(es) em itálico ou sublinhado.

${ }^{5}$ AUGÉ, H. et al. Tout va bien! 2 - livre de l’élève. Paris: Clé International, 2005. 167p., p.75; CAPELLE, G.; CAVALLI, M.; GIDON, N. Fréquence jeunes 1 - livre de l'élève. Vanves: Hachette F.L.E., 1994. 160p., p.67; CAPELLE, G.; GIDON, N. Le Nouvel Espaces 1 - Livre de l’élève. Vanves: Hachette F.L.E., 1995. 206p., p.127; GIRARDET, J.; CRIDLIG. Panorama 1 - Livre de l’élève. Paris: Clé International, 2000. 191p., p.121; GIRARDET, J.; PÉCHEUR, J. Campus 1 - Livre de l'élève. Paris: Clé International, 2002, p.135; POISSONQUINTON, S.; SALA, M. Initial 2 - livre de l'élève. Paris: Clé International, 2000. 126p., p.81; TREVISI, S. et al. Café Crème 2 - Livre de l'élève. Vanves: Hachette F.L.E., 1997. 192p., p.96.

${ }^{6}$ Foi adotado o sistema de referência autor-data conforme a ABNT NBR 10520.

${ }^{7}$ Alunos do curso de francês inscritos na escola CAVC - Idiomas do Centro Acadêmico Visconde de Cairu, da Faculdade de Economia e Administração da Universidade de São Paulo.
} 
pelos professores, visando a um posterior estudo comparativo do emprego das expressões restritivas nas traduções (dissertação de mestrado); (v) viabilidade e estudo comparativo das soluções encontradas por tradutores para as traduções de três autores contemporâneos (um francês, um brasileiro e um americano) nas outras duas línguas (tese de doutoramento).

Por ocasião de uma bolsa de estudos para professores de francês em Quebec, Qc, Canadá, oferecida pela Associação dos Professores de Francês do Estado de São Paulo em conjunto com o Consulado do Canadá no Brasil, verificamos junto a francófonos a pertinência do tema a ser estudado. Queríamos verificar se o binômio "ne... que” colocava os mesmos problemas a eles ou era apenas uma impressão de uma não-nativa, no caso, lusófona, com os problemas de aprendizado em decorrência da similaridade “ne x não”. Obtivemos indícios afirmativos com o seminário apresentado na disciplina Théorie et pratique de la traduction, da Faculdade de Letras, da Universidade Laval (Anexo A), que justificava plenamente, a nosso ver, a continuidade do estudo com a aplicação de questionário, com exemplos e suas traduções, a alunos anglófonos, francófonos e lusófonos para a verificação da recepção dos mesmos.

\section{TEMA E JUSTIFICATIVA}

O tema em estudo é o binômio "ne... que” e suas interpretações. Como apresentado no item anterior, a mola motivadora do estudo foi a dificuldade de alunos brasileiros em apreender o valor atribuído ao binômio pelos métodos de ensino. A primeira barreira constituía-se na simplificação da explicação "ne... que" = "seulement”, de valor neutro. Um número considerável ${ }^{8}$ de alunos a lia como negação do complemento devido à partícula "ne", cuja presença induzia o aluno a erro: "ne = negação do complemento". Mesmo quando a lia como restrição ou exclusão do complemento da negação, o aluno não a considerava como de valor neutro, mas sim como julgamento de valor, em geral negativo (ex.: “Je n'ai fait que

\footnotetext{
${ }^{8}$ Não é possível precisar a quantidade, pois não foi realizada nenhuma coleta de dados nesse sentido, mas houve um número suficiente para chamar nossa atenção para o problema.
} 
l'exercice cinq.” $\Rightarrow$ o aluno ficou aquém do esperado). Constatou-se então uma primeira linha de pesquisa em aquisição de língua.

A partir dessa experiência, outra linha de pesquisa foi-se delineando, a da tradução. Os estudiosos verificados nesta pesquisa em geral atribuem-lhe valor neutro, o mesmo do advérbio "seulement". Cremos ser essa atribuição equivocada pelo fato de o advérbio “seulement” possuir um valor etimológico positivo. Sendo assim, um estudo preliminar em tradução foi realizado. Traduzimos exemplos retirados dos primeiros 10\% das páginas de cada letra do Dictionnaire alphabétique et analogique de la langue française (1981), também conhecido como Le Petit Robert (Anexo B). Constatamos nessa ocasião que nem sempre o binômio "ne... que" foi traduzido por "somente", e a cada escolha feita emitiu-se julgamento de valor em relação ao tema exposto no texto pelo binômio escolhido em substituição ao advérbio "somente".

Além do dicionário, fizemos um levantamento nos primeiros $10 \%$ das páginas ${ }^{9}$ das seguintes obras: Les Mots, de Jean-Paul Sartre (1964), Les Possédés, Adaptation, de Albert Camus (1962), Mémoires de Guerre: le Salut, de Charles de Gaulle (1959), e La Poétique de L'Espace, de Gaston Bachelard (1961), todas disponibilizadas pelo Projet American and French Research on the Treasury of the French Language (ARTFL) da Universidade de Chicago nos Estados Unidos nos endereços eletrônicos:

<www.lib.uchicago.edu/efts/ARTFL/philologic/manual.html>, $<$ www.lib.uchicago.edu/efts/ARTFL/databases/TLF/>.

\footnotetext{
${ }^{9}$ Esse valor aleatório de $10 \%$ foi estabelecido visando a manter certa proporcionalidade entre as obras escolhidas, nada mais do que isso.
} 
Para cada autor, encontramos o número de ocorrências abaixo:

\begin{tabular}{|l|c|c|c|c|}
\hline & Bachelard & Camus & De Gaulle & Sartre \\
\hline ne... que & 92 & 48 & 689 & 67 \\
\hline sans que & 17 & 7 & 222 & 23 \\
\hline rien... que & 6 & 7 & 120 & 11 \\
\hline bien... que & 36 & 26 & 312 & 20 \\
\hline autre... que & 14 & 10 & 186 & 22 \\
\hline Nul autre... que & 0 & 0 & 0 & 0 \\
\hline pour peu... que & 0 & 0 & 11 & 0 \\
\hline Peu... que & 4 & 1 & 47 & 7 \\
\hline
\end{tabular}

Após a verificação do material de pesquisa, da bibliografia e da pertinência, iniciamos a busca de uma linha de pesquisa.

Num segundo momento, começamos a leitura de estudos já efetuados, dando origem à presente "Revisão da literatura”. Verificamos que, para se efetuar qualquer análise do binômio “ne... que”, deveríamos conhecer os conceitos atribuídos às classificações feitas, “advérbio”, “advérbio de negação”, “pronome”, “pronome relativo”, “pronome indefinido”, “conjunção”, “conjunção subordinada”, “introdutor”, etc. Os termos assim utilizados ainda correspondiam aos seus conceitos originais ou a metalinguagem utilizada já havia "evoluído” e não mais correspondia aos conceitos anteriores? Assim começamos o capítulo da "Revisão da literatura” que, com o passar das leituras, foi-se detalhando cada vez mais. Pretendemos obter uma conclusão a partir desses conceitos e estabelecer relações com os conceitos sugeridos pelo Prof. M. Jacques Ouellet (2004), baseados na teoria psicomecância de Gustave Guillaume (1971, 1973), cuja linha de pesquisa seguimos para desenvolver esta dissertação. 


\section{Problematização}

Como o “que” é uma palavra que marca conceitos de naturezas diferentes exercendo funções diferentes, segundo gramáticas normativas e semânticas, o problema é identificar, compreender e explicar o funcionamento do "que” restritivo encontrado nas expressões "ne... que”, "sans que”, “rien que”, "bien que”, “autre que”, "nul autre que” e "pour peu que”.

Enquanto alguns gramáticos e lingüistas classificam o "que” restritivo como advérbio ou conjunção usada com valor restritivo, outros o classificam como "négation exceptive ou exclusive”. Apesar dessa classificação, não sabemos qual o elo entre a natureza do "que”, suas funções e seu valor restritivo. É o “que” que tem valor restritivo ou o termo ao qual está associado (“ne”, “sans”, “rien”, “bien”, “autre”, "nul autre” e “pour peu”)?

Na realidade, o "que” com valor restritivo é estudado sob diferentes pontos de vista, e às vezes são-lhe atribuídas naturezas diferentes, mas sem se definir sua função restritiva como tal. Conseqüentemente, não há consenso sobre sua natureza, suas características e sobre o que o diferencia do “que” não-restritivo.

Enfim, tentaremos estabelecer quais são os valores semânticos expressos pelo "que” restritivo em francês segundo sua natureza e suas funções distinguindo seu valor das unidades a ele associadas.

Com esse intuito, primeiramente para estabelecermos a revisão da literatura, faremos uma revisão das gramáticas e dos estudos de várias naturezas nos quais os empregos do "que” restritivo foram estudados e as obras que versam sobre a restrição e a negação. Estas obras servem de referência e possuem um importante leitorado. Num segundo momento, exporemos o quadro teórico escolhido para a análise de nosso objeto de estudo, um desenvolvimento a partir da teoria psicomecânica de Gustave Guillaume (1971, 1973). Finalmente, analisaremos e classificaremos o "que" encontrado nos exemplos de uso restritivo, fornecido pelo corpus composto pelas gramáticas e pelos estudos consultados, pelo Dictionnaire alphabétique et analogique de la langue française, também conhecido como "Le Petit Robert", e por artigos coletados nos jornais eletrônicos franceses Le Monde e Libération durante o mês de julho de 2006 (Anexo C). 


\section{CAPÍTULO I}

\section{REVISÃO DA LITERATURA}

Este capítulo foi concebido para verificar o estado da questão em diversas linhas teóricas, já que estas fazem referência a um leitorado importante, composto por estudiosos da área e leigos. Objetivamos: (a) levantar a etimologia das partículas "ne” e "que”; (b) verificar como a negação e a restrição foram conceituadas; e (c) constatar como a expressão "ne... que” é definida por estudiosos da língua francesa. Esperamos encontrar, na etimologia das partículas formadoras do binômio "ne... que”, indícios que nos ajudem a compreender seu comportamento. Na verificação dos diversos conceitos adotados para negação e restrição pelos diversos gramáticos e lingüistas, esperamos compreender: (i) o vínculo, se o há realmente, entre as partículas "ne” e “que”; (ii) havendo vínculo entre ambas, se elas mantêm o mesmo sentido individual, quando apenas somandas, ou se formam um terceiro sentido e em que medida. Durante o processo de investigação do vínculo entre as partículas “ne” e "que”, consultamos obras que tratam do francês, do francês moderno, da subordinação, da relativa, da interrogação direta e indireta, dos pronomes interrogativos e relativos e dos advérbios.

Para alcançarmos esses objetivos, consultamos gramáticas e estudos de várias linhas teóricas, tentando averigüar a coerência terminológica dentro de uma mesma linha teórica e entre diferentes linhas. A escolha dessas linhas deveu-se ao leitorado importante de cada uma. Há realmente diferença entre as linhas ou a nomenclatura mudou mas o conceito é o mesmo? 


\section{ETIMOLOGia}

Ao longo dos anos, o significado das partículas "ne" e "que” foi alterado. Segundo Dauzat, Dubois e Mitterand ${ }^{10}$ (1993),

“*ne 842, Serments (non); fin IXe s., Cantilène sainte Eulalie (no); 980, Valenciennes (ne); forme proclitique du lat. Non (v. non). \| nenni 1130, Chanson de Guillaume (nenil); XVe s., G. (nenny); de nen il (forme atone de non), avec le verbe faire sous-ent., phrase servant de réponse négative. (v. oui.)”

De acordo com Bloch e Wartburg ${ }^{11}$ (1989),

“ne. Lat. nõn avec un développement partic. Devant consonne dû à la position proclitique de ce mot accessoire; v. non, L'a. fr. a eu en outre une forme nen devant voyelle, cf. nennil. It. non, no, esp. no, a. pr. non devant voyelle, no devant consonne. Ne ne s'emploie en combinaison avec des particules telles que pas, point, etc., qu'en gallo-roman; ne tend aujourd'hui à disparaître dans les parlers pop. au profit de ces particules plus expressives et qui portent l'accent, surtout au profit de pas. Pour ne au sens de "ni”, v. ni."

Clédat $^{12}$ (1947) nos mostra que:

"Ne et non sont les adverbes latins ne (ni- comme prefixe dans nihil, v. annihiler) et non = ne unum, cf. allemand nein; le latin ne est apparent à innegative (v. en $1^{\circ}$ ) et à $a$ - préfixe privative. Nul est le latin nullum, formé de ne et d'un derive de unum, ullum, il a produit nullité, annuler, annulation. Nenni est formé de non et du pronom il, cf. oui au mot ce, pronom ${ }^{1}$.

A côté de ne, le latin avait nec, conjonction négative représentée en français moderne par ni; c'était jadis ne, conserve dans la locution archaïque "ne plus,

\footnotetext{
${ }^{10}$ DAUZAT, A.; DUBOIS, J.; MITTERAND, H. Dictionnaire Étymologique et historique du français. Paris: Larousse, 1993, p. 502.

${ }^{11}$ BLOCH, O.; WARTBURG, W. Dictionnaire Étymologique de la Langue Française. $8^{\mathrm{a}}$ edição. Paris: Presses Universtaires de France, 1989, p. 428.

${ }^{12}$ CLEDAT, L. Dictionnaire Étymologique de la Langue Française. Paris: Librairie Hachette, 1947, p. 440.
} 
ne moins”. Le latin nec est prefixe dans négliger, v. lire ${ }^{4}$, et dans négoce, v. oiseux. Il est Racine dans negare (supin negatum), devenu nier, derive: niable, composés: dénier, d’où déni et indéniable, et renier; dérivés et composés savants: négatif, négation, dénégation, rénégat, "qui a renié”, abnégation, renoncement. - Sur néant et ses dérivés, voy. être ${ }^{1}$."

Observamos nesse momento que a partícula "ne” possuía e ainda possui um valor de negação originado no latim, perdendo um pouco de sua força para as partículas complementares que formam a negação em francês moderno: “pas”, "point”, "guère”, “plus", etc. Esse movimento de transferência de "força”, a saber, a negação que se concentrava na partícula “ne” e passou a concentrar-se nas partículas complementares no francês moderno, faz-nos pensar no conceito de negação de Gustave Guillaume ${ }^{13}$ (1973) que veremos mais adiante.

Quanto à partícula “que”, Dauzat, Dubois e Mitterand ${ }^{14}$ (1993) apresentam:

“1. que pron. V. qui.

2. *que conj., IX ${ }^{\mathrm{e}}$ s., sainte Eulalie; lat. quia, parce que (devenu qui, puis que).

que adv. exclamatif 980, Passion; de que, conj.”

“*qui, que, quoi 842, Serments (qui, que); 1080, Roland (quei); lat. qui (d’abord nominatif masc. Sing. Et plur.; au IV ${ }^{\mathrm{e}}$ s., forme commune masc., fém, et neutre) et cui (datif sing., employé comme cas régime après prép. jusqu’au $\mathrm{XIII}^{\mathrm{e}}$ s., puis confondu avec le précédent); que est derive du lat. quem (acc. masc. sing., devenu forme commune du régime direct); quoi est derive du lat. quid. || quiconque 1160, Benoit; d'un anc. qui qu'onques, “qui... jamais”, influencé par le lat. quicumque, de même sens, d'où la graphie en un seul mot et sans s adverbial. || quoique 1080, Roland (que, que); XII s., Delb. (quoi que).”

\footnotetext{
${ }^{13}$ GUILLAUME, G. Leçons de linguistique de Gustave Guillaume 1948-1949 : Grammaire particulière du français et grammaire générale (IV). Québec : Les Presses de l’Université Laval / Paris : Librairie C. Klincksieck, 1973.

${ }^{14}$ DAUZAT, A.; DUBOIS, J.; MITTERAND, H., Dictionnaire Étymologique et historique du français. Paris: Larousse, 1993, p. 637-638.
} 
Para Bloch e Wartburg ${ }^{15}$ (1989):

“Que, conj. It. che, esp. a. pr. que. Le lat. du Bas-Empire avait la tendance de simplifier le système des conjonctions, p. ex.: il a laissé tomber peu à peu ut. La conj. favorite était quod, mais depuis le $\mathrm{IV}^{\mathrm{e}}$ s. quia s'étend de plus en plus au détriment de quod. Par la suite quia est simplifié de deux façons: qui devant voyelle, qua devant consonne. Qua vit sous la forme $c a$ au moyen âge en Italie, en Sardaigne, en Espagne, et d'y est conserve dans beaucoup de dialectes. Qui vit surtout en gallo-roman, dans l'Italie centrale, mais aussi en ibero-roman. Son fréquent usage l'affaiblit en que (bien attesté dans les textes dp. VIII ${ }^{\mathrm{e}}$ s.), de sorte qu'il en vient phonétiquement à s'identifier avec le pron. relatif quem et même souvent à s'écrire quem. De là le fr. que, le toscan (d'où it.) che, cat. esp. port. que."

Segundo Clédat ${ }^{16}$ (1947), “que” é derivado de “qui”:

"Qui nominatif, que accusatif, est le latin qui nominatif, quem accusatif. Quiconque, latin quicumque, signifie: celui qui, quel qu'il soit, cf. quelconque, à quel. Le latin avait aussi un datif cui, qui est arrivé à se confondre avec la forme du nominatif, et qui est l'origine de notre pronom relatif qui après une préposition et du pronom interrogatif complément direct. Le latin avait encore, entre autres formes, un neutre quid, qui est devenu notre pronom neutre interrogatif à double forme, que et quoi (cf. me et moi), et notre pronom neutre exclamatif que, qui signifie: 'Quelle quantité! En quelle quantité, combien!'

Notre conjonction que n’est pas autre chose qu’un emploi spécial du pronom relatif neutre: 'Je crois qu'il vient' équivaut à 'Je crois ce que (je vais dire): il vient'. Cf. quia.

Le pronom neutre interrogatif que équivaut parfois à l'autre forme, quoi, précédée de pour: ‘Que ne vient-il?’ Quid a la même valeur en latin.

\footnotetext{
${ }^{15}$ BLOCH, O.; WARTBURG, W. Dictionnaire Étymologique de la Langue Française. $8^{\text {a }}$ edição. Paris: Presses Universitaires de France, 1989, p. 524.

${ }^{16}$ CLEDAT, L. Dictionnaire Étymologique de la Langue Française. Paris: Librairie Hachette, 1947, p. 540.
} 
En latin classique, quid était la forme interrogative et quod la forme relative du neutre, de là 'mettre um quid pro (pour) quod', devenu: faire un quiproquo, prendre une chose ou une personne pour une autre.

Le mot quidam est un mot tout latin (pronom qui + le suffixe d'indétermination-dam), qui équivaut à ‘quelqu’un', voy. Quel.

Le pronom latin qui se trouve à l'origine des mots car, cote, comme, quand, quant, quel, quia, quasi, voy. ces différents mots et quibus, quorum.”

Não observamos até o momento nenhuma menção a "que” com valor restritivo nos dicionários etimológicos consultados. Esse fato sugere que uma de nossas hipóteses, a de que as partículas “ne” e “que” separadas possuem significados diferentes, quando juntas formam um terceiro independente.

\section{NEGAÇÃO E RESTRIÇÃO}

\subsection{NEGAÇÃO}

A negação por si só já é merecedora de um estudo à parte, como realizou Gaatone ${ }^{17}$ (1971), por exemplo, na sua obra Étude Descriptive du système de la négation en français contemporain. Verificamos divergência filosófica, entre os autores pesquisados quanto à definição do que venha a ser uma asserção, que se manifesta no uso de “afirmação" por “asserção"18 (CHARAUDEAU, 1992, p. 551). Levando-se em conta a dificuldade para definir-se a "negação” e, a partir dela, a “restrição”, que utiliza o binômio “ne... que” para manifestar-se, observamos outra dificuldade, a de classificação experimentada pelo citado binômio. Talvez caiba aqui uma nova abordagem em sua explicação, visto que ele se inicia com a partícula “ne” tradicionalmente ligada à negação. Tentaremos expor esse ponto de

\footnotetext{
${ }^{17}$ GAATONE, D. Étude descriptive du système de la négation en français contemporain. Genebra: Librairie Droz, Publication romanes et françaises, 1971.

${ }^{18}$ CHARAUDEAU, P. Grammaire du sens et de l'expression. Paris: Hachette Éducation, 1992.
} 
vista, mesmo que apenas brevemente, no intuito de levantar hipóteses que nos ajudem a esclarecer o binômio em estudo.

Mauger $^{19}$ (1968) não define a negação, apenas a apresenta do modo como é realizada em francês moderno: partículas, posição e uso.

Segundo Damourette e Pichon ${ }^{20}$ (1939), a negação em francês é formada por duas partículas, sendo elas “ne” e seu possível par “pas”, “jamais” e “rien”. Historicamente, explicam-nos os autores, a negação francesa originou-se da partícula "ne” derivada do latim $n \tilde{n} n^{21}$. Conjectura-se que, devido à sua característica monossilábica e monofônica [n], passouse a reforçá-la com palavras puramente afirmativas, "pas” (do latim passus, passo) ${ }^{22}$ (ROBERT électronique, 1997, PAS), “rien” (do latim ren, coisa) ${ }^{23}$, “jamais” (do latim jam, já, + magis, mais) $)^{24}$, e que, devido à evolução natural da transferência de valor, a tendência seria abandonar a partícula “ne” e conservar o seu par, seja ele “pas”, “rien”, seja “jamais”. Explicação essa também fornecida por Grevisse ${ }^{25}$ (2006). Porém, essa explicação histórica não satisfaz Damourette e Pichon ${ }^{26}$ (1939) por não contemplar os valores do taxiema "ne" quando só ou em presença de “que” e quando não totalmente negativo nem completamente afirmativo ou positivo. Os autores sugerem estudos individuais das partículas acima mencionadas, dos quais surgirão negações parciais e negações plenas, como é o caso de "ne... pas”, “ne... rien” e "ne... jamais”, que são exemplos das intersecções dos dois grupos de taxiemas, "ne” e “pas”, "ne” e "rien”, “ne” e "jamais"27.

De acordo com Damourette e Pichon (1939), há três gêneros de empregos da partícula “ne”. O primeiro com as partículas complementares “pas”, “rien”, “jamais” etc. (partículas forclusivas) forma a negação banal:

\footnotetext{
${ }^{19}$ MAUGER, G. Grammaire pratique du français d'aujourd'hui. Paris: Librairie Hachette, 1968, p. 373-378.

${ }^{20}$ DAMOURETTE, J.; PICHON, E. Des mots à la pensée: essai de grammaire de la langue française, 19111927. Paris: D'artrey, 1939, t.I, v. II, c. VII, p. 130.

${ }^{21}$ Id., ibid., p. 130.

${ }^{22}$ ROBERT, P. Le Petit Robert version électronique. Paris : Dictionnaires Le Robert, 1997. 1 CD-ROM.

${ }^{23}$ Id., ibid., RIEN.

${ }^{24}$ Id., ibid., JAMAIS.

${ }^{25}$ GREVISSE, M. Le bon usage. $13^{\mathrm{e}}$ edição, $6^{\mathrm{e}}$ reimpressão. Paris: Duculot, 2006, p. 1447.

${ }^{26}$ DAMOURETTE, J.; PICHON, E., 1939, op. cit., p. 130.

${ }^{27}$ Id., ibid., p. 130-131.
} 
“Depuis une heure que je cherche ma casquette, je ne peux pas me rappeler où je l'ai mise.

(Courteline, Les Linottes, II, p. 61)

Nous respirons, notre cœur bat, nous n'y pensons pas, nous ne sentons rien.

(Gil Robin. La femme et la Lune. VI, p. 65)

Quand elles sont méritantes, je ne néglige jamais l’occasion de récompenser mes servantes.

(Thomas Raucat. L'Honorable Partie de Campagne, V, p. 113).”28

O segundo com a partícula “que” forma a negação de exceção, na qual é excluído da negação o complemento que segue essa última partícula: “Claudia? fit le père. C’est vrai, elle n'a que moi et il m'en coûte de la quitter. (Jacques Bainville. Jaco et Lori. V, p. 114),29. Finalmente, o terceiro gênero inclui diversos casos isolados nas subordinadas. Devido a este último gênero, os autores nomearam a partícula "ne” de discordancial, pois acreditam que apresente um conflito entre o que o sujeito deseja ou espera e o que é possível de acontecer ${ }^{30}$.

“Son petit cousin se présentait au cercle. Il craignait qu’il ne fût blackboulé.

(A. France. Les Lys rouge. XII, p. 172)”31

A negação dessa discordância é feita com a negação do verbo da oração principal, no caso "craindre":

“Louis ne craint pas qu’Elisabeth parte”32

ou no caso do verbo "ne pas douter”, no qual podemos encontrar ou não o discordancial:

“... sa parfaite connaissance de Venise, grâce à laquelle je ne doutais pas qu’il ne m'eût découvert un logis à ma convenance.”

“Je ne doutai point que l'amour causât ces douleurs.””33

\footnotetext{
${ }^{28}$ DAMOURETTE, J.; PICHON, E. Des mots à la pensée: essai de grammaire de la langue française, 19111927. Paris: D'artrey, 1939, t.I, v. II, c. VII, p. 130.

${ }^{29}$ Id., ibid., p. 131.

${ }^{30}$ Id., ibid., p. 131.

${ }^{31}$ Id., ibid., p. 132.

${ }^{32}$ Id., ibid., p. 133.

${ }^{33}$ Id., ibid., p. 133.
} 
Segundo os autores, o emprego do discordancial após a negação da primeira oração deve-se à intenção de corrigir a agressividade da negação ${ }^{34}$.

Concluindo segundo Damourette e Pichon (1939a), a negação na língua francesa moderna envolve dois conjuntos de taxiemas independentes que se podem intersectar formando-a. A negação é então composta de duas partes: o discordancial, que mostra a incompatibilidade do fato negado com todos os fatos possíveis contidos nesse grupo; e o forclusivo, que afirma que o fato negado não aparece de forma alguma no seu campo de conhecimento, a saber, a negação completa ${ }^{35}$. Essa idéia de independência dos dois grupos é apresentada no exemplo fornecido pelos autores, no qual ambos os taxiemas estão presentes, mas não constituem uma negação de sentido:

“Et la discipline y régnait, impérieuse autant et plus qu'elle $n$ 'avait jamais fait dans aucune armée du roi de Prusse. (Claude Farrère. Les condamnés à mort. I. 3, p. 13)”36

Nesse caso, ainda segundo os autores, o forclusivo é amplo, mas o discordancial não é geral, pois essa disciplina que reinava nas forças armadas da Prússia não o era nas forças americanas às quais C. Ferrère se referia ${ }^{37}$.

Assim sendo, é através dessa forma de relação entre o discordancial e o forclusivo que os autores explicam, como veremos no item 2 a seguir, a expressão "ne... que”.

Essa idéia de discordancial e forclusivo defendida por Damourette e Pichon (1939) lembra-nos a de Gustave Guillaume (1973) que veremos a seguir.

Segundo Grevisse ${ }^{38}$ (2006), há várias formas de negar-se em francês: com um verbo com sentido negativo, "refuser"; com a preposição "sans"; com a locução conjuntiva subordinativa "sans que”; com a conjunção coordenativa “ni”; com as frases-palavras “non”, “ni”; com os prefixos a-, in- (asocial, impossible), além dos primeiros advérbios de negação

\footnotetext{
${ }^{34}$ DAMOURETTE, J.; PICHON, E. Des mots à la pensée: essai de grammaire de la langue française, 19111927. Paris: D'artrey, 1939, t.I, v. II, c. VII, p. 134.

${ }^{35}$ Id., ibid., p. 144.

${ }^{36}$ Id., ibid., p. 144.

${ }^{37}$ Id., ibid., p. 144.

${ }^{38}$ GREVISSE, M. Le bon usage. $13^{\mathrm{e}}$ edição, $6^{\mathrm{e}}$ reimpressão. Paris: Duculot, 2006.
} 
“non” e “ne”39. A partícula "ne” em geral é acompanhada por “pas”, “point”, “aucun”, “aucunement”, “guère”, “jamais”, “nul”, “nullement”, “personne”, “plus”, “que” ou “rien”, ou por uma das expressões “âme qui vive”, “que ce soit”, “quoi que ce soit”, “de ma vie”, “de (tel temps)”, “de longtemps”, “nulle part” etc. ${ }^{40}$. Esse acompanhamento surgiu como reforço à idéia de negação da partícula "ne”. Inicialmente de valor positivo, "pas”, “point”, “mie”, “goutte”, “mot”, “noix” etc. adquiriram conotação negativa por contágio/transferência, deixando assim o seu valor original: "pas" = passo; "point" = ponto ${ }^{41}$. "Pas" e "point" são as duas partículas conservadas atualmente na negação, as outras se perderam no tempo, segundo o autor, mas “point” exprime negação mais forte que a expressa por "pas" ${ }^{42}$. Grevisse (2006) classifica como absolutas as negações formadas com advérbios ou palavras que se tornaram advérbios, “pas”, “point”, “nullement” e “aucunement”, e como relativas as formadas com os determinantes indefinidos ou com os pronomes indefinidos (“aucun”, “nul”, “personne”, “rien”), ou ainda com os advérbios (“guère”, “jamais”, “plus”, “nulle part”) ${ }^{43}$.

Gaatone $^{44}$ (1971), em seu Étude descriptive du système de la négation en français contemporain, estuda, em um corpus composto por obras literárias do século XX, jornais, obras científicas e revistas diversas, a negação na sua forma escrita. Segundo o autor, não existe apenas uma forma de negar em francês, mas sim várias, todas agrupadas sob a rubrica “negação”. Sugere ainda o termo négatifs (negativos) para abarcar todas as formas de negação que trazem a mesma informação que "pas” (p.ex.: in-, non) ${ }^{45}$ e que não são negações plenas, mas contêm “certaines affinités de sens entre tous ces termes où il s'agit toujours plus ou moins d'une quantité nulle»46.

Na primeira parte de sua obra, analisa o que chama de morfemas da negação

\footnotetext{
${ }^{39}$ GREVISSE, M. Le bon usage. $13^{\mathrm{e}}$ edição, $6^{\mathrm{e}}$ reimpressão. Paris: Duculot, 2006 p. 1445-1448.

${ }^{40}$ Id., ibid., p. 1451-1454.

${ }^{41}$ Id., ibid., p.1447-1448; 1461-1463.

42 Id., ibid., p. 1451-1452.

43 Id., ibid., p. 1451-1454.

${ }^{44}$ GAATONE, D. Étude descriptive du système de la négation en français contemporain. Genebra: Librairie Droz, Publication romanes et françaises, 1971, p. 8.

${ }^{45}$ Id., ibid., p. 8.

${ }^{46}$ Id., ibid., p. 133.
} 
propriamente dita - a negação prefixal, o "non” e os funcionamentos de "pas / ne... pas" e “point/ne... point”; na segunda, o “ne” e as marcas redundantes da negação - os funcionamentos de “ne”, “de” e "ni”; na terceira, as palavras e os grupos de palavras pertencentes ao sistema de negação sintáxica - os funcionamentos de “jamais/ne... jamais”, "plus/ne... plus”, “guère/ne... guère”, “nullement, aucunement/ne... nullement, aucunement”, “nulle part/ne... nulle part”, “personne/ne... personne”, “rien/ne... rien”, “aucun/ne... aucun”, "pas un/ne pas un”, “nul/ne... nul”, "sans/sans... que”; e finalmente, na quarta parte, os termos satélites da negação - locuções adverbiais e pronomes. $\mathrm{O}$ funcionamento de “que/ne... que” está no apêndice 1 da obra ${ }^{47}$.

Gaatone (1971) parece compartilhar as idéias de J. Marouzeau e sobretudo de H. Frei: “J. Marouzeau ${ }^{48}$ et H. Frei ${ }^{49}$ ont observé qu’on préfère souvent en français un mot ou un énoncé négatif à un mot ou à un énoncé positif porteur du même sens (ainsi pas riche, pas malin, pas propre, pas bon, pas joli, etc...). Le premier voit là un emploi lié à une appréciation subjective, donc affectif, stylistique, alors que le second y voit l'effet du besoin d'invariabilité transformant deux mots entièrement différents (bon/mauvais) en une opposition régulière (bon/pas bon). ${ }^{50}$

Vislumbramos na divisão de seu livro o que ele considera como negação "real”, chamada de "négation proprement dite: in-, non, pas, point" ${ }^{\text {. }}$. Segundo esse conceito, a negação propriamente dita no par "ne... pas" recai sobre "pas" ${ }^{52}$, e não como os outros autores aqui citados o crêem, porque em francês moderno a partícula "pas” é suficiente para negar termos não-verbais incorrendo na supressão da partícula “ne” mesmo na língua culta:

“Moi, dit Moulû, je pourrais pas rester chez moi, ça me donnerait le cafard.

\footnotetext{
${ }^{47}$ GAATONE, D. Étude descriptive du système de la négation en français contemporain. Genebra: Librairie Droz, Publication romanes et françaises, 1971, p. 227-237.

${ }^{48}$ J. Marouzeau, Notre langue, Paris: Bibliothèque des chercheurs et des curieux, 1955, p. 165, apud GAATONE, 1971, p. 7.

${ }^{49}$ H. Frei, Grammaire des fautes, Paris: Geuthner, 1929, p.157, apud GAATONE, 1971, p. 7

${ }^{50}$ GAATONE, 1971, op. cit., p. 7.

${ }^{51}$ Id., ibid., p. 9.

${ }^{52}$ Id., ibid., p. 47.
} 
(97, p. 247)” (SARTRE, 1949 apud GAATONE, 1971, p. 47) ${ }^{53}$

Gaatone discorda de Damourette e Pichon (1939) no que concerne a vários exemplos de omissão do “ne”, que não são explicados e admitidos como tal pelos autores, e ao conceito de progresso da negação:

"Il nous semble en revanche que les cas d'emploi de ne discordantiel s'expliquent par son conditionnement automatique dans quelques contextes bien définis et, exceptionnellement, dans des contextes proches des premiers par la structure et le sens. Les cas d'omission sont dus, à notre avis, aux hésitations des usagers de la langue dans l'emploi d'un élément linguistique sans fonction distinctive et peu stable." ${ }^{54}$

O autor compartilha a idéia de H. Frei ${ }^{55}$ (1929 apud GAATONE, 1971, p. 9) de ser a negação “contaminante” em vários graus dos termos positivos vizinhos a ela, aos quais dá o nome de termos satélites que não ocupam um lugar determinado no estudo gramatical, mas encontram-se dispersos em várias partes das gramáticas.

De acordo com Gaatone ${ }^{56}$ na conclusão de sua obra, "ne... pas” e sua variante "pas” constituem no francês moderno a negação absoluta, isto é, a negação do predicado, enquanto “in-” e "non”, as negações de termos particulares do enunciado. Acredita que a partícula "ne” tem em francês moderno um papel secundário e redundante na negação em vias de desaparecimento, como visto em vários casos de hesitação de seu uso nos exemplos da língua oral por ele estudados.

"Par ailleurs, son omission fréquente à certains niveaux de langue, même comme élément de redondance de la négation, aura pour résultat de rompre le lien principal unissant pas à tous les autres termes négatifs et par là, d’ôter à la négation dans son sens large, son caractère de système syntaxique.(...) [dans la langue parlée] Pour cette dernière, avec l'affaiblissement progressif de ne et

\footnotetext{
${ }^{53}$ SARTRE, J.P. La Mort dans l'âme. Paris: Gallimard, 1949, 293p. apud GAATONE, 1971, p. 47.

${ }^{54}$ GAATONE, $D$. Étude descriptive du système de la négation en français contemporain. Genebra: Librairie Droz, Publication romanes et françaises, 1971, p. 9.

${ }^{55}$ Id., ibid., p. 50.

${ }^{56}$ Id., ibid., p. 206.
} 
des autres marques de la négation $d e, n i$, il devient difficile de parler de la négation en tant que système grammatical. On ne peut plus y voir en réalité qu'un ensemble de termes apparantés uniquement par leur valeur de quantité nulle, donc seulement sur le plan sémantique.”57

Segundo Buyssens ${ }^{58}$ (1975), sob o ponto de vista do sentido, a negação não age sobre o significado do verbo, nem sobre o tempo verbal, nem sobre o modo, como também não age sobre o tipo de frase, seja ela assertiva, interrogativa, seja de desejo. A negação age sobre o fato real ou irreal. Sendo assim, outros advérbios não considerados de negação podem exercer essa função. O autor dá como exemplo “Tu n’es pas allé à la reunion. - J’y suis bien allé, mais tu n’y étais plus”, no qual “bien” serve para negar a negação e constitui uma anti-négation.

Já podemos observar que não há um consenso sobre o que vem a ser um advérbio e qual é o de negação. Isso traz um problema para a expressão "ne... que”, geralmente classificada como tal.

De acordo com Arrivé, Gadet e Galmiche ${ }^{59}$ (1986), sob o ponto de vista dos estudos da língua natural, a negação é freqüentemente descrita como fenômeno semântico derivado da lógica na qual a negação equivale à "inversion de la valeur de vérité” ${ }^{60}$ enquanto sob o ponto de vista gramatical o termo "negação" é composto de palavras que geram esse mesmo valor semântico. Os autores recomendam a subordinação do aspecto gramatical ao semântico por ser este último o significado da negação, “une donnée relativement stable de l'intuition linguistique” ${ }^{\prime}$.

Sendo a negação definida a partir de uma relação lógica, ela incide sobre a proposição

\footnotetext{
${ }^{57}$ GAATONE, D. Étude descriptive du système de la négation en français contemporain. Genebra: Librairie Droz, Publication romanes et françaises, 1971, p. 206-207.

${ }^{58}$ BUYSSENS, E.; ROSETTI, A. (org.) La classification des adverbes. Revue roumaine de linguistique. Editura Academiei Republicii Socialiste România, Bucareste, vol. 20, n 5, p.461-463,1975, p. 462.

${ }^{59}$ ARRIVÉ, M., GADET, F., GALMICHE, M. La grammaire d'aujourd'hui: guide alphabétique de linguistique française. Paris: Flammarion, 1986, p. 396.

${ }^{60}$ Id., ibid., p. 396.

${ }^{61}$ Id., ibid., p. 397.
} 
inteira: se P é verdadeiro, então não-P é falso (ex.: "Paul est venu/Paul n'est pas venu"62). Embora essa consideração possa ser feita, ela não exclui outras interpretações como no exemplo dado pelos autores, “les élèves n’ont pas cassé les vitres”, no qual cabe a interpretação de os alunos terem quebrado outra coisa que não os vidros, ou não os terem quebrado, mas sim sujado ${ }^{63}$. Há formas de contornar essa ambigüidade, seja pela focalização (ex.: “ce ne sont pas les élèves qui...”64), seja pelo uso do prefixo “non” (ex.: "il a choisi un exemple non littéraire” ${ }^{65}$ ) ou dos prefixos “im-”, “ir-” (ex.: “imprévisible, irréversible”66). No uso da negação pode-se, segundo os autores, fazê-la de forma implícita (ex.: “il n’a pas vu

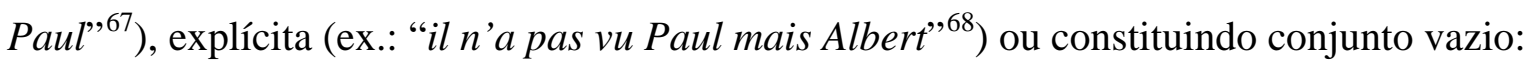

“personne pour les humains: il n'a pas vu personne; rien pour les non animés: il n'a rien vu; nulle part pour un syntagme locatif: il ne se sent bien nulle part; jamais pour un syntagme à valeur temporelle: il n'est jamais venu (...) ne... aucun pour diverses spécifications (...): aucun chat noir n'est méchant. Ne... plus (...) la continuité temporelles: il ne va plus au cinéma; ne... guère (...) exclusion partielle: il ne va guère au cinéma; il n’y avait guère d'élèves." 69

Segundo Wagner e Pinchon ${ }^{70}$ (1991), a negação pode ser simples (ex.: “non”) ou composta (ex.: “ne... jamais”), atribuir uma negação total (ex.: “ne”) ou parcial (ex.: “jamais”). Os advérbios compostos apresentam um termo constante "ne” e outro variável que modula a intensidade e o alcance da negação (“pas” e "point” para negações plenas e “jamais”, “plus” e “que” para negações parciais) $)^{71}$. Notamos aqui uma diferença com relação

\footnotetext{
${ }^{62}$ ARRIVÉ, M., GADET, F., GALMICHE, M. La grammaire d'aujourd'hui: guide alphabétique de linguistique française. Paris: Flammarion, 1986., p. 397.

${ }^{63}$ Id., ibid., p. 397.

${ }^{64}$ Id., ibid., p. 397.

${ }^{65}$ Id., ibid., p. 397.

${ }^{66}$ Id., ibid., p. 397.

${ }^{67}$ Id., ibid., p. 397.

${ }^{68}$ Id., ibid., p. 397.

${ }^{69}$ Id., ibid., p. 397-398.

${ }^{70}$ WAGNER, R. L.; PINCHON, J. Grammaire du français classique et moderne. Paris : Hachette Supérieur, 1991.

${ }^{71}$ Id., ibid., p. 418.
} 
a Damourette e Pichon ${ }^{72}$, que crêem serem negações plenas “pas”, “rien” e "jamais”. São exemplos de negação plena ou total as expressões “ne... pas”, “ne... point”, “ne... guère”, “ne... jamais”, “ne... plus”, “ne... rien”, e de negação parcial "ne”73. A negação total não implica nem limitação nem restrição exclusiva, mas a parcial $\operatorname{sim}^{74}$. A negação parcial limitada tem como representantes as expressões adverbiais “ne... guère”, "ne... jamais”, “ne... plus" porque agem sobre um determinante do verbo ou sobre um atributo ${ }^{75}$. Finalmente, a negação parcial “ne... que” é restritiva porque exclui da negação toda pessoa, toda coisa ou todo fato representados após o termo "que"76.

Riegel, Pellat e Rioul ${ }^{77}$ (1994) atribuem a negação a um tipo lógico de frase, para negar ou refutar, em oposição à afirmação ${ }^{78}$. Como os autores citados, Riegel, Pellat e Rioul (1994) atribuem duas partículas para a formação da negação, “ne” e "pas”, “plus”, “jamais” (advérbios de negação), “personne”, “rien” (pronomes), “aucun” (determinante). Para os autores, a negação pode variar segundo o registro de língua e a distinção entre oral e escrito (omissão da partícula “ne” no oral) ${ }^{79}$.

Quando definida como o oposto de um ato real (na dimensão lexical: "petit/grand; cher/pas cher"), a negação mostra ter muitas interpretações diferentes do sentido inverso (nas dimensões gramaticais e semânticas). Os termos negativos "ne” e "pas” são tradicionalmente classificados como advérbios, mas, na realidade, são muito diferentes deles [devido à sua posição na frase (podem ocupar diferentes posições: Maintenant, il pleut, ou Il pleut maintenant), ao sentido temporal (maintenant), espacial (ici, là), por exemplo] e funcionam

\footnotetext{
${ }^{72}$ DAMOURETTE, J.; PICHON, E. Des mots à la pensée: essai de grammaire de la langue française, 19111927. Paris: D'artrey, 1939, t. I, v. II, c. VII, p. 131.

${ }^{73}$ WAGNER, R. L.; PINCHON, J., 1991, op. cit., p. 418.

${ }^{74}$ Id., ibid., p. 417.

${ }^{75}$ Id., ibid., p. 426.

${ }^{76}$ Id., ibid., p. 426.

${ }^{77}$ RIEGEL, M; PELLAT, J.-C.; RIOUL, R. Grammaire méthodique du français. Paris: Presses Universitaires de France, 1994.

${ }^{78}$ Id., ibid., p. 389.

${ }^{79}$ Id., ibid., p. 410-411.
} 
como "marqueurs de négation" ${ }^{80}$. Há ainda o problema de não sabermos exatamente qual segmento da frase é afetado pela negação.

A negação pode ser total com "ne... pas”, “ne... point” ou parcial com "personne”, “rien” [pronomes negativos que representam a negação de um grupo nominal: "Personne n'est venu (vs quelqu'un est venu)”], “aucun” [determinante negativo que indica a ausência ou nega a existência de um referente do grupo nominal: “Il n'a lu aucun livre de Simenon (vs il a lu un / des / plusieurs livres de Simenon)”] e “aucun moment”, “nulle part” [complemento circunstancial de tempo ou de lugar, negado por um grupo preposicional contendo um termo negativo ou por um advérbio ou uma locução adverbial de sentido negativo: “(1) Elle ne vient à aucun moment / jamais (vs elle vient souvent / toujours)”] ${ }^{81}$.

Segundo Weinrich ${ }^{82}$ (1989), a negação “de objeção” é uma forma de o interlocutor mostrar o seu desacordo em relação ao discurso emitido pelo locutor e manifestar-se por morfemas livres (ex.: “non” em relação ao seu par, ao seu binário “oui”), principalmente, mas não exclusivamente, nos diálogos ${ }^{83}$. A negação pode ter graus e nuanças, como no exemplo fornecido pelo autor: "tu es fatigué?”, “pas maintenant” ${ }^{\text {84 }}$. Há ainda a negação integrada, formada pelo binômio "non pas”, como no exemplo "bizarrement, le docteur m'a conseillé non pas de prendre un tranquillisant, mais de marcher le plus possible”85.

A négation liée é formada por um morfema descontínuo, composto por uma prénegação “ne” e uma negação principal "pas” ou “rien”, por exemplo, separadas pelo verbo conjugado e possivelmente por objetos pronominais. Dentre as possíveis negações "liées”, temos a simples ("ne... pas”, o caso mais comum, “ne... point”"86); a negação-zero ("ne... personne”, “ne... rien”, “ne... aucun(e)”87); a negação adverbial [de tempo (“ne... jamais”), de

\footnotetext{
${ }^{80}$ RIEGEL, M; PELLAT, J.-C.; RIOUL, R. Grammaire méthodique du français. Paris: Presses Universitaires de France, 1994, p. 411.

${ }^{81}$ Id., ibid., p. 411-412.

${ }^{82}$ WEINRICH, H. Grammaire textuelle du français. Paris: Didier/Hatier, 1989.

${ }^{83}$ Id., ibid., p. 507.

${ }^{84}$ Id., ibid., p. 509.

${ }^{85}$ Id., ibid., p. 509.

${ }^{86}$ Id., ibid., p. 513.

${ }^{87}$ Id., ibid., p. 515-516.
} 
posição ("ne... nulle part”), de seqüência (“ne... plus”, “ne... pas encore”) ${ }^{88}$ ]; a negação por “joncteurs”, que pode ser formada por “joncteurs” simples (“ni... ni”), conjunção (“que”) e relativos ${ }^{89}$; a negação atenuada ou "semi-négation" segundo a definição do autor e que só é possível com alguns verbos, sobretudo aqueles de modalidade que exprimem "une nuance de douceur, parfois aussi de politesse cérémonieuse” (ex.: pouvoir, savoir, oser, se tromper, cesser), e expressões cristalizadas [ex.:

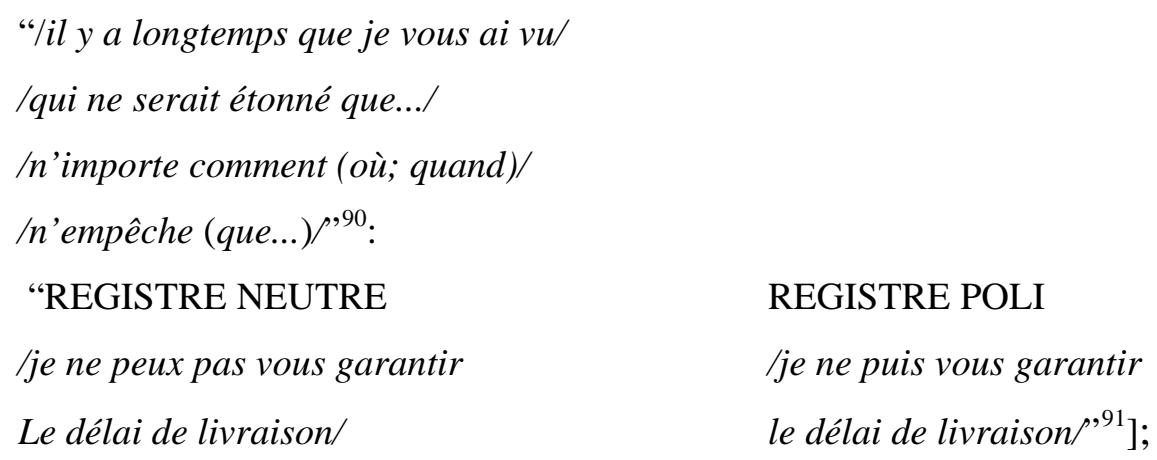

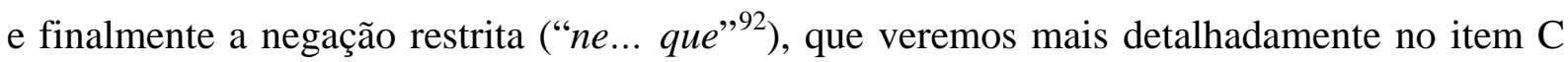
deste capítulo.

Segundo Charaudeau 93 (1992), há uma grande confusão entre os termos “asserção”, “afirmação” e "negação”. Muitas vezes, “afirmação” é utilizado como sinônimo de “asserção”, quando na realidade ela pode ser "afirmativa” ou “negativa”, considerando-se "l'événement de discours qui met en relation différents éléments" 94 , como observamos nos exemplos: “' 'Le plombier est venu’ est affirmée 'la venue du plombier', et dans: 'Le plombier n'est pas venu' est niée 'la venue du plombier’”95. Assim é “le mode de relation que ces êtres entretiennent entre eux lorsqu'on parle”96 que levamos em consideração. Charaudeau (1992) resume suas noções a:

\footnotetext{
${ }^{88}$ WEINRICH, H. Grammaire textuelle du français. Paris: Didier/Hatier, 1989, p. 517-519.

${ }^{89}$ Id., ibid., p. 519-521.

${ }^{90}$ Id., ibid., p. 522.

${ }^{91}$ Id., ibid., p. 522.

${ }^{92}$ Id., ibid., p. 522-524.

${ }^{93}$ CHARAUDEAU, P. Grammaire du sens et de l'expression. Paris: Hachette Éducation, 1992.

${ }^{94}$ Id., ibid., p. 551.

${ }^{95}$ Id., ibid., p. 551.

${ }^{96}$ Id., ibid., p. 551.
} 
“- l’Assertion comme 'propos sur le monde', que celui-ci apparaisse sous forme positive ou négative.

l'Assertion comme 'acte d'énonciation' sous forme de modalité délocutive.

l'Affirmation comme forme positive d'un 'propos'.

l'Affirmation comme 'acte d'énonciation' sous forme de modalité élocutive" 97 .

A negação é reconhecida formalmente pela presença de partículas negativas. Charaudeau considera as partículas reconhecidas por todos, "ne” em conjunto com "pas”, “point”, “rien”, “personne” etc., como negação do enunciado; o prefixo “non”, "pas”, “point”, “plus”, como a negação condensada de um processo ou de uma qualificação (ex.: “C'est un cas de non-respect des règles" é uma condensação de "Les règles n'ont pas été respectées." $\left.{ }^{98}\right)$; a repetição de “non”, o uso de “non pas”, "non point”, "pas du tout” e outras formas exclamativas, como "négation-réplique"99.

A negação simples “ne... pas de” ou "sans” nega a existência de qualquer quantidade mas também a unidade de referência (ex.: "Il n'a pas de meubles chez lui”; "Il s'est présenté sans arme(s)”100). “Aucun”, “nul” são utilizados na negação para assinalar a ausência total de quantidade e também podem ser utilizados para seres humanos, assim como "personne” e “rien” [ex.: “Il n'a manifesté aucune réaction”, “Nul n'est qualifié pour en parler”, “Personne (nul) n'est venu”, “Rien, ni personne ne changera le cours des choses”101].

A grande diferença entre Charaudeau (1992) e os outros autores estudados é que ele considera a asserção como uma verdade, podendo ser explicitada de forma positiva ou negativa. Os outros autores consideram a asserção como uma verdade sempre positiva, e a negação, como a forma de representar o aspecto falso em relação a essa verdade, a oposição a essa verdade, por isso a confusão terminológica no uso de “asserção” e “afirmação”. Para os outros autores vistos, os exemplos “Ele não é alto. Ele é baixo” teriam como asserção de base

\footnotetext{
${ }^{97}$ CHARAUDEAU, P. Grammaire du sens et de l'expression. Paris: Hachette Éducation, 1992, p. 552.

${ }^{98}$ Id., ibid., p. 555.

${ }^{99}$ Id., ibid., p. 557.

${ }^{100}$ Id., ibid., p. 274-275.

${ }^{101}$ Id., ibid., p. 275-276.
} 
“Ele é baixo” e "Ele não é alto”, uma variação da primeira. A negação nada mais é do que uma forma de mostrar um fato não verdadeiro, positivo e seu oposto a ele. Para Charaudeau (1992), ambas seriam asserções de base. Nesse exemplo vemos claramente a asserção de base “Ele é baixo”, mas no caso de "Le plombier n’est pas venu”, é a chegada do bombeiro que é negada e não sua existência ou uma característica sua ${ }^{102}$. Torna-se então mais difícil encontrar a “asserção de base positiva” dos autores acima porque ela é verdadeira no caso dado.

Esse fato implica um paradoxo, pois se a negação é o oposto de uma afirmação, sinônimo de asserção como definido pelos autores citados e se temos uma asserção verdadeira negativa, como o exemplo dado por Charaudeau (“Le plombier n'est pas venu' est niée 'la venue du plombier’”103), a negação como definida tradicionalmente, ou seja, o oposto dessa “afirmação” negativa exemplificada por Charaudeau, passa a ser uma frase "afirmativa” (“Le plombier est venu” ${ }^{104}$ ). Por conseguinte, a negação é explicitada por termos positivos sem nenhum termo tradicionalmente tido como marcador da negação, no caso “ne”, “pas”, ou verbos de valor negativo, tais como "oser" etc.

Além de Damourette e Pichon (1939), Wagner e Pinchon (1991) possuem a mesma idéia de Guillaume (1973) sobre a negação, mas sob diferentes etiquetas. Damourette e Pichon (1939) atribuem-lhe um valor pleno e parcial, enquanto para Wagner e Pinchon (1991) lhe atribuem um valor total e parcial. Gustave Guillaume a classifica como in esse e in fieri (4, p. 135).

Assim como os autores citados, Charaudeau (1992) vê o binômio “ne... pas” como a negação absoluta do enunciado, que chama de "degré zéro de la négation" "105. A partir do momento em que Charaudeau (1992) e os autores acima admitem uma negação "absoluta” e “total”, também admitem uma negação parcial. Isso significa que, em algum momento da evolução da língua francesa, essa nuança surgiu e se mantem até hoje. Podemos considerar alguns aspectos.

\footnotetext{
${ }^{102}$ CHARAUDEAU, P. Grammaire du sens et de l'expression. Paris: Hachette Éducation, 1992, p. 551.

${ }^{103}$ Id., ibid., p. 551.

${ }^{104}$ Id., ibid., p. 551.

105 Id., ibid., p. 558.
} 
Primeiro, o surgimento da segunda partícula como reforço à partícula de negação "ne”, que se acreditava "fraca” por ser monossilábica. Segundo, a transferência do valor de negação de "ne" propriamente dito ao seu par "pas" e "point”, no caso da negação total, como vimos acima. Terceiro, a nuança da negação, os graus de negação pela introdução de “plus”, “pas encore", "guère" ${ }^{106}$. Até o momento, vemos um movimento de transferência e de nuança considerados por Gustave Guillaume (1973) e, por conseguinte, por Jacques Ouellet (2004) em sua obra.

\subsection{RESTRIÇÃO}

Mauger (1968), não define nem trabalha a restrição francesa como tal, apenas aponta o "ne... que" como um binômio que "exprime une affirmation restreinte"107 no capítulo de negação.

Damourette e Pichon (1939) tratam da restrição de sentido nos casos de substantivos de sentidos diferentes de acordo com os termos que os acompanham. Fornecem o exemplo do termo “operação” em relação a um militar, a um cirurgião etc. ${ }^{108}$ e acrescentam que esse fenômeno é mais comum com a substantivação do adjetivo (ex.: “les bleus”, soldados jovens e novos, adversários dos “blancs”"109).

Outro "sentido" que atribuem à restrição é o de exclusão do termo introduzido pelo “que” da forclusão ${ }^{110}$. O aspecto interessante desse "sentido" reduz-se ao fato de que a restrição passa a ser definida pelo aspecto negativo, e não afirmativo. Ela já não tem o valor etimológico de "somente" ainda positivo no nosso imaginário, mas é a negação de todo o resto, excluindo o complemento. Ao contrário de "somente”, “só” e “apenas” tem valor

\footnotetext{
${ }^{106}$ CHARAUDEAU, P. Grammaire du sens et de l'expression. Paris: Hachette Éducation, 1992, p. 558-559.

${ }^{107}$ MAUGER, G. Grammaire pratique du français d'aujourd'hui. Paris: Librairie Hachette, 1968, p. 377.

${ }^{108}$ DAMOURETTE, J.; PICHON, E. Des mots à la pensée: essai de grammaire de la langue française, 19111927. Paris: D'artrey, 1939, t. II, l. IV, c. XIII, p. 177.

${ }^{109}$ Id., ibid., p. 177.

${ }^{110}$ Id., ibid., t. VI, l. VI, c. V, p. 207.
} 
etimológico negativo (“L’élément phrastique introduit par que est présenté comme seul excepté de la forclusion, comme revalidé, si l’on peut ainsi parler, vis-à-vis du fait principal”111). Somente as interpretações do locutor e do interlocutor atribuem-lhe um "valor interpretativo" positivo, neutro ou negativo. Os exemplos a seguir ajudam-nos a visualizar esse aspecto: “Je mange seulement des légumes” e “Je ne mange que des légumes”.

Grevisse $^{112}$ (2006) cita no § 208, página 263, a restrição ou especialização como um artifício, a introdução de um sema e um procedimento lógico para a mudança de sentido de uma palavra. O autor cita novamente a restrição, como um fato e não ela em si na análise da "locução" “ne... que"113 equivalente a "seulement”. Menciona também que esse valor restritivo pode ser manifestado pela conjunção da partícula "que” com "sans”, "autre”, "autre chose", "autrement" a partícula "que" a exemplo da transferência do valor negativo também ocorrida com as partículas "pas" e "point" "116.

Segundo Gaatone ${ }^{117}$ (1971), os termos "que” e "ne... que” não fazem parte do sistema de negação do francês moderno, uma vez que se opõem nas mesmas condições a "ne... pas

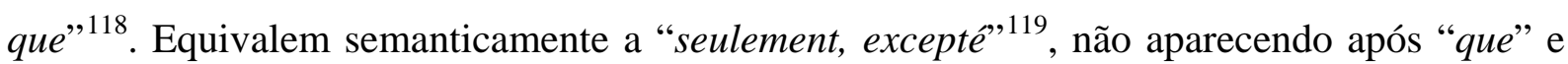
“ne... que” as marcas redundantes da negação. O autor exemplifica o uso de "que” sozinho:

"Il revivait les angoisses de son adolescence quand il allait subir des épreuves... toujours préparé qu’à moitié... (105, p. 91)

\footnotetext{
${ }^{111}$ DAMOURETTE, J.; PICHON, E. Des mots à la pensée: essai de grammaire de la langue française, 19111927. Paris: D'artrey, 1939, t. VI, l. VI, c. V, p. 207.

${ }^{112}$ GREVISSE, M. Le bon usage. 13e edição, 6 e reimpressão. Paris: Duculot, 2006.

${ }^{113}$ Id., ibid., p. 1454.

${ }^{114}$ Id., ibid., p. 1455.

${ }^{115}$ Id., ibid., p. 1462.

${ }^{116}$ Id., ibid., p. 1455, p. 1461.

${ }^{117}$ GAATONE, D. Étude descriptive du système de la négation en français contemporain. Genebra: Librairie Droz, Publication romanes et françaises, 1971.

${ }^{118}$ Id., ibid., p. 209.

${ }^{119}$ Id., ibid., p. 209.
} 
Allez, madame Pascal, pas d'histoire! Nous sommes entre nous. Vraiment, que des amis. (35, p. 113)”120 (GAATONE, 1971, p. 209).

“Ne... que” é exemplificado com um verbo, com palavras negativas (“jamais”, “plus”, “guère”, "personne”), com "pas” e com "faire” ["ne faire que” para restringir o verbo em si: “Ce vocabulaire ne fait pas qu'augmenter; il se modifie... (42, p. 145)”,"121].

Segundo Weinrich ${ }^{122}$ (1989), a restrição é classificada como “négation restreinte”, sendo formada pelos morfemas descontínuos “ne”, pela pré-negação “qui pose la 'tenaille négative”, e pelo “que”, que restringe excluindo da negação o determinante do verbo que aparece imediatamente após o morfema "que” ${ }^{123}$. No item C abaixo, essa construção é melhor explicada.

Wagner e Pinchon ${ }^{124}$ (1991) não trabalham o conceito de restrição como tal, apenas apresentam-no como um subitem de advérbios de negação e como se manifesta. Existe a negação total, a parcial e a limitada ${ }^{125}$. A restrição exclusiva é formada pelo advérbio composto "ne... que" 126 e será melhor explicada no item $\mathrm{C}$ abaixo.

Arrivé, Gadet e Galmiche ${ }^{127}$ (1986) definem a exceção, e não a restrição. Segundo os autores, a exceção cobre dois tipos de fenômenos: as intrínsecas (os casos que não seguem as regras estabelecidas, como o plural de substantivos não formados com “s”) e as que obedecem a uma regra temporária, ainda não bem definida, ou a uma mais geral. Como marcas de

\footnotetext{
${ }^{120}$ (105) TRIOLET, E.: Luna-Park. Paris: Gallimard, 1959, 251p.; (35) CARCO, F.: Les belles manières. Genève, Ed. du Milieu du Monde, 1945, 256p. apud GAATONE, 1971, p. 209.

${ }^{121}$ (42) COHEN, M.: Nouveaux regards sur la langue française. Paris, E. sociales, 1963, 315p., apud GAATONE, 1971, p. 210.

${ }_{122}$ WEINRICH, H. Grammaire textuelle du français. Paris: Didier/Hatier, 1989.

${ }^{123}$ Id., ibid., p. 522.

${ }^{124}$ WAGNER, R. L.; PINCHON, J. Grammaire du français classique et moderne. Paris : Hachette Supérieur, 1991.

${ }^{125}$ Id., ibid., p. 386-395.

${ }^{126}$ Id., ibid., p. 395.

${ }^{127}$ ARRIVÉ, M., GADET, F., GALMICHE, M. La grammaire d'aujourd'hui: guide alphabétique de
} linguistique française. Paris: Flammarion, 1986. 
exceção, reconhecem “seul”, “seulement”, “ne... que”, “sauf”, “excepté”, dentre outros (“il ne travaille que le dimanche; il ne travaille pas, sauf le dimanche, et il travaille seulement le dimanche") ${ }^{128}$.

Segundo Riegel, Pellat e Rioul ${ }^{129}$ (1994), a restrição é tratada na negação exceptiva ou restritiva e não é uma negação propriamente dita. Formulada por "ne... que”, equivale a “somente”, “unicamente”130 e será explicada mais detalhadamente abaixo.

Charaudeau $^{131}$ (1992) é um dos poucos autores que trabalha a restrição como um item separado. Sob essa égide, agrupa entre outros os termos “mais”, "bien que”, “quand bien même”. Na asserção restritiva, temos a negação parcial da asserção de base como vemos no exemplo a seguir:

"Il est fort mais bête.

Élément constitutif commun: 'Il s'agit des qualifications de quelqu'un.'

Assertion implicite, conséquence possible de l'assertion de base: 'S'il est fort (qualité positive), on pourrait penser qu’il soit intelligent (qualité positive) ${ }^{\prime 132}$.

Vejamos abaixo alguns exemplos de outros termos, relatores segundo o autor, que podem ser caracterizados segundo:

- sua posição:

o antes da asserção de base com valor:

- de certeza:

- “Évidement”: “Évidement il est grand mais pas assez pour jouer au basket-ball”,133;

\footnotetext{
${ }^{128}$ ARRIVÉ, M., GADET, F., GALMICHE, M. La grammaire d'aujourd'hui: guide alphabétique de linguistique française. Paris: Flammarion, 1986., p. 262-263.

${ }^{129}$ RIEGEL, M; PELLAT, J.-C.; RIOUL, R. Grammaire méthodique du français. Paris: Presses Universitaires de France, 1994.

${ }^{130}$ Id., ibid., p. 412.

${ }^{131}$ CHARAUDEAU, P. Grammaire du sens et de l'expression. Paris: Hachette Éducation, 1992.

${ }^{132}$ Id., ibid., p. 515.
} 
- “Bien que”: “Bien qu'il soit grand, il ne l'est pas suffisamment pour jouer au basket-ball”,134;

- “Avoir beau”: “Il a beau être arrivé le premier, il n’est pas le plus fort" ${ }^{\text {135; }}$

- "Malgré": "Malgré son savoir-faire, il a échoué dans la négociation"136;

- de probabilidade:

- “En supposant”: “En supposant qu'il vienne..."137;

- “Quitte à...”: “Quitte à perdre de l'argent, je jouerai jusqu’à l'aube" ${ }^{138}$;

- de adesão:

- “J'admets que...”: “J'admets qu'il y a quelque chose à revoir, cependant...”, “J'admets qu'il y ait quelque chose à revoir, cependant..."139;

o antes da asserção restritiva:

- de oposição simples (“mais”, “or”, “pourtant”, “cependant”, “par contre”, “en revanche” etc.): “Certes, il fait son régime sérieusement, cependant il ne maigrit pas" ${ }^{140}$;

- oposição marcada ou inversão ("par contre”, "en revanche”, “au contraire” etc.): “Il n'a pas honte à l'avouer; au contraire, il s'en félicite" $^{\text {141. }}$

- retificação (“néanmoins”, “il n’en demeure pas moins vrai que”, “sauf que” etc.; sentimentos de quem fala: "heureusement”, “malheureusement” etc.): “Certes, il fait son régime sérieusement, il

${ }^{133}$ CHARAUDEAU, P. Grammaire du sens et de l'expression. Paris: Hachette Éducation, 1992, p. 516.

${ }^{134}$ Id., ibid., p. 516.

${ }^{135}$ Id., ibid., p. 516.

${ }^{136}$ Id., ibid., p. 516.

${ }^{137}$ Id., ibid., p. 516.

${ }^{138}$ Id., ibid., p. 516.

${ }^{139}$ Id., ibid., p. 516.

${ }^{140}$ Id., ibid., p. 517.

${ }^{141}$ Id., ibid., p. 517. 
n'en demeure pas moins vrai qu'il ne maigrit pas”, "Il fait son régime sérieusement, malheureusement il ne maigrit pas"142.

Segundo Charaudeau (1992), há ainda outra diferença presente na restrição, a restrição simples e a concessiva. A simples possui na sua asserção restritiva o relator de restrição: "Il est fort mais il est bête"143, e a concessiva o tem diante da asserção de base: “Bien qu'il soit fort, il est bête" 144 .

Verificamos aqui que em nenhum momento Charaudeau (1992) cita o binômio "ne... que” no capítulo da restrição, mas o faz no dos quantificadores ${ }^{145}$, da argumentação e das relações lógicas ${ }^{146}$ e no da afirmação e negação ${ }^{147}$, sempre em relação a uma quantificação ou a um processo.

Segundo o autor, os quantificadores podem ser caracterizados por artigo indefinido (ex.: "Ce matin, j'ai acheté un disque au supermarché"148), numerais (ex.: "Il y a quatre chaises autour de la table»149), adjetivos indefinidos (ex.: "Il travaille plusieurs heures par jour”150), advérbios de quantidade (ex.: “Il y a beaucoup de vin”151) e expressões diversas, como "plein de, un grand nombre de, une quantité incroyable de, etc."152. Essa determinação pode ser feita através de quantidade ou de intensidade forte (“beaucoup”) ou fraca (“peu”), determinada (“dix”) ou indeterminada ("plusieurs”), relativa em relação a um limite ("trop $d e$ ”), totalizadora (“tous”) ou nula (“aucun”) ${ }^{153}$. A forma da quantidade ou intensidade totalizadora também pode ser expressa pelo binômio “ne... que” seguido de plural. Essa forma

\footnotetext{
${ }^{142}$ CHARAUDEAU, P. Grammaire du sens et de l'expression. Paris: Hachette Éducation, 1992, p. 517.

${ }^{143}$ Id., ibid., p. 518.

${ }^{144}$ Id., ibid., p. 518.

${ }^{145}$ Id., ibid., p.237-277.

${ }^{146}$ Id., ibid., p. 493-550.

${ }^{147}$ Id., ibid., p. 551-567.

${ }^{148}$ Id., ibid., p. 237.

${ }^{149}$ Id., ibid., p. 239.

${ }^{150}$ Id., ibid., p. 240.

${ }^{151}$ Id., ibid., p. 239.

${ }^{152}$ Id., ibid., p. 238.

${ }^{153}$ Id., ibid., p. 239-240.
} 
assinala a totalidade pela exclusão de todo o resto: “'Il ne fait que dire des bêtises' (et rien d'autre)" ${ }^{\text {,154 }}$.

Charaudeau (1992) trabalha a argumentação e as relações lógicas através de operadores lógicos como a conjunção, a disjunção, a restrição, a oposição, a causal, a implicação, a explicação e a hipótese ${ }^{155}$. Na restrição, encontramos, como vimos acima, marcas e formas que se caracterizam pela posição (antes da asserção de base / antes da asserção restritiva), pelo valor semântico (certeza / probabilidade) e pelo tipo de construção morfológica (indicativo / subjuntivo / infinitivo / substantivo), podendo ser ainda restrição simples ou concessiva, retificação negativa ou positiva ${ }^{156}$. Encontraremos o binômio "ne... que” como exemplo de restrição com operador diante da asserção restritiva: “J'ai tout fait pour le satisfaire. N'empêche qu'il est mécontent."157.

No capítulo “Afirmação e negação”, o autor trabalha os problemas de terminologia e de definições de asserção, afirmação e negação, assim como suas marcas, suas formas, suas particularidades semânticas e seu discurso ${ }^{158}$. Encontraremos o binômio “ne... que” em particularidades semânticas e nuanças do sentido da negação como vimos acima e veremos no item abaixo.

\subsubsection{O BINÔMIO “NE... QUE”}

Para estabelecer a revisão da literatura da expressão “ne... que”, fizemos uma revisão das gramáticas normativas e descritivas, assim como das obras semânticas nas quais os empregos do "que" restritivo foram estudados e daquelas que versam sobre a restrição e a negação.

A análise da palavra “que”, realizada por diversos gramáticos, inscreve-se em diversos quadros teóricos. Dentre os representantes da linha normativa, escolhemos Grevisse (2006),

\footnotetext{
${ }^{154}$ CHARAUDEAU, P. Grammaire du sens et de l'expression. Paris: Hachette Éducation, 1992, p. 273.

${ }^{155}$ Id., ibid., p. 493-550.

${ }^{156}$ Id., ibid., p. 515-521.

${ }^{157}$ Id., ibid., p. 517.

${ }^{158}$ Id., ibid., p. 551-567.
} 
Mauger (1968) e Wagner e Pinchon (1991). Com efeito, mesmo após várias críticas feitas aos gramáticos tradicionais, Grevisse (2006) ainda é uma referência para todos os estudiosos do francês. Apesar de ser normativo da década de 60, Mauger (1968) ainda é impresso e possui seu leitorado. Wagner e Pinchon (1991), também normativos, dão-nos outra visão sobre o tema estudado. Na lingüística descritiva, escolhemos Weinrich (1989) por seu estudo da língua francesa pelo viés da análise textual. Finalmente, no quadro da teoria semântica, escolhemos os lingüistas Arrivé, Gadet e Galmiche (1986), Charaudeau (1992) e Wilmet (1997). Suas obras, centradas no estudo do sentido e da expressão, nos fornecerão outra abordagem, mais atual, do tema estudado.

O “que” restritivo não é classificado como tal na maior parte das obras. Para vários autores, trata-se de uma manifestação da falsa negação ou da restrição geral. Entre esses teóricos, encontramos Arrivé e Chevalier (1970), que fazem um comentário crítico sobre a teoria da negação desenvolvida por Damourette e Pichon (1939); as teses de Fintel (1994) sobre a restrição expressa pelos quantificadores e de Gaatone (1971) sobre o sistema de negação no francês contemporâneo, no qual o “que” restritivo também é classificado como negação restritiva.

No momento em que procuramos a palavra "que” nas gramáticas consultadas, encontramo-la como advérbio, conjunção subordinada, pronome interrogativo e pronome relativo, mas sob diferentes terminologias (GREVISSE, 2006, p. 1740-1741; WAGNER, R. L.; PINCHON, J., 1991, p. 678; WEINRICH, 1989, p. 662; WILMET, 1997, p. 647-648). Em Grevisse (2006) e Wagner e Pinchon (1991), temos as terminologias tradicionais:

“Dieu! QUE le son du Cor est triste au fond des bois! (VIGNY, Poèmes ant. et mod., Cor.)”"159 (advérbio de intensidade);

“Je vois QUE vous comprenez"160 (conjunção subordinada);

“Que dites-vous?”"161 (pronome interrogativo);

"Octave ô fou que tu es!”162 (pronome relativo);

\footnotetext{
${ }^{159}$ GREVISSE, M. Le bon usage. $13^{\mathrm{e}}$ edição, $6^{\mathrm{e}}$ reimpressão. Paris: Duculot, 2006, p. 615.

${ }^{160}$ Id., ibid., p. 1536.

${ }^{161}$ WAGNER, R. L.; PINCHON, J. Grammaire du français classique et moderne. Paris : Hachette Supérieur, 1991, p. 220.

${ }^{162}$ Id., ibid., p. 224.
} 
mas também temos introdutor ${ }^{163}$ (GREVISSE, 2006, p. 1741) para a conjunção subordinativa, ao mesmo tempo que Weinrich (1989) o chama de morphème ${ }^{164}$ exclamatif $^{1}$ (WEINRICH, 1989, p. 662):

"QUE tout le monde sorte!”"165 (introdutor);

“/ que vous êtes joli! que vous me semblez beau! p"166 (morfema exclamativo);

em Wagner e Pinchon (1991), temos "particule liant thème et prédicat” (partícula ligando tema e predicado) e "que” "introduit le complément du comparatif” (introduz o complemento do comparativo) para a conjunção de subordinação ${ }^{167}$ :

“'C'est une chose honteuse que de trahir

La douce chose que d'aimer!' (MOLIÈRE)”168 (partícula ligando tema e predicado);

“'La mer a un parfum plus suave que les roses, nous le humions avec délices.' (G. FlAUBERT)” ${ }^{169}$ (partícula conjuntiva que introduz o complemento do comparativo);

em Weinrich (1989), temos a conjonction de contenu para a conjunção subordinativa, morphème $^{170}$ interrogatif $^{171}$ para 0 pronome interrogativo, pro-conjonction ${ }^{172}$ para $a$ conjunção subordinativa, relatif de prédication para o pronome relativo e, relatif ${ }^{173}$ também $^{2}$

\footnotetext{
163 « Nous appelons introducteur un mot invariable qui sert à introduire un mot, un syntagme, une phrase: VoICI votre journal. [...] Il se distingue de la préposition ou des conjonctions en ceci qu'il ne sert pas à unir. » (GREVISSE, Le bon usage. $13^{\mathrm{e}}$ edição, $6^{\mathrm{e}}$ reimpressão. Paris: Duculot, 2006, p.1558)

164 «Les morphèmes sont des signes grammaticaux dont les significations sont de simples consignes pour aider à comprendre les textes. (...) Ils sont traités prioritairement dans la grammaire et se prêtent au regroupement, en fonction de leurs traits pertinents communs, en PARADIGMES, c'est-à-dire en classes et sous-classes faciles à délimiter et à visualiser, comme par exemple les classes de morphèmes suivantes: articles, prépositions, conjonctions et adverbes. » (WEINRICH, H. Grammaire textuelle du français. Paris: Didier/Hatier, 1989, p.28)

${ }^{165}$ GREVISSE, 2006, op. cit., p. 1561.

${ }^{166}$ WEINRICH, op. cit., p. 471.

${ }^{167}$ WAGNER, R. L.; PINCHON, J. Grammaire du français classique et moderne. Paris : Hachette Supérieur, 1991, p. 678-679.

${ }^{168}$ Id., ibid., p. 67.

${ }^{169}$ Id., ibid., p. 150.

${ }^{170}$ Cf. nota 164.

${ }^{171}$ WEINRICH, op. cit., p. 662.

${ }^{172}$ Id., ibid., p. 662.

${ }^{173}$ Id., ibid., p. 662.
} 
para o pronome relativo:
"l’hôtesse annonce que l'avion partira immédiatement"" (conjunção de conteúdo);
"/et que signalent les morphèmes interrogatifs? $\div$ ils signalent un blanc dans l'information préalable/"175 (morfema interrogativo);
“/ s'il ne vous croît pas et qu'il mette vos intentions en doute, donnez-le par écrit ${ }^{p 176}$ (pro-conjunção que com o subjuntivo);
“/ méchant que vous êtes $\rho^{177}$ (relativo de predicação);
"il y a ici mon docteur que je crois excellent" ${ }^{178}$ (relativo);

em Wilmet (1997), temos pronominal para o pronome relativo, enchâsseur conjonctionnel para a conjunção subordinativa e adverbial para o advérbio ${ }^{179}$ :

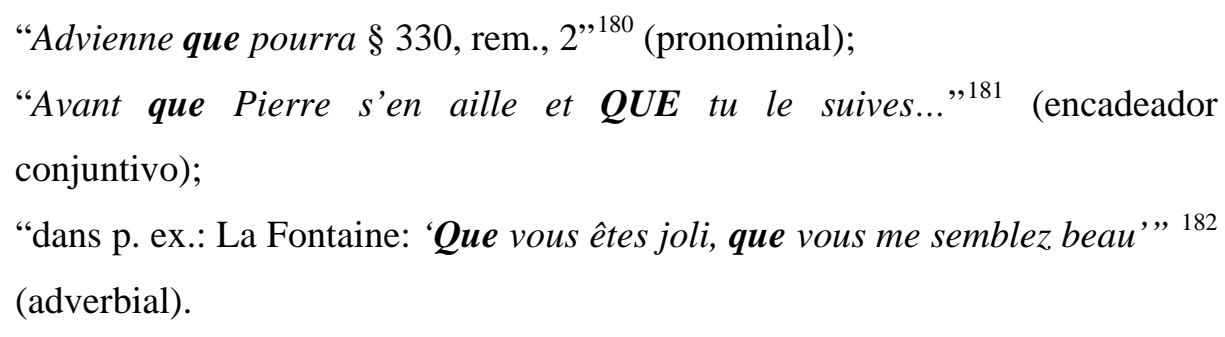

Segundo Damourette e Pichon (1939), a partícula “ne” da expressão “ne... que” é, como na negação, um discordancial. A diferença em relação à negação francesa moderna recai sobre a partícula “que”, que possui caráter parecido com os forclusivos pas, rien, jamais etc., mas indica que o complemento logo a seguir não está em discordância com o fato abrangido pelo discordancial, e sim que é excluído da forclusão implícita:

“N’ayez donc pas peur, méchants que vous êtes!

\footnotetext{
${ }^{174}$ WEINRICH, H. Grammaire textuelle du français. Paris: Didier/Hatier, 1989, p. 466.

${ }^{175}$ Id., ibid., p. 542.

${ }^{176}$ Id., ibid., p. 473.

${ }^{177}$ Id., ibid., p. 488.

${ }^{178}$ Id., ibid., p. 476.

${ }^{179}$ WILMET, M. Grammaire critique du Français. Louvain-la-Neuve: Hachette Supérieur/Duculot, 1997, p. 647-648.

${ }^{180}$ Id., ibid., p. 647.

${ }^{181}$ Id., ibid., p. 547.

${ }^{182}$ Id., ibid., p. 549.
} 
Je n’aime que vous, je ne suis qu'à vous. (Paul Geraldy. Toi et Moi. VIII, p. 42).

Vous êtes le seul objet qui ne soit pas en discordance avec mon amour, le seul objet qui lui convienne. A vous est la seule situation qui ne soit pas en discordance avec mon être” ${ }^{\text {183. }}$

A essa partícula “que” os autores dão o nome de uniceptif ${ }^{184}$, e para que tenha esse valor é condição que haja o que chamam de atmosfera forclusiva anterior, representada pelo termo "rien” no exemplo abaixo:

“Cette créature, RIEN qu'en passant dans la rue, appartenait à tout le monde... (Maupassant. L'Epingle, après Monsieur Parent; p. 210)" ${ }^{185}$.

Embora seja essencial e quase universal a presença da atmosfera forclusiva, há casos nos quais ela não aparece:

“Aux premiers, on NE les apprend PAS, ou que difficultueusement et sans fruit (R. de Montesquieu. Les pas effacés, t. III, p. 208)”"186.

Outros forclusivos podem anular o caráter uniceptivo de "que”:

“Les choses ne sont jamais qu'elles-mêmes, elles sont des images venues de nous et dont on les pare. (A. Thooris van Borre. Réflexes courts; dans Le Lien Médical, $14^{\mathrm{e}}$ année, $\mathrm{n}^{\circ}$ 8, août 1938, p. 20)

Sc. 'les choses ne sont jamais elles-mêmes seulement; elles sont aussi quelque chose d'autre" ${ }^{187}$.

As diversas teorias, tradicionais ou modernas, não reconhecem no "que” uma natureza restritiva, mas sim um emprego restritivo nas expressões "ne... que”, "sans... que”, "rien que”, "bien que”, "autre que”, "nul autre que” e "pour peu que” ou o "que” sozinho

${ }^{183}$ DAMOURETTE, J.; PICHON, E. Des mots à la pensée: essai de grammaire de la langue française, 19111927. Paris: D'artrey, 1939, t. I, l. II, c. VII, p. 144.

${ }^{184}$ Id., ibid., p. 144.

${ }^{185}$ Id., ibid., t. VI, l. VI, c. V, p. 213.

${ }^{186}$ Id., ibid., p. 214.

${ }^{187}$ Id., ibid., p. 217. 
[““M'en parlez pas... - Si c'est pas malheureux!... - J'avais qu'elle’ (CARCO)”188]. Em geral, os lingüistas classificam o “que” de sentido restritivo como um advérbio, sob o título de negação, apesar de seu valor positivo. A expressão “ne... que”, por exemplo, é classificada como négation exceptive por Wilmet ${ }^{189}$ (1997), négation restreinte por Weinrich ${ }^{190}$ (1989), restriction exclusive por Wagner e Pinchon ${ }^{191}$ (1991) e négation exclusive por Charaudeau $^{192}$ (1992).

Enquanto Wilmet $^{193}$ (1997), Weinrich ${ }^{194}$ (1989) e Charaudeau ${ }^{195}$ (1992) a consideram como expressão de exclusão, Wagner e Pinchon ${ }^{196}$ (1991) a cosideram como locução subordinativa que pode ter um sentido restritivo retomando o uso antigo.

\section{SÍNTESE DAS TEORIAS SOBRE “NE... QUE”}

Segundo Damourette e Pichon (1939), o uniceptivo “que” pode validar grupos nominais, adjetivais e "affonctieuses":

“On ne voit que sa tête violette et soufflée. (Jules Renard. Journal, 1889; p. 20)" ${ }^{197}$ (substantival);

“A parler comme ça, tu n’es pas drôle, Etienne, tu n’es que bête. (Mme EJ, le 23 juin 1939)" ${ }^{198}$ (adjetival);

“Elle n’a que voulu amener Suzy à quitter, par rosserie, Jacques. (Georges Le

\footnotetext{
${ }^{188}$ ROBERT, Paul. Dictionnaire alphabétique \& analogique de la langue française. s.e. Paris: Société du nouveau Littré, 1981, NE, p. 1260.

${ }^{189}$ WILMET, M. Grammaire critique du Français. Louvain-la-Neuve: Hachette Supérieur/Duculot, 1997, p. 514.

${ }^{190}$ WEINRICH, H. Grammaire textuelle du français. Paris: Didier/Hatier, 1989, p. 522.

${ }^{191}$ WAGNER, R. L.; PINCHON, J. Grammaire du français classique et moderne. Paris : Hachette Supérieur, 1991, p. 426.

${ }^{192}$ CHARAUDEAU, P. Grammaire du sens et de l'expression. Paris: Hachette Éducation, 1992, p. 561.

${ }^{193}$ WILMET, 1997, op. cit., p. 308.

${ }^{194}$ WEINRICH, 1989, op. cit., p. 412.

195 CHARAUDEAU, 1992, op. cit., p. 274.

${ }^{196}$ WAGNER, R. L.; PINCHON, J., 1991, op. cit., p. 427.

${ }^{197}$ DAMOURETTE, J.; PICHON, E. Des mots à la pensée: essai de grammaire de la langue française, 19111927. Paris: D'artrey, 1939, t. VI, l. VI, c. V, p. 219.

198 Id., ibid., p. 221.
} 
Cardonnel, dans Le Journal, p. 4, col. 4)”"199 (“affonctieuse”).

No caso de validação de verbos, utilizam-se os verbos auxiliares “avoir" e "faire”:

“On obéit à des lois très obscures et on n’en tire aucun orgueil, parce qu'en

France, on n'est jamais très fier de n'avoir qu'à obéir. (P. Géraldy. La guerre, Madame, p. 64)" ${ }^{200}$;

“ 'Jean ne fait que sauter' signifie que Jean saute sans cesse; 'Jean ne fait que de sauter’ signifie Jean vient à peine de faire le saut”201.

A questão da expressão "ne... que” é por si complexa. Sua classificação não encontra consenso entre os pesquisadores. Segundo o gramático Mauger ${ }^{202}$ (1968), é uma afirmação restritiva equivalente a "seulement”, como observamos no seguinte exemplo:

"Nous ne mangeons que des légumes"203,

bem como no exemplo retirado do Le Petit Robert:

“'Les sanglots... qui n'éclatèrent que quand je me retrouvai seul' (PROUST)”204.

Embora o sentido de "seulement" seja aceitável em nível semântico em alguns exemplos, em outros, essa equivalência não o é. Verificamos que o sentido do exemplo dado pelo autor estaria comprometido se substituíssemos "ne... que” por "seulement":

"Il ne fait que sortir, il ne fait que de sortir",205,

no qual temos na primeira proposição "ne... que” equivalente a "sans cesse”,206 e, na segunda,

\footnotetext{
${ }^{199}$ DAMOURETTE, J.; PICHON, E. Des mots à la pensée: essai de grammaire de la langue française, 19111927. Paris: D'artrey, 1939, t. VI, l. VI, c. V, p. 222.

${ }^{200}$ Id., ibid., p. 222.

${ }^{201}$ Id., ibid., p. 222-223.

${ }^{202}$ MAUGER, G. Grammaire pratique du français d'aujourd'hui. Paris: Librairie Hachette, 1968.

${ }^{203}$ Id., ibid., p. 377.

${ }^{204}$ ROBERT, Paul. Dictionnaire alphabétique \& analogique de la langue française. s.e. Paris: Société du nouveau Littré, 1981, ÉCLATER, p. 598.

${ }^{205}$ MAUGER, 1968, op. cit., p. 377.

${ }^{206}$ Id., ibid., p. 377.
} 
a "il vient seulement de sortir" 207.

Segundo Grevisse ${ }^{208}$ (2006), a expressão “ne... que” é classificada como locution restrictive, em frases afirmativas e negativas, e equivale a "seulement", como vemos abaixo:

“Qui N'entend QU une cloche N'entend QU'un son”"209 (prov.).

No Le Petit Robert, encontramos diversos exemplos que corroboram essa definição, como em:

“'La fonction éducatrice de l'art n'existe que dans la mesure où l'intention éducatrice est absente’ (Th. MAULNIER)”210.

Porém, no caso de:

“'Ses paroles n'étaient qu'une réponse affaiblie, docile, presque un simple écho de mes paroles' (PROUST)”211,

não podemos utilizá-lo sem comprometer o real sentido da frase.

Wagner e Pinchon ${ }^{212}$ (1991), em sua gramática morfológica, apresentam a "négation restreinte partielle” com a expressão “ne... que”, um advérbio composto ${ }^{213}$, formando assim uma "restriction exclusive”. Eles a apresentam com dois valores diferentes. Um afirmativo:

“Je ne suis qu'un pauvre homme" ${ }^{214}$,

e outro negativo:

"Il n’y a pas que lui qui le sache”215.

\footnotetext{
${ }^{207}$ MAUGER, G. Grammaire pratique du français d'aujourd'hui. Paris: Librairie Hachette, 1968, p. 377.

${ }^{208}$ GREVISSE, M. Le bon usage. 13 edição, $6{ }^{\mathrm{e}}$ reimpressão. Paris: Duculot, 2006, p. 1454.

${ }^{209}$ Id., ibid., p. 1454.

${ }^{210}$ ROBERT, Paul. Dictionnaire alphabétique \& analogique de la langue française. s.e. Paris: Société du nouveau Littré, 1981, EDUCATEUR, TRICE, p. 606

${ }^{211}$ Id., ibid., ÉCHO, p. 596.

${ }^{212}$ WAGNER, R. L.; PINCHON, J. Grammaire du français classique et moderne. Paris : Hachette Supérieur, 1991.

${ }^{213}$ Id., ibid., p. 426.

${ }^{214}$ Id., ibid., p. 427.

${ }^{215}$ Id., ibid., p. 427.
} 
Para eles, a expressão "ne... que” e a palavra "seulement” não são sinônimos, mas exprimem uma idéia de restrição e de limitação. Reconhecemos essa limitação no exemplo colhido no corpus:

$$
\begin{aligned}
& \text { “'M'en parlez pas... - Si c'est pas malheureux!... - J'avais qu'elle' } \\
& \text { (CARCO)” }{ }^{216} \text {. }
\end{aligned}
$$

Segundo Arrivé, Gadet e Galmiche ${ }^{217}$ (1986), a expressão “ne... que” é uma maneira de excluir o complemento, que não permite outra interpretação, por exemplo:

$$
\text { "il ne travaille que le dimanche; il ne travaille pas, sauf le dimanche" }{ }^{218} \text {. }
$$

No Le Petit Robert, encontramos:

“'Louis XIV «ne voulait de grandeur que par émanation de la sienne » (STSIM.)" ${ }^{219}$.

Arrivé, Gadet e Galmiche (1986) definem a negação como o oposto da afirmação, e essa negação pode recair sobre toda a frase ou somente sobre uma de suas partes, como no exemplo seguinte:

$$
\text { “les élèves n'ont pas cassé les vitres”,220, }
$$

o que permite imaginar que os alunos não quebraram outras coisas.

Ao mesmo tempo que Arrivé, Gadet e Galmiche (1986) classificam a expressão “ne... que” como uma exclusão, também a classificam como a negação de um complemento da frase ou como uma exceção:

"il ne lit que des romans (toute autre forme de lecture est exclue)”,221,

\footnotetext{
${ }^{216}$ ROBERT, Paul. Dictionnaire alphabétique \& analogique de la langue française. s.e. Paris: Société du nouveau Littré, 1981, NE, p. 1260.

${ }^{217}$ ARRIVÉ, M., GADET, F., GALMICHE, M. La grammaire d'aujourd'hui: guide alphabétique de linguistique française. Paris: Flammarion, 1986, p. 396-401.

${ }^{218}$ Id., ibid., p. 262.

${ }^{219}$ ROBERT, 1981, op. cit., ÉMANATION, p. 620.

${ }^{220}$ ARRIVÉ, M., GADET, F., GALMICHE, M., 1986, op. cit., p. 397.

${ }^{221}$ Id., ibid., p. 398.
} 
mas isso não se aplica ao seguinte caso:

“'Tu me lâcherais à la face les sales preuves que tu n'es qu'une bourrique' (MAC ORLAN)"222

porque a expressão popular, nesse sentido específico, não compara a pessoa a outros animais, mas aos burros ou aos asnos. Ao tentarmos substituir "bourrique” por "tigre”, por exemplo, mudamos completamente o sentido inicial da frase.

Segundo Riegel, Pellat e Rioul (1994), a “négation exceptive (ou restrictive)”223 é feita pelo binômio "ne... que” e equivale a "seulement, uniquement", como no exemplo seguinte:

“Marcello ne s’intéresse qu’au cinéma”, “Marcello s’intéresse seulement au cinéma"224.

Isso se verifica em diversos exemplos do corpus, como em:

“MACHINE [...] II. (1559). Objet fabriqué, généralement complexe (V. Mécanisme), destiné à transformer l'énergie (V. Moteur) et à utiliser cette transformation (se distingue en principe de appareil et de outil, qui ne font qu'utiliser l'énergie)”225,

mas há casos em que não sabemos sobre quais complementos recai a negação, como no exemplo seguinte:

“'Je n’ai d’amour que pour les caractères d’un idéalisme absolu, martyrs, héros, utopistes' (RENAN)”,226,

no qual podemos ter somente "amor” por essas pessoas ("Eu tenho somente amor, e nenhum outro sentimento, pelos de caráter idealista, mártires, heróis e utopistas”) ou ter amor somente por “essas pessoas” (“Eu tenho amor somente pelos de caráter idealista, mártires, heróis,

\footnotetext{
${ }^{222}$ ROBERT, Paul. Dictionnaire alphabétique \& analogique de la langue française. s.e. Paris: Société du nouveau Littré, 1981, FACE, p. 746.

${ }^{223}$ RIEGEL, M; PELLAT, J.-C.; RIOUL, R. Grammaire méthodique du français. Paris: Presses Universitaires de France, 1994, p. 412.

${ }^{224}$ Id., ibid., p. 412.

${ }^{225}$ ROBERT, 1981, op. cit., MACHINE, p. 1124.

${ }^{226}$ Id., ibid., CARACTÈRE, p. 252.
} 
utopistas e por ninguém mais”).

Apesar de essas definições de négation restreinte (negação restrita), locution restreinte (locução restrita), exclusive (exclusiva) e exceptive (excludente) explicarem vários exemplos, a maior parte na realidade, ainda há casos para os quais não podemos adotar essas teorias, como notamos abaixo:

“'Ses paroles n'étaient qu'une réponse affaiblie, docile, presque un simple écho de mes paroles' (PROUST)",227.

Ainda que seja uma négation restreinte (negação restrita), não se comporta como uma negação, mas como uma afirmação restrita que inclui a partícula negativa “ne”. Essa estrutura, bem ressaltada pelos autores, influencia os outros termos da frase, com exceção do verbo e do sujeito. Para que recaia sobre o verbo, devemos utilizar a construção "ne faire que”, seguida de infinitivo:

“/je ne fait que prêcher la vérité/"228.

Weinrich (1989) considera a negação “ne... que” como uma négation restreinte (negação restrita) de morfema descontínuo, que exclui o objeto de toda negação que comporta a frase: “elle ne parle que le français”, na qual “le français” é “OBJET EXCLU DE LA NÉGATION PRINCIPALE”229. Essa negação também pode ser total ou parcial. Um dos exemplos do corpus mostra isso muito bem em:

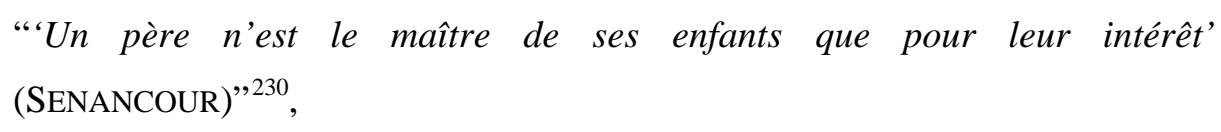

e no exemplo:

“Je ne veux d'autre gage que votre parole”231,

\footnotetext{
${ }^{227}$ ROBERT, Paul. Dictionnaire alphabétique \& analogique de la langue française. s.e. Paris: Société du nouveau Littré, 1981, ÉCHO, p. 596.

${ }^{228}$ WEINRICH, H. Grammaire textuelle du français. Paris: Didier/Hatier, 1989, p. 523.

${ }^{229}$ Id., ibid., p. 523.

${ }^{230}$ ROBERT, 1981, op. cit., MAITRE, MAITRESSE, p. 1134.

${ }^{231}$ Id., ibid., GAGE, p. 842.
} 
que não aceita a substituição da expressão “ne... que” por "seulement”, mas significa "ne veux pas d'autre gage sauf votre parole”. Entretanto, no exemplo seguinte, nem um nem outro são aceitos por modificar o sentido da frase:

“'Son Dieu prétendu n'est qu’un être malfaisant' (Rouss.)”232 (sentido mais negativo).

Seu pretenso Deus é somente um ser “malfaisant” (sentido atenuado, quase concessivo).

Segundo Wilmet (1997), “ne... que” é uma négation exceptive ${ }^{233}$ (negação exceptiva):

“Je n’avais du goût qu’à cause de toi. (Colette, Claudine à Paris, coll. du Livre de poche, 13) [= “j’avais du goût, mais seulement à cause de toi”]”234,

cujo “que” é um auxiliaire exceptif que anula a predicação negativa de "ne” e a substitui por uma positiva ${ }^{235}$. Esse “que” exceptif também pode ser considerado como um ligateur, uma conjunção que perdeu sua conotação primeira, mas que continua a atuar como connecteur vide $^{236}$ (conector vazio, conector zero):

“Marie attend que Pierre s'en aille”237,

ou como um tipo de “comparatif” non ligateur ${ }^{238}$ :

“Pierre n’aime que Marie (Marie est comparée à tout ce qui n’est pas elle)”239.

Em Charaudeau (1992), a forma negativa “ne... que” é uma expressão discursiva

\footnotetext{
${ }^{232}$ ROBERT, Paul. Dictionnaire alphabétique \& analogique de la langue française. s.e. Paris: Société du nouveau Littré, 1981, MALFAISANT, ANTE, p. 1138.

${ }^{233}$ WILMET, M. Grammaire critique du Français. Louvain-la-Neuve: Hachette Supérieur/Duculot, 1997, p. 163.

${ }^{234}$ Id., ibid., p. 163.

${ }^{235}$ Id., ibid., p. 514.

${ }^{236}$ Id., ibid., p. 550.

${ }^{237}$ Id., ibid., p. 550.

${ }^{238}$ Id., ibid., p. 551.

${ }^{239}$ Id., ibid., p. 551.
} 
quantitativa a partir do momento em que marca a totalidade, por exclusão de todo o resto, e restrita, quando tem o mesmo eixo semântico que a asserção implícita (a de base, a principal).

Há termos contáveis e não-contáveis, e para exprimir seus múltiplos utilizamos diversos artifícios. No caso dos não-contáveis, há expressões para transmitir o conceito de forte, neutro ou fraco, segundo o contexto, mas para cada Emissor e Receptor esses conceitos terão valores subjetivos. É o que ocorre com o termo "à peine”, que tem a noção de "faible" para "la quantité des êtres non dénombrables" e "l'intensité à des propriétés et des processus" ${ }^{240}$, como vemos abaixo:

"Je commence à peine le travail" "241.

Essa idéia também é transmitida pelo seguinte exemplo do corpus do Le Petit Robert: “Cette région n'est accessible que par avion”"242.

Essa noção de quantidade e de intensidade pode ser expressa de maneira plena ou restrita. Uma das formas de exclusão plena se caracteriza pela forma de exclusão de todo o resto, e aqui pela expressão "ne... que”, como vemos no exemplo:

“'Il ne fait que dire des bêtises' (et rien d'autre)”243.

E no corpus do Le Petit Robert:

"Il ne sait lire que l'imprimé"244.

O outro ponto importante em Charaudeau (1992) é a equivalência entre o termo "seul” - não "seulement" - e a négation exclusive "ne... que" como marcadores e formas do que chama de "l'Implication absolue réciproque"245. Esse fenômeno existe sob a condição de a asserção $1\left(A_{1}\right)$ implicar obrigatoriamente a asserção $2\left(A_{2}\right)$ e vice-versa $\left(A_{2} \Rightarrow A_{1}\right)$, como no

\footnotetext{
${ }^{240}$ CHARAUDEAU, P. Grammaire du sens et de l'expression. Paris: Hachette Éducation, 1992, p. 257-258.

${ }^{241}$ Id., ibid., p. 258.

${ }^{242}$ ROBERT, Paul. Dictionnaire alphabétique \& analogique de la langue française. s.e. Paris: Société du nouveau Littré, 1981, ACCESSIBLE, p. 12.

${ }^{243}$ CHARAUDEAU, 1992, op. cit., p. 273.

${ }^{244}$ ROBERT, 1981, op. cit., IMPRIMÉ, ÉE, p. 972.

${ }^{245}$ CHARAUDEAU, 1992, op. cit., p. 535.
} 
exemplo seguinte:

“Il n'y a que Maille qui m'aille” (Publicidade) ${ }^{246}$,

mas quando o autor analisa "l'actualisation et l'article” (atualização e artigo), faz a equivalência entre “ne... que” e "seulement":

“une négation dite exclusive (qui ne nie pas l’être impliqué, mais tous les autres possibles), exprimée par ne... que ou seulement:

'Je ne bois que de l'eau'; 'Je te demande seulement de la patience”,247.

Outra classificação, segundo Charaudeau (1992), sobre o termo "seul” e a expressão "ne... que” é ligada à "l'explication conditionnelle [...] exclusive»"248, na qual $\mathrm{A}_{1}$ trabalha como a condição de existência de $A_{2}$, como observamos abaixo:

"Tu n'iras au cinéma que si tu as fini ton travail",249.

Essa frase exemplifica muito bem o tom de ameaça que a restrição pode conter quando é seguida do marcador "si".

Charaudeau (1992) estuda a língua francesa pelo viés semântico, e devido a isso encontramos a expressão “ne... que” também classificada como Négation. Essa Négation pode ser enunciativa ou condensada ${ }^{250}$. Em ambos os casos, a expressão é apresentada como uma expressão que transmite uma noção de gradação em relação ao termo que a segue. Particularmente, o autor descreve a expressão "ne... que” como "négation exclusive”,251, como observamos abaixo:

“Il ne fait que manger!” (pressuposto: “il ne fait pas autre chose”) ${ }^{252}$.

\footnotetext{
${ }^{246}$ CHARAUDEAU, P. Grammaire du sens et de l'expression. Paris: Hachette Éducation, 1992, p. 535.

${ }^{247}$ Id., ibid., p. 177.

${ }^{248}$ Id., ibid., p. 538.

${ }^{249}$ Id., ibid., p. 538.

${ }^{250}$ Id., ibid., p. 555.

${ }^{251}$ Id., ibid., p. 559.

${ }^{252}$ Id., ibid., p. 559.
} 
Verificamos a mesma situação em outro exemplo do Le Petit Robert:

“Se dit d'un dispositif électrique (filtre) qui ne laisse passer qu'une bande de fréquence" ${ }^{253}$.

Outra classificação feita por Charaudeau (1992) da expressão “ne... que” é a de “identificateurs à valeurs de discrimination [...] sur le mode de l'exclusivité” (p. 294) para animado e inanimado, espaço, tempo e modo. Essa discriminação de identificação serve para distinguirmos um ou vários membros de um grupo em relação aos outros membros do mesmo grupo e podemos fazê-la por diferenciação, por exclusividade e por “l'apanage”254. No caso da expressão “ne... que”, essa distinção é feita por exclusividade e também depende da sua posição na frase:

“Il n'y a qu'un chameau qui puisse traverser le désert. 'Seulement (uniquement, exclusivement, rien que) un chameau peut traverser le désert.' (présupposé: un chameau peut traverser le désert; posé: un chameau et personne d'autre),255.

Apesar da expressão “ne... que” ser classificada como negação nas gramáticas normativas de francês e ter uma das duas principais partículas da negação francesa, ela possui um caráter excludente e afirmativo; a sinonímia da expressão “ne... que” com o advérbio francês "seulement" 256 também deve ser considerada. Sua definição não apresenta correspondência inversa, senão com a conjunção “mais”.

Deixamos as considerações de Paillard ${ }^{257}$ (1992) para o capítulo III, pois utilizaremos seus critérios ao analisarmos os exemplos coletados no corpus jornalístico.

\footnotetext{
${ }^{253}$ ROBERT, Paul. Dictionnaire alphabétique \& analogique de la langue française. s.e. Paris: Société du nouveau Littré, 1981, PASSE-BANDE, p. 1370.

${ }^{254}$ CHARAUDEAU, P. Grammaire du sens et de l'expression. Paris: Hachette Éducation, 1992, p. 294.

${ }^{255}$ Id., ibid., p. 297.

${ }^{256}$ ROBERT, 1981, op. cit., SEULEMENT, p. 1808.

${ }^{257}$ PAILLARD, D. Repérage : construction et spécification. In : BOUSCAREN, J. La théorie d'Antoine

Culioli. Paris : Ophrys, 1992. p.75-88.
} 


\section{CONCLUSÃO SOBRE O BINÔMIO “NE... QUE”}

Observamos que há diferentes conceitos para asserção, afirmação, negação, o papel de “ne” e "pas” na negação total e a terminologia adotada. Embora Gaatone ${ }^{258}$ (1971) considere a partícula "pas” como a negação principal do binômio “ne... pas” e não mais a partícula “ne”, ele classifica esta última como integrante dos termos negativos ${ }^{259}$, e declara: "En tant qu'élément autonome de l'énoncé, ne est toujours porteur d’un sens négatif et son emploi ou non-emploi sont pertinents”260. Essa é apenas uma das incoerências encontradas. Num momento, “ne” já não possui o caráter negativo, e no outro o possui (quando sozinho em subordinadas e em proposições independentes e principais, ou com os verbos negativos cesser, oser, pouvoir, savoir ${ }^{261}$, ou ainda com termos de valor sintático negativo ${ }^{262}$ ).

Outra questão observada refere-se à definição de "asserção" e ao uso indevido de “afirmação” para "asserção verdadeira”, conforme nos mostra Charaudeau quando diz que uma “asserção negativa” pode ser verdadeira ${ }^{263}$. Sendo a asserção verdadeira construída com as partículas "ne” e “pas”, definir a negação como o oposto ou o falso da afirmação (= “asserção verdadeira”) implica defini-la como uma asserção afirmativa:

“'Le plombier n'est pas venu' est niée 'la venue du plombier’.”" 264 = asserção verdadeira, por conseguinte, "afirmação";

"Le plombier est venu”265 = asserção falsa, por conseguinte, "negação”.

A sugestão de Wilmet (1997), de nomear o binômio “ne... que” négation exceptive e $^{266}$ e a de Weinrich (1989) de nomear négation restreinte (negação restrita) morfema

\footnotetext{
${ }^{258}$ GAATONE, D. Étude descriptive du système de la négation en français contemporain. Genebra: Librairie Droz, Publication romanes et françaises, 1971, p. 206.

${ }^{259}$ Id., ibid., p. 67.

${ }^{260}$ Id., ibid., p. 69.

${ }^{261}$ Id., ibid., p.69-80.

${ }^{262}$ Id., ibid., p. 133.

${ }^{263}$ CHARAUDEAU, P. Grammaire du sens et de l'expression. Paris: Hachette Éducation, 1992, p. 551.

${ }^{264}$ Id., ibid., p. 551.

${ }^{265}$ Id., ibid., p. 551.

${ }^{266}$ WILMET, M. Grammaire critique du Français. Louvain-la-Neuve: Hachette Supérieur/Duculot, 1997, p. 163.
} 
descontínuo, que exclui o objeto de toda negação que comporta a frase ${ }^{267}$, são bem interessantes. Os autores reconhecem o valor negativo da partícula "ne”, não contradizem a definição anterior a ela, a da negação, e mostram que o binômio "ne... que” faz parte de uma negação parcial que exclui da total o seu complemento. Concordamos que a explicação adquire uma "tournure" complexa, mas, como mostrou Charaudeau ${ }^{268}$, nem todas as asserções verdadeiras são afirmativas. A tentativa de explicar o binômio "ne... que” pela definição afirmativa (equivalente a "seulement" ${ }^{269}$ ) demonstra um esforço para em sustentar a tese de que todos os nossos pensamentos são positivos por princípio, o que Gaatone ${ }^{270}$ (1971) mostrou-nos não ser, aparentemente, mais verdadeiro para a França.

Concluindo este capítulo, observamos que somente Paillard ${ }^{271}$ chamou-nos a atenção para o "valor” da substituição de “ne... que” por "seulement”. Em seus exemplos, mostrounos que algumas substituições não alteram a intenção do locutor e outras a alteram completamente: “c. il n'est plus que médecin / il n'est plus seulement médecin”272.

\subsubsection{OS BINOMIOS “SANS QUE”, “RIEN QUE”, “BIEN QUE”, “AUTRE QUE”, “NUL AUTRE QUE” E “POUR PEU QUE”}

Grevisse (2006) nos diz que a expressão “sans que” pode ser considerada como uma expressão adverbial de modo ou de conseqüência não realizada ${ }^{273}$, como no exemplo:

“'Les dentes lui poussèrent sans qu'il PLEURÂT une seule fois' (FLAUB., Tr. contes, S. Julien, I), ${ }^{274}$,

\footnotetext{
${ }^{267}$ WEINRICH, H. Grammaire textuelle du français. Paris: Didier/Hatier, 1989, p. 523.

${ }^{268}$ CHARAUDEAU, P. Grammaire du sens et de l'expression. Paris: Hachette Éducation, 1992, p. 551.

${ }^{269}$ GREVISSE, M. Le bon usage. $13^{\mathrm{e}}$ edição, $6^{\mathrm{e}}$ reimpressão. Paris: Duculot, 2006, p. 1454.

${ }^{270}$ GAATONE, D. Étude descriptive du système de la négation en français contemporain. Genebra:

Librairie Droz, Publication romanes et françaises, 1971, p. 7.

${ }^{271}$ PAILLARD, D. Repérage : construction et spécification. In : BOUSCAREN, J. La théorie d'Antoine

Culioli. Paris : Ophrys, 1992. p.75-88, p. 83-84.

${ }^{272}$ Id., ibid., p. 84.

${ }^{273}$ GREVISSE, 2006, op. cit., p. 1647.

${ }^{274}$ Id., ibid., p. 1647.
} 
ou como um sintagma composto por uma preposição, “sans”, e uma conjunção subordinativa “que”, dando ao conjunto um valor restritivo:

“'Une cousine [...] était restée sept ans cloîtrée dans sa chambre à coucher [...], sans se lever QU'une fois ou deux par semaine' (PROUST, Rech., t. II, p. 304), 275 ,

ou ainda como uma locução conjuntiva de subordinação:

“'Il lui arrivait, désormais, sans MÊME que Tonton la battît, d'avoir de ces crises de larmes' (CARCO, Rue Pigalle, cit. Sandfeld, t. II, p. 419)”276.

Para Wagner e Pinchon (1991), o uso moderno da construção "sans... que” é uma retomada do sentido "sinon", “excepté”, atribuído a "que” nas frases interrogativas ou dubitativas $^{277}$, como no exemplo:

“'Votre manne m'a fait passer trois jours délicieux sans vous quitter que pour manger, s’il faut dire la vérité' (P. MERIMEE),"278,

mas, em geral, a expressão "sans... que” é uma locução subordinativa que introduz uma conseqüência:

“'Il était clair pour moi que les deux coquins s'entendaient et qu'ils avaient imaginé cette vente aux enchères par le ministère d'un huissier priseur, pour faire monter à un prix immodéré, sans qu'on pût le leur reprocher, le manuscrit dont je souhaitais la possession' (A. FRANCE)"279.

Segundo Weinrich (1989), “sans que” é uma conjunção privativa de sentido de “complétion” e de "objection”"280, sempre dando a idéia de falta ou de falta de pressuposto.

\footnotetext{
${ }^{275}$ GREVISSE, M. Le bon usage. 13e edição, 6 ${ }^{\mathrm{e}}$ reimpressão. Paris: Duculot, 2006, p. 1455.

${ }^{276}$ Id., ibid., p. 1537.

${ }^{277}$ WAGNER, R. L.; PINCHON, J. Grammaire du français classique et moderne. Paris : Hachette Supérieur, 1991, p. 427.

${ }^{278}$ Id., ibid., p. 427.

${ }^{279}$ Id., ibid., p.633-634.

${ }^{280}$ WEINRICH, H. Grammaire textuelle du français. Paris: Didier/Hatier, 1989, p. 464.
} 
Sendo assim, ela não teria o sentido de restrição que lhe é atribuído por Grevisse (2006) e Wagner e Pinchon (1991).

De acordo com Wilmet (1997), "sans que” (preposição + conjunção) e "sans même que” (preposição + advérbio + conjunção) são conjunções subordinativas de exclusão, e não de restrição ${ }^{281}$.

Charaudeau (1992) faz menção somente ao aspecto negativo do termo “sans”, assim como ao do termo "rien” em relação à quantidade nula ${ }^{282}$. Esse aspecto é uma "négation simple”283, que nega a existência de uma quantidade, mas também a existência do objeto ao qual faz referência:

$$
\text { “Il s'est présenté sans arme(s),284. }
$$

O autor também classifica o termo "sans" como uma "conjonction d'association" (conjunção associativa), na qual os dois elementos envolvidos não estão "sur le même plan d'égalité" ${ }^{285}$ no caso acima, o fato de que a pessoa poderia possuir uma arma mas não a ter no preciso momento.

Enquanto que a expressão “rien que”, segundo Grevisse (2006), adquiriu o sentido de "seulement" com o tempo, como no exemplo:

“'Qui se levait la première, le matin, RIEN QUE pour sentir l'air froid sur sa peau nue?' (ANOUIHL., Antig., p. 29)"286,

\footnotetext{
${ }^{281}$ WILMET, M. Grammaire critique du Français. Louvain-la-Neuve: Hachette Supérieur/Duculot, 1997, p. 547-548.

${ }^{282}$ CHARAUDEAU, P. Grammaire du sens et de l'expression. Paris: Hachette Éducation, 1992, p. 243.

${ }^{283}$ Id., ibid., p. 274.

${ }^{284}$ Id., ibid., p. 275.

${ }^{285}$ Id., ibid., p. 510-502.

${ }^{286}$ GREVISSE, M. Le bon usage. 13 edição, 6 ${ }^{e}$ reimpressão. Paris: Duculot, 2006, p. 1462.
} 
mas, ao contrário da expressão “ne... que”, composta por advérbios, a expressão “rien que” é uma construção composta por um pronome indefinido e uma conjunção subordinativa.

Wagner e Pinchon (1991) não tratam da expressão “rien que”. Eles analisam somente o pronome indefinido "rien” de sentido negativo e o substantivo "rien” de sentido positivo ${ }^{287}$.

Nem Weinrich ${ }^{288}$ (1989) nem Wilmet ${ }^{289}$ (1997) tratam do assunto.

Segundo Charaudeau (1992), a expressão “rien... que”, assim como a expressão “ne... que”, são “identificateurs à valeurs de discrimination [...] sur le mode de l'exclusivité" 290 para animado e inanimado, espaço, tempo e modo. Por exemplo:

“Après le repas, il n'aime fumer que le cigare. 'Après le repas, il aime fumer seulement (uniquement, exclusivement) le cigare' (présuposée: il aime fumer le cigare; posé: il n'aime fumer rien d’autre que le cigare),"291,

mas a função principal do termo "rien", assim como o termo "sans", é de negar a existência de um objeto e também a sua ausência ${ }^{292}$.

E para Grevisse (2006), “bien que” é uma locução conjuntiva mais utilizada na escrita que na fala ${ }^{293}$. Em Wagner e Pinchon (1991), essa expressão é classificada como uma oposição concessiva, construída na base da conjunção “que”:

“'C'était un assez beau cavalier bien qu'il eût les épaules étroites qu'étoffaient de lourdes épaulettes d'argent' (ARAGON)" ${ }^{294}$.

\footnotetext{
${ }^{287}$ WAGNER, R. L.; PINCHON, J. Grammaire du français classique et moderne. Paris : Hachette Supérieur, 1991, p. 206-210.

${ }^{288}$ WEINRICH, H. Grammaire textuelle du français. Paris: Didier/Hatier, 1989.

${ }^{289}$ WILMET, M. Grammaire critique du Français. Louvain-la-Neuve: Hachette Supérieur/Duculot, 1997.

${ }^{290}$ CHARAUDEAU, P. Grammaire du sens et de l'expression. Paris: Hachette Éducation, 1992, p. 294.

${ }^{291}$ Id., ibid., p. 297.

${ }^{292}$ Id., ibid., p. 274.

${ }^{293}$ GREVISSE, M. Le bon usage. $13^{\mathrm{e}}$ edição, $6^{\mathrm{e}}$ reimpressão. Paris: Duculot, 2006, p. 1652.
} 
Segundo Weinrich (1989) e Wilmet (1997), a expressão “bien que” é uma conjunção subordinativa concessiva:

“j'ai froid bien qu'il fasse chaud”295.

Para Charaudeau (1992), a “corrélation temporelle” é estabelecida uma vez que uma “relation d’interdépendance” entre dois eventos tem lugar ${ }^{296}$. Essa correlação temporal é expressa pela "vision de réalisation" (os modos) e a "vision de situation”"297 (os tempos verbais). Então, essa correlação pode ainda ser de diferentes “dépendances”298, e uma delas ser de “restriction” (restrição) expressa pela construção "bien que”" ${ }^{299}$ :

“Je veux bien l'aider financièrement, bien que lui-même ne m'ait jamais prêté de l'argent" 300 .

Podemos supor que outras pessoas já o fizeram. Apesar dessa característica restritiva, ela não é estabelecida sobre a mesma base de “que” como advérbio da expressão "ne... que”, mas sobre a base de uma conjunção, que tampouco possui o mesmo sentido que atribuímos a “seulement”. Não podemos substituir uma pela outra como os autores citados aqui o propõem para a expressão "ne... que”. Por conseguinte, podemos verificar aqui que falamos de diferentes tipos de restrição sob a mesma terminologia:

“Bien qu'il ait des responsabilités importantes, il n'est pas dépourvu pour autant de sentiments" ${ }^{301}$.

Essa frase é um exemplo de uma “restriction concessive”302.

\footnotetext{
${ }^{294}$ WAGNER, R. L.; PINCHON, J. Grammaire du français classique et moderne. Paris : Hachette Supérieur, 1991, p. 651.

${ }^{295}$ WEINRICH, H. Grammaire textuelle du français. Paris: Didier/Hatier, 1989, p. 463.

${ }^{296}$ CHARAUDEAU, P. Grammaire du sens et de l'expression. Paris: Hachette Éducation, 1992, p. 484.

${ }^{297}$ Id., ibid., p. 484.

${ }^{298}$ Id., ibid., p. 485.

${ }^{299}$ Id., ibid., p. 487.

${ }^{300}$ Id., ibid., p. 487.

${ }^{301}$ Id., ibid., p. 514.

${ }^{302}$ Id., ibid., p. 518.
} 
Ao mesmo tempo em que as expressões "autre que” e "nul autre que” não chegam a ser trabalhadas pelos autores mencionados até agora, a expressão “pour peu que”, somente é apresentada por Grevisse (2006) e por Charaudeau (1992).

O primeiro a classifica como locução adverbial de condição ${ }^{303}$, construída com uma conjunção:

$$
\text { "Il le fera pour peu que vous lui en PARLIEZ (AC.)."304 }
$$

Já para Charaudeau (1992), a expressão “pour peu que” é uma “implication conditionnelle” ${ }^{305}$ que introduz uma segunda asserção obrigatoriamente negada pela primeira $\left(\mathrm{A}_{1}\right)$. Essa implicação condicional pode ainda ser modulada por marcas restritivas. Infelizmente, o autor não dá nenhum exemplo com “pour peu que”.

${ }^{303}$ GREVISSE, M. Le bon usage. $13^{\mathrm{e}}$ edição, 6 e reimpressão. Paris: Duculot, 2006, p. 1667.

${ }^{304}$ Id., ibid., p. 1674.

${ }^{305}$ CHARAUDEAU, P. Grammaire du sens et de l’expression. Paris: Hachette Éducation, 1992, p. 532-533. 


\section{CAPÍTULO II}

\section{QUADRO TEÓRICO}

Utilizando o estudo de semântica gramatical desenvolvido pelo Prof. Jacques Ouellet $^{306}$ (2004), baseado na teoria psicomecânica de Gustave Guillaume $\left(1971^{307}, 1973^{308}\right)$, definiremos os conceitos de palavra simples e composta, expressão, locução e sintagma, advérbio e advérbio de negação, conjunção e conjunção subordinada, pronome, pronome relativo, interrogativo e indefinido, além daquele de restrição. Para tanto, exporemos rapidamente a teoria de Gustave Guillaume (1971, 1973), bem como seus conceitos sobre negação, restrição e o binômio “ne... que”.

\section{TeOria de Gustave Guillaume}

Segundo Fuchs e Le Goffic ${ }^{309}$ (1992), o trabalho estruturalista de Guillaume distribuise no período de 1919 a $1958^{310}$ opondo significante/significado, língua/linguagem e sincronia/diacronia.

Guillaume baseia-se na noção de sistema:

“Un système est un être abstrait, de pure relation, que l'intelligence voit par ses yeux propres, après en avoir fait la découverte en elle-même, au titre de

\footnotetext{
${ }^{306}$ OUELLET, J. Précis de sémantique grammaticale du français, notes de cours. Québec: Département de langues et linguistique de l’Université Laval, 2004.

${ }^{307}$ GUILLAUME, G. Leçons de linguistique de Gustave Guillaume 1948-1949: Psycho-systématique du langage. Principes, méthodes et applications I (B). Québec: Les Presses de l'université Laval / Paris : Librairie C. Klincksieck, 1971.

${ }^{308}$ Id. Leçons de linguistique de Gustave Guillaume 1948-1949: Grammaire particulière du français et grammaire générale (IV). Québec: Les Presses de l’université Laval / Paris : Librairie C. Klincksieck, 1973. ${ }^{309}$ FUCHS, C.; LE GOFFIC, P. Les linguistiques contemporaines: repères théoriques. Paris: Hachette, 1992. ${ }^{310}$ Id., ibid., p. 41.
} 
son existence plus ou moins masquée sous les faits de réalité sensible”, 311

para buscar a intenção primeira do locutor quando este se utiliza do código para transmitir essa intenção:

“un système ne devient observable qu'après un travail intellectif de reconstruction, lequel travail, très spécial, transcende, outrepasse la donnée d'observation directe, et par là suscite la défiance, illégitime, d'esprits prudents, imbus d'un positivisme excessif, et d'ailleurs périmé, dont les autres grandes sciences d'observation créées en science théorique ont su se dégager et se dégagent de plus en plus.”312

Na teorização de sua psicossistemática ou psicomecânica, Guillaume (1971) considera como base a separação entre a forma, o significante, a matéria e o significado:

“Toute la psycho-systématique est une étude des coupes par lesquelles la pensée délimite en elle-même, au sein de son activité, certains grands procès, et recoupe ensuite interceptivement ces procès, par le moyen de nouvelles coupes transversales qui, selon qu'elles sont précoces, ou tardives dans le mouvement qu'elles attaquent, confèrent au signe représentatif du mouvement une valeur différente.”313

Fuchs e Le Goffic (1992) exemplificam a teoria de Guillaume (1971) como um filme cinematográfico, o fluxo contínuo do pensamento, composto por vários quadros de fotos que representam, cada um, a expressão do pensamento pela linguagem ${ }^{314}$. Cada quadro encarado separadamente é considerado como um corte. Há dois tipos de cortes: a. transversal, do universal ao particular (ainda no abstrato); b. precoce e tardio, do abstrato ao concreto (na realização do discurso). No corte precoce e tardio (b), temos no precoce a língua ("la

\footnotetext{
${ }^{311}$ GUILLAUME, G. Leçons de linguistique de Gustave Guillaume 1948-1949: Psycho-systématique du langage. Principes, méthodes et applications I (B). Québec: Les Presses de l'université Laval / Paris : Librairie C. Klincksieck, 1971, p. 10.

${ }^{312}$ Id., ibid., p. 14-15.

${ }^{313}$ Id., ibid, p. 209.

${ }^{314}$ FUCHS, C.; LE GOFFIC, P. Les linguistiques contemporaines: repères théoriques. Paris: Hachette, 1992, p. 42.
} 
langue”), subjacente, contida em nós, e a nossa disposição, cuja unidade de "puissance” é a palavra, a partir da qual construímos o discurso. Esse discurso construído para durar o tempo de efeito é o corte tardio, a concretização momentânea do pensamento, constituído por unidades de efeito, a frase ${ }^{315}$. Temos assim, em princípio, um psicomecanismo gerador, no qual a palavra é a unidade da língua, e a frase a unidade do discurso ${ }^{316}$. Por conseguinte, o domínio da morfologia é o plano da "puissance”, e o da sintaxe, o plano de efeito ${ }^{317}$. É o que podemos ver resumidamente no quadro abaixo ${ }^{318}$ :

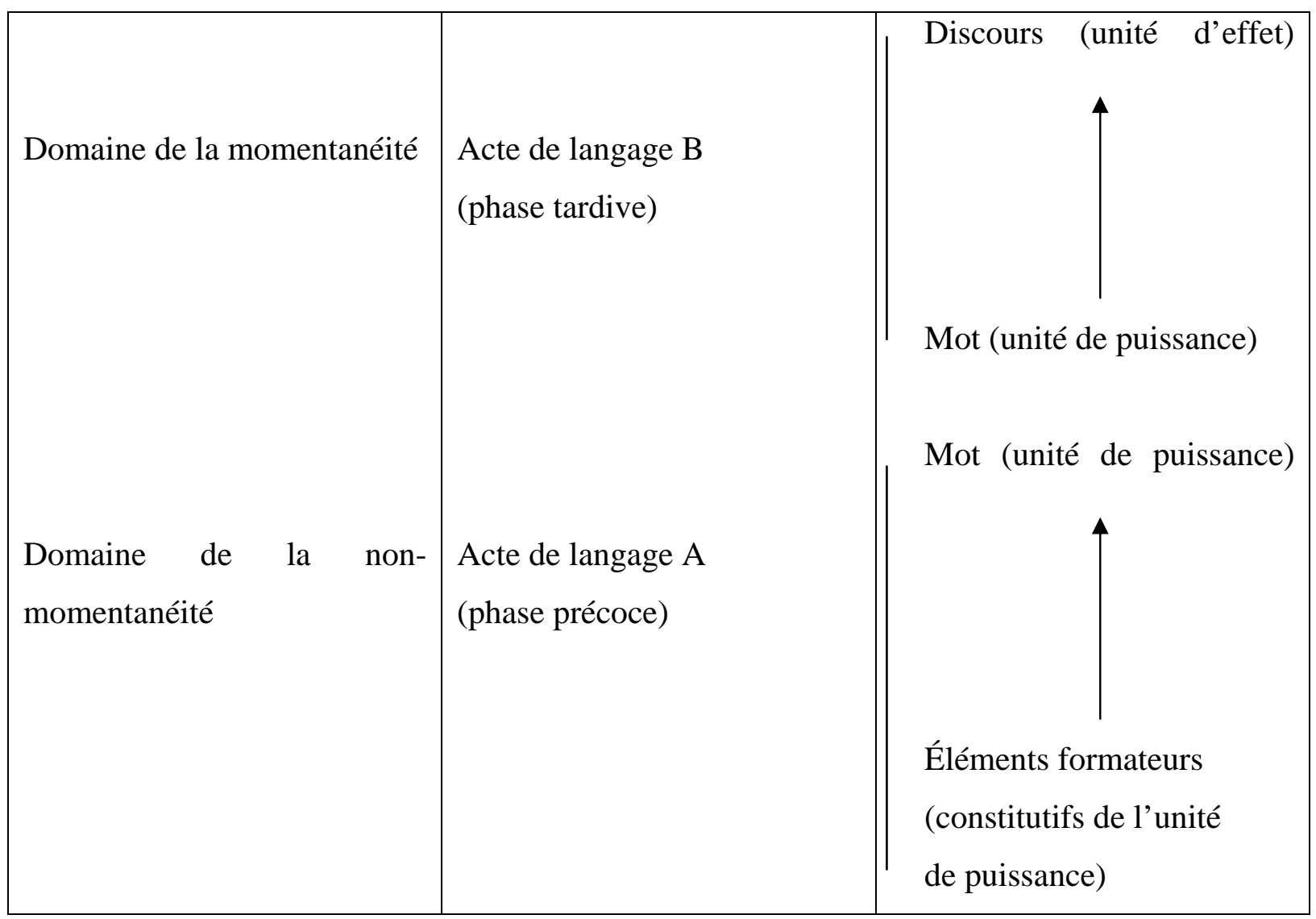

${ }^{315}$ GUILLAUME, G. Leçons de linguistique de Gustave Guillaume 1948-1949: Grammaire particulière du français et grammaire générale (IV). Québec: Les Presses de l’université Laval / Paris : Librairie C.

Klincksieck, 1973, p. 13.

${ }^{316}$ Id., ibid., p. 13.

${ }^{317}$ Id., ibid., p. 25.

${ }^{318}$ Id., ibid., p. 15. 
Segundo Dubois et al. (1998), “a lingüística de Guillaume é uma lingüística de posição: existe uma linha contínua sobre a qual se colocam momentos do pensar”319. Esse momento do pensar está representado, por exemplo, no uso do artigo indefinido "un” (do universal ao particular) ${ }^{320}$. No discurso, teremos o segundo corte chamado precoce ou tardio, dependendo do aspecto temporal ao qual está relacionado:

“un enfant est toujours l'ouvrage de sa mère” (corte precoce, generalizante);

“un enfant entra” (corte tardio, específico) ${ }^{321}$.

Esse corte tardio e precoce nem sempre se efetua nessa mesma direção, ou seja, do geral para específico, como nos mostram Fuchs e Le Goffic nos exemplos:

"l’homme entra" (corte precoce, específico);

"l'homme est mortel" (corte tardio, generalizante) ${ }^{322}$.

No caso da negação, temos:

“La négation est un procès psychique inscrit entre l'existant et l'inexistant, et qui se développe en direction du second terme - l'inexistant - lequel en marque l'aboutissant. Soit donc figurativement :

existant $\rightarrow$ inexistant (zéro)”323.

Essa negação apresenta-se de duas formas: a. in fieri (incompleta, inacabada), formada apenas pela partícula "ne”; e b. in esse (completa, acabada) formada pelas partículas "ne” e “pas”, “point”, “personne”, “rien”324, “aucun” e “jamais”,325. Segundo Guillaume (1973), a negação in fieri induz ao pensamento negativo, mas não a completa nem a conclui. É uma negação incompleta. Negação ainda, mas não total e para tanto, precisamos da segunda partícula do binômio. Essa incompletude da negação permite-nos exemplos como:

\footnotetext{
${ }^{319}$ DUBOIS, J. et al. Dicionário de lingüística. Frederico Barros et al.10ª edição. São Paulo: Editora Cultrix Ltda, 1998, p. 494.

${ }^{320}$ FUCHS, C.; LE GOFFIC, P. Les linguistiques contemporaines: repères théoriques. Paris: Hachette, 1992, p. 42.

${ }^{321}$ Id., ibid., p. 43.

${ }^{322}$ Id., ibid., p. 43.

${ }^{323}$ Id., ibid., p. 135.

${ }^{324}$ Id., ibid., p. 135.

${ }^{325}$ Id., ibid., p. 141.
} 
“Je $n$ 'ose le faire,

Et cela voudra dire, non pas que je ne me sens pas le courage de le faire, mais que je discerne, finement, des motifs de m'abstenir" ${ }^{326}$.

Essa nuança depende do discurso. Em cada caso há uma gradação diferente, sendo difícil e vã sua determinação.

Nos casos de “ne” expletivo, Guillaume (1973) os explica como sendo apenas a aparente emoção do locutor, por conseguinte, o não-valor da negação. Procurando mais a fundo o desejo do locutor, vemos no exemplo "Je crains qu'il ne vienne"327 o desejo subjacente do locutor (“Je désire la non-venue” e "Je crains la venue”, ${ }^{328}$ ) e "en face du verbe craindre, de visée positive, afin de marquer mieux le sens désidératif, qui est négatif, on a recours à la négation $n e$ dite explétive” ${ }^{329}$.

Temos então o caráter imanente de negação da partícula “ne”, que será completada ou não pela presença da segunda partícula do binômio (“pas”, “point”, “personne”, "rien”, “aucun” e “jamais”), e o caráter transcendente do movimento de negação.

No caso do binômio "ne... que", temos o corte mediano, entre o precoce e o tardio, do processo de negação iniciado pela partícula “ne”, feito pela partícula positiva “que”, como observamos no exemplo:

“il ne boit que de l'eau [...]

L'effet de sens final est l'idée d'une restriction: 'il boit, restrictivement, à l'exclusion d'autre chose, de l'eau',330.

Segundo a teoria psicomecânica, não há três palavras iguais com funções diferentes, como no caso da palavra “que”. Há, sim, uma só palavra com três empregos diferentes no

\footnotetext{
${ }^{326}$ GUILLAUME, G. Leçons de linguistique de Gustave Guillaume 1948-1949: Grammaire particulière du français et grammaire générale (IV). Québec: Les Presses de l'université Laval / Paris : Librairie C. Klincksieck, 1973, p. 136.

${ }^{327}$ Id., ibid., p. 137.

${ }^{328}$ Id., ibid., p. 137.

${ }^{329}$ Id., ibid., p. 137.

${ }^{330}$ MOIGNET, G. Systématique de la langue française. Paris: Klincksieck, 1981, p. 205-206.
} 
discurso, a de interrogativo, a de relativo e a de indefinido ${ }^{331}$, o que nos leva concluir que a partícula “que” de “ne... que” também se enquadra nesse caso.

\section{Estudo do Prof. M. JACQUES OUELleT}

Esse estudo é fundamentado na teoria da gramática semântica desenvolvida pelo Prof. Jacques Ouellet ${ }^{332}$ (2004) para estabelecer quais são os valores semânticos expressos, qual a natureza do "que” restritivo em francês e quais são as funções que ele exerce no binômio. Seu método de análise é baseado no sistema de representação conceitual, que produz os componentes formadores dos conceitos, e nos estudos do sistema de representação semiológico, que assegura a formação de signos e palavras que marcam conceitos.

O sistema conceitual questiona três níveis de operação: a produção de morfemas e de lexemas para formar os conceitos (a paradigmática), a instituição de relações de determinação entre lexemas e morfemas que formam os conceitos (a sintagmática) e a associação de conceitos que formam as frases (a sintaxe). A análise dessas três operações da linguagem (paradigmática, sintagmática e sintaxe) constitui a análise gramatical. Inicialmente, a análise paradigmática é centrada nos morfemas que constituem um sistema de valores semânticos. Esse sistema opõe uma série de noções, como o gênero, no qual há a oposição de morfemas femininos e masculinos. Outros paradigmas compreendidos nesse sistema são a extensão e o número para o substantivo; a extensão, o número e a voz para o particípio; a extensão, o número, a voz e o caso para o pronome; a extensão, o número e o caso para o jonctif (juntivo); o modo, o aspecto, o tempo, a pessoa e a extensão para o verbo e a extensão para o modal. A análise sintagmática trata das funções do suporte (aquela do determinado) e do aporte (aquela do determinante) nas relações que se instituem entre os componentes dos conceitos. Essas relações podem ser de designação, de predicação ou ainda de modalização entre o suporte e o

\footnotetext{
${ }^{331}$ MOIGNET, G. Esquisse d'une histoire psycho-mécanique de la phrase interrogative. Langages, 3, p.49-66, junho 1966, p. 50.

332 OUELLET, J. Précis de sémantique grammaticale du français, notes de cours. Québec: Département de langues et linguistique de l’Université Laval, 2004.
} 
aporte. A relação de designação caracteriza o conteúdo de um conjunto atribuindo-lhe uma propriedade específica (p.ex.: chemise blanche, onde “chemise” é o suporte de designação, o que é determinado, e "blanche”, o aporte de designação, o que determina). A relação de predicação caracteriza o contenant de um conjunto atribuindo-lhe uma propriedade genérica [p.ex.: “De ces îles, DEUX sont inhabitées”333, onde “deux” atribui uma característica genérica ao contenant sem especificar o conteúdo, por isso devemos acrescentar “îles”]. A relação de modalização caracteriza uma relação de appartenance (pertencimento) particular a um conjunto, um modo de appartenance a esse conjunto (p.ex.: Je vais très bien, onde "très" evoca uma modalidade que atua sobre “bien”). Finalmente, a análise sintática se interessa por essas mesmas relações, mas instituídas agora entre os conceitos, no nível da frase.

O conceito como tal é constituído por um componente lexical e outro gramatical. Por sua vez, o componente lexical é constituído por lexemas e morfemas lexicais; e o componente gramatical, por morfemas gramaticais comuns a todos os conceitos de uma mesma categoria, por exemplo, o gênero, o número e a extensão no caso do substantivo. Os morfemas gramaticais caracterizam cada conceito determinando sua natureza e, por conseguinte, condicionam as funções que esse conceito pode exercer na frase.

Definiremos o que é um conceito e estabeleceremos o que é uma palavra composta, um sintagma, um advérbio, um pronome relativo e uma conjunção para distinguir o "que" restritivo do “que” não-restritivo. Também tentaremos estabelecer o que é uma restrição, uma afirmação restritiva, uma negação e uma negação restritiva.

${ }^{333}$ GREVISSE, M. Le bon usage. 13e edição, 6 reimpressão. Paris: Duculot, 2006, p. 1012. 


\subsection{O CONCEITO E SUAS RELAÇÕES SINTAGMÁTICAS}

De acordo com Ouellet (2004), o conceito é representado por uma palavra oral ou escrita. A palavra oral é constituída por uma seqüência de fonemas, e a escrita, por uma seqüência de letras do alfabeto, também chamadas de grafemas ${ }^{334}$. Definiremos posteriormente o termo “palavra”. Esse signo, a palavra:

“[...] a comme fonction caractéristique de symboliser un concept, une unité de signification qui associe une composante lexicale qui en représente la valeur particulière à une composante grammaticale qui évoque la valeur générale commune à tous les concepts de même nature.»335

Segundo o autor, "un concept se compose de notions associées par les relations grammaticales qui lui confèrent le type de signification qui caractérise une partie du discours” ${ }^{336}$. Essas noções atribuem uma função gramatical de suporte ou de aporte em relação a outra noção. No exemplo chemise blanche, “chemise” é o suporte de designação, o que é determinado, e "blanche”, o aporte de designação, o que determina. Retomamos aqui a definição de Dubois et al. (1998) em relação à psicomecânica: “A lingüística de Guillaume é uma lingüística de posição: existe uma linha contínua sobre a qual se colocam momentos do pensar." 337

Há dois tipos de noções, a gramatical, “qui sont communes à tous les concepts d’une même catégorie”, e a lexical, “qui les opposent les uns aux autres”: “47) Le langage est source de malentendus” (SAINT-EXUPÉRY ${ }^{338}$, 2000, p.73 apud OUELLET, 2004, p. 24). Aqui observamos que o componente lexical é constituído pelas noções marcadas por mal, en e tend,

\footnotetext{
${ }^{334}$ OUELLET, J. Précis de sémantique grammaticale du français, notes de cours. Québec: Département de langues et linguistique de l’Université Laval, 2004, p. 16.

${ }^{335}$ Id., ibid., p. 16.

${ }^{336}$ Id., ibid., p. 23.

${ }^{337}$ DUBOIS, J. et al. Dicionário de lingüística. Frederico Barros et al.10ª edição. São Paulo: Editora Cultrix Ltda, 1998, p. 494.

${ }^{338}$ SAINT-EXUPÉRY, A. Le petit prince. Paris: Gallimard, Folio 3200, 2000.
} 
e o gramatical (propriedades comuns a todos os conceitos de uma mesma categoria) comporta as noções de ação terminada, de plural, de masculino e de substantivo ${ }^{339}$.

Essas noções, gramatical e lexical, que formam o conceito ajudam a caracterizar uma propriedade do conjunto do qual esse conceito faz parte. Ele é extensivo, indefinido, abrangente, universal e generalizante como o adjetivo, por exemplo, ou extensivo e definido como o substantivo. Por conseguinte, cada parte do discurso é caracterizada pelo tipo de propriedade do conjunto pelos quais é composta, seja ela formada por um sintagma composto por verbo-substantivo, seja por um composto por adjetivo-substantivo.

Esse conjunto sobre o qual discorremos possui um “contenant, c'est-à-dire un lieu d'appartenance plus ou moins extensif”, um “contenu, l'individu qui appartient à ce lieu” e "une relation d'appartenance du contenu au contenant” ${ }^{340}$ e manifesta-se em três tipos de relações: a de designação, em que o determinante age sobre o "contenu de l'ensemble" determinado; a de predicação, em que o determinante age sobre o conjunto como “contenant”; e a de modalização, em que o determinante age sobre a relação entre "contenu” e “contenant” ${ }^{341}$. Teremos então:

- relação de designação de:

o substantivo nominal: “197) Un beau vert”342;

“202) Max fait un travail utile / Le travail est nécessaire

$$
\text { à l'homme"343; }
$$

o substantivo particípio: “218) Elle a perdu un pendant d’oreille [...]”344;

o adjetivo nominal: “199) Un livre vert”345;

o adjetivo particípio: “216) [...] Un ciel rougissant / Un ciel rougi”346;

- relação de predicação:

\footnotetext{
${ }^{339}$ OUELLET, J. Précis de sémantique grammaticale du français, notes de cours. Québec: Département de langues et linguistique de l’Université Laval, 2004, p. 24.

${ }^{340}$ Id., ibid., p. 54.

${ }^{341}$ Id., ibid., p. 54.

${ }^{342}$ Id., ibid., p. 55.

${ }^{343}$ Id., ibid., p. 56.

${ }^{344}$ Id., ibid., p. 58.

${ }^{345}$ Id., ibid., p. 55.

${ }^{346}$ Id., ibid., p. 58.
} 
o pronominal:

- artigo: "Le cuivre est un métal”347 (quantificadores extensivos definidos e indefinidos, respectivamente);

- numeral: “Deux de ses fils ont gagné des prix”348;

- "numeral indefinido”: “234) Beaucoup se reconnaissent dans ses personnages" ${ }^{349}$;

- pronome pessoal casual e não-casual:

- pessoal não-casual: “moi”, “toi”, “nous”, “vous”, “soi”, “lui”;

- pessoal casual: “je”, “me”, “tu”, “te”, “nous”, “vous”, “on”, “se”, “il”, “le”, “lui”, “leur”, “y”, “en”;

o verbal: “261) Cette nuit-là je ne le vis pas se mettre en route. Il s’était évadé sans bruit. Quand je réussis à le rejoindre il marchait décidé, d’un pas rapide" $^{\text {350; }}$

o juntivo: estão nessa categoria as conjunções e os relativos devido a suas características em comum, aqui no caso de predicação verbal indeterminada ${ }^{351}$. São exemplos de juntivos os pronomes relativos casuais (“qui”, “que”, “où”, “dont”) e não-casuais (“qui”, “quoi”, “où”, “quel”):

- “263) Elle ne sait pas ce qu'il veut faire”;

- “264) On souhaite que la guerre cesse” ${ }^{352}$;

- relação de modalização:

o adverbial:

- de um substantivo nominal ou pronominal: “289) Seulement son père est venu le voir, seulement lui..”353;

\footnotetext{
${ }^{347}$ OUELLET, J. Précis de sémantique grammaticale du français, notes de cours. Québec: Département de langues et linguistique de l’Université Laval, 2004, p. 60.

${ }^{348}$ Id., ibid., p. 60.

${ }^{349}$ Id., ibid., p. 60.

${ }^{350}$ SAINT-EXUPÉRY, 2000, p. 93 apud OUELLET, 2004, p. 64.

${ }^{351}$ OUELLET, 2004, op. cit.p. 65.

${ }^{352}$ Id., ibid., p. 65.

${ }^{353}$ Id., ibid., p. 68.
} 
- de um adjetivo nominal ou pronominal: “290) Un ciel infiniment bleu" $^{354}$;

- de um verbo: “292) Ces ouvriers travaillent fort”"355;

- de uma preposição: “294) Politiquement, ils sont très à gauche”356;

- de outro advérbio: “296) Elle peut réussir cette épreuve très facilement" $^{357}$;

o preposicional: “297) On les a conduits de Montréal à Québec pendant la nuit" $^{358}$;

o de coordenação: “298) Pierre, Paul et Jean sont venus”359;

o verbal:

- transitivo e objeto: “310) Annie mange sa pomme” ${ }^{360}$;

- intransitivo: “322) L’eau coula sur le plancher”361,

- reflexivo: “364) L’affaire tournait à la tragédie”362.

Discorreremos rapidamente sobre os conceitos de palavra simples, palavra composta, locução, expressão, sintagma, advérbio, advérbio de negação, pronome, pronome relativo e conjunção na tentativa de classificar, segundo o estudo de Ouellet (2004), o “que” da expressão "ne... que” dos exemplos coletados no corpus jornalístico. Tentaremos verificar se há um tipo específico de “que” que atua como valor restritivo.

${ }^{354}$ OUELLET, J. Précis de sémantique grammaticale du français, notes de cours. Québec: Département de langues et linguistique de l’Université Laval, 2004, p. 68.

355 Id., ibid., p. 68.

${ }^{356}$ Id., ibid., p. 68.

${ }^{357}$ Id., ibid., p. 68.

${ }^{358}$ Id., ibid., p. 69.

${ }^{359}$ Id., ibid., p. 69.

${ }^{360}$ Id., ibid., p. 70.

${ }^{361}$ Id., ibid., p. 72.

${ }^{362}$ Id., ibid., p. 78. 
Segundo Ouellet (2004):

“(u)n mot est une séquence de sons ou de lettres qui est le signe d’un concept.

Ce signe marque la plus petite unité conceptuelle apte à remplir une fonction dans une phrase ou à constituer une phrase à elle seule.”363

O autor faz menção ao conceito de palavra simples de Togeby (1965), "le mot se définit [...] comme appartenant à l'inventaire comprenant les unités les plus petites capables de jouer le rôle de phrase” (p. 91 apud OUELLET, 2004, p. 11). As palavras são ainda definidas na escrita por espaços em branco antes e depois dela. Assim no exemplo fornecido por Ouellet (2004), retirado da obra Le Petit Prince, de Saint-Exupéry (2000, p. 15 apud OUELLET, 2004, p. 11), “Dessine-moi un mouton”, temos quatro palavras simples constituídas por seqüências de letras que marcam conceitos.

O signo formado por uma seqüência de sons lingüísticos (fonemas) na língua oral e por uma seqüência de letras (grafemas) na língua escrita representa um conceito, uma unidade de significação formada por um componente lexical e outro gramatical. O componente lexical especifica a característica particular, enquanto o gramatical remete ao grupo de conceitos de mesma natureza (ex.: os substantivos). Como as palavras, os signos devem comportar um conceito. As interjeições não são consideradas como signos, uma vez que não possuem função gramatical na frase. Desse modo, sons onomatopaicos desprovidos de conceitos em uma língua, como o português, podem tê-los em outras, como em algumas línguas africanas. Tudo depende do sistema no qual estão inseridos.

Existem ainda signos homófonos e homógrafos gramaticais, ou seja, homônimos gramaticais, que serão considerados como dois signos, duas palavras diferentes a partir do momento que representam conceitos de diferentes naturezas (ex.: fort substantivo, fort adjetivo e fort advérbio $)^{364}$, o que contraria a afirmação de Moignet ${ }^{365}$. Este nos diz que:

"La psycho-systématique ne peut admettre trois mots qui, un interrogatif, un

\footnotetext{
${ }^{363}$ OUELLET, J. Précis de sémantique grammaticale du français, notes de cours. Québec: Département de langues et linguistique de l’Université Laval, 2004, p. 11.

${ }^{364}$ Id., ibid., p. 21.

${ }^{365}$ MOIGNET, G. Esquisse d'une histoire psycho-mécanique de la phrase interrogative. Langages, 3, p. 49-66, junho 1966, p. 50.
} 
relatif, un indéfini; elle postule un dénominateur commun aux trois emplois $^{2}$. "366 (apud MOIGNET, 1966, p. 50).

Segundo Ouellet (2004), um conceito só pode conter um componente gramatical, mas pode ser formado por mais de um componente lexical. Assim são formados os conceitos complexos que possuem mais de um componente lexical mas só um gramatical. É esse fator que diferencia os conceitos complexos (a palavra composta na gramática normativa) dos sintagmas. Estes últimos são uma seqüência de signos que representam conceitos individuais com seus respectivos componentes gramaticais, enquanto os primeiros, os conceitos complexos, são vários signos que representam um só componente gramatical [ex.: “autoroute” (dois lexemas, um componente gramatical, um substantivo, uma função sintática); “auto” e "route” (dois lexemas, dois componentes gramaticais, dois substantivos, duas funções sintáticas na mesma frase)]:

$$
\text { “L’autoroute menait à la ville / L’auto roulait sur la route”367. }
$$

Ouellet (2004) não teoriza especificamente os conceitos de locução e de expressão. Supomos, então, que sejam adotados os desenvolvidos por Guillaume (1971, 1973), ou seja, os da gramática tradicional, pois não faz menção a eles.

\footnotetext{
366 “2. H. Frei, Interrogatif et Indéfini (P. Geuthner, Paris, 1940), propose une explication synchronique et systématique du problème (à l'exclusion du relatif). Il considère la valeur interrogative comme fondamentale, et écrit : 'Passer de l'interrogatif à l'indéfini, c'est passer du sens de langue au sens de parole, ou, comme cela peut s'exprimer dans la terminologie saussurienne, de la valeur à la signification. [...] Lorsqu'un Indo-Européen, si un tel peuple a jamais existé, employait l'interrogatif * $k w i$-comme un indéfini, il faisait passer le mot de la valeur de 'qui ?', qu'il avait dans la langue à la signification de 'quelqu'un', qu'il pouvait revêtir dans la parole.' Pour nous, le mot en langue est une forme porteuse d'une matière subtile, qui n'est autre qu'un refus de substance notionnelle, pouvant se résoudre en discours, soit en appel d'information (fonction d'interrogatif), soit en indétermination (fonction d'indéfini), soit, encore en instrument de translation nominalisatrice de phrase (fonction de relatif). Cf. notre ouvrage Le Pronom personnel français ; essai de psycho-systématique historique (C. Klincksieck, Paris, 1965) Chap. I : 'La catégorie pronominale', pp. 9-20.” (MOIGNET, G. Esquisse d'une histoire psycho-mécanique de la phrase interrogative. Langages, 3, p. 49-66, junho 1966, p. 50)

${ }^{367}$ OUELLET, J. Précis de sémantique grammaticale du français, notes de cours. Québec: Département de langues et linguistique de l’Université Laval, 2004, p. 31.
} 
O sintagma, segundo Ouellet (2004), é:

"L'association de deux ou plus de deux concepts par de tels rapports grammaticaux forme un syntagme si la séquence ainsi constituée a une fonction grammaticale dans une phrase. [...]

19) La maison blanche semble la plus grande.”368

Assim, temos "plus grande" reportando-se a "la” e formando o sintagma "la plus grande” (três lexemas, três componentes gramaticais, três funções sintáticas na mesma frase).

Advérbio é definido por Ouellet (2004) como um “adjetivo modal”:

"La modalisation est une relation syntagmatique où l'apport lexical ou l'événement représenté détermine une propriété de la relation d'appartenance qui définit un ensemble extensif. On distingue ainsi l'adjectif modal dit adverbe, du substantif modal dit préposition, du substantif modal dit coordonnant, de même que la détermination opérée par l'événement verbal par rapport au support passif du verbe.”369

Ainda segundo o autor:

“L’adverbe est un concept qui évoque une modalité lexicale d’un ensemble extensif de nature adjectivale : il détermine une modalité d'appartenance à un tel ensemble, ce qui fait qu'il ne remplit en syntaxe que des fonctions modales par rapport à d'autres concepts, qu'il détermine un substantif nominal ou pronominal : [...]

Un adjectif nominal ou pronominal :

290) Un ciel infiniment bleu [...]

Un verbe :

292) Ces ouvriers travaillent fort [...]

Une préposition :

${ }^{368}$ OUELLET, J. Précis de sémantique grammaticale du français, notes de cours. Québec: Département de langues et linguistique de l’Université Laval, 2004, p. 12.

${ }^{369}$ Id., ibid., p. 68. 
294) Politiquement, ils sont très à gauche [...]

Ou un autre adverbe :

296) Elle peut réussir cette épreuve très facilement" ${ }^{370}$.

Como Ouellet (2004) não teoriza especificamente sobre o advérbio de negação. Supomos, então, que sejam adotados os desenvolvidos por Guillaume (1971, 1973), como já descrito acima, uma vez que faz menção ao caráter universal e específico na sua análise sobre paradigmas de extensão ${ }^{371}$.

No que diz respeito ao pronome, Ouellet (2004) considera a existência de duas séries de pronomes. A primeira, de pronomes pessoais (“moi”, “toi”, “nous”, “vous”, “soi”, “lui”) e relativos (“qui”, “quoi”, “où”, “quel”), e a segunda, de pronomes pessoais casuais (“je”, “me”, “tu”, “te”, “nous”, “vous”, “on”, “se”, “il”, “le”, “lui”, “leur”, “y”, “en”) e relativos casuais (“qui”, “que”, “où”, “dont”) ${ }^{372}$. Os pronomes pessoais manifestam a mesma valência sintática que os outros pronomes, e os relativos exigem uma relação particular com o verbo:

“383) Savez-vous à qui / à quel ami / pourquoi / d’où il téléphone ?

384) Est-ce qu'il pense à toi et à nous ou seulement à lui-même?”373.

Os pronomes pessoais e relativos casuais exigem uma relação com o verbo e excluem qualquer uma com a preposição. De acordo com o autor ${ }^{374}$, a morfologia dos pronomes casuais é herança dos pronomes em latim, como vimos na etimologia da partícula "que” no capítulo I (DAUZAT, A.; DUBOIS, J.; MITTERAND, H., 1993, p. 637-638; BLOCH, O.; WARTBURG, W., 1989, p. 524; CLÉDAT, L., 1947, p. 540). Essa herança manifesta-se nos casos em que os pronomes pessoais e relativos casuais assumem em francês moderno:

\footnotetext{
${ }^{370}$ OUELLET, J. Précis de sémantique grammaticale du français, notes de cours. Québec: Département de langues et linguistique de l'Université Laval, 2004, p. 68.

${ }^{371}$ Id., ibid., p. 43.

${ }^{372}$ Id., ibid., p. 80-81.

${ }^{373}$ Id., ibid., p. 80-81.

${ }^{374}$ Id., ibid., p. 81.
} 
nominativo (“il” e “qui”), acusativo (“le” e “que”), dativo (“lui”), locativo (“y” e “où”) e ablativo (“en" e “dont”)

Especificamente sobre o pronome relativo, Ouellet (2004) afirma que:

"La morphologie grammaticale des relatifs casuels représente une relation qui en conditionne la fonction par rapport au verbe subordonné, ce qui exclut que cette relation soit représentée par une préposition.»376

Como mostrado anteriormente, os pronomes relativos casuais apresentam-se sob a forma de nominativo (“qui”), acusativo (“que”), dativo (ø), locativo (“où”) e ablativo (“dont”) ${ }^{377}$. No caso específico do acusativo, “que” representa uma situação passiva em relação a um evento verbal, e o pronome faz referência a um ser animado ou inanimado ${ }^{378}$, como vemos nos exemplos a seguir:

"en fonction objet

413) La personne que tu vois / La pierre qu’il a lancée ou en fonction attribut :

414) L'homme $q u$ 'il devient / La chose inerte $q u$ 'est cette pierre”379.

Ouellet (2004) classifica numa mesma categoria os juntivos, as conjunções e os pronomes relativos devido às suas características comuns: "Une caractéristique fondamentale d'un jonctif est qu'il fait de son support extensif le lieu d'une prédication verbale indéterminée» ${ }^{380}$. Por exemplo:

“263) Elle ne sait pas ce $q u$ 'il veut faire

\footnotetext{
${ }^{375}$ OUELLET, J. Précis de sémantique grammaticale du français, notes de cours. Québec: Département de langues et linguistique de l’Université Laval, 2004, p. 81.

${ }^{376}$ Id., ibid., p. 85.

377 Id., ibid., p. 81.

${ }^{378}$ Id., ibid., p. 85

${ }^{379}$ Id., ibid., p. 85.

${ }^{380}$ Id., ibid., p. 65.
} 
264) On souhaite que la guerre cesse”381,

e:

“ont comme particularité d’admettre un complément de désignation évoquant une prédication verbale, ce qui est le fait aussi bien du conjonctif :

571) Le fait qu'il soit venu n’y change rien [...]

Que du relatif :

576) Il ne sait de qui il devrait se méfier”382.

\subsection{RELAÇÕES SINTÁXICAS}

Segundo o autor, enquanto a análise sintagmática examina as relações na formação dos conceitos e as relações internas da própria palavra, a análise sintática estuda as relações entre os sintagmas e as frases formados pelas palavras. Aqui vemos relações de base análogas às encontradas na sintagmática: “L’association d’un support évoquant 'ce dont on parle’ à un apport évoquant 'ce qu'on dit' de ce support.”’383 Como na sintagmática (item 2.1), observamos “des rapports de désignation si l'apport porte sur le contenu de l'ensemble support, [...] de prédication si cet apport porte sur cet ensemble en tant que contenant, et [...] de modalisation si cet apport porte sur la relation qui associe contenu et contenant”384.

Teremos então:

- na designação sintática, o complemento de designação (“complément de désignation” ${ }^{385}$ ):

o substantival: “535) [...] un gâteau maison”386;

o adjectival: “535) un gâteau délicieux [...]”387;

\footnotetext{
${ }^{381}$ OUELLET, J. Précis de sémantique grammaticale du français, notes de cours. Québec: Département de langues et linguistique de l’Université Laval, 2004, p. 65.

${ }^{382}$ Id., ibid., p. 107.

${ }^{383}$ Id., ibid., p. 101.

${ }^{384}$ Id., ibid., p. 101.

${ }^{385}$ Id., ibid., p. 102.

${ }^{386}$ Id., ibid., p. 102.

${ }^{387}$ Id., ibid., p. 102.
} 
o pronominal: “551) La maison est jolie”388; “555) La plus grande de ses chemises est sa verte" ${ }^{389}$;

o do verbo auxiliar: “562) Cet ingénieur a travaillé trois jours à ce projet”; “563) Ses amis sont rentrés tôt” ${ }^{390}$;

o do juntivo evocando predicação verbal:

- com conjuntivo: “571) Le fait qu’il soit venu n’y change rien”; “573) Il se défend comme il peut" ${ }^{391}$;

- com relativo: “574) C’est l'affaire dont il vous a parlé”392;

- na predicação sintática, o complemento de predicação:

o nominal e pronominal: “578) Les alpinistes, épuisés, ont dressé leur tente”393;

o verbal: sujeito e predicado: “580) Les doryphores circulaient un peu partout à travers l'herbe et sur le trottoir en ciment qui prolongeait l'escalier” (Le Clezio 1967:19 apud OUELLET, 2004, p. 109) $)^{394}$

o atributiva:

- do suporte ativo do verbo faz referência ao sujeito gramatical ou ao sujeito lógico do verbo e pode ter natureza nominal, adjetival, pronominal ou verbal (no infinitivo):

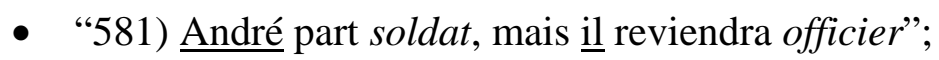

- “583) Amélie marchait heureuse sur la plage”;

- “584) Ses amies arrivèrent les dernières”;

- “587) Les visiteurs vont admirer ces monuments”395;

- do suporte passivo do verbo é um determinante predicativo do suporte passivo do verbo ou do particípio passivo ${ }^{396}$ e faz referência ao sujeito gramatical ou ao sujeito lógico do verbo se o verbo é reflexivo:

\footnotetext{
388 OUELLET, J. Précis de sémantique grammaticale du français, notes de cours. Québec: Département de langues et linguistique de l'Université Laval, 2004, p. 105.

${ }^{389}$ Id., ibid., p. 104.

${ }^{390}$ Id., ibid., p. 106.

${ }^{391}$ Id., ibid., p. 107.

${ }^{392}$ Id., ibid., p. 107.

${ }^{393}$ Id., ibid., p. 108.

${ }^{394}$ LE CLÉZIO, Jean-Marie Gustave. Terra amata. Paris: Gallimard, 1967. 243p.

${ }^{395}$ OUELLET, 2004, op. cit., p. 110.
} 
- “590) À l'automne, les forêts deviennent multicolores”397;

- “591) Eugène semble renoncer à son projet”398;

- “600) Le vin rend Marie euphorique $\Rightarrow$ Il la rend euphorique" ${ }^{399}$;

- “619) Ella aperçut ses amies qui sortaient $\Rightarrow$ Elle les aperçut qui sortaient ${ }^{300}$;

- “621) On a laissé brûler le feu $\Rightarrow$ On l’a laissé brûler" ${ }^{401}$;

- “631) Ces chansons, on les entend chanter tous les jours" ${ }^{\text {"02 }}$;

- na modalização sintática, o complemento modal:

o de suporte substantival ou pronominal;

o de suporte adverbial;

o de suporte sintagma preposicional;

o de suporte verbal.

No exemplo "535) [...] un gâteau maison” 403 , temos "gâteau” na função de suporte, o núcleo, e "maison" na de aporte. Observamos que os aportes de designação do substantivo e do pronome podem ser sintagmas preposicionais, relativos e conjuntivos, como nos exemplos abaixo:

- designação do substantivo:

o sintagma preposicional: "547) Une robe à fleurs; Un bulletin de vote; Une maison en pierre" ${ }^{404}$;

o sintagma relativo: “548) Les enfants qui vont à l'école. L’arrangement dont nous avons parlé ; La ville où il travaille" ${ }^{\text {405; }}$

\footnotetext{
${ }^{396}$ OUELLET, J. Précis de sémantique grammaticale du français, notes de cours. Québec: Département de langues et linguistique de l’Université Laval, 2004, p. 116.

${ }^{397}$ Id., ibid., p. 111.

${ }^{398}$ Id., ibid., p. 111.

${ }^{399}$ Id., ibid., p. 112.

${ }^{400}$ Id., ibid., p. 113.

${ }^{401}$ Id., ibid., p. 113.

${ }^{402}$ Id., ibid., p. 114.

${ }^{403}$ Id., ibid., p. 102.

${ }^{404}$ Id., ibid., p. 104.
} 
o sintagma conjuntivo: “549) Le jour qu'il est venu ; Le fait qu'il vous ait aidé ; Un professeur comme on n'en trouve plus" 406

- designação do pronome:

o sintagma preposicional: “558) $\underline{\text { Un }}$ de ses amis est venu le voir”407;

o sintagma relativo: “560) Ceux qui travaillent n'ont pas le temps de se faire du souci" ${ }^{408 ;}$

o sintagma conjuntivo: “Ce qu’il est gentil de vous aider !”409.

${ }^{405}$ OUELLET, J. Précis de sémantique grammaticale du français, notes de cours. Québec: Département de langues et linguistique de l’Université Laval, 2004, p. 104.

${ }^{406}$ Id., ibid., p. 104.

${ }^{407}$ Id., ibid., p. 105.

${ }^{408}$ Id., ibid., p. 105.

${ }^{409}$ Id., ibid., p. 105. 


\section{CAPÍTULO III}

\section{ANÁLISE DO CORPUS}

\section{Metodologia}

Aplicando o método comparativo, analisaremos os exemplos de emprego restritivo encontrados no corpus. Inicialmente definiremos as diferentes naturezas do "que” com base na teoria da semântica gramatical. Em seguida, analisaremos as funções sintáticas e verificaremos quais as condições mais favoráveis (qual complemento e posição na frase) para a manifestação do sentido restritivo do termo “que”. Por fim, escolheremos os exemplos mais significativos do emprego do "que" restritivo para verificar a equivalência direta com a classificação de Paillard ${ }^{410}$ (1992).

\section{CORPUS JORNALÍSTICO}

Analisaremos e classificaremos os exemplos de emprego do "que" restritivo fornecidos pelo corpus composto por exemplos retirados de artigos dos jornais eletrônicos Le Monde e Libération, coletados no período de $1^{\circ}$ a 30 de julho de 2006. Devido a problemas de acesso, não foi possível coletar artigos diários do jornal Libération, o que ocasionou algumas janelas.

A escolha do corpus jornalístico deveu-se a intenção de examinar exemplos atuais, “não engessados”. Em decorrência dessa escolha , não há uniformidade nem no tema dos artigos nem nos autores. Portanto, os artigos escritos por vários autores foram retirados de

\footnotetext{
${ }^{410}$ PAILLARD, D. Repérage : construction et spécification. In : BOUSCAREN, J. La théorie d'Antoine Culioli. Paris : Ophrys, 1992. p.75-88.
} 
vários cadernos dos jornais escolhidos. Assim, esperamos mostrar também se há ou não um texto típico no qual a expressão “ne... que” aparece e que não representa um estilo típico de algum autor determinado.

\section{ANÁLISE}

\subsection{SEgundo PaILlard (1992)}

Paillard (1992) nos diz que a noção de "repérage"411 (determinação) ocupa uma posição central na teoria de Culioli e essa determinação é caracterizada por um operador que relaciona dois termos simples ou complexos. Essa relação pode ser do tipo “construction” (construção) e "spécification" (especificação) ${ }^{412}$. O tipo construção implica forte dependência entre o termo determinante (a base da construção) e o termo determinado (ex.: "Sur la table il

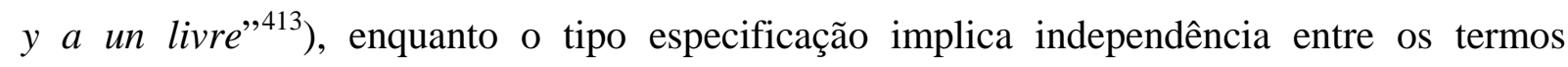
determinante e determinado (ex.: "Le livre est sur la table" ${ }^{414}$ ). Teremos, assim, a relação de tipo construção de um termo mais ligada à predicação de existência e à quantificação, e a relação de tipo especificação mais ligada à qualificação do termo.

Segundo o autor, embora em alguns casos "ne... que” e "seulement" tenham valor semântico comum, nem sempre podem ser tomados um pelo outro sem comprometimento do enunciado $^{415}$. Ele classifica os enunciados em três grupos: grupo A, com uma interpretação próxima, mas não idêntica: “a1. il n’y a qu'un livre sur la table / il y a seulement un livre sur la table”; “a2. il n'est pas que médecin / il n’est pas seulement médecin”416; grupo B, no qual

\footnotetext{
${ }^{411}$ PAILLARD, D. Repérage : construction et spécification. In : BOUSCAREN, J. La théorie d’Antoine Culioli. Paris : Ophrys, 1992. p.75-88, p. 75.

${ }^{412}$ Id., ibid., p. 76.

${ }^{413}$ Id., ibid., p. 77.

${ }^{414}$ Id., ibid., p. 77.

${ }^{415}$ Id., ibid., p. 83, nota 6: “Je n’envisagerai pas ici les autres marqueurs de restriction comme uniquement, juste, simplement ; comparer : je prendrai seulement le plat du jour / je ne prendrai que le plat du jour / je prendrai juste le plat du jour / je prendrai simplement le plat du jour."

${ }^{416}$ Id., ibid., p. 84.
} 
somente um deles é possível: "b1. je ne fais que passer / *je fais seulement passer”; "b2. je voulais seulement lui dire deux mots / *je ne voulais que lui dire deux mots”417; e grupo C, no qual ambos são possíveis, mas com alteração de interpretação: “c. il n'est plus que médecin / il n'est plus seulement médecin" ${ }^{418}$. Paillard nos diz ainda que, para os grupos B e C, "ne... que” é uno com “seulement” em relação ao “résultat de chemins différents que l'on peut représenter en termes de repérages” ${ }^{419}$. Sendo assim:

“Ne... que signifie qu’étant donné une classe, un repère sélectionne un terme et ne sélectionne pas les autres termes de la classe. [...] Dans ce cas l’unicité du terme est le résultat d'un repérage de type construction. Seulement signifie qu'étant donné une classe de termes, cette classe est spécifiée comme identique à un terme sélectionné par ailleurs sur cette classe. Le repérage est de type spécification. [...]

Ainsi, ne... que gère le rapport du terme à la classe en termes de coexistence (sélection positive et négative) alors que seulement gère ce rapport en termes d'exclusion” ${ }^{420}$.

Essa definição refere-se a enunciados do grupo B, e "ne... que" é interpretado do ponto de vista temporal como “ne... plus” para enunciados do grupo C.

Tentaremos analisar os exemplos abaixo segundo os critérios estabelecidos por Paillard (1992), procurando por marcadores que justifiquem a não possibilidade de troca (grupo B) ou a possibilidade com alteração de sentido (grupo C), e sob o ponto de vista de falante do português do Brasil (a). Foi pedido a colegas franco-quebequenses (G. Boudreau e V. Tremblay), estudantes de pós-graduação em lingüística francesa e espanhola, que classificassem de forma espontânea alguns exemplos. Cada exemplo será analisado em três fases: a. substituindo-se o binômio "ne... que” por "seulement” em francês; b. considerando-

\footnotetext{
${ }^{417}$ PAILLARD, D. Repérage : construction et spécification. In : BOUSCAREN, J. La théorie d’Antoine Culioli. Paris : Ophrys, 1992. p.75-88, p. 84.

${ }^{418}$ Id., ibid., p. 84.

${ }^{419}$ Id., ibid., p. 84.

${ }^{420}$ Id., ibid., p. 84-85.
} 
se as apreciações de nossas colegas franco-quebequenses, e c. traduzindo-se para o português e considerando-se suas possibilidades e interpretações.

Acreditamos ser importante o enfoque dado pela língua portuguesa, pois ainda mantemos em uso a conotação negativa do termo "apenas" de origem negativa "adv. 1 . Difìcilmente, com dificuldade, ùnicamente” (TORRINHA, 1939, p.97), “adv. penosamente, com dificuldade” (AULETE, 1958, v. 1, p.396), enquanto que o termo "somente” conserva seu aspecto etimológico positivo: “Adv. unicamente, exclusivamente, só, apenas; quando muito, tão só (...)” (AULETE, 1958, v. 5, p.4748) e "sòmente, com sentido adversativo, constitue galicismo. Diga-se: mas, porém, todavia, contudo, não obstante, o que é é que etc. Em Eça topa-se o uso afrancesado. Os clássicos têm sòmente por excepto.” (AMARAL, 1938, v.1, p.332).

\subsection{SEGUNDO OUELLET (2004)}

Aplicando-se o método comparativo, analisaremos os exemplos, de emprego restritivo encontrados no corpus jornalístico. Uma primeira análise consistirá em definir as diferentes naturezas do "que" com base na teoria da semântica gramatical. Trata-se de um termo independente do "ne”? É o mesmo conceito em todos os casos? Trata-se de um advérbio, uma conjunção, um relativo ou outro tipo de conceito? Qual a diferença entre esses tipos de conceitos? Essa análise será o índice “d” de cada exemplo. Procuramos, com isso, determinar se há freqüência maior de alguma natureza do “que” ou alguma função sintática de seu complemento recorrente. Tentaremos visualizar se podemos cruzar essa informação com a classificação segundo os critérios de Paillard, bem como se há algum reflexo na morfologia e na sintaxe dos possíveis marcadores encontrados nos exemplos analisados. 


\subsection{EXEMPLOS:}

Resumidamente, cada exemplo constará de: exemplo original retirado do corpus jornalístico; a. exemplo em francês apresentando as possíveis substituições de "ne... que” por "seulement” com nossa análise segundo os critérios de Paillard; b. classificação feita pelas colegas franco-quebequenses segundo o critério de Paillard; c. possíveis traduções para o português do exemplo original; d. classificação morfológica da partícula “que” e sintática de seu complemento, visando a encontrar algum padrão comum com os critérios de Paillard.

1) "Le 21 juin chez Sotheby's, le galeriste new-yorkais Jeffrey Deitch a acquis un panneau de 1966 pour 1,18 million de livres sterling. 'On ne connaissait que quatre autres oeuvres de cette série, et en dehors de la nôtre il n'en restait qu'une seule en mains privées.', précise Grégoire Billault, spécialiste de Sotheby's.” (AZIMI, R. L'art cinétique atteint des records. Le Monde. Disponível em: < http://www.lemonde.fr/web/article/0,1-0,36790675,0.ht$\underline{\mathrm{ml}}>$. Acesso em 01 jul. 2006.)

a. "Le 21 juin chez Sotheby's, le galeriste new-yorkais Jeffrey Deitch a acquis un panneau de 1966 pour 1,18 million de livres sterling. 'On connaissait seulement quatre autres oeuvres de cette série, et en dehors de la nôtre il n'en restait qu'une seule en mains privées', précise Grégoire Billault, spécialiste de Sotheby's.”

Segundo Robert ${ }^{421}$ (1997, CONNAÎTRE): “- Ne connaître que : tenir compte seulement de. Il ne connaît que son devoir, que la consigne. considérer, s'intéresser”" (grifos do autor). Assim, classificamos esse primeiro exemplo como do tipo C, pois como vimos em Robert (1997), “ne connaître que” é uma expressão sinônima de “On ne s’intéressait qu’à 4 autres œuvres de cette série”, e, por opção, ignorávamos as outras obras da mesma série. Quando substituímos “ne... que” por "seulement”, mudamos o sentido da frase (“On connaissait seulement 4 autres œuvres de cette série”), pois agora eles não mais se

${ }^{421}$ ROBERT, P. Le Petit Robert électronique, 1997, CONNAÎTRE ; Le Petit Robert, 2000, CONNAîTRE, p. 498. 
interessam por apenas 4 outras obras da série, mas conhecem apenas 4 outras obras de uma série de 10 , por exemplo.

De acordo com Franckel e Lebaud ${ }^{422}$ (1990), o verbo “connaître” marca uma relação de localização pré-construída entre o sujeito e o complemento. A existência das obras é marcada pelo valor intrínseco do verbo “connaître”, que indica “existência”, e, a partir de sua localização pelo sujeito, é reconhecida pelo sujeito, no nosso caso, “on”.

b. Para Boudreau e Tremblay, tanto o exemplo com "ne... que" quanto aquele com “seulement” são integrantes do grupo A estabelecido por Paillard. É indiferente o uso de um ou de outro termo, pois não há alteração de sentido.

c. As traduções para o português do exemplo coletado poderiam ser:

X1. Considerávamos apenas quatro outras obras dessa série, e, afora a nossa, restava apenas uma em mãos particulares.

X2. Interessávamo-nos por apenas quatro outras obras dessa série, e, afora a nossa, restava apenas uma em mãos particulares.

X3. Conhecíamos somente quatro outras obras dessa série, e, afora a nossa, restava somente uma em mãos particulares.

d. Temos o "que” de natureza adverbial nos dois exemplos acima, com complementos na função de atributo do suporte passivo do verbo, chamado tradicionalmente de objeto direto.

2) "'On ne connaissait que quatre autres oeuvres de cette série, et en dehors de la nôtre il n'en restait qu'une seule en mains privées.', précise Grégoire Billault, spécialiste de Sotheby's.” (AZIMI, R. L'art cinétique atteint des records. Le Monde. Disponível em: < http://www.lemonde.fr/web/article/0,1-0,36-790675,0.html>. Acesso em 01 jul. 2006.)

a. Segundo Robert ${ }^{423}$ (1997, RESTER): “ $\diamond$ Impers. Il ne restait qu'un bout de pain. Il en reste un fond de bouteille. "Et s'il n'en reste qu'un, je serai celui-là! » (ugo $)$. Quatre ôté de neuf, (il) reste cinq ( $\Rightarrow$ différence)". Classificamos esse exemplo como do grupo A,

\footnotetext{
${ }^{422}$ FRANCKEL, J.-J.; LEBAUD, D. Les figures du sujet. A propos des verbes de perception, sentiment, connaissance, 1990, p.107-108.

${ }^{423}$ ROBERT, P. Le Petit Robert électronique, 1997, RESTER.
} 
segundo os critérios de Paillard, pois representa apenas uma quantidade selecionada e funciona como o exemplo fornecido por ele mesmo ${ }^{424}$ : “a1. il n'y a qu'un livre sur la table / il y a seulement un livre sur la table”, e lembramos o que o autor nos disse: "A. Enoncés où ne...que et seulement sont tous les deux possibles avec une interprétation très proche”. Aqui, encontramos nossa diferença lusófona entre “apenas” e “somente”. Interpretação próxima significa interpretação parecida, mas não a mesma. No caso, para nós, a interpretação não é tão “próxima” assim, pois o valor semântico do texto pode ser alterado substancialmente segundo o cotexto. Desse modo, teremos assim na segunda parte do exemplo " 'et en dehors de la nôtre il n'en restait qu'une seule en mains privées"” (“e, à parte a nossa, ainda restava apenas uma em mãos particulares, infelizmente”) contra “'et en dehors de la nôtre *il en restait seulement une seule en mains privées" " ("e, à parte a nossa, restava somente uma em mãos particulares, felizmente”) ou “'et en dehors de la nôtre il en restait une seule en mains privées'”. Quadro esse que esperavam reverter logo, adquirindo a obra. A dúvida que nos resta aqui é se não seria mais um caso do grupo B do que do grupo A devido a essa grande diferença de valor semântico em português.

b. Para Boudreau e Tremblay, tanto o exemplo com “ne... que” quanto aquele com “seulement” são integrantes do grupo A estabelecido por Paillard. É indiferente o uso de um ou de outro termo sem alteração de interpretação.

c. As traduções para o português do exemplo coletado poderiam ser:

X4. Considerávamos apenas quatro outras obras dessa série, e, afora a nossa, restava apenas uma em mãos particulares.

X5. Considerávamos apenas quatro outras obras dessa série, e, afora a nossa, restava uma só em mãos particulares.

X6. Interessávamo-nos por apenas quatro outras obras dessa série, e, afora a nossa, restava apenas uma em mãos particulares.

X7. Interessávamo-nos por apenas quatro outras obras dessa série, e, afora a nossa, restava uma só em mãos particulares.

X8. Conhecíamos somente quatro outras obras dessa série, e, afora a nossa, restava

${ }^{424}$ PAILLARD, D. Repérage : construction et spécification. In : BOUSCAREN, J. La théorie d’Antoine Culioli. Paris : Ophrys, 1992. p.75-88, p. 84. 
somente uma em mãos particulares. (felizmente)

d. Temos o "que” de natureza adverbial nos dois exemplos acima, com complementos na função de atributo do suporte passivo do verbo, chamado tradicionalmente de objeto direto.

3) "Le 5 février, la finale du championnat d'Europe de handball opposant la France à la Croatie - un événement pourtant inscrit sur la liste française - n'a été retransmise que sur le canal de la chaîne payante, propriétaire des droits.” (BOUCHERON, J.-B. Vers un Mondial en crypté?. Le Monde. Chronique réalisée par le Centre de droit et d'économie du sport de Limoges (www.cdes.fr). Disponível em: < $\underline{\text { http://www.lemonde.fr/web/article/0,1-0,3679082- }}$ $\underline{1,0 . h t m l}>$. Acesso em 01 jul. 2006.)

a. "Le 5 février, la finale du championnat d'Europe de handball opposant la France à la Croatie - un événement pourtant inscrit sur la liste française - a été retransmise seulement sur le canal de la chaîne payante, propriétaire des droits.”

Classificamos essa substituição como pertencente ao grupo B pois segundo os critérios de Paillard, "ne... que” seleciona o canal pago e os não-pagos, e "seulement" seleciona somente o canal pago. Ora, Boucheron não concorda com a decisão da transmissão nem com a seleção única da transmissão, e mostra-a no uso do termo "pourtant” porque a final fazia parte da lista francesa e, portanto, era de ampla divulgação. O uso de "seulement" e "pourtant" concomitantes, embora gramaticalmente correto, parece-nos incorreto pelo contexto, contradizendo-se. Essa agramaticalidade nos parece plausível porque o valor positivo de “seulement" contradiz o valor negativo de "pourtant", expresso como ressalva na forma de um aposto.

b. Boudreau e Tremblay consideraram as duas possíveis sem alteração de significado, classificando, assim, o exemplo como fazendo parte do grupo A.

c. As traduções para o português do exemplo coletado poderiam ser:

X9. Em cinco de fevereiro, a final do campeonato europeu de handebol opondo França e Croácia, embora inscrita na lista francesa, foi transmitida apenas pelo canal pago que detinha seus direitos de retransmissão.

X10. Em cinco de fevereiro, a final do campeonato europeu de handebol opondo 
França e Croácia, embora inscrita na lista francesa, foi transmitida somente pelo canal pago que detinha seus direitos de retransmissão.

Esta última tradução parece-nos indicar que foi por pura opção desse canal transmitilo, e não por uma imposição contratual excluindo todos os outros, o que minimiza a indignação e a discordância de Boucheron quanto ao fato.

d. Temos o "que" de natureza adverbial no exemplo acima, com complemento na função de aporte modal de modo tradicionalmente chamado de adjunto adverbial de modo.

4) “L'objectif étant d'empêcher qu'une partie du public soit privée de l'accès à un tel événement, on ne peut que souhaiter que ce raté soit sans lendemain.” (BOUCHERON, J.-B. Vers un Mondial en crypté?. Le Monde. Chronique réalisée par le Centre de droit et d'économie du sport de Limoges (www.cdes.fr). Disponível em: < $\underline{\text { http://www.lemonde.fr- }}$ /web/article/0,1-0,36-790821,0.html>. Acesso em 01 jul. 2006.)

a. "L'objectif étant d'empêcher qu'une partie du public soit privée de l'accès à un tel événement, on peut seulement souhaiter que ce raté soit sans lendemain.”

Classificamos esse exemplo como do tipo B, pois acreditamos enquadrar-se, como nos exemplos dados por Paillard dos verbos "faire" e "vouloir", no grupo de verbos que representam a classe de processos possíveis, marcando assim a seleção de “souhaiter” e a nãoseleção dos outros processos. “On peut” várias coisas tanto em francês quanto em português.

Segundo Franckel e Lebaud ${ }^{425}$ (1990), o verbo “souhaiter” apresenta uma relação préconstruída, assim como o verbo “connaître”. O sujeito localizador e o sujeito ao qual é atribuído o "souhait” podem coincidir ou não. No nosso caso, coincidem. "On” é ao mesmo tempo “destino" a quem é feito o "souhait” e localizador do ponto de partida desse desejo. Pelo tipo de complemento emcontrado em nosso exemplo, “que ce raté soit sans lendemain”, podemos ainda classificar o verbo "sohaiter” como "processive” (processo a ser desenvolvido ou não). No exemplo acima, espera-se que esse processo não tenha andamento nem prosseguimento.

\footnotetext{
${ }^{425}$ FRANCKEL, J.-J.; LEBAUD, D. Les figures du sujet. A propos des verbes de perception, sentiment, connaissance. 1990, p. 121.
} 
b. Boudreau e Tremblay classificam-no como do tipo A, ou seja, é indiferente o uso de “ne... que" ou de "seulement".

c. As traduções para o português do exemplo coletado poderiam ser:

X11. Como o objetivo é evitar que uma parte do público seja privada do acesso a tal evento, podemos apenas desejar que essa falha não aconteça mais. (mas sem muita esperança)

X12. Como o objetivo é evitar que uma parte do público seja privada do acesso a tal evento, podemos somente desejar que essa falha não aconteça mais. (realmente)

d. Temos o "que” de natureza adverbial no exemplo acima, com complemento na função de atributo do suporte passivo do verbo, chamado tradicionalmente de objeto direto.

5) “Dans la mesure où ce succès peut permettre la production et l'existence concomitantes d'aventures plus singulières, on ne peut que s'en réjouir.” (MANDELBAUM, J. Les mille et une vies du documentaire. Le Monde. Disponível em: < de.fr/web/article/0,1-0,36-790657,0.html>, <http://www.lemonde.fr/web/-article/0,1-0,36790657@45-1,0.html>. Acesso em 01 jul. 2006.)

a. "Dans la mesure où ce succès peut permettre la production et l'existence concomitantes d'aventures plus singulières, on peut seulement s'en réjouir.”

Como no exemplo 4, classificamos esse exemplo como do tipo B, pois acreditamos enquadrar-se, como no exemplo dado por Paillard do verbo "faire”, no grupo de verbos que representam a classe de processos possíveis, marcando assim a seleção de “se réjouir” e a nãoseleção dos outros processos.

b. Para Tremblay esse exemplo é do grupo A, enquanto Boudreau o classifica como do grupo B.

c. As traduções para o português do exemplo coletado poderiam ser:

X13. $?{ }^{426} \mathrm{Na}$ medida em que esse sucesso pode permitir a produção e a existência concomitantes de aventuras mais singulares, podemos apenas ficar felizes.

\footnotetext{
${ }^{426}$ Empregamos o ponto de interrogação para mostrar nossa dúvida quanto ao uso de tais formas de expressão em português.
} 
X14. ?Na medida em que esse sucesso pode permitir a produção e a existência concomitantes de aventuras mais singulares, só podemos ficar felizes.

X15. ?Na medida em que esse sucesso pode permitir a produção e a existência concomitantes de aventuras mais singulares, podemos somente ficar felizes.

d. Temos o "que" de natureza adverbial no exemplo acima, com complemento na função de atributo do suporte passivo do verbo, chamado tradicionalmente de objeto direto.

6) “Le bilan boursier du premier semestre reste mitigé. L'indice Standard \& Poor's 500 ne progresse que d'un peu moins de $2 \%$ depuis le début de l'année, alors que le Nasdaq recule de 1,5 \%.” (DUCOURTIEUX, C. Les places boursières rebondissent. Le Monde. Disponível em: < http://www.lemonde.fr/web/article/0,1-0,36-790649,0.html>. Acesso em 01 jul. 2006.)

a. “Le bilan boursier du premier semestre reste mitigé. L'indice Standard \& Poor's 500 progresse seulement d'un peu moins de 2 \% depuis le début de l'année, alors que le Nasdaq recule de $1,5 \%$.”

Classificamos esse exemplo como do tipo B, pois cremos que o verbo "progresser", assim como o verbo "faire”, apresenta várias possibilidades, várias formas e não somente uma específica, mostrada pelo uso do termo "seulement".

b. Boudreau considera esse exemplo do tipo B, enquanto Tremblay o considera do tipo A.

c. As traduções para o português do exemplo coletado poderiam ser:

X16. O balanço da bolsa do primeiro semestre fica amenizado. O índice Standard \& Poor's 500 aumenta apenas um pouco menos de $2 \%$ desde o começo do ano, enquanto o Nasdaq recua em 1,5\%. (quando deveria ter sido maior o índice de aumento da pobreza)

$\mathrm{X} 17 .{ }^{* 427} \mathrm{O}$ balanço da bolsa do primeiro semestre fica amenizado. O índice Standard \& Poor’s 500 aumenta somente um pouco menos de $2 \%$ desde o começo do ano, enquanto o Nasdaq recua em 1,5\%. (o que é um bom resultado)

X18. O balanço da bolsa do primeiro semestre fica amenizado. O índice Standard \&

$\overline{427}$ Empregamos o asterisco para indicar a agramaticalidade de algumas formas. 
Poor's 500 aumenta um pouco menos de $2 \%$ desde o começo do ano, enquanto o Nasdaq recua em $1,5 \%$.

No exemplo com “apenas”, temos o sentido de “a pena”, “quase não”, enquanto para "somente" esperava-se um aumento de pobreza maior que não foi atingido, o que contradiz a primeira oração “[...] o primeiro semestre fica amenizado”.

d. Temos o "que" de natureza adverbial no exemplo acima, com complemento na função de atributo do suporte ativo do verbo, tradicionalmente chamado de adjunto adverbial de quantidade.

7) “Ce ne sont encore que des contre-plongées de lumières blanches et des lignes blafardes, projetées au son du mot "robot" épelé au Vocoder, mais la limpidité de la puissance numérique et la cohérence graphique impressionnent déjà.” (DAVET, S. Daft Punk, fastueux crescendo électro. Le Monde. Disponível em: <http://www.lemonde.fr/web/article/0,1-0,36790686,0.html>. Acesso em 01 jul. 2006.)

a. "Ce sont encore seulement des contre-plongées de lumières blanches et des lignes blafardes, projetées au son du mot "robot" épelé au Vocoder, mais la limpidité de la puissance numérique et la cohérence graphique impressionnent déjà.”

Classificamo-lo como do grupo B, pois, embora Paillard ${ }^{428}$ nos mostre em seu exemplo “c. il n’est plus que médecin / il n’est plus seulement médecin” que "plus” marca a passagem do tempo, no nosso exemplo, “encore” marca a não passagem do tempo e não altera a interpretação da oração em decorrência disso. Entretanto, o verbo "être” nos mostra no uso de "ne... que" todas as opções selecionadas que "seulement" descarta por especificar somente “des contre-plongées" e nada mais do que isso.

b. Para Tremblay, faz parte do grupo B. Para Boudreau, há duas situações: ( i ) faz parte do grupo B se conservar o termo "encore": *Ce sont encore seulement des...; e ( ii ) e do grupo A se não conservar o termo "encore": Ce sont seulement des...

c. As traduções para o português do exemplo coletado poderiam ser:

${ }^{428}$ PAILLARD, D. Repérage : construction et spécification. In : BOUSCAREN, J. La théorie d’Antoine Culioli. Paris : Ophrys, 1992. p.75-88, p. 84. 
X19. São, ainda, apenas contre-plongées, projetados ao som da palavra "robô" soletrada no Vocoder, mas a clareza da potência digital e a coerência gráfica já im pressionam. (com a tecnologiadesenvolvida já deveríamos fazer mais do que isso)

X20. São, ainda, somente contre-plongées, projetados ao som da palavra "robô" soletrada no Vocoder, mas a clareza da potência digital e a coerência gráfica já impressionam. (com a tecnologia desenvolvida só podemos fazer isso)

Os exemplos acima, para serem gramaticais em português, precisam ter o termo “ainda” entre vírgulas, o que altera o sentido da frase original.

d. Temos o "que” de natureza adverbial no exemplo acima, com complemento na função de atributo do suporte passivo do verbo, tradicionalmente chamado de predicativo do sujeito.

8) “Tout n'ira ensuite que crescendo.” (DAVET, S. Daft Punk, fastueux crescendo électro. Le Monde. Disponível em: <http://www.lemonde.fr/web/article/0,1-0,36790686,0.ht$\underline{\mathrm{ml}}>$. Acesso em 01 jul. 2006.)

a. "Tout ira ensuite seulement crescendo."

Classificamos esse exemplo como pertencente ao grupo B, pois é agramatical quando construído com o termo "seulement”. Embora o uso de "ensuite" determine temporalidade, não é o mesmo caso do grupo $\mathrm{C}$, pois não configura uma mudança de interpretação que acontece, e sim a limitação, a especificação da seleção com o uso de “seulement”.

b. Tremblay e Boudreau também o classificam desse modo.

c. As traduções para o português do exemplo coletado poderiam ser:

X21. Em seguida, tudo segue apenas num “crescendo.”

X22. Em seguida, tudo segue somente num “crescendo”.

Em ambos os casos, precisamos acrescentar "num” para ser gramatical em português.

d. Temos o "que" de natureza adverbial no exemplo acima, com complemento na função de atributo do suporte ativo do verbo, tradicionalmente chamado de adjunto adverbial de modo. 
9) “Colette Renard, en gouvernante dévote, mais qui n'a pas toujours été que cela, forme un duo d'enfer, si on ose, avec Bruno Cremer.” (DHOMBRES, D. Maigret chez les

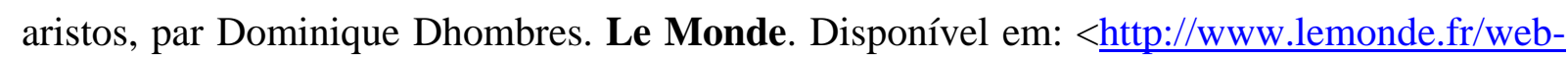
larticle/0,1-0,36-790688,0.html>. Acesso em 01 jul. 2006.)

a. “Colette Renard, en gouvernante dévote, mais qui n’a pas toujours été seulement cela, forme un duo d'enfer, si on ose, avec Bruno Cremer.”

Consideramos o exemplo acima como pertencente ao grupo C. Quando substituímos “ne... que” por "seulement”, obtemos não mais a oração original, mas uma parecida com o exemplo fornecido por Paillard: “il n'est plus que médecin / il n'est plus seulement médecin." ${ }^{429}$ Cremos que os advérbios "pas toujours" atuam da mesma forma no aspecto temporal que "plus" no exemplo por ele fornecido. "Ela era outra coisa além de uma governanta devota.”

b. Tremblay o classifica como do grupo C, e Boudreau, como do grupo B.

c. As traduções para o português do exemplo coletado poderiam ser:

X23. Colette Renard, governanta devota, mas que nem sempre foi apenas isso, forma um duo dos infernos, se é que podemos dizer assim, com Bruno Cremer.

X24. Colette Renard, governanta devota, mas que nem sempre foi somente isso, forma um duo dos infernos, se é que podemos dizer assim, com Bruno Cremer.

X25. Colette Renard, governanta devota, mas que sempre foi mais do que isso, forma um duo dos infernos, se é que podemos dizer assim, com Bruno Cremer.

Consideramos que em português esse duplo sentido também é possível. Ao longo do tempo, Colette foi desenvolvendo outras atividades além de ser governanta.

d. Temos o "que" de natureza adverbial no exemplo acima, com complemento na função de atributo do suporte passivo do verbo, tradicionalmente chamado de predicativo do sujeito.

\footnotetext{
${ }^{429}$ PAILLARD, D. Repérage : construction et spécification. In : BOUSCAREN, J. La théorie d'Antoine Culioli. Paris : Ophrys, 1992. p.75-88, p. 84.
} 
10) “'Le ministre des affaires étrangères ne parle pas l'anglais, ni l'espagnol, ni aucune autre langue que le français, écrivait Raphaëlle Bacqué.’ " (SOLÉ, R. Les vacances d'un ministre, par Robert Solé. Le Monde. Disponível em: < $\underline{\text { http://www.lemonde.fr/web/ar- }}$ ticle/0,1-0,36-790658,0.html>. Acesso em 01 jul. 2006.)

a. “'Le ministre des affaires étrangères ne parle pas l'anglais, ni l'espagnol, ni aucune autre langue seulement le français, écrivait Raphaëlle Bacqué.’ ”

Classificamos o exemplo como pertencente ao grupo $\mathrm{B}$, pois cremos que a negação total de “ne... pas” não admite o uso de "seulement”. Essa substituição limitaria a seleção e a não-seleção de "parler”.

b. Tremblay e Boudreau o consideram como do grupo B.

c. As traduções para o português do exemplo coletado poderiam ser:

X26. O ministro das relações exteriores não fala nem inglês, nem espanhol, nem qualquer outra língua exceto o francês, escreveu Raphaëlle Bacqué.

X27. O ministro das relações exteriores não fala nem inglês, nem espanhol, nem qualquer outra língua, apenas o francês, escreveu Raphaëlle Bacqué.

X28. O ministro das relações exteriores não fala nem inglês, nem espanhol, nem qualquer outra língua, senão o francês, escreveu Raphaëlle Bacqué.

X29. O ministro das relações exteriores não fala nem inglês, nem espanhol, nem qualquer outra língua, somente o francês, escreveu Raphaëlle Bacqué.

Acreditamos que antes de "apenas" e "somente” faz-se necessário o uso de vírgula para manter-se o sentido original da oração.

d. Temos o "que” de natureza adverbial no exemplo acima, com complemento na função de atributo do suporte passivo do verbo, chamado tradicionalmente de objeto direto.

11) “Ce n'est que six semaines plus tard, interrogé à l'antenne par Thierry Ardisson, qu'il a dénoncé ‘un tissu de mensonges'. ” (SOLÉ, R. Les vacances d'un ministre, par Robert Solé. Le Monde. Disponível em: <http://www.lemonde.fr/web/article/0,1-0,36790658,0.ht$\underline{\mathrm{ml}}>$. Acesso em 01 jul. 2006.) 
a. “C'est seulement six semaines plus tard, interrogé à l'antenne par Thierry Ardisson, qu'il a dénoncé 'un tissu de mensonges'. ”

Classificamos o exemplo como do tipo A, pois não há alteração significativa de sentido entre as duas possibilidades, embora o haja bastante em português.

b. Tremblay e Boudreau o classificam como do tipo A. São os dois possíveis com interpretações bem próximas uma da outra.

c. As traduções para o português do exemplo coletado poderiam ser:

X30. Foi apenas seis semanas mais tarde, questionado no rádio por Thierry Ardisson, que ele denunciou “uma trama de mentiras”. (o entrevistado deveria ter feito essa denúncia muito antes)

X31. Foi somente seis semanas mais tarde, questionado no rádio por Thierry Ardisson, que ele denunciou "uma trama de mentiras". (o entrevistado pode fazer essa denúncia seis semanas mais tarde sem comprometimento da justiça ou da ética)

d. Temos o "que” de natureza adverbial no exemplo acima, com complemento na função de atributo do suporte passivo do verbo, tradicionalmente chamado de predicativo do sujeito.

12) “Un événement privé ne mérite de figurer dans Le Monde que dans deux circonstances : s'il a une incidence sur la vie publique ou s'il est indispensable pour connaître la personnalité d'un dirigeant.” (SOLÉ, R. Les vacances d'un ministre, par Robert Solé. Le Monde. Disponível em: <http://www.lemonde.fr/web/article/0,1-0,36-790658,0.html>. Acesso em 01 jul. 2006.)

a. "Un événement privé mérite de figurer dans Le Monde seulement dans deux circonstances : s'il a une incidence sur la vie publique ou s'il est indispensable pour connaître la personnalité d'un dirigeant.”

Classificamos esse exemplo como do tipo A quando temos equivalência quase perfeita entre o uso de um termo ou de outro.

b. Tremblay o classifica como do tipo A, e Boudreau, como do tipo B.

c. As traduções para o português do exemplo coletado poderiam ser: 
X32. Um evento particular merece figurar no Le Monde apenas em duas circunstâncias: se houver incidência na vida pública ou se for indispensável para conhecermos a personalidade de um dirigente. (circunstâncias específicas e não em outras)

X33. Um evento particular merece figurar no Le Monde somente em duas circunstâncias: se houver incidência na vida pública ou se for indispensável para conhecermos a personalidade de um dirigente. (circunstâncias específicas, pré-determinadas)

Continuamos encontrando em português a diferença entre “apenas” e "somente”, bem como a valoração do texto decorrente do uso de uma ou de outra.

d. Temos o "que” de natureza adverbial no exemplo acima, com complemento na função de modal de tempo, tradicionalmente chamado de adjunto adverbial de tempo.

13) “Les principaux dirigeants du PS et 900 délégués se sont retrouvés, samedi $1^{\mathrm{er}}$ juillet, à Paris lors d'une convention nationale exceptionnelle destinée à approuver le projet socialiste pour 2007. Le texte, déjà connu, ne sera plus complété que par quelques amendements. Vendredi soir, la direction du parti examinait, parmi 2000 propositions additionnelles envoyées par les fédérations, celles qui pourraient s'ajouter aux mesures déjà arbitrées.” (MANDRAUD, I. Les socialistes adoptent leur projet pour 2007. Le Monde.

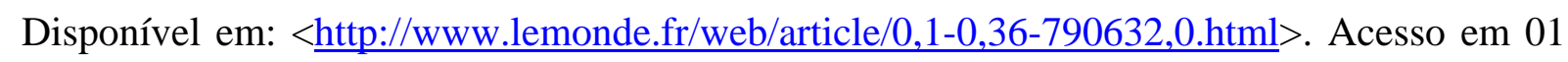
jul. 2006.)

a. "Les principaux dirigeants du PS et 900 délégués se sont retrouvés, samedi $1^{\mathrm{er}}$ juillet, à Paris lors d'une convention nationale exceptionnelle destinée à approuver le projet socialiste pour 2007. Le texte, déjà connu, ne sera plus complété seulement par quelques amendements. Vendredi soir, la direction du parti examinait, parmi 2000 propositions additionnelles envoyées par les fédérations, celles qui pourraient s'ajouter aux mesures déjà arbitrées.”

Classificamos o exemplo como pertencente ao grupo C e o enquadramos no mesmo caso de temporalidade fornecido por Paillard como visto acima. O projeto já não será completado por meras alterações, pois foi proposto um total de 2000.

b. Tremblay classifica-o como pertencente ao grupo A, e Boudreau, ao grupo B. 
c. As traduções para o português do exemplo coletado poderiam ser:

X34. Os principais dirigentes do PS e 900 delegados encontraram-se no sábado, dia $1^{\circ}$ de julho, em Paris, por ocasião de uma convenção nacional extraordinária, destinada a aprovar o programa socialista para 2007. O texto, já conhecido, será completado não apenas por algumas alterações. Na sexta-feira à noite, a direção do partido examinava, entre 2000 proposições adicionais enviadas pelas federações, aquelas que poderiam ser acrescentadas às medidas já votadas.

X35. Os principais dirigentes do PS e 900 delegados encontraram-se no sábado, dia $1^{\circ}$ de julho, em Paris, por ocasião de uma convenção nacional extraordinária, destinada a aprovar o programa socialista para 2007. O texto, já conhecido, será completado não somente por algumas alterações. Na sexta-feira à noite, a direção do partido examinava, entre 2000 proposições adicionais enviadas pelas federações, aquelas que poderiam ser acrescentadas às medidas já votadas.

Em português, o uso de "somente” contraria a quantidade extra de proposições feitas.

d. Temos o "que" de natureza adverbial no exemplo acima, com complemento na função de aporte modal de modo, tradicionalmente chamado de adjunto adverbial de modo.

14) “Actuellement, la plate-forme iTunes d'Apple n'est accessible que depuis le baladeur numérique iPod.” (VULSER, N. Droits d'auteur : ce qui va changer. Le Monde. Disponível em: <http://www.lemonde.fr/web/article/0,1-0,36-790680,0.html>. Acesso em 01 jul. 2006.)

a. “Actuellement, la plate-forme iTunes d'Apple est accessible seulement depuis le baladeur numérique iPod.”

Classificamos esse exemplo como do grupo B. A substituição não é possível, pois a acessibilidade, assim como o verbo “faire”, aceitam várias seleções e não-seleções como descritas por Paillard ${ }^{430}$ em seu exemplo: "b1. je ne fais que passer / *je fais seulement passer"; "b2. je voulais seulement lui dire deux mots / *je ne voulais que lui dire deux

${ }^{430}$ PAILLARD, D. Repérage : construction et spécification. In : BOUSCAREN, J. La théorie d'Antoine Culioli. Paris : Ophrys, 1992. p.75-88, p. 84. 
mots."431

b. Tremblay e Boudreau o classificaram como do grupo A, com substituição possível sem alteração significativa de interpretação.

c. As traduções para o português do exemplo coletado poderiam ser:

X36. Atualmente, a plataforma iTunes da Apple é acessível apenas a partir do aparelho digital iPod. (e de nenhum outro mais, o que é lamentável)

X37. Atualmente, a plataforma iTunes da Appel é acessível somente a partir do aparelho digital iPod. (único caminho possível por razões tecnológicas)

X38. Atualmente, a plataforma iTunes da Appel só é acessível a partir do aparelho digital iPod. (e de nenhum outro mais, o que é lamentável)

d. Temos o "que" de natureza adverbial no exemplo acima, com complemento na função de aporte modal de modo, tradicionalmente chamado de adjunto adverbial de modo.

15) “La situation était potentiellement explosive : pour 2000 détenus, le SMPR n'aurait disposé, à partir de juillet, que de moins d'un poste d'infirmier en équivalent temps plein.” (GUILBERT, N. Des moyens provisoires pour la psychiatrie à Fresnes. Le Monde. Disponível em: <http://www.lemonde.fr/cgi-bin/ACHATS/acheter.cgi?offre=ARCHIVES\&type_item=ART_ARCH_30J\&objet_id=951140>. Acesso em 01 jul. 2006.)

a. "La situation était potentiellement explosive : pour 2000 détenus, le SMPR aurait disposé, à partir de juillet, seulement de moins d'un poste d'infirmier en équivalent temps plein.”

Classificamos o exemplo acima como pertencente ao grupo B, pois o verbo “disposer de” coloca à disposição a opção selecionada e as não-selecionadas, como visto no exemplo do verbo "faire" dado por Paillard.

b. Tremblay e Boudreau também o classificam dessa forma.

c. As traduções para o português do exemplo coletado poderiam ser:

X39. A situação era potencialmente explosiva: para 2000 detentos, o SMPR teria

${ }^{431}$ Id., ibid., p. 84. 
disponibilizado, a partir de julho, menos que um cargo de enfermeiro equivalente a tempo integral.

Observamos que esse exemplo traduzido para o português não comporta "apenas” nem “somente”. Se usados, devem ser deslocados de suas posições originais, alterando, assim, completamente o sentido inicial:

X40. A situação era potencialmente explosiva: para 2000 detentos, o SMPR teria apenas disponibilizado, a partir de julho, menos que um cargo de enfermeiro equivalente a tempo integral.

X41. ?A situação era potencialmente explosiva: para 2000 detentos, o SMPR teria disponibilizado, a partir de julho, apenas menos que um cargo de enfermeiro equivalente a tempo integral.

X42. A situação era potencialmente explosiva: para 2000 detentos, o SMPR teria somente disponibilizado, a partir de julho, menos que um cargo de enfermeiro equivalente a tempo integral.

X43. ?A situação era potencialmente explosiva: para 2000 detentos, o SMPR teria disponibilizado, a partir de julho, somente menos que um cargo de enfermeiro equivalente a tempo integral.

X44. A situação era potencialmente explosiva: para 2000 detentos, o SMPR apenas teria disponibilizado, a partir de julho, menos que um cargo de enfermeiro equivalente a tempo integral.

X45. A situação era potencialmente explosiva: para 2000 detentos, o SMPR somente teria disponibilizado, a partir de julho, menos que um cargo de enfermeiro equivalente a tempo integral.

X46. A situação era potencialmente explosiva: para 2000 detentos, o SMPR só teria disponibilizado, a partir de julho, menos que um cargo de enfermeiro equivalente a tempo integral.

Em ambos os casos, o uso de "apenas" e de "somente” modulariam o verbo, e não o complemento "moins d'un poste d'infirmier".

d. Temos o "que” de natureza adverbial no exemplo acima, com complemento na função de aporte modal de destinatário, tradicionalmente chamado de objeto indireto. 
16) “Aujourd'hui, on ne peut plus faire que ça : être courageux.” (VINCENT, E. JEAN-MARIE LEBLANC DIRECTEUR DU TOUR DE FRANCE « C'est un geste courageux et un bon exemple pour les autres directeurs sportifs ». Le Monde. Disponível em: $<$ http://www.lemonde.fr/cgi-bin/ACHATS/acheter.cgi?offre=ARCHIVES\&type_item=ART_ARCH_30J\&objet_id=951163>. Acesso em 01 jul. 2006.)

a. "Aujourd'hui, on ne peut plus faire seulement ça : être courageux.”

Classificamos o exemplo coletado como sendo do grupo C, pois a negação "ne... plus" implica temporalidade, assim como o exemplo fornecido por Paillard ${ }^{432}$ : “c. il n'est plus que médecin / il n’est plus seulement médecin.” Devemos ser outras coisas além de corajosos. A presença do advérbio “aujourd'hui” não altera em nada a interpretação. O marcador fundamental é a negação “ne... plus”.

b. Tremblay o classifica como do grupo B, enquanto Boudreau, como do grupo A.

c. As traduções para o português do exemplo coletado poderiam ser:

$\mathrm{X} 47$. ?Hoje não podemos mais fazer apenas isso: ser corajosos.

X48. ?Hoje não podemos mais fazer somente isso: ser corajosos.

X49. Hoje só podemos ser uma coisa: corajosos.

d. Temos o "que" de natureza adverbial no exemplo acima, com complemento na função de atributo do suporte passivo do verbo, chamado tradicionalmente de objeto direto.

17) “L'équipementier, qui avait six 'clients' au début de la compétition, devance son principal concurrent, Nike, qui n'en a plus que deux - le Brésil et le Portugal.” (COUDERT, G. Adidas, en force. Le Monde. Disponível em: < http://www.lemonde.fr/cgibin/ACHATSlacheter.cgi?offre=ARCHIVES\&type_item=ART_ARCH_30J\&objet_id=951201>. Acesso em 01 jul. 2006.)

a. 'L'équipementier, qui avait six 'clients' au début de la compétition, devance son principal concurrent, Nike, qui n’en a plus seulement deux - le Brésil et le Portugal.”

${ }^{432}$ PAILLARD, D. Repérage : construction et spécification. In : BOUSCAREN, J. La théorie d’Antoine Culioli. Paris : Ophrys, 1992. p.75-88, p. 84. 
Classificamos esse exemplo como sendo do grupo C, pois, como o exemplo acima, com a negação “ne... plus” apresenta o aspecto temporal evocado por Paillard em sua classificação. Embora esse exemplo também apresente características do grupo A, restrição e especificação quanto a uma determinada quantidade, a negação “ne... plus” é mais influente na interpretação e na construção do discurso. "A empresa ultrapassa a Nike que não tinha mais do que 2 clientes na competição” contra “A empresa ultrapassa a Nike que não tem mais somente 2 na competição. Ela tem mais clientes agora”. Isso não pode ser devido à especificação posterior feita pelo autor do artigo, na qual somos informados de que a Nike só tem o Brasil e Portugal como clientes ainda competindo nesse campeonato.

b. Tremblay também considera esse exemplo como pertencente ao grupo B, enquanto Boudreau o classifica como do grupo B.

c. As traduções para o português do exemplo coletado poderiam ser:

X50. A empresa esportiva, que tinha seis “clientes" no começo da competição, ultrapassa sua principal concorrente, a Nike, que tem não apenas dois - Brasil e Portugal.

X51. A empresa esportiva, que tinha seis "clientes" no começo da competição, ultrapassa sua principal concorrente, a Nike, que tem não somente dois - Brasil e Portugal. (esperamos saber quais são os outros clientes)

X52. A empresa esportiva, que tinha seis “clientes" no começo da competição, ultrapassa sua principal concorrente, a Nike, que já não tem só dois - Brasil e Portugal.

d. Temos o "que" de natureza adverbial no exemplo acima, com complemento na função de atributo do suporte passivo do verbo, chamado tradicionalmente de objeto direto.

18) "En huitièmes de finale, les choses risquent de se corser face à Ana Ivanovic $\left(n^{\circ} 19\right)$, une joueuse qui ne rappelle pas que des bons souvenirs à Mauresmo.” (AFP. Wimbledon : deux Françaises qualifiées pour les huitièmes de finale. Le Monde. Disponível em: <http://www.lemonde.fr/web/article/0,1-0,36-790938,0.html>. Acesso em 02 jul. 2006.)

a. "En huitièmes de finale, les choses risquent de se corser face à Ana Ivanovic (n¹9), une joueuse qui ne rappelle pas seulement des bons souvenirs à Mauresmo.” 
Classificamos esse caso como do grupo A, no qual a substituição de “ne... que” por “seulement” não implica alterações significativas de interpretação e pode ser feita sem maiores preocupações.

b. Tremblay o classifica como do tipo C.

c. As traduções para o português do exemplo coletado poderiam ser:

X53. Nas oitavas de final, a situação corre o risco de endurecer diante de Ana Ivanovic $\left(\mathrm{n}^{\circ} 19\right)$, uma jogadora que lembra não apenas os bons momentos à Amélie Mauresmo.

X54. Nas oitavas de final, a situação corre o risco de endurecer diante de Ana Ivanovic ( $\left.n^{0} 19\right)$, uma jogadora que não lembra somente os bons momentos à Amélie Mauresmo.

d. Temos o "que” de natureza adverbial no exemplo acima, com complemento na função de atributo do suporte passivo do verbo, chamado tradicionalmente de objeto direto.

19) “Cela n'eut pas que des effets négatifs, bien au contraire.” (LALLEMENT, B. Une complainte pour "Libé", par Bernard Lallement. Le Monde. Disponível em: < $\underline{\text { http://www.le- }}$ monde.fr/web/article/0,1-0,36-791233,0.html>. Acesso em 03 jul. 2006.)

a. "Cela n'eut pas seulement des effets négatifs, bien au contraire.”

Classificamos esse exemplo como pertencente ao grupo B, pois, embora esteja no passado simples, o verbo “avoir” aqui indica, junto com o complemento "bien au contraire”, que a seleção única de "seulement” não existiu.

b. Tremblay também o classifica como pertencente ao grupo B.

c. As traduções para o português do exemplo coletado poderiam ser:

X55. Isso teve não apenas efeitos negativos, muito pelo contrário.

X56. Isso teve não somente efeitos negativos, muito pelo contrário.

X57. Não é que isso só tenha tido efeitos negativos, muito pelo contrário.

d. Temos o "que" de natureza adverbial no exemplo acima, com complemento na função de atributo do suporte passivo do verbo, chamado tradicionalmente de objeto direto.

Tremblay (2007) ainda nos diz que: “Les phrases avec la négation comme l'exemple C ne fonctionnent pas bien avec ce test. On ne sait pas si on doit enlever la négation et mettre 
seulement 'seulement', ou si on laisse la négation et qu'on ajoute seulement, si on laisse la négation, on laisse le ne. Il y a peut-être deux types de phrases: ne + que, et ne pas + que, faudrait voir s'il y a une différence.

Aussi, le remplacement par seulement sonne très 'français', en québécois, on remplacerait par 'juste'. (Il voit juste moi) Des fois, on a l'impression que le remplacement peut se faire avec 'juste', mais pas avec 'seulement'” (informação pessoal) ${ }^{433}$.

Lembramos que um dos sentidos de “juste” em francês moderno é de "aquém”, de "não suficiente" 434 .

Os exemplos acima são os mais significativos dentre todos os encontrados. Após alguns há repetição de casos, que deixamos de lado, mas que constam do Anexo C. Os exemplos abaixo só foram classificados e colocados aqui para mostrar essa repetição.

20) “'Si le Sénégal, qui a refusé de juger Hissène Habré il y a sept ans, s'engage maintenant, nous ne pouvons que nous réjouir", a réagi Reed Brody de Human Rights Watch (HRW), chef de file des ONG de défense des droits de l'homme qui assistent les victimes de l'ancien dictateur tchadien.” (AFP. L'ancien dictateur tchadien Hissène Habré sera jugé au Sénégal. Le Monde. Disponível em: < $\underline{\text { http://www.lemonde.fr/web/article/0,1- }}$ 0,36-790997,0.html>. Acesso em 02 jul. 2006.)

a. Grupo A.

b. Tremblay: A

c. X58. ?Se o Senegal, que se recusou a julgar Hissène Habré há 7 anos, engajarse/manifestar-se agora, podemos apenas ficar felizes. (a única coisa que podemos fazer

\footnotetext{
${ }^{433}$ Informação fornecida por Tremblay, via mensagem eletrônica em 2007.

434 “6 Qui suffit à peine. 1 . court. Repas trop juste pour dix personnes. C'est un peu juste. 1. court, jeune. Il a été reçu, mais c'était juste! (Personnes) Fam. Être un peu juste : manquer d'argent. (...) 3• D'une manière trop stricte, en quantité à peine suffisante. Compter, prévoir un peu juste. Arriver bien juste, au tout dernier moment (cf. De justesse). Cela lui coûte juste la peine de se baisser. Il a bu juste un verre de vin.

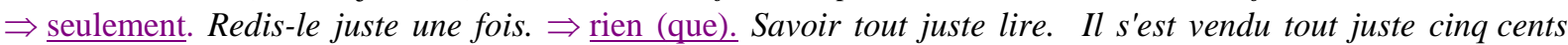
exemplaires. $\Rightarrow$ tout (tout au plus). C'est tout juste passable (cf. À peine)." (ROBERT, P. Le Petit Robert électronique, 1997, JUSTE.)
} 
é...)

X59. ?Se o Senegal, que se recusou a julgar Hissène Habré há 7 anos, engajarse/manifestar-se agora, podemos somente ficar felizes.

X60. !Se o Senegal, que se recusou a julgar Hissène Habré há 7 anos, engajarse/manifestar-se agora, só podemos ficar felizes. (única ação possível)

d. Advérbio - atributo do suporte passivo do verbo, chamado tradicionalmente de objeto direto

21) “'Après notre match, les gars ne parlaient que de Ronaldo dans le vestiaire, a raconté Alex Ferguson, l'entraîneur du club mancunien.” (LESPRIT, B. Cristiano Ronaldo brille en sélection et irrite ses fans de Manchester. Le Monde. Disponível em: $<$ http://www.le-monde.fr/web/article/0,1-0,36-791113,0.html>. Acesso em 03 jul. 2006.)
a. Grupo A
b. Tremblay: A
c. X61. No vestiário, após nosso jogo, os rapazes falavam apenas de Ronaldo, disse Alex Ferguson, treinador do clube Manchester. (restritivo?)

X62. No vestiário, após nosso jogo, os rapazes falavam somente de Ronaldo, disse Alex Ferguson, treinador do clube Manchester. (concessivo?)

X63. ?No vestiário, após nosso jogo, os rapazes falavam só de Ronaldo, disse Alex Ferguson, treinador do clube Manchester.

X64. No vestiário, após nosso jogo, os rapazes só falavam de Ronaldo, disse Alex Ferguson, treinador do clube Manchester. (não criticavam?)

X65. No vestiário, após nosso jogo, os rapazes não falavam de outra coisa além de Ronaldo, disse Alex Ferguson, treinador do clube Manchester. (restritivo)

d. Advérbio - atributo do suporte passivo do verbo, chamado tradicionalmente de objeto indireto

22) “Comme si la France tout entière n'attendait que cela : se regarder, se 
contempler, s'admirer en son beau miroir.” (GREILSAMER, L. Le ciel et la Terre à domicile, par Laurent Greilsamer. Le Monde. Disponível em: < $\underline{\text { http://www.lemon- }}$ de.fr/web/article/0,1-0,36-791170,0.html>. Acesso em 03 jul. 2006.)

a. Grupo C

b. Tremblay: A

c. X66. Como se a França inteira esperasse apenas isso : ver-se, contemplar-se, admirar-se em seu belo espelho.

X67. Como se a França inteira esperasse somente isso : ver-se, contemplar-se, admirar-se em seu belo espelho.

X68. Como se a França inteira esperasse só isso : ver-se, contemplar-se, admirar-se em seu belo espelho.

X69. Como se a França inteira não esperasse nada além disso: ver-se, contemplar-se, admirar-se em seu belo espelho.

X70. Como se a França inteira não esperasse mais (do) que isso : ver-se, contemplar-se, admirar-se em seu belo espelho.

d. Advérbio - atributo do suporte passivo do verbo, chamado tradicionalmente de objeto direto

23) "L'arrivée d'Edouard de Rothschild ne pouvait que conduire au divorce d'avec le directeur de Libération.” (LALLEMENT, B. Une complainte pour "Libé", par Bernard Lallement. Le Monde. Disponível em: <http://www.lemonde.fr/web/article/0,1-0,36791233,0.html>. Acesso em 03 jul. 2006.)

\section{a. Grupo A}

b. Tremblay: A

c. X71. A chegada de Edouard de Rothschild podia apenas levar ao divórcio do diretor do Libération.

X72. ?A chegada de Edouard de Rothschild apenas podia levar ao divórcio do 
diretor do Libération. (nada mais do que isso; impossível outro resultado)

X73. A chegada de Edouard de Rothschild podia somente levar ao divórcio do diretor do Libération.

X74. ?A chegada de Edouard de Rothschild podia só levar ao divórcio do diretor do Libération.

X75. A chegada de Edouard de Rothschild só podia levar ao divórcio do diretor do Libération.

d. Advérbio - atributo do suporte passivo do verbo, chamado tradicionalmente de objeto direto

24) “En effet, résoudre un problème en distribuant des subsides n'est plus une option disponible : quand les caisses sont vides, la démagogie et la lâcheté ne peuvent que s'effacer devant l'intelligence et le courage.” (BLANC, C.; BOCKEL, J.-M.; LAMBERT, A. Ensemble, modernisons la France, par Christian Blanc, Jean-Marie Bockel et Alain Lambert. Le Monde. Disponível em: <http://www.lemonde.fr/web/article/0,1-0,36$\underline{791239,0 . h t m l}>$. Acesso em 03 jul. 2006.)

\section{a. Grupo A}

b. Tremblay: A

c. X76. De fato, resolver um problema distribuindo subsídios já não é uma opção disponível : quando os caixas estão vazios, a demagogia e a traição podem apenas se apagar diante da inteligência e da coragem.

X77. ! ${ }^{435}$ De fato, resolver um problema distribuindo subsídios já não é uma opção disponível : quando os caixas estão vazios, a demagogia e a traição podem somente se apagar diante da inteligência e da coragem.

X78. ?De fato, resolver um problema distribuindo subsídios já não é uma opção disponível : quando os caixas estão vazios, a demagogia e a traição não encontram outra

\footnotetext{
${ }^{435}$ Empregamos o ponto de exclamação para mostrar nossa dúvida quanto à manutenção do sentido original da frase.
} 
opção além de se apagar diante da inteligência e da coragem.

X79. De fato, resolver um problema distribuindo subsídios já não é uma opção disponível : quando os caixas estão vazios, a demagogia e a traição só podem se apagar diante da inteligência e da coragem.

d. Advérbio - atributo do suporte passivo do verbo, chamado tradicionalmente de objeto direto

25) “Ensuite, on ne peut réformer que de façon globale et cohérente.” (BLANC, C.; BOCKEL, J.-M.; LAMBERT, A. Ensemble, modernisons la France, par Christian Blanc, Jean-Marie Bockel et Alain Lambert. Le Monde. Disponível em:

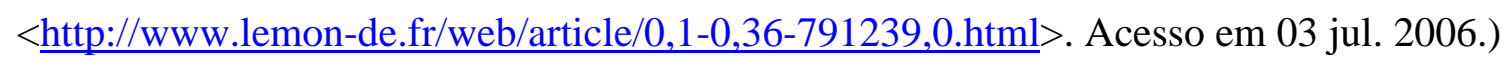
a. Grupo C
b. Tremblay: A??
c. X80. Depois, podemos reformar apenas de maneira global e coerente.

X81. !Depois, podemos apenas reformar de maneira global e coerente.

X82. Depois, podemos reformar somente de maneira global e coerente.

X83. !Depois, podemos somente reformar de maneira global e coerente.

X84. Depois, podemos reformar só de maneira global e coerente.

X85. Depois, só podemos reformar de maneira global e coerente.

d. Advérbio - modal de modo, tradicionalmente chamado de adjunto adverbial de modo

26) "Il n'y a pas que le temps passé à la tête de l'entreprise qui fasse de Louis Gallois une exception.” (BOSTNAVARON, F. Louis Gallois, un eurosceptique à la tête d'EADS. Le Monde. Disponível em: <http://www.lemonde.fr/web/article/0,1-0,36-

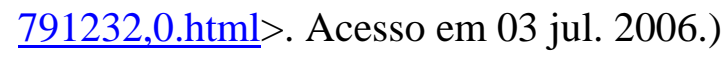

a. Grupo C 
b. Tremblay: B

c. X86. Apenas o período passado à frente da companhia que faça de Louis Gallois uma exceção.

X87. Somente o período passado à frente da companhia que faça de Louis Gallois uma exceção.

X88. Só o período passado à frente da companhia que faça de Louis Gallois uma exceção.

d. Advérbio - atributo do suporte passivo do verbo, chamado tradicionalmente de objeto direto

27) Il n'aime surtout pas gaspiller et n'entend pas que d'autres le fassent.” (BOSTnAVARON, F. Louis Gallois, un eurosceptique à la tête d'EADS. Le Monde. Disponível em: <http://www.lemonde.fr/web/article/0,1-0,367912-32,0.html>. Acesso em 03 jul. 2006.)

a. Grupo C

b. Tremblay: B

c. X89. Ele não gosta nem um pouco de desperdiçar e não compreende que outros o façam. (não é “ne... que”)

d. Advérbio - atributo do suporte passivo do verbo, chamado tradicionalmente de objeto indireto

28) “Au Brésil, il n'y en a que pour Zinédine Zidane depuis samedi $1^{\text {er }}$ juillet.” (GASNIER, A. Le Brésil célèbre le "genio" de Zidane. Le Monde. Disponível em:

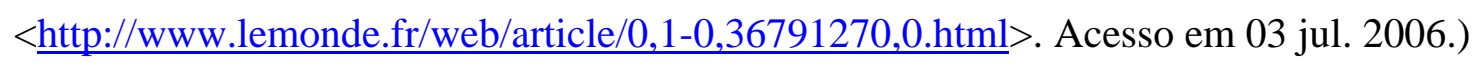
a. Grupo C
b. Tremblay: A
c. X90. ?No Brasil, depois de sábado, dá apenas Zinédine Zidane. 
X91. ?No Brasil, depois de sábado, dá somente Zinédine Zidane.

X92. No Brasil, depois de sábado, só dá Zinédine Zidane.

d. Advérbio - atributo do suporte passivo do verbo, chamado tradicionalmente de objeto direto

29) “On est dans une société individualiste où les gens regardent leur télé, ne sortent que par petits groupes ou par tribus...” (POTET, F. Georges Vigarello : "Tout d'un coup, une explosion positive". Le Monde. Disponível em: < $\underline{\text { http://www.lemon- }}$ de.fr/web/article/0,1-0,36791271,0.html> . Acesso em 03 jul. 2006.)

a. Grupo C

b. Tremblay: A

c. X93. Vivemos numa sociedade individualista na qual as pessoas assistem a suas TVs, saem apenas em pequenos grupos ou em tribos...

X94. Vivemos numa sociedade individualista na qual as pessoas assistem a suas TVs, saem somente em pequenos grupos ou em tribos...

X95. Vivemos numa sociedade individualista na qual as pessoas assistem a suas TVs, saem só em pequenos grupos ou em tribos...

X96. !Vivemos numa sociedade individualista na qual as pessoas assistem a suas TVs, só saem em pequenos grupos ou em tribos...

d. Advérbio - atributo do suporte ativo do verbo

30) “'[...] Mais je ne suis pas non plus ici pour remplacer Lance Armstrong’, précise-t-il. Hincapie, qui n'a pas peur des mots puisque ce ne sont que des mots, avoue sans peine sa cruelle déception de ne pas avoir remporté le prologue mais ajoute, si l'on avait encore des doutes sur sa touchante assurance, qu'il se sent 'en grande forme'." (ARAGON, J.-L. Discovery Channel favorite à sa propre succession. Le Monde. Disponível em: < http://www.lemonde.fr/web/article/0,1-0,36-791222,0.html>. Acesso em 03 jul. 2006.) 
a. Grupo A

b. Tremblay: A

c. X97. Mas também não estou aqui para substituir Lance Armstrong, esclarece. Hincapie, que não tem medo das palavras porque são apenas palavras, admite sem dificuldade sua terrível decepção de não ter ganhado a preliminar, mas acrescenta que se ainda tínhamos dúvidas sobre sua tocante certeza, que ele se sente em grande forma.

X98. Mas também não estou aqui para substituir Lance Armstrong, esclarece. Hincapie, que não tem medo das palavras porque são somente palavras, admite sem dificuldade sua terrível decepção de não ter ganhado a preliminar, mas acrescenta que se ainda tínhamos dúvidas sobre sua tocante certeza, que ele se sente em grande forma.

X99. Mas também não estou aqui para substituir Lance Armstrong, esclarece. Hincapie, que não tem medo das palavras porque nada mais são (do) que palavras, admite sem dificuldade sua terrível decepção de não ter ganhado a preliminar, mas acrescenta que se ainda tínhamos dúvidas sobre sua tocante certeza, que ele se sente em grande forma.

d. Advérbio - atributo do suporte passivo do verbo, chamado tradicionalmente de predicativo do sujeito

31) "L'Américain ne possédait que 2 misérables secondes d'avance au classement général, mais là n'est pas la question.” (ARAGON, J.-L. Discovery Channel favorite à sa propre succession. Le Monde. Disponível em: < $\underline{\text { http://www.lemonde.fr/web/article/0,1- }}$ $\underline{0,36-791222,0 . h t m l}>$. Acesso em 03 jul. 2006.)

\section{a. Grupo C}

b. Tremblay: A

c. X100. O Americano possuía apenas 2 miseráveis segundos de vantagem na classificação geral, mas não é essa a questão.

X101. !O Americano apenas possuía 2 miseráveis segundos de vantagem na classificação geral, mas não é essa a questão.

X102. O Americano possuía somente 2 miseráveis segundos de vantagem na 
classificação geral, mas não é essa a questão.

X103. !O Americano somente possuía 2 miseráveis segundos de vantagem na classificação geral, mas não é essa a questão.

X104. O Americano possuía só 2 miseráveis segundos de vantagem na classificação geral, mas não é essa a questão.

X105. !O Americano só possuía 2 miseráveis segundos de vantagem na classificação geral, mas não é essa a questão.

d. Advérbio - atributo do suporte passivo do verbo, chamado tradicionalmente de objeto direto

32)“ 'Nous sommes ici pour gagner, il n'y a pas le moindre doute là dessus, et le fait qu'Ullrich et Basso ne soient pas là ne change rien à l'affaire', affirme l'un des lieutenants de Landis, l'Espagnol Miguel Angel Martin Perdiguero, qui n'affiche ici d'autre prétention que d'aider son leader à gagner.” (ARAGON, J.-L. Discovery Channel favorite à sa propre succession. Le Monde. Disponível em: < http://www.lemonde.fr/web/article/0,1-0,36-791271,0.html>. Acesso em 03 jul. 2006.)

a. Grupo B

b. Tremblay: B

c. X106. Estamos aqui para ganhar, não há a menor dúvida sobre isso, e o fato de que Ulrich e Basso não estejam aqui nada muda, afirma um dos colegas de equipe de Landis, o espanhol Miguel Angel Martin Perdiguero, que aqui não afirma outra pretensão senão a de ajudar seu líder a ganhar.

d. Advérbio - atributo do suporte passivo do verbo, chamado tradicionalmente de objeto indireto

33) “Ce n'est pas le cas avec Radio Classique, qui ne diffuse que quatre concerts complets cette année.” (PECQUEUR, A. Le succès d'audience de Radio Classique pousse France Musique à revoir sa grille. Le Monde. Disponível em: < $\underline{\text { http://www.lemon- }}$ 
de.fr/web/arti-cle/0,1-0,36-791216,0.html >. Acesso em 03 jul. 2006.)

a. Grupo C

b. Tremblay: A

c. X107. Não é o caso da Rádio Classique, que transmite apenas 4 concertos completos por ano.

X108. Não é o caso da Rádio Classique, que transmite somente 4 concertos completos por ano.

X109. Não é o caso da Rádio Classique, que transmite só 4 concertos completos por ano.

X110. Não é o caso da Rádio Classique, que só transmite 4 concertos completos por ano.

d. Advérbio - atributo do suporte passivo do verbo, chamado tradicionalmente de objeto direto

34) "Pour cela, la station, qui ne dispose que de 70 fréquences (contre 500 pour France Musique), espère obtenir 'entre 15 et 25 fréquences de plus d'ici deux ans', dit M. Olivennes.” (PECQUEUR, A. Le succès d'audience de Radio Classique pousse France Musique à revoir sa grille. Le Monde. Disponível em: < $\underline{\text { http://www.lemonde.fr/web/ar- }}$

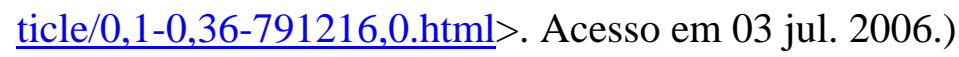

a. Grupo C

b. Tremblay: A

c. X111. Para tanto, a estação, que dispõe apenas de 70 freqüências (contra 500 da France Musique), espera obter entre 15 e 25 freqüências a mais em dois anos, diz M. Olivennes.

X112. ?Para tanto, a estação, que dispõe de apenas 70 freqüências (contra 500 da France Musique), espera obter entre 15 e 25 freqüências a mais em dois anos, diz M. Olivennes. 
X113. Para tanto, a estação, que dispõe somente de 70 freqüências (contra 500 da France Musique), espera obter entre 15 e 25 freqüências a mais em dois anos, diz M. Olivennes.

X114. ? Para tanto, a estação, que dispõe de somente 70 freqüências (contra 500 da France Musique), espera obter entre 15 e 25 freqüências a mais em dois anos, diz M. Olivennes.

X115. Para tanto, a estação, que dispõe só de 70 freqüências (contra 500 da France Musique), espera obter entre 15 e 25 freqüências a mais em dois anos, diz M. Olivennes.

X116. Para tanto, a estação, que só dispõe de 70 freqüências (contra 500 da France Musique), espera obter entre 15 e 25 freqüências a mais em dois anos, diz M. Olivennes.

d. Advérbio - atributo do suporte passivo do verbo, chamado tradicionalmente de objeto indireto

35) "Pour la belette, plus étrange, il n'en a fallu que dix." (DAGEN P. Les bisons, le cheval et la belette. Le Monde. Disponível em: < $\underline{\text { http://www.lemonde.fr/web/article/0,1- }}$ $\underline{0,36-791286,0 . h t m l}>$. Acesso em 03 jul. 2006.)

\section{a. Grupo A}

b. Tremblay: A

c. X117. Para a doninha, mais estranha, precisou de apenas 10 (traços).

X118. Para a doninha, mais estranha, precisou de somente 10 (traços).

X119. Para a doninha, mais estranha, precisou só de 10 (traços).

X120. Para a doninha, mais estranha, precisou de não mais (do) que 10 (traços).

d. Advérbio - atributo do suporte passivo do verbo, chamado tradicionalmente de objeto direto

36) “La Ryder Cup, cela fait plusieurs semaines que les golfeurs n'ont plus que ça en tête.” (ARAGON, J.-L. L'Anglais John Bickerton remporte l'Open de France. Le Monde. Disponível em: <http://www.lemonde.fr/web/article/0,1-0,36-791227,0.html>. 
Acesso em 03 jul. 2006.)

a. Grupo C

b. Tremblay: B

c. X121. Quanto à Copa Ryder, há várias semanas que os golfistas têm apenas isso na cabeça.

X122. Quanto à Copa Ryder, há várias semanas que os golfistas têm somente isso na cabeça.

X123. Quanto à Copa Ryder, há várias semanas que os golfistas têm só isso na cabeça.

X124. ?Quanto à Copa Ryder, há várias semanas que os golfistas só têm isso na cabeça.

X125. ?Quanto à Copa Ryder, há várias semanas que os golfistas não têm mais nada na cabeça.

X126. Quanto à Copa Ryder, há várias semanas que os golfistas não têm nada além disso na cabeça.

d. Advérbio - atributo do suporte passivo do verbo, chamado tradicionalmente de objeto direto

37) “'Mais le vin, ce n'est pas que le goût, c'est aussi le partage, ça ne se boit pas seul, c'est toute une culture.” (ARAGON, J.-L. Le champion de France, Florent Brard, n'est pas avide de gloire. Le Monde. Disponível em: http://www.lemonde.fr/web/article/0,1-0,36-791224,0.html>. Acesso em 03 jul. 2006.)

a. Grupo C

b. Tremblay: C

c. X127. Mas o vinho é não apenas o paladar, é também o compartilhar, não se bebe só, é todo um rito.

X128. Mas o vinho é não somente o paladar, é também o compartilhar, não se 
bebe só, é todo um rito.

X129. Mas o vinho é não só o paladar, é também o compartilhar, não se bebe só, é todo um rito.

d. Advérbio - atributo do suporte passivo do verbo, chamado tradicionalmente de predicativo do sujeito

38) "Pour Eusebio Unzue, son directeur sportif chez Caisse d'Epargne-Iles Baléares, le titre de champion de France de Florent Brard n'est que 'la confirmation de la classe innée’ qu'il avait repérée chez lui il y a six ans.” (ARAGON, J.-L. Le champion de France, Florent Brard, n'est pas avide de gloire. Le Monde. Disponível em: http://www.lemonde.fr/web-/article/0,1-0,36-791224,0.html>. Acesso em 03 jul. 2006.)

a. Grupo C

b. Tremblay: A

c. X130. Para Eusébio Unzue, seu diretor esportivo na Caisse d’Epargne-Iles Baléares, o título de campeão da França de Florent Brard é apenas a confirmação de uma classe inata/de berço.

X131. Para Eusébio Unzue, seu diretor esportivo na Caisse d'Epargne-Iles Baléares, o título de campeão da França de Florent Brard é somente a confirmação de uma classe inata/de berço.

X132. Para Eusébio Unzue, seu diretor esportivo na Caisse d'Epargne-Iles Baléares, o título de campeão da França de Florent Brard é só a confirmação de uma classe inata/de berço.

X133. Para Eusébio Unzue, seu diretor esportivo na Caisse d'Epargne-Iles Baléares, o título de campeão da França de Florent Brard nada mais é do que a confirmação de uma classe inata/de berço.

d. Advérbio - atributo do suporte passivo do verbo, chamado tradicionalmente de predicativo do sujeito 
39) “Aujourd'hui, il relativise. 'Je suis super-content d'être champion de France, mais ce n'est que du vélo, du sport, pas un métier.”” (ARAGON, J.-L. Le champion de France, Florent Brard, n'est pas avide de gloire. Le Monde. Disponível em: http://www.lemonde.fr/web/article/0,1-0,36-791224,0.html> . Acesso em 03 jul. 2006.)

\section{a. Grupo A}

b. Tremblay: A

c. X134. Hoje, ele relativiza. Estou supercontente de ser campeão da França, mas é apenas uma bicicleta, um esporte, não uma profissão.

X135. Hoje, ele relativiza. Estou supercontente de ser campeão da França, mas é somente uma bicicleta, um esporte, não uma profissão.

X136. Hoje, ele relativiza. Estou supercontente de ser campeão da França, mas é só uma bibicleta, um esporte, não uma profissão.

X137. ?Hoje, ele relativiza. Eu estou supercontente de ser campeão da França, mas nada mais é do que uma bibicleta, um esporte, não uma profissão.

d. Advérbio - atributo do suporte passivo do verbo, chamado tradicionalmente de predicativo do sujeito

40) “Le défenseur français Eric Abidal a suggéré une autre explication. 'Nous nous sommes forgé un état d'esprit, a-t-il assuré. C'est tout un groupe qui a joué. Nous n'avons de qualités que par le collectif.”' (CEAUX, P. Le rêve brésilien n'était qu'un mirage. Le Monde. Disponível em: <http://www.lemonde.fr/web/article/0,1-0,36-791268,0.html>. Acesso em 03 jul. 2006.)
a. Grupo C
b. Tremblay: B
c. X138. O defensor francês Eric Abidal sugeriu uma outra explicação. "Forçamos um estado de espírito”, assegurou. “Um grupo inteiro jogou. Temos qualidades apenas coletivamente.” 
X139. O defensor francês Eric Abidal sugeriu uma outra explicação. "Forçamos um estado de espírito”, assegurou. "Um grupo inteiro jogou. Temos qualidades somente coletivamente.”

X140. O defensor francês Eric Abidal sugeriu uma outra explicação. "Forçamos um estado de espírito”, assegurou. "Um grupo inteiro jogou. Temos qualidades só coletivamente.”

X141. O defensor francês Eric Abidal sugeriu uma outra explicação. "Forçamos um estado de espírito”, assegurou. "Um grupo inteiro jogou. Só temos qualidades coletivamente."

X142. O defensor francês Eric Abidal sugeriu uma outra explicação. "Forçamos um estado de espírito”, assegurou. “Um grupo inteiro jogou. Só coletivamente temos qualidades.”

X143. O defensor francês Eric Abidal sugeriu uma outra explicação. "Forçamos um estado de espírito”, assegurou. “Um grupo inteiro jogou. Nossas qualidades só aparecem no coletivo.”

d. Advérbio - atributo do suporte passivo do verbo

41) "Il n'y a que de rares contributeurs du site pour faire le raccourci.” (BOUVIER, P. Libération.fr fait peau neuve et se veut plus "interactif". Le Monde. Disponível em:

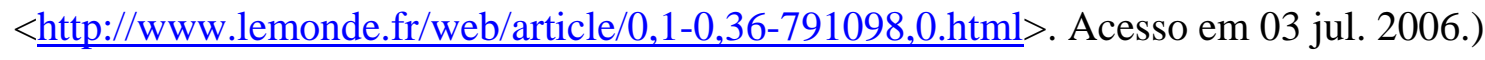

a. Grupo C

b. Tremblay: B

c. X144. ?Há apenas raros colaboradores do site que podem fazer o resumo.

X145. ?Há somente raros colaboradores do site que podem fazer o resumo.

X146. Raros são os colaboradores do site que podem fazer o resumo.

X147. São raros os colaboradores do site que podem fazer o resumo.

d. Advérbio - atributo do suporte passivo do verbo, chamado tradicionalmente de objeto direto 
42) “Ce sont aussi les inconvénients du système de pouvoir très fermé qu'il a mis en place : Vladimir Poutine ne disposerait que d'un nombre limité de cadres fiables.” (NOUGAYRÈDE, N. Vladimir Poutine, tsar du gaz. Le Monde. Disponível em: < $\underline{\text { http://www.lemonde.fr/web/article/0,1-0,36-791244,0.html }>, ~<\underline{h t p}: / / w w w . l e m o n d e . f r / w-~}$ eb/article/0,1-0,36-791244@45-1,0.html>; < 791244@45-2,0.html>. Acesso em 03 jul. 2006.)

a. Grupo C

b. Tremblay: A??

c. X148. ?São também as inconveniências do sistema de poder muito fechado que ele colocou em prática : Vladimir Putin disporia de apenas um número limitado de cargos de confiança.

X149. São também as inconveniências do sistema de poder muito fechado que ele colocou em prática : Vladimir Putin disporia apenas de um número limitado de cargos de confiança.

X150. ?São também as inconveniências do sistema de poder muito fechado que ele colocou em prática : Vladimir Putin disporia de somente um número limitado de cargos de confiança.

X151. São também as inconveniências do sistema de poder muito fechado que ele colocou em prática : Vladimir Putin disporia somente de um número limitado de cargos de confiança.

X152. São também as inconveniências do sistema de poder muito fechado que ele colocou em prática : Vladimir Putin disporia só de um número limitado de cargos de confiança.

X153. São também as inconveniências do sistema de poder muito fechado que ele colocou em prática : Vladimir Putin só disporia de um número limitado de cargos de confiança.

d. Advérbio - atributo do suporte passivo do verbo, chamado tradicionalmente de objeto indireto 
43) “Ces textes ne sont que les productions les plus récentes d'une liste devenue impressionnante de cris d'alarme lancés par experts et scientifiques.” (KEMPF, H. Energie et climat : sortir de la frénésie, par Hervé Kempf. Le Monde. Disponível em: <http://www.lemonde.fr/web/article/0,1-0,36-791622,0.html > . Acesso em 04 jul. 2006.)
a. Grupo C
b. Tremblay: A
c. X154. Esses textos são apenas as produções mais recentes de uma lista impressionante de alarmes dados por especialistas e cientistas.

X155. Esses textos são somente as produções mais recentes de uma lista impressionante de alarmes dados por especialistas e cientistas.

X156. Esses textos são só as produções mais recentes de uma lista impressionante de alarmes dados por especialistas e cientistas.

X157. Esses textos são simplesmente as produções mais recentes de uma lista impressionante de alarmes dados por especialistas e cientistas.

d. Advérbio - atributo do suporte passivo do verbo, chamado tradicionalmente de predicativo do sujeito

44) "Dans cette optique, le développement des énergies renouvelables ne sert que d'alibi écologique à une politique sur le fond inchangée.” (KEMPF, H. Energie et climat : sortir de la frénésie, par Hervé Kempf. Le Monde. Disponível em: < $\underline{\text { http://www.lemon- }}$ de.fr/web/article/0,1-0,36-791622,0.html>. Acesso em 04 jul. 2006.)

\section{a. Grupo A}

b. Tremblay: A

c. X158. Nessa ótica, o desenvolvimento de energias renováveis serve apenas de álibi ecológico a uma política num panorama inalterado.

X159. Nessa ótica, o desenvolvimento de energias renováveis serve somente de álibi ecológico a uma política num panorama inalterado. 
X160. Nessa ótica, o desenvolvimento de energias renováveis serve só de álibi ecológico a uma política num panorama inalterado.

X161. Nessa ótica, o desenvolvimento de energias renováveis só serve de álibi ecológico a uma política num panorama inalterado.

d. Advérbio - atributo do suporte passivo do verbo, chamado tradicionalmente de objeto indireto

45) "La question, maintenant, est de savoir comment ce double mouvement d'identification à la life politics et de triangulation peut s'étendre et se développer. A l'évidence, le deuxième chapitre de son livre en ligne sur le site Désirs d'avenir paraît insuffisamment mûri. Les observateurs n'ont retenu que la critique des 35 heures qui, elle aussi, a fait l'objet d'une triangulation parfaite : critique des limites de cette loi honnie par la droite, mais insistance sur les dégâts réels ou supposés causés sur les couches populaires.” (LAÏDI, Z. Le véritable apport de Mme Royal, par Zaki Laïdi. Le Monde. Disponível em: < http://www.lemonde.fr-/web/article/0,1-0,36-791686,0.html>. Acesso em 04 jul. 2006.)

\section{a. Grupo C}

b. Tremblay: A

c. X162. A questão agora é saber como esse duplo movimento de identificação com a life politics e de triangulação pode estender-se e desenvolver-se. Evidentemente, o segundo capítulo de seu livro on line no site “Désirs d'avenir” parece insuficientemente amadurecido. Os observadores consideraram apenas a crítica das 35h, que também foi objeto de uma triangulação perfeita : crítica de limites dessa lei denunciada pela direita, mas insistência nos estragos reais ou imaginados, causados pelas camadas populares.

X163. A questão agora é saber como esse duplo movimento de identificação com a life politics e de triangulação pode estender-se e desenvolver-se. Evidentemente, o segundo capítulo de seu livro on line no site "Désirs d'avenir" parece insuficientemente amadurecido. Os observadores consideraram somente a crítica das 35h, que também foi 
objeto de uma triangulação perfeita : crítica de limites dessa lei denunciada pela direita, mas insistência nos estragos reais ou imaginados causados pelas camadas populares.

X164. A questão agora é saber como esse duplo movimento de identificação com a life politics e de triangulação pode estender-se e desenvolver-se. Evidentemente, o segundo capítulo de seu livro on line no site "Désirs d’avenir" parece insuficientemente amadurecido. Os observadores consideraram só a crítica das 35h, que também foi objeto de uma triangulação perfeita: crítica de limites dessa lei denunciada pela direita, mas insistência nos estragos reais ou imaginados causados pelas camadas populares.

X165. A questão agora é saber como esse duplo movimento de identificação com a life politics e de triangulação pode estender-se e desenvolver-se. Evidentemente, o segundo capítulo de seu livro on line no site "Désirs d'avenir" parece insuficientemente amadurecido. Os observadores só consideraram a crítica das 35h, que também foi objeto de uma triangulação perfeita: crítica de limites dessa lei denunciada pela direita, mas insistência nos estragos reais ou imaginados causados pelas camadas populares.

d. Advérbio - atributo do suporte passivo do verbo, chamado tradicionalmente de objeto direto

46) "Les équipes africaines ne progresseront que lorsqu'elles seront libérées de leurs problèmes d'infrastructures.” (BARTH, E. "Des guerriers, pas des techniciens". Le Monde. Disponível em: <http://www.lemonde.fr/web/article/0,1-0,36-792014,0.html>. Acesso em 05 jul. 2006.)

a. Grupo A

b. Tremblay: A

c. X166. As equipes africanas progredirão apenas quando se libertarem de seus problemas de infra-estrutura.

X167. As equipes africanas progredirão somente quando se libertarem de seus problemas de infra-estrutura.

X168. ?As equipes africanas progredirão só quando se libertarem de seus 
problemas de infra-estrutura.

X169. ?As equipes africanas só progredirão quando se libertarem de seus problemas de infra-estrutura.

d. Advérbio - atributo do suporte ativo do verbo

47) "Voilà les réformes qui nous rendront la croissance et l'emploi et qui amélioreront la justice sociale et la force du pays. Elles ne dépendent que de nousmêmes.” (BALLADUR, E. Laissez de Gaulle en paix !, par Edouard Balladur. Le Monde. Disponível em: http://www.lemonde.fr/web/article/0,1-0,36-792173,0.html>. Acesso em 05 jul. 2006.)

a. Grupo C

b. Tremblay: A

c. X170. Essas são as reformas que nos proporcionarão crescimento e emprego e que melhorarão a justiça social e a força do país. Elas dependem apenas de nós mesmos.

X171. Essas são as reformas que nos proporcionarão crescimento e emprego e que melhorarão a justiça social e a força do país. Elas dependem somente de nós mesmos.

X172. Essas são as reformas que nos proporcionarão crescimento e emprego e que melhorarão a justiça social e a força do país. Elas dependem só de nós mesmos.

X173. Essas são as reformas que nos proporcionarão crescimento e emprego e que melhorarão a justiça social e a força do país. Elas só dependem de nós mesmos.

d. Advérbio - atributo do suporte passivo do verbo, chamado tradicionalmente de objeto indireto

48) “Certes, dans les premiers matches du Mondial, il a semblé moins à l'aise que d'habitude, mais l'équipe ne tournait pas bien rond non plus. Il le savait, et cela l'a énervé. N'empêche que, dimanche 9 juillet, elle jouera la finale, contre l'Italie.” (CAUSSÉ, B. Willy Sagnol fait parler son autorité. Le Monde. Disponível em: http://www.lemonde.fr/web/article/0,1-0,36-792521,0.html>. Acesso em 06 jul. 2006.) 
a. Grupo C

b. Tremblay: B

c. X174. !Embora nas primeiras partidas do Mundial ele tenha parecido menos à vontade do que de costume, a equipe também não estava nos seus melhores dias. Ele sabia disso, o que o deixou irritado. Não obstante, no domingo, dia 9 de julho, ela jogará a final contra a Itália.

d. Advérbio - atributo do suporte passivo do verbo, chamado tradicionalmente de objeto direto

49) “Alors Willy Sagnol n'a qu'un message : que les grincheux se le tiennent pour dit.” (CAUSSÉ, B. Willy Sagnol fait parler son autorité. Le Monde. Disponível em: http://www.lemonde.fr/web/article/0,1-0,36-792521,0.html>. Acesso em 06 jul. 2006.)

a. Grupo A

b. Tremblay: A

c. X175. Sendo assim, Willy Sagnol tem apenas uma mensagem: que os rabugentos se dêem por satisfeitos.

X176. Sendo assim, Willy Sagnol tem somente uma mensagem: que os rabugentos se dêem por satisfeitos.

X177. Sendo assim, Willy Sagnol tem só uma mensagem: que os rabugentos se dêem por satisfeitos.

d. Advérbio - atributo do suporte passivo do verbo, chamado tradicionalmente de objeto direto

50) “Le reste de la presse européenne, pour l'essentiel, n'a d'yeux que pour Zidane.” (BÉLOEIL, M.; VINOGRADOFF, L. Le baiser de Zidane. Le Monde. Disponível em: http://www.lemonde.fr/web/article/0,1-0,36-792491,0.html>; <http://www.lemonde.fr/web/article/0,1-0,36-792491@45-1,0.html>. Acesso em 06 jul. 2006.) 
a. Grupo A

b. Tremblay: B (expression fixe)

c. X178. Grande parte da imprensa européia tem olhos apenas para Zidane.

X179. Grande parte da imprensa européia tem olhos somente para Zidane.

X180. Grande parte da imprensa européia tem olhos só para Zidane.

X181. Grande parte da imprensa européia só tem olhos para Zidane.

d. Advérbio - modal de destinação, tradicionalmente chamado de predicativo do objeto

51) “Au terme d'une élection à suspense, Andres Obrador et Felipe Calderon ne sont départagés que par 236000 voix (0,57 point).” (AFP. Mexique : le conservateur Felipe Calderon a remporté l'élection présidentielle sur le fil. Le Monde. Disponível em:

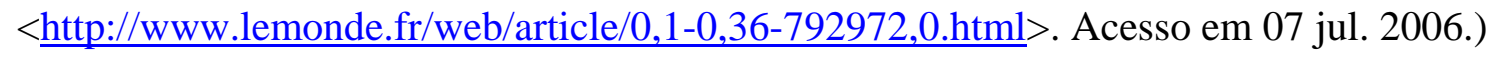

a. Grupo B

b. Tremblay: A

c. X182. No final de uma eleição emocionante, Andres Obrador e Felipe Calderon têm uma diferença de apenas 236.000 votos (0,57 pontos).

X183. No final de uma eleição emocionante, Andres Obrador e Felipe Calderon têm uma diferença de somente 236.000 votos ( 0,57 pontos).

X184. No final de uma eleição emocionante, Andres Obrador e Felipe Calderon têm uma diferença só de 236.000 votos (0,57 pontos).

X185. No final de uma eleição emocionante, Andres Obrador e Felipe Calderon têm uma diferença de só 236.000 votos (0,57 pontos).

d. Advérbio - atributo do suporte passivo do verbo, chamado tradicionalmente de objeto direto preposicionado

52) “Entre 1967 et 1986, le nombre d'équipes différentes qui se qualifiaient pour les quarts de finale variait entre 28 et 30 . Au cours des dix ans qui ont suivi, ce chiffre tombe à 
26, et lors de la période la plus récente (2000-2004), il n'y en a eu que 21.” (MILANOVIC, B. Le foot, industrie sans frontières, par Branko Milanovic Le Monde. Disponível em: http://www.lemonde.fr/web/article/0,1-0,36-793211,0.html>. Acesso em 07 jul. 2006.)

a. Grupo C

b. Tremblay: A

c. X186. Entre 1967 e 1986, o número de equipes diferentes que se qualificaram para as quartas-de-final variava entre 28 e 30. No decorrer dos 10 anos subseqüentes, esse número caiu para 26 e, mais recentemente (2000-2004), houve apenas 21.

X187. Entre 1967 e 1986, o número de equipes diferentes que se qualificaram para as quartas-de-final variava entre 28 e 30 . No decorrer dos 10 anos subseqüentes, esse número caiu para 26 e, mais recentemente (2000-2004), houve somente 21.

X188. Entre 1967 e 1986, o número de equipes diferentes que se qualificaram para as quartas-de-final variava entre 28 e 30. No decorrer dos 10 anos subseqüentes, esse número caiu para 26 e, mais recentemente (2000-2004), houve não mais (do) que 21.

d. Advérbio - atributo do suporte passivo do verbo, chamado tradicionalmente de objeto direto

53) "La marge moyenne de victoire parmi les huit meilleures équipes nationales de la Coupe du monde n'a fait que décroître, passant de plus de 2 buts dans les années 1950 à environ 1,5 but dans les années 1960, 1970 et 1980, et à seulement 0,88 but pour la Coupe du monde de 2002.” (MILANOVIC, B. Le foot, industrie sans frontières, par Branko Milanovic Le Monde. Disponível em: http://www.lemonde.fr/web/article/0,1-0,36793211,0.html>. Acesso em 07 jul. 2006.)
a. Grupo C
b. Tremblay: B
c . X189. ?A margem de vitória entre as 8 melhores equipes nacionais da Copa do Mundo apenas fez cair, passando de mais de 2 gols nos anos 50 a 1,5 gol em média nos 
anos 60, 70 e 80, e somente 0,88 gols na Copa do Mundo de 2002.

X190. ?A margem de vitória entre as 8 melhores equipes nacionais da Copa do Mundo fez somente cair, passando de mais de 2 gols nos anos 50 a 1,5 gol em média nos anos 60, 70 e 80, e somente 0,88 gols na Copa do Mundo de 2002.

X191. A margem de vitória entre as 8 melhores equipes nacionais da Copa do Mundo só fez cair, passando de mais de 2 gols nos anos 50 a 1,5 gol em média nos anos 60, 70 e 80, e somente 0,88 gols na Copa do Mundo de 2002.

d. Advérbio - atributo do suporte passivo do verbo, chamado tradicionalmente de objeto direto

54) "Eto'o peut jouer pour n'importe quel club espagnol, italien ou anglais, mais dans le cadre de compétitions entre nations, il ne peut jouer que pour le Cameroun.” (MILANOVIC, B. Le foot, industrie sans frontières, par Branko Milanovic Le Monde. Disponível em: http://www.lemonde.fr/web/article/0,1-0,36-793211,0.html>. Acesso em 07 jul. 2006.)

a. Grupo C

b. Tremblay: A

c. X192. Eto’o pode jogar em qualquer clube espanhol, italiano ou inglês, mas nos campeonatos internacionais, pode jogar apenas por Camarões.

X193. Eto’o pode jogar em qualquer clube espanhol, italiano ou inglês, mas nos campeonatos internacionais, pode jogar somente por Camarões.

X194. Eto’o pode jogar em qualquer clube espanhol, italiano ou inglês, mas nos campeonatos internacionais, pode jogar só por Camarões.

X195. Eto’o pode jogar em qualquer clube espanhol, italiano ou inglês, mas nos campeonatos internacionais, só pode jogar por Camarões.

d. Advérbio - atributo do suporte passivo do verbo, chamado tradicionalmente de objeto direto 
55) “Depuis vingt-cinq ans et le début de la libéralisation des marchés financiers, les Etats n'ont eu de cesse que de lever une à une les restrictions à l'innovation financière.” (LE BOUCHER, E. Penalty contre le capitalisme. Le Monde. Disponível em: http://www.lemonde.fr/web/article/0,1-0,36-793496,0.html>. Acesso em 08 jul. 2006.)

\section{a. Grupo A}

b. Tremblay: B

c. X196. Após 25 anos e o início da liberalização dos mercados financeiros, os Estados não pararam de aumentar uma a uma as restrições à inovação financeira.

d. Advérbio - atributo do suporte passivo do verbo, chamado tradicionalmente de objeto direto preposicionado

56) “(...) Sur le terrain, les juges de touche ne voient que les hors-jeu palestiniens, tandis qu'aucun attaquant israélien n'est sanctionné, même pour faute grave commise dans la surface de ‘destruction’ du camp adverse.” (SOLÉ, R. Mots en guerre , par ROBERT SOLÉ. Le Monde. Disponível em: http://www.lemonde.fr/web/article/0,1-0,36793545,0.html>. Acesso em 08 jul. 2006.)

\section{a. Grupo A \\ b. Tremblay: A}

c. X197. Em campo, os bandeirinhas viam apenas as saídas palestinas, enquanto nenhum ataque israelense foi penalizado, mesmo as faltas graves cometidas na grande área do campo adversário.

X198. Em campo, os bandeirinhas viam somente as saídas palestinas, enquanto nenhum ataque israelense foi penalizado, mesmo as faltas graves cometidas na grande área do campo adversário.

X199. Em campo, os bandeirinhas viam só as saídas palestinas, enquanto nenhum ataque israelense foi penalizado, mesmo as faltas graves cometidas na grande área do campo adversário. 
X200. Em campo, os bandeirinhas só viam as saídas palestinas, enquanto nenhum ataque israelense foi penalizado, mesmo as faltas graves cometidas na grande área do campo adversário.

d. Advérbio - atributo do suporte passivo do verbo, chamado tradicionalmente de objeto direto

57) “Hector Chemla (courriel) dénonce 'la désinformation permanente’ du journal : 'Des assassins qualifiés d'activistes... Il ne manque plus que l'adjectif 'héroïque' pour donner plus de poids au mot résistance.' " (SOLÉ, R. Mots en guerre , par ROBERT SOLÉ. Le Monde. Disponível em: http://www.lemonde.fr/web/article/0,1-0,367935$\underline{45,0 . h t m l}>$. Acesso em 08 jul. 2006.)
a. Grupo A
b. Tremblay: B
c. X201. Hector Chemla (e.mail) denuncia 'a desinformação permanente' do jornal : 'Assassinos qualificados de ativistas... Falta apenas o adjetivo 'herói’ para dar mais peso à palavra resistência.

X202. ?Hector Chemla (e.mail) denuncia ‘a desinformação permanente’ do jornal : ‘Assassinos qualificados de ativistas... Falta somente o adjetivo 'herói’ para dar mais peso à palavra resistência.

X203. Hector Chemla (e.mail) denuncia ‘a desinformação permanente’ do jornal : 'Assassinos qualificados de ativistas... Falta só o adjetivo 'herói' para dar mais peso à palavra resistência.

X204. Hector Chemla (e.mail) denuncia ‘a desinformação permanente’ do jornal : 'Assassinos qualificados de ativistas... Só falta o adjetivo 'herói' para dar mais peso à palavra resistência.

d. Advérbio - atributo do suporte passivo do verbo, chamado tradicionalmente de objeto direto 
58) “Pièce paradoxalement épurée, truffée pourtant de références, elle se lit comme le manifeste d'une conscience qui ne trouve de paix momentanée que dans l'action spectaculaire.” (BOISSEAU, R. Joseph Nadj ensorcelle Avignon. Le Monde. Disponível em: <http://www.lemonde.fr/web/article/0,1-0,36-793560,0.html $>$. Acesso em 09 jul. 2006.)

a. Grupo A

c. X205. Peça paradoxalmente refinada, apesar de repleta de referências, é lida como o manifesto de uma consciência que encontra paz momentânea apenas na ação espetacular.

X206. Peça paradoxalmente refinada, apesar de repleta de referências, é lida como o manifesto de uma consciência que encontra paz momentânea somente na ação espetacular.

X207. Peça paradoxalmente refinada, apesar de repleta de referências, é lida como o manifesto de uma consciência que encontra paz momentânea só na ação espetacular.

X208. Peça paradoxalmente refinada, apesar de repleta de referências, é lida como o manifesto de uma consciência que só encontra paz momentânea na ação espetacular.

d. Advérbio - modal de origem, tradicionalmente chamado de adjunto adverbial de tempo

59) “' 'On ne peut être que déçu, profondément déçu.” (AFP. Raymond Domenech : "L'homme du match, c'est Materazzi". Le Monde. Disponível em: http://www.lemonde.fr/web/article/0,1-0,36-793802,0.html>. Acesso em 10 jul. 2006.)

\section{a. Grupo C}

b. Tremblay: A (avec juste...)

c. X209. ?Podemos ficar apenas decepcionados, profundamente decepcionados.

X210. ?Podemos ficar somente decepcionados, profundamente decepcionados. X211. ?Podemos ficar só decepcionados, profundamente decepcionados. 
X212. Só podemos ficar decepcionados, profundamente decepcionados.

d. Advérbio - atributo do suporte passivo do verbo, chamado tradicionalmente de predicativo do sujeito reduzida de infinitivo

60) “'On n'a été mis en danger que sur les coups francs et les corners. Je pense qu'on a vu une grande équipe de France'.” (AFP. Raymond Domenech : "L'homme du match, c'est Materazzi". Le Monde. Disponível em: http://www.lemonde.fr/web/article/0,1-0,36-793802,0.html>. Acesso em 10 jul. 2006.)

a. Grupo A

b. Tremblay: A

c. X213. Ficamos em perigo apenas nos tiros de meta e nos escanteios. Acredito termos visto um grande time da França.

X214. Ficamos em perigo somente nos tiros de meta e nos escanteios. Acredito termos visto um grande time da França.

X215. Ficamos em perigo só nos tiros de meta e nos escanteios. Acredito termos visto um grande time da França.

X216. Só ficamos em perigo nos tiros de meta e nos escanteios. Acredito termos visto um grande time da França.

d. Advérbio - modal de tempo, tradicionalmente chamado de adjunto adverbial de tempo

61) “Kofi Annan clamait pour sa part, en ouverture du Mondial, à quel point il en était envieux : alors que la FIFA compte 207 membres, les Nations Unis n'en dénombrent que 191.” (MANACH, J.-M. L'Italie a gagné, mais à quel prix ?. Le Monde. Disponível em: $\quad$ http://www.lemonde.fr/web/article/0,1-0,36-793818,0.html $>$. Acesso em 10 jul. 2006.)

a. Grupo A 
b. Tremblay: A

c. X217. Kofi Annan clamava de sua parte, na abertura do Mundial, a que ponto ele o invejava: enquanto a FIFA conta com 207 membros, as Nações Unidas conta apenas com 191.

X218. Kofi Annan clamava de sua parte, na abertura do Mundial, a que ponto ele o invejava: enquanto a FIFA conta com 207 membros, as Nações Unidas conta somente com 191.

X219. Kofi Annan clamava de sua parte, na abertura do Mundial, a que ponto ele o invejava: enquanto a FIFA conta com 207 membros, as Nações Unidas conta só com 191.

d. Advérbio - atributo do suporte passivo do verbo, chamado tradicionalmente de objeto direto

62) "Selon un haut responsable iranien, la réunion de Bruxelles est surtout destinée à éclaircir des points de la proposition occidentale jugés obscurs, tandis que le ministre des affaires étrangères iranien, Manouchehr Mottaki, a dit le 9 juillet que l'Iran n'y répondrait que dans la semaine du 14 au 22 août.” (AFP. Nucléaire : nouvelle rencontre entre Européens et Iraniens à Bruxelles. Le Monde. Disponível em: http://www.lemonde.fr/web/article/0,1-0,36-794225,0.html>. Acesso em 11 jul. 2006.)
a. Grupo C
b. Tremblay: A

c. X220. Segundo um alto funcionário iraniano, a reunião de Bruxelas destina-se, sobretudo, a esclarecer os pontos da proposta ocidental considerados obscuros, enquanto o Ministro de Relações Exteriores o iraniano Manouchehr Mottaki, disse em 9 de julho que o Irã responderia apenas na semana de 14 a 22 de agosto.

X221. Segundo um alto funcionário iraniano, a reunião de Bruxelas destina-se, sobretudo, a esclarecer os pontos da proposta ocidental considerados obscuros, enquanto o Ministro de Relações Exteriores o iraniano Manouchehr Mottaki, disse em 9 de julho que o Irã responderia somente na semana de 14 a 22 de agosto. 
X222. Segundo um alto funcionário iraniano, a reunião de Bruxelas destina-se, sobretudo, a esclarecer os pontos da proposta ocidental considerados obscuros, enquanto o Ministro de Relações Exteriores o iraniano Manouchehr Mottaki, disse em 9 de julho que o Irã responderia só na semana de 14 a 22 de agosto.

X223. Segundo um alto funcionário iraniano, a reunião de Bruxelas destina-se, sobretudo, a esclarecer os pontos da proposta ocidental considerados obscuros, enquanto o Ministro de Relações Exteriores o iraniano Manouchehr Mottaki, disse em 9 de julho que o Irã só responderia na semana de 14 a 22 de agosto.

d. Advérbio - modal de tempo, tradicionalmente chamado de adjunto adverbial de tempo

63) “'Monsieur le président, explique-t-il au juge Jean-Claude Kross, j'avais vendu ma voiture, apporté beaucoup d'argent pour acheter des balles... Mais on pouvait pas en acheter. En tout, je n'ai tiré que quinze balles !” (AFP. Procès des Français de Guantanamo : nouvelle journée d'explications. Le Monde. Disponível em: < http://www.lemonde.fr/web/article/0,1-0,36-794228,0.html>. Acesso em 11 jul. 2006.)

a. Grupo C

b. Tremblay: A

X224. “Senhor Meritíssimo”, explica ao juiz Jean-Claude Kross, “eu tinha vendido meu carro e ganhado muito dinheiro para comprar balas... Mas não podemos mais comprálas. No total, consegui apenas 15 balas!”

X225. “Senhor Meritíssimo”, explica ao juiz Jean-Claude Kross, “eu tinha vendido meu carro e ganhado muito dinheiro para comprar balas... Mas não podemos mais comprálas. No total, consegui somente 15 balas!”

X226. “Senhor Meritíssimo”, explica ao juiz Jean-Claude Kross, “eu tinha vendido meu carro e ganhado muito dinheiro para comprar balas... Mas não podemos mais comprálas. No total, consegui só 15 balas!”

X227. “Senhor Meritíssimo”, explica ao juiz Jean-Claude Kross, “eu tinha vendido 
meu carro e ganhado muito dinheiro para comprar balas... Mas não podemos mais comprálas. No total, só consegui 15 balas!”

d. Advérbio - atributo do suporte passivo do verbo, chamado tradicionalmente de objeto direto

64) “'Moi aussi, enchaîne Mourad Benchellali, je n'ai tiré que quinze coups. Et j'ai détesté ça.' ” (AFP. Procès des Français de Guantanamo : nouvelle journée d'explications. Le Monde. Disponível em: <http://www.lemonde.fr/web/article/0,1-0,36-794228,0.html>. Acesso em 11 jul. 2006.)

a. Grupo C

b. Tremblay: A

c. X228. “Eu também”, acrescenta Mourad Benchellali, “consegui apenas 15 tiros. E odiei isso.”

X229. “Eu também”, acrescenta Mourad Benchellali, “consegui somente 15 tiros. E odiei isso.”

X230. “Eu também”, acrescenta Mourad Benchellali, “consegui só 15 tiros. E odiei isso.”

X231. "Eu também”, acrescenta Mourad Benchellali, “só consegui 15 tiros. E odiei isso.”

d. Advérbio - atributo do suporte passivo do verbo, chamado tradicionalmente de objeto direto

65) "Or, la plupart du temps, il ne s'agit que de provocations, pour trouver une écoute.” (LAUDIN, A. "Le Panthéon est le culte des grands hommes, pas des victimes". Le Monde. Disponível em: http://www.lemonde.fr/web/article/0,1-0,36-793437,0.html>. Acesso em 12 jul. 2006.)

a. Grupo C 
b. Tremblay: A

c. X232. Ora, na maior parte do tempo, trata-se apenas de provocações para encontrar um ouvinte.

X233. Ora, na maior parte do tempo, trata-se somente de provocações para encontrar um ouvinte.

X234. Ora, na maior parte do tempo, trata-se só de provocações para encontrar um ouvinte.

X235. Ora, na maior parte do tempo, são só provocações para encontrar um ouvinte.

d. Advérbio - atributo do suporte passivo do verbo, chamado tradicionalmente de objeto indireto

66) “On en a parlé, pourtant. Pendant des années, on n'a même parlé que de cela : car Dreyfus était innocent.” (s/a. L'hommage de Jacques Chirac au capitaine Dreyfus. Le Monde. Disponível em: <http://www.lemonde.fr/web/article/0,1-0,36-794609@451,0.ht$\underline{\mathrm{ml}}>$. Acesso em 12 jul. 2006.)

a. Grupo C

b. Tremblay: B

c. X236. No entanto, nós falamos. Durante anos, realmente falamos apenas disso: porque Dreyffus era inocente.

X237. ?No entanto, nós falamos. Durante anos, realmente falamos somente disso: porque Dreyffus era inocente.

X238. No entanto, nós falamos. Durante anos, realmente falamos só disso: porque Dreyffus era inocente.

X239. No entanto, nós falamos. Durante anos, realmente só falamos disso: porque Dreyffus era inocente.

X240. No entanto, nós falamos. Durante anos, e realmente não falamos de outra coisa: porque Dreyffus era inocente. 
d. Advérbio - atributo do suporte passivo do verbo, chamado tradicionalmente de objeto direto

67) “Il n'y aurait jamais dû y avoir d'affaire Dreyfus : cette médiocre machination aurait pu être dévoilée dès le départ. Mais, parce que la haute hiérarchie ne pouvait s'être trompée, le capitaine devait à tout prix rester coupable. On invoquait l'intérêt supérieur de la nation. Il ne s'agissait que de dissimuler les défaillances de quelques responsables.” (s/a. L'hommage de Jacques Chirac au capitaine Dreyfus. Le Monde. Disponível em:

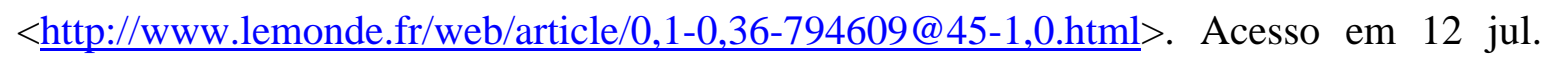
2006.)

a. Grupo C

b. Tremblay: A

c. X241. Nunca deveria ter havido o caso Dreyffys: essa maquinação medíocre poderia ter sido desvelada desde o início. Mas como a alta hierarquia não podia ter-se enganado, o capitão devia a todo custo continuar ser o culpado. Invocamos o interesse superior da nação. Tratava-se apenas de disfarçar as falhas de alguns responsáveis.

X242. Nunca deveria ter havido o caso Dreyffys: essa maquinação medíocre poderia ter sido desvelada desde o início. Mas como a alta hierarquia não podia ter-se enganado, o capitão devia a todo custo continuar ser o culpado. Invocamos o interesse superior da nação. Tratava-se somente de disfarçar as falhas de alguns responsáveis.

X243. ?Nunca deveria ter havido o caso Dreyffys: essa maquinação medíocre poderia ter sido desvelada desde o início. Mas como a alta hierarquia não podia ter-se enganado, o capitão devia a todo custo continuar ser o culpado. Invocamos o interesse superior da nação. Tratava-se só de disfarçar as falhas de alguns responsáveis.

X244. Nunca deveria ter havido o caso Dreyffys: essa maquinação medíocre poderia ter sido desvelada desde o início. Mas como a alta hierarquia não podia ter-se enganado, o capitão devia a todo custo continuar ser o culpado. Invocamos o interesse superior da nação. Só se pensava em disfarçar as falhas de alguns responsáveis. 
d. Advérbio - atributo do suporte passivo do verbo, chamado tradicionalmente de objeto indireto

68) “Il n'est payé que par un petit nombre de contribuables honnêtes ou qui n'ont pas la possibilité d'échapper à la vigilance du fisc : notamment gros et moyens salariés, travailleurs intellectuels indépendants, dont les revenus sont déclarés, etc.” (TARDY, M. Les nouveaux impôts. Le Monde. Disponível em: http://www.lemonde.fr/cgibin/ACHATS/acheter.cgi?offre=ARCHIVES\&type_item=ART_ARCH_30J\&objet_id=952586 $>$.

Acesso em 13 jul. 2006.)

a. Grupo C

b. Tremblay: A

c. X245. Ele é pago apenas por um pequeno número de contribuintes honestos ou que não têm a possibilidade de escapar à vigilância do fisco: especialmente grandes e médios assalariados e trabalhadores intelectuais independentes, cujos ganhos são declarados etc.

X246. Ele é pago somente por um pequeno número de contribuintes honestos ou que não têm a possibilidade de escapar à vigilância do fisco: especialmente grandes e médios assalariados e trabalhadores intelectuais independentes, cujos ganhos são declarados etc.

X247. Ele é pago só por um pequeno número de contribuintes honestos ou que não têm a possibilidade de escapar à vigilância do fisco: especialmente grandes e médios assalariados e trabalhadores intelectuais independentes, cujos ganhos são declarados etc.

X248. Ele só é pago por um pequeno número de contribuintes honestos ou que não têm a possibilidade de escapar à vigilância do fisco: especialmente grandes e médios assalariados e trabalhadores intelectuais independentes, cujos ganhos são declarados etc.

X249. Ele simplesmente é pago por um pequeno número de contribuintes honestos ou que não têm a possibilidade de escapar à vigilância do fisco: especialmente grandes e médios assalariados e trabalhadores intelectuais independentes, cujos ganhos são 
declarados etc.

d. Advérbio - modal de modo, tradicionalmente chamado de adjunto adverbial de modo

69) “Alors, le 31 août 2005, lorsqu'il apprend que sa quatorzième demande de libération a été acceptée mais qu'elle ne sera effective que le 3 octobre suivant, Lucien Léger lance à son avocat : 'Je ne suis plus à huit jours près.' Il a 68 ans.” (TALÈS, I. Le plus ancien prisonnier de France. Le Monde. Disponível em: http://www.lemonde.fr/web/article/0,1-0,36-795048,0.html>. Acesso em 13 jul. 2006.)

a. Grupo A

b. Tremblay: A

c. X250. Então, em 31 de agosto de 2005, quando ficou sabendo que seu $14^{\circ}$ pedido de libertação foi aceito mas que será válido apenas em 3 de outubro, Lucien Léger diz a seu advogado: “Ñão vou morrer por mais 8 dias.” Ele tem 68 anos.

X251. Então, em 31 de agosto de 2005, quando ficou sabendo que seu $14^{\circ}$ pedido de libertação foi aceito mas que será válido somente em 3 de outubro, Lucien Léger diz a seu advogado: “Ñ̃̃o vou morrer por mais 8 dias.” Ele tem 68 anos.

X252. Então, em 31 de agosto de 2005, quando ficou sabendo que seu $14^{\circ}$ pedido de libertação foi aceito mas que será válido só em 3 de outubro, Lucien Léger diz a seu advogado: “Ñão vou morrer por mais 8 dias.” Ele tem 68 anos.

X253. Então, em 31 de agosto de 2005, quando ficou sabendo que seu $14^{\circ}$ pedido de libertação foi aceito mas que só será válido em 3 de outubro, Lucien Léger diz a seu advogado: “Ñão são mais 8 dias que vão fazer diferença.” Ele tem 68 anos.

d. Advérbio - modal de tempo, tradicionalmente chamado de adjunto adverbial de tempo

70) “M. Sarkozy, qui n'avait pu ‘sauver’ Patrick Devedjian ni François Fillon lors de la composition du gouvernement, n'avait obtenu que la nomination à ses côtés de deux 
de ses proches : Brice Hortefeux (collectivités territoriales) et Christian Estrosi (aménagement du territoire).” (MONTVALON, J.-B. De. La "citadelle" sarkozyste s'ouvre aux nouveaux convertis. Le Monde. Disponível em: <http://www.lemonde.fr/web/article/0,1-0,36-795538,0.html>. Acesso em 14 jul. 2006.)
a. Grupo C
b. Tremblay: A
c. X254. M. Sarkozy, que não pôde “evitar” nem Patrick Devedjian nem François Fillon no momento da composição do governo, de seu lado obteve apenas a nomeação de seus dois aliados: Brice Hortefeux (interior) e Christian Estrosi (administração regional).

X255. M. Sarkozy, que não pôde “evitar” nem Patrick Devedjian nem François Fillon no momento da composição do governo, de seu lado obteve somente a nomeação de seus dois aliados: Brice Hortefeux (interior) e Christian Estrosi (administração regional).

X256. M. Sarkozy, que não pôde “evitar” nem Patrick Devedjian nem François Fillon no momento da composição do governo, de seu lado obteve só a nomeação de seus dois aliados: Brice Hortefeux (interior) e Christian Estrosi (administração regional).

X257. M. Sarkozy, que não pôde “evitar” nem Patrick Devedjian nem François Fillon no momento da composição do governo, de seu lado só obteve a nomeação de seus dois aliados: Brice Hortefeux (interior) e Christian Estrosi (administração regional).

d. Advérbio - atributo do suporte passivo do verbo, chamado tradicionalmente de objeto direto

71) “Oubliées, les attaques de Jean-Louis Borloo qui, à l'automne 2004, en appelait à une 'contre-offensive de la République' face aux 'bushistes, adeptes des communautés, du libéralisme et de la religion', et qui estimait que les propositions de M. Sarkozy sur l'immigration n'étaient que 'littérature’.” (MONTVALON, J.-B. De. La "citadelle" sarkozyste s'ouvre aux nouveaux convertis. Le Monde. Disponível em: < $\underline{\text { http://www.le- }}$

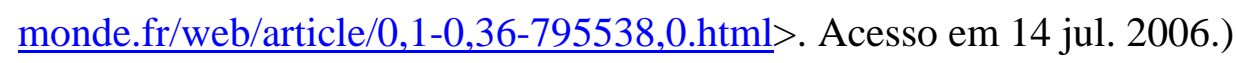


a. Grupo C

b. Tremblay: A

c. X258. Foram esquecidos os ataques de Jean-Louis Borloo, que, no outono de 2004, apelava para uma "contra-ofensiva da República” em face dos "bushistas, adeptos das comunidades, do liberalismo e da religião”, e que avaliava que as propostas do sr. Sarkozy sobre a imigração eram apenas “retórica”.

X259. Foram esquecidos os ataques de Jean-Louis Borloo, que, no outono de 2004, apelava para uma “contra-ofensiva da República” em face dos "bushistas, adeptos das comunidades, do liberalismo e da religião”, e que avaliava que as propostas do sr. Sarkozy sobre a imigração eram somente "retórica”.

X260. Foram esquecidos os ataques de Jean-Louis Borloo, que, no outono de 2004, apelava para uma “contra-ofensiva da República” em face dos "bushistas, adeptos das comunidades, do liberalismo e da religião”, e que avaliava que as propostas do sr. Sarkozy sobre a imigração eram só "retórica”.

X261. Foram esquecidos os ataques de Jean-Louis Borloo, que, no outono de 2004, apelava para uma “contra-ofensiva da República” em face dos "bushistas, adeptos das comunidades, do liberalismo e da religião”, e que avaliava que as propostas do sr. Sarkozy sobre a imigração não passavam de “retórica”.

d. Advérbio - atributo do suporte passivo do verbo, chamado tradicionalmente de predicativo do sujeito 


\section{CONSIDERAÇÕES FINAIS}

Wilmet (1997) define o binômio "ne... que" como négation exceptive, ${ }^{436}$ enquanto Weinrich (1989) o define como négation restreinte (negação restrita) de morfema descontínuo que exclui o objeto de toda negação que comporta a frase ${ }^{437}$. Essas definições são bem interessantes, pois reconhecem o valor negativo da partícula “ne”, não contradizem a definição da negação, e mostram que o binômio “ne... que” faz parte de uma negação parcial em que exclui da negação total o seu complemento.

Considerando o movimento de transferência da negação da partícula "ne” para o forclusivo observado por todos os autores consultados e as observações feitas por Guillaume (1973) sobre a negação in fieri (incompleta, inacabada), formada apenas pela partícula "ne”, e sobre a negação in esse (completa, acabada), formada pelas partículas “ne” e "pas”, “point”, “personne”, “rien” ${ }^{438}$, “aucun” e “jamais”439, de corte precoce e tardio, podemos levantar a hipótese de que o mesmo fenômeno acontece com o binômio "ne... que”, concentrando seu valor restritivo na partícula “que”. Isso já pode ser verificado no exemplo coletado por Grevisse: "Que puis-je prendre ici QUE l’occasion de la détresse à laquelle je cédai[...] ? (GIDE, Poerte étr., VII).”440 Restará saber qual a natureza do “que” restritivo: se advérbio, juntivo pronome relativo causal ou juntivo conjunção.

Observamos pela análise feita segundo os critérios de Paillard ${ }^{441}$ (1992) que os casos mais interessantes são os dos grupos B e C. Estes apresentam verbos modalizadores

\footnotetext{
${ }^{436}$ WILMET, M. Grammaire critique du Français. Louvain-la-Neuve: Hachette Supérieur/Duculot, 1997, p. 163.

${ }^{437}$ WEINRICH, H. Grammaire textuelle du français. Paris: Didier/Hatier, 1989, p. 523.

${ }^{438}$ GUILLAUME, G. Leçons de linguistique de Gustave Guillaume 1948-1949 : Grammaire particulière du français et grammaire générale (IV). Québec : Les Presses de l’université Laval / Paris : Librairie C. Klincksieck, 1973, p. 135.

${ }^{439}$ Id., ibid., p. 141.

${ }^{440}$ GREVISSE, M. Le bon usage. 13e edição, $6^{e}$ reimpressão. Paris: Duculot, 2006, p. 1455.

${ }^{441}$ PAILLARD, D. Repérage : construction et spécification. In : BOUSCAREN, J. La théorie d'Antoine

Culioli. Paris : Ophrys, 1992. p.75-88.
} 
(“pouvoir”) e advérbios (“encore”, “ensuite”, “pas”, “toujours”). Em nossa análise, encontramos uma maior incidência do grupo B e alguns do grupo C. O pequeno número de representantes do grupo A deveu-se à seleção feita visando a encontrar exemplos mais problemáticos e ao conseqüente descarte dos primeiros. Verificamos em análise comparada que o nosso alto índice de grupo B corresponde aproximadamente ao encontrado por Tremblay e Boudreau (7/10 contra 6/10, respectivamente). Tremblay ainda observa que no Quebec a opção mais usual seria por “juste” em vários casos em vez de "seulement”. Resta saber se essa opção deve-se a uma das acepções de "juste" ou à influência do inglês tão próximo. Para nós, lusófonos, o termo "somente” em português parece ser concessivo, positivo enquanto os termos “apenas” e "só”, restritivos, negativos.

Outra análise feita, a de ocorrências do "que” de natureza adverbial, pronominal ou juntiva, e a análise sintática de seu complemento mostraram-nos que não há um complemento “típico” de um dos grupos. Há, sim, uma incidência maior de complementos objeto direto em relação às outras funções.

\begin{tabular}{|l|l|c|c|c|l|}
\hline $\begin{array}{c}\text { Ex.: } \\
\mathrm{n}^{\text {o }}\end{array}$ & \multicolumn{1}{|c|}{ Tipo } & Nosso & T & B & \multicolumn{1}{|c|}{ Classe } \\
\hline 2 & Ne rester que 1 & A & A & A & $\begin{array}{l}\text { Adv - atributo do suporte } \\
\text { passivo do verbo }\end{array}$ \\
\hline 11 & N'être que & A & A & A & $\begin{array}{l}\text { Adv - atributo do suporte } \\
\text { passivo do verbo }\end{array}$ \\
\hline 12 & Ne mériter que & A & A & A & $\begin{array}{l}\text { Adv - aporte modal de } \\
\text { tempo }\end{array}$ \\
\hline 18 & Ne rappeller pas que & A & C & - & $\begin{array}{l}\text { Adv - atributo do suporte } \\
\text { passivo do verbo }\end{array}$ \\
\hline 3 & Pourtant... n’a été & B & A & A & $\begin{array}{l}\text { Adv - aporte modal de } \\
\text { modo }\end{array}$ \\
\hline
\end{tabular}




\begin{tabular}{|c|c|c|c|c|c|}
\hline 4 & Ne pouvoir que & $\mathrm{B}$ & $\mathrm{A}$ & $\mathrm{A}$ & $\begin{array}{l}\text { Adv - atributo do suporte } \\
\text { passivo do verbo }\end{array}$ \\
\hline 5 & Ne pouvoir que & $\mathrm{B}$ & $\mathrm{A}$ & $\mathrm{B}$ & $\begin{array}{l}\text { Adv - atributo do suporte } \\
\text { passivo do verbo }\end{array}$ \\
\hline 6 & Ne progresser que de & $\mathrm{B}$ & $\mathrm{A}$ & $\mathrm{B}$ & $\begin{array}{l}\text { Adv - atributo do suporte } \\
\text { ativo do verbo }\end{array}$ \\
\hline 8 & N'aller ensuite que & $\mathrm{B}$ & $\mathrm{B}$ & $\mathrm{B}$ & $\begin{array}{l}\text { Adv - Adv - atributo do } \\
\text { suporte ativo do verbo }\end{array}$ \\
\hline 10 & Ne parler pas ... que & $\mathrm{B}$ & $\mathrm{B}$ & $\mathrm{B}$ & $\begin{array}{l}\text { Adv - atributo do suporte } \\
\text { passivo do verbo }\end{array}$ \\
\hline 14 & N'être accessible que & $\mathrm{B}$ & A & $\mathrm{A}$ & $\begin{array}{l}\text { Adv - aporte modal de } \\
\text { modo }\end{array}$ \\
\hline 15 & Ne disposer que & $\mathrm{B}$ & $\mathrm{B}$ & $\mathrm{B}$ & $\begin{array}{l}\text { Adv - aporte modal de } \\
\text { destinatário }\end{array}$ \\
\hline 19 & N'avoir pas que & $\mathrm{B}$ & $\mathrm{B}$ & - & $\begin{array}{l}\text { Adv - atributo do suporte } \\
\text { passivo do verbo }\end{array}$ \\
\hline 1 & Ne connaître que 4 & $\mathrm{C}$ & $\mathrm{A}$ & $\mathrm{A}$ & $\begin{array}{l}\text { Adv - atributo do suporte } \\
\text { passivo do verbo }\end{array}$ \\
\hline 7 & N'être encore que & $\mathrm{C}$ & $\mathrm{B}$ & $\mathrm{B}$ & $\begin{array}{l}\text { Adv - atributo do suporte } \\
\text { passivo do verbo }\end{array}$ \\
\hline 9 & N'être pas toujours que & $\mathrm{C}$ & $\mathrm{C}$ & $\mathrm{B}$ & $\begin{array}{l}\text { Adv - atributo do suporte } \\
\text { passivo do verbo }\end{array}$ \\
\hline 13 & N’être plus complété que & $\mathrm{C}$ & $\mathrm{A}$ & $\mathrm{B}$ & $\begin{array}{l}\text { Adv - aporte modal de } \\
\text { modo }\end{array}$ \\
\hline 16 & Ne pouvoir plus faire que & $\mathrm{C}$ & $\mathrm{B}$ & $\mathrm{A}$ & $\begin{array}{l}\text { Adv - atributo do suporte } \\
\text { passivo do verbo }\end{array}$ \\
\hline 17 & N'avoir plus que 2 & $\mathrm{C}$ & $\mathrm{C}$ & $\mathrm{B}$ & $\begin{array}{l}\text { Adv - atributo do suporte } \\
\text { passivo do verbo }\end{array}$ \\
\hline
\end{tabular}


Observamos no quadro acima que os exemplos do grupo $C$ apresentam advérbios de tempo ou negação “ne... plus” que também aludem à linha temporal. No grupo B, notamos uma maior incidência de verbos significativos em si, por exemplo, “pouvoir” e "aller”, que, assim como o verbo “faire”, admitem não só uma seleção específica, mas também a seleção do complemento e a não-seleção dos outros processos ou das outras possibilidades. Para Tremblay, há uma maior incidência de exemplos do grupo A (10/19), enquanto para Boudreau, do grupo B (9/16).

Seria interessante realizar uma pesquisa em região de fronteira, onde ambos povos tenham maior intimidade com a língua vizinha e maior fluência. Poderíamos então aplicar exemplos equivalentes nas duas línguas e saber se há alguma influência socioeconômico e cultural em sua classificação. 


\section{BibliografiA}

ARRIVÉ, M.; GADET, F.; GALMICHE, M. La grammaire d'aujourd'hui: guide alphabétique de linguistique française. Paris: Flammarion, 1986. 719p.

ARRIVÉ, M; CHEVALIER, J.-C. La négation. Initiation à la linguistique, série A, La grammaire lectures. Editions Klincksieck, Paris, p. 147-155, 1970.

ATKINS, S.; CLEAR, Jeremy; OSTLER, Nicholas. “Corpus Design Criteria”. Literary and Linguisitc Computing, vol. 7, $\mathrm{n}^{\circ}$ 1, p. 1-16, 1992.

AUGÉ, H. et al. Tout va bien! 2 - livre de l'élève. Paris: Clé International, 2005. 167p.

BACHELARD, G. La Poetique de L'Espace. 1957. Paris: P. U. F., 1961. 214p.

BLOCH, O.; WARTBURG, W. Dictionnaire Étymologique de la Langue Française. $8^{\mathrm{a}}$ edição. Paris: Presses Universtaires de France, 1989. 682p.

BUYSSENS, E.; ROSETTI, A. (org.) La classification des adverbes. Revue roumaine de linguistique. Editura Academiei Republicii Socialiste România, Bucareste, vol. 20, n 5, p.461-463,1975.

CAMUS, A. Les Possédes Adaptation. In: Théâtre, Récits, Nouvelles, Ed. R. Quilliot, 1959. Paris: Gallimard, 1962. 298p.

CAPELLE, G.; CAVALLI, M.; GIDON, N. Fréquence jeunes 1 - livre de l'élève. Vanves: Hachette F.L.E., 1994. 160p.

CAPELle, G.; GIDON, N. Le Nouvel Espaces 1 - Livre de l'élève. Vanves: Hachette F.L.E., 1995. 206p.

CHARAUDEAU, P. Grammaire du sens et de l'expression. Paris: Hachette Éducation, 1992. 927p.

CHEVAlIER, J.-C.; BLANCHE-BENVENISTE, C.; ARRIVÉ, M.; PEYTARD, J. Grammaire Larousse du français contemporain. Paris: Librairie Larousse, 1971.

CLEDAT, L. Dictionnaire Étymologique de la Langue Française. Paris: Librairie Hachette, 1947. 694p.

DAMOURETTE, J.; PICHON, E. Des mots à la pensée: essai de grammaire de la langue française, 1911-1927. Paris: D'artrey, 1939, t.I, 674p. 
Des mots à la pensée: essai de grammaire de la langue française, 1911-1927. Paris: D'artrey, 1939, t. II. 539p.

Des mots à la pensée: essai de grammaire de la langue française, 1911-1927. Paris: D'artrey, 1939, t. VI. 2780p.

DAUZAT, A.; DUBOIS, J.; MITTERAND, H. Dictionnaire Étymologique et historique du français. Paris: Larousse, 1993. 762p.

DUBOIS, J. et al. Dicionário de lingüística. Frederico Barros et al.10a edição. São Paulo: Editora Cultrix Ltda, 1998. 653p.

FINTEL, Kai von. Restrictions on Quantifier Domains. EUA: Amherst University of Massachussetts, Graduate Linguistic Student Association (G.L.S.A.), Department of Linguistics, South College, 1994.

FRANCKEL, J.-J.; LEBAUD, D. Les figures du sujet. A propos des verbes de perception, sentiment, connaissance. Paris: Ophrys, 1990. 239p.

FUCHS, C.; LE GOFFIC, P. Les linguistiques contemporaines: répères théoriques. Paris: Hachette, 1992. 158p.

GAATONE, D. Étude descriptive du système de la négation en français contemporain. Genebra: Librairie Droz, Publication romanes et françaises, 1971. 237p.

GAULLE, Ch. De. Mémoires de Guerre: le Salut. Paris: Plon, 1959. 649p.

GIRARDET, J.; CRIDLIG. Panorama 1 - Livre de l’élève. Paris: Clé International, 2000. 191p.

GIRARDET, J.; PÉCHEUR, J. Campus 1 - Livre de l’élève. Paris: Clé International, 2002. 205p.

GOMES, R.; GRUNEBERG, A.; JOB, B. Rendez-vous à l'annexe - Méthode de français par la vidéo - niveau 1. Paris: Cle International, 1995a. 128p.

Rendez-vous à l’annexe - Méthode de français par la vidéo - niveau 2. Paris: Cle International, 1995b. 127p.

Rendez-vous à l’annexe - Méthode de français par la vidéo - niveau 4. Paris: Cle International, 1996. 128p.

GREVISSE, M. Le bon usage. $13^{\mathrm{e}}$ edição, $6^{\mathrm{e}}$ reimpressão. Paris: Duculot, 2006. 1762p. 
GUILlaUME, G. Leçons de linguistique de Gustave Guillaume 1948-1949: Psychosystématique du langage. Principes, méthodes et applications I (B). Québec: Les Presses de l’université Laval / Paris : Librairie C. Klincksieck, 1971. 222p.

Leçons de linguistique de Gustave Guillaume 1948-1949: Grammaire particulière du français et grammaire générale (IV). Québec : Les Presses de l'université Laval / Paris : Librairie C. Klincksieck, 1973. 256p.

LE GOFFIC, P. Grammaire de la phrase française. Paris: Hachette supérieur, D.L. 1994, c1993. 591p.

MAUGER, G. Grammaire pratique du français d'aujourd'hui. Paris: Librairie Hachette, 1968. 420p.

MOIGNET, G. Esquisse d'une histoire psycho-mécanique de la phrase interrogative. Langages, 3, p.49-66, junho1966.

Systématique de la langue française. Paris: Klincksieck, 1981. 346p.

OUELLET, J. Précis de sémantique grammaticale du français, notes de cours. Québec: Département de langues et linguistique de l’Université Laval, 2004. 141p.

PAILLARD, D. Repérage : construction et spécification. In : BOUSCAREN, J. La théorie d’Antoine Culioli. Paris : Ophrys, 1992. p.75-88.

POISSON-QUINTON, S.; SALA, M. Initial 2 - livre de l'élève. Paris: Clé International, 2000. 126p.

RIEGEL, M; PELLAT, J.-C.; RIOUL, R. Grammaire méthodique du français. Paris: Presses Universitaires de France, 1994. 646p.

ROBERT, P. Le Petit Robert version électronique. Paris : Dictionnaires Le Robert, 1997. 1 CD-ROM.

ROBERT, Paul. Dictionnaire alphabétique $\&$ analogique de la langue française. s.e. Paris: Société du nouveau Littré, 1981. 2173p.

SARTRE,J.-P. Les Mots. Paris: Gallimard, 1964. 213p.

TOGEBY, Knud, 1949. Qu'est-ce qu'un mot?. In: Herslund, M. Choix d'articles 1943-1974, Revue Romane, número especial 15. Copenhague: Akademisk Forlang, p.51-65, 1978. TREVISI, S. et al. Café Crème 2 - Livre de l’élève. Vanves: Hachette F.L.E., 1997. 192p. 
WAGNER, R. L.; PINCHON, J. Grammaire du français classique et moderne. Paris : Hachette Supérieur, 1991. 687p.

WEINRICH, H. Grammaire textuelle du français. Paris: Didier/Hatier, 1989. 671p.

WILMET, M. Grammaire critique du Français. Louvain-la-Neuve: Hachette Supérieur/Duculot, 1997.

\section{Corpus jornalístico}

AFP. L'ancien dictateur tchadien Hissène Habré sera jugé au Sénégal. Le Monde. Disponível

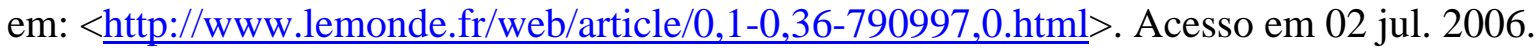
AFP. Mexique : le conservateur Felipe Calderon a remporté l'élection présidentielle sur le fil. Le Monde. Disponível em: <http://www.lemonde.fr/web/article/0,1-0,36-792972,0.html>. Acesso em 07 jul. 2006.

AFP. Nucléaire : nouvelle rencontre entre Européens et Iraniens à Bruxelles. Le Monde. Disponível em: http://www.lemonde.fr/web/article/0,1-0,36-794225,0.html>. Acesso em 11 jul. 2006.

AFP. Procès des Français de Guantanamo : nouvelle journée d'explications. Le Monde. Disponível em: <http://www.lemonde.fr/web/article/0,1-0,36-794228,0.html>. Acesso em 11 jul. 2006.

AFP. Quatre tentes pour sans-abri brûlées à Paris. Le Monde. Disponível em: < http://www.lemonde.fr/web/article/0,1-0,36-797882,0.html>. Acesso em 23 jul. 2006.

AFP. Raymond Domenech : "L'homme du match, c'est Materazzi". Le Monde. Disponível em: http://www.lemonde.fr/web/article/0,1-0,36-793802,0.html>. Acesso em 10 jul. 2006. AFP. Wimbledon : deux Françaises qualifiées pour les huitièmes de finale. Le Monde. Disponível em: <http://www.lemonde.fr/web/article/0,1-0,36-790938,0.html>. Acesso em 02 jul. 2006.

ARAGON, J.-L. Discovery Channel favorite à sa propre succession. Le Monde. Disponível em: <http://www.lemonde.fr/web/article/0,1-0,36-791222,0.html>. Acesso em 03 jul. 2006. 
ARAGON, J.-L. L'Américain Floyd Landis, grâce à sa confiance, gagne son premier Tour de France. Disponível em: < http://www.lemonde.fr/web/article/0,1-0,36-798087,0.html>. Acesso em 24 jul. 2006.

ARAGON, J.-L. L'Anglais John Bickerton remporte l'Open de France. Le Monde. Disponível em: < http://www.lemonde.fr/web/article/0,1-0,36-791227,0.html>. Acesso em 03 jul. 2006.

ARAGON, J.-L. Le champion de France, Florent Brard, n'est pas avide de gloire. Le Monde. Disponível em: http://www.lemonde.fr/web/article/0,1-0,36-791224,0.html>. Acesso em 03 jul. 2006.

AZIMI, R. L'art cinétique atteint des records. Le Monde. Disponível em:

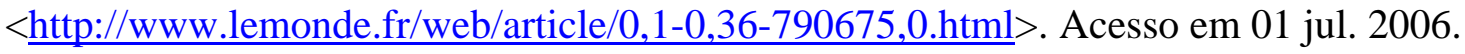

BALLADUR, E. Laissez de Gaulle en paix !, par Edouard Balladur. Le Monde. Disponível em: http://www.lemonde.fr/web/article/0,1-0,36-792173,0.html> . Acesso em 05 jul. 2006.

BARTH, E. "Des guerriers, pas des techniciens". Le Monde. Disponível em: < http://www.lemonde.fr/web/article/0,1-0,36-792014,0.html>. Acesso em 05 jul. 2006.

BÉLOEIL, M.; VINOGRADOFF, L. Le baiser de Zidane. Le Monde. Disponível em: http://www.lemonde.fr/web/article/0,1-0,36-792491,0.html>;

< http://www.lemonde.fr/web/article/0,1-0,36-792491@45-1,0.html>. Acesso em 06 jul. 2006.

BLANC, C.; BOCKEL, J.-M.; LAMBERT, A. Ensemble, modernisons la France, par Christian Blanc, Jean-Marie Bockel et Alain Lambert. Le Monde. Disponível em: $<$ http://www.lemonde.fr/web/article/0,1-0,36-791239,0.html > . Acesso em 03 jul. 2006.

BOISSEAU, R. Joseph Nadj ensorcelle Avignon. Le Monde. Disponível em: < http://www.lemonde.fr/web/article/0,1-0,36-793560,0.html>. Acesso em 09 jul. 2006.

BOStnAVARON, F. Louis Gallois, un eurosceptique à la tête d'EADS. Le Monde.

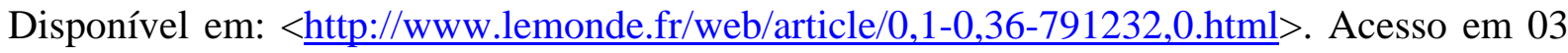
jul. 2006.

BOUCHERON, J.-B. Vers un Mondial en crypté?. Le Monde. Chronique réalisée par le Centre de droit et d'économie du sport de Limoges (www.cdes.fr). Disponível em: http://www.lemonde.fr/web/article/0,1-0,36-790821,0.html. Acesso em 01 jul. 2006.

BOUVIER, P. Libération.fr fait peau neuve et se veut plus "interactif". Le Monde. Disponível em: <http://www.lemonde.fr/web/article/0,1-0,36-791098,0.html>. Acesso em 03 jul. 2006. 
CAUSSÉ, B. Willy Sagnol fait parler son autorité. Le Monde. Disponível em: http://www.lemonde.fr/web/article/0,1-0,36-792521,0.html>. Acesso em 06 jul. 2006.

CEAUX, P. Le rêve brésilien n'était qu'un mirage. Le Monde. Disponível em: < http://www.lemonde.fr/web/article/0,1-0,36-791268,0.html>. Acesso em 03 jul. 2006.

COUDERT, G. Adidas, en force. Le Monde. Disponível em: < $\underline{\text { http://www.lemonde.fr/cgi- }}$ bin/ACHATS/acheter.cgi?offre=ARCHIVES\&type_item=ART_ARCH_30J\&objet_id=95120 1>. Acesso em 01 jul. 2006.

DAGEN P. Les bisons, le cheval et la belette. Le Monde. Disponível em: < http://www.lemonde.fr/web/article/0,1-0,36-791286,0.html>. Acesso em 03 jul. 2006.

DAVET, S. Daft Punk, fastueux crescendo électro. Le Monde. Disponível em: < http://www.lemonde.fr/web/article/0,1-0,36-790686,0.html>. Acesso em 01 jul. 2006.

DHOMBRES, D. Maigret chez les aristos, par Dominique Dhombres. Le Monde. Disponível em: < http://www.lemonde.fr/web/article/0,1-0,36-790688,0.html > . Acesso em 01 jul. 2006.

DUCOURTIEUX, C. Les places boursières rebondissent. Le Monde. Disponível em: < http://www.lemonde.fr/web/article/0,1-0,36-790649,0.html>. Acesso em 01 jul. 2006.

GASNIER, A. Le Brésil célèbre le "genio" de Zidane. Le Monde. Disponível em: < http://www.lemonde.fr/web/article/0,1-0,36-791270,0.html>. Acesso em 03 jul. 2006.

GREILSAMER, L. Le ciel et la Terre à domicile, par Laurent Greilsamer. Le Monde. Disponível em: < http://www.lemonde.fr/web/article/0,1-0,36-791170,0.html>. Acesso em 03 jul. 2006.

GUILBERT, N. Des moyens provisoires pour la psychiatrie à Fresnes. Le Monde. Disponível em: $\quad<$ http://www.lemonde.fr/cgibin/ACHATS/acheter.cgi?offre=ARCHIVES\&type_item=A-

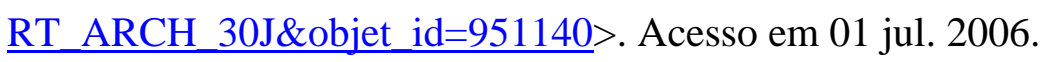

KEMPF, H. Energie et climat : sortir de la frénésie, par Hervé Kempf. Le Monde. Disponível em: <http://www.lemonde.fr/web/article/0,1-0,36-791622,0.html>. Acesso em 04 jul. 2006.

LAÏDI, Z. Le véritable apport de Mme Royal, par Zaki Laïdi. Le Monde. Disponível em: <http://www.lemonde.fr/web/article/0,1-0,36-791686,0.html>. Acesso em 04 jul. 2006.

LALLEMENT, B. Une complainte pour "Libé", par Bernard Lallement. Le Monde. Disponível em: < http://www.lemonde.fr/web/article/0,1-0,36-791233,0.html>. Acesso em 03 jul. 2006. 
LAUDIN, A. "Le Panthéon est le culte des grands hommes, pas des victimes". Le Monde. Disponível em: http://www.lemonde.fr/web/article/0,1-0,36-793437,0.html>. Acesso em 12 jul. 2006.

LE BOUCHER, E. Penalty contre le capitalisme. Le Monde. Disponível em: http://www.lemonde.fr/web/article/0,1-0,36-793496,0.html>. Acesso em 08 jul. 2006.

LESPRIT, B. Cristiano Ronaldo brille en sélection et irrite ses fans de Manchester. Le Monde. Disponível em: <http://www.lemonde.fr/web/article/0,1-0,36-791113,0.html>. Acesso em 03 jul. 2006.

MANACH, J.-M. L'Italie a gagné, mais à quel prix ?. Le Monde. Disponível em: < http://www.lemonde.fr/web/article/0,1-0,36-793818,0.html>. Acesso em 10 jul. 2006.

MANDELBAUM, J. Gérard Oury, ou l'art du rire populaire. Le Monde. Disponível em: < $\underline{\text { http://www.lemonde.fr/web/article/0,1-0,36-797051,0.html }>\text {; }}$

< http://www.lemonde.fr/web/article/0,1-0,36-797051@45-1,0.html>. Acesso em 20 jul 2006.

MANDELBAUM, J. Les mille et une vies du documentaire. Le Monde. Disponível em: http://www.lemonde.fr/web/article/0,1-0,36-790657,0.html, http://www.lemonde.fr/web/article/0,1-0,36-790657@45-1,0.html. Acesso em 01 jul. 2006. MANDRAUD, I. Les socialistes adoptent leur projet pour 2007. Le Monde. Disponível em: < http://www.lemonde.fr/web/article/0,1-0,36-790632,0.html>. Acesso em 01 jul. 2006.

MILANOVIC, B. Le foot, industrie sans frontières, par Branko Milanovic Le Monde. Disponível em: http://www.lemonde.fr/web/article/0,1-0,36-793211,0.html>. Acesso em 07 jul. 2006.

MONTVALON, J.-B. De. La "citadelle" sarkozyste s'ouvre aux nouveaux convertis. Le Monde. Disponível em: <http://www.lemonde.fr/web/article/0,1-0,36-795538,0.html> Acesso em 14 jul. 2006.

NOUGayRÈDE, N. Vladimir Poutine, tsar du gaz. Le Monde. Disponível em: <http://www.lemonde.fr/web/article/0,1-0,36-791244,0.html $>, \quad<$ http://www.lemonde.fr/web/article/0,1-0,36-791244@45-1,0.html>; < http://www.lemonde.fr/web/article/0,1-0,36791244@45-2,0.html>. Acesso em 03 jul. 2006. 
PECQUEUR, A. Le succès d'audience de Radio Classique pousse France Musique à revoir sa grille. Le Monde. Disponível em: <http://www.lemonde.fr/web/article/0,1-0,36791216,0.html>. Acesso em 03 jul. 2006.

POTET, F. Georges Vigarello : "Tout d'un coup, une explosion positive". Le Monde. Disponível em: <http://www.lemonde.fr/web/article/0,1-0,36-791271,0.html>. Acesso em 03 jul. 2006.

s/a. L'hommage de Jacques Chirac au capitaine Dreyfus. Le Monde. Disponível em: < http://www.lemonde.fr/web/article/0,1-0,36-794609@45-1,0.html>. Acesso em 12 jul. 2006. SOLÉ, R. Les vacances d'un ministre, par Robert Solé. Le Monde. Disponível em: < http://www.lemonde.fr/web/article/0,1-0,36-790658,0.html>. Acesso em 01 jul. 2006.

SOLÉ, R. Mots en guerre, par ROBERT SOLÉ. Le Monde. Disponível em: http://www.lemonde.fr/web/article/0,1-0,36-793545,0.html>. Acesso em 08 jul. 2006.

TALÈS, I. Le plus ancien prisonnier de France. Le Monde. Disponível em: http://www.lemonde.fr/web/article/0,1-0,36-795048,0.html>. Acesso em 13 jul. 2006.

TARDY, M. Les nouveaux impôts. Le Monde. Disponível em: http://www.lemonde.fr/cgibin/ACHATS/acheter.cgi?offre=ARCHIVES\&type_item=ART_ARCH_30J\&objet_id=95258 $\underline{6}>$. Acesso em 13 jul. 2006.

VINCENT, E. JEAN-MARIE LEBLANC DIRECTEUR DU TOUR DE FRANCE « C'est un geste courageux et un bon exemple pour les autres directeurs sportifs ». Le Monde. Disponível em: <http://www.lemonde.fr/cgibin/ACHATS/acheter.cgi?offre=ARCHIVES\&type_item=ART_ARCH_30J\&objet_id=951163>. Acesso em 01 jul. 2006.

VULSER, N. Droits d'auteur : ce qui va changer. Le Monde. Disponível em: < http://www.lemonde.fr/web/article/0,1-0,36-790680,0.html>. Acesso em 01 jul. 2006. 


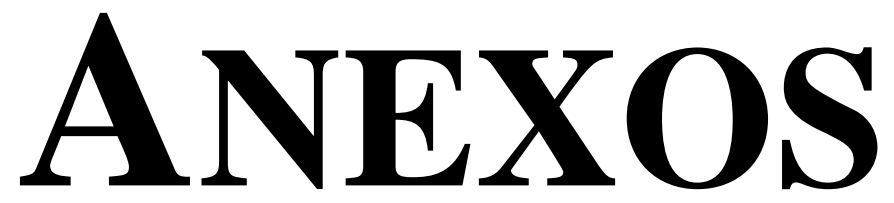




\section{ANEXo A - RESUltados do QUESTIONÁRIO APLICADO NO CURSO THÉORIE ET PRATIQUE DE LA TRADUCTION, FACULDADE DE LETRAS, UNIVERSIDADE LAVAL}

Grupo formado por 11 franco-quebequenses, 1 tunisiana de língua materna escrita francês e oral árabe, 1 japonês, 1 chinesa e 1 coreana.

\section{ANÁLISE 1}

\begin{tabular}{|c|c|c|c|c|c|}
\hline \multicolumn{3}{|c|}{$\begin{array}{l}\text { Situation } 1 \text { : Au parc, deux collègues de } \\
\text { travail parlent de leur famille. L'une } \\
\text { raconte à l'autre au sujet de son fils de } 15 \\
\text { ans. }\end{array}$} & \multicolumn{3}{|c|}{$\begin{array}{l}\text { Situation } 2 \text { : Deux collègues de travail } \\
\text { parlent de leur famille. L'une raconte à } \\
\text { l'autre au sujet de sa fille de } 15 \text { ans. }\end{array}$} \\
\hline & $\begin{array}{l}\text { FRANCO- } \\
\text { PHONES }\end{array}$ & $\begin{array}{c}\text { NON-FRANCO- } \\
\text { PHONES }\end{array}$ & & $\begin{array}{l}\text { FRANCO- } \\
\text { PHONES }\end{array}$ & $\begin{array}{c}\text { NON-FRANCO- } \\
\text { PHONES }\end{array}$ \\
\hline \multicolumn{3}{|c|}{ 1. Il n’aime que le cinéma. } & \multicolumn{3}{|c|}{ 1. Elle n’aime que le cinéma. } \\
\hline positive & 2 & 1 & positive & 2 & 0 \\
\hline neutre & 1 & 0 & neutre & 3 & 1 \\
\hline négative & 9 & 2 & négative & 7 & 2 \\
\hline \multicolumn{3}{|c|}{ 2. Il ne mange que des légumes. } & \multicolumn{3}{|c|}{ 2. Elle ne mange que des légumes. } \\
\hline positive & 5 & 0 & positive & 6 & 1 \\
\hline neutre & 2 & 1 & neutre & 2 & 1 \\
\hline négative & 4 & 2 & négative & 4 & 1 \\
\hline
\end{tabular}




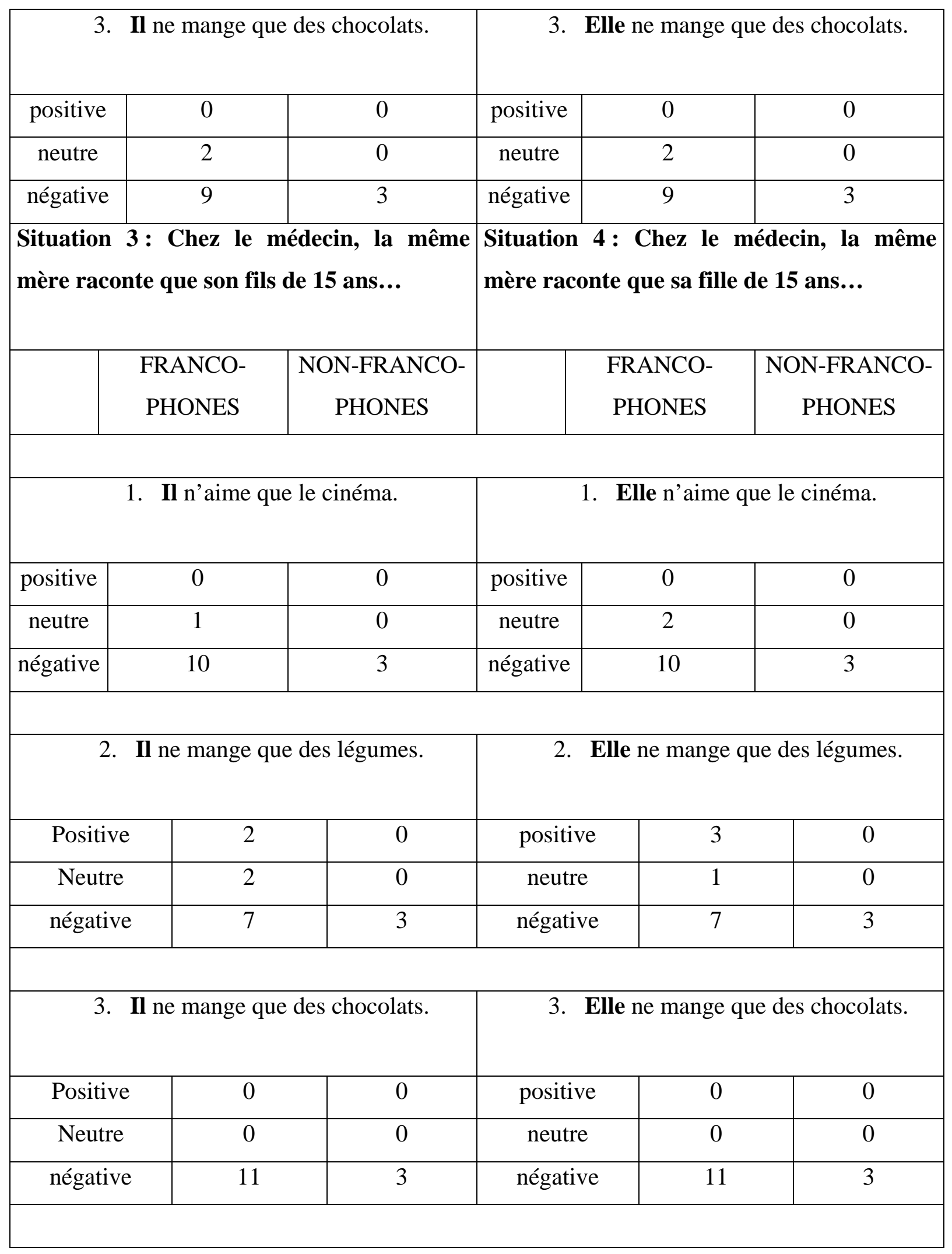




\section{ANÁLISE 2}

\begin{tabular}{|c|c|c|c|c|c|}
\hline \multicolumn{3}{|c|}{$\begin{array}{l}\text { Situation } 1 \text { : Au parc, deux collègues de } \\
\text { travail parlent de leur famille. L'une raconte } \\
\text { à l'autre au sujet de son fils de } 15 \text { ans. }\end{array}$} & \multicolumn{3}{|c|}{$\begin{array}{l}\text { Situation } 3 \text { : Chez le médecin, la même } \\
\text { mère raconte que son fils de } 15 \text { ans... }\end{array}$} \\
\hline & $\begin{array}{l}\text { FRANCO- } \\
\text { PHONES }\end{array}$ & $\begin{array}{l}\text { NON- } \\
\text { FRANCO- } \\
\text { PHONES }\end{array}$ & & $\begin{array}{l}\text { FRANCO- } \\
\text { PHONES }\end{array}$ & $\begin{array}{l}\text { NON- } \\
\text { FRANCO- } \\
\text { PHONES }\end{array}$ \\
\hline \multicolumn{6}{|c|}{ 1. Il n’aime que le cinéma. } \\
\hline positive & 2 & 1 & positive & 0 & 0 \\
\hline neutre & 1 & 0 & neutre & 1 & 0 \\
\hline négative & 9 & 2 & négative & 10 & 3 \\
\hline
\end{tabular}

2. Il ne mange que des légumes.

\begin{tabular}{|c|c|c|c|c|c|}
\hline positive & 5 & 0 & positive & 2 & 0 \\
\hline neutre & 2 & 1 & neutre & 2 & 0 \\
\hline négative & 4 & 2 & négative & 7 & 3 \\
\hline
\end{tabular}

3. Il ne mange que des chocolats.

\begin{tabular}{|c|c|c|c|c|c|}
\hline positive & 0 & 0 & positive & 0 & 0 \\
\hline neutre & 2 & 0 & neutre & 0 & 0 \\
\hline négative & 9 & 3 & négative & 11 & 3 \\
\hline
\end{tabular}




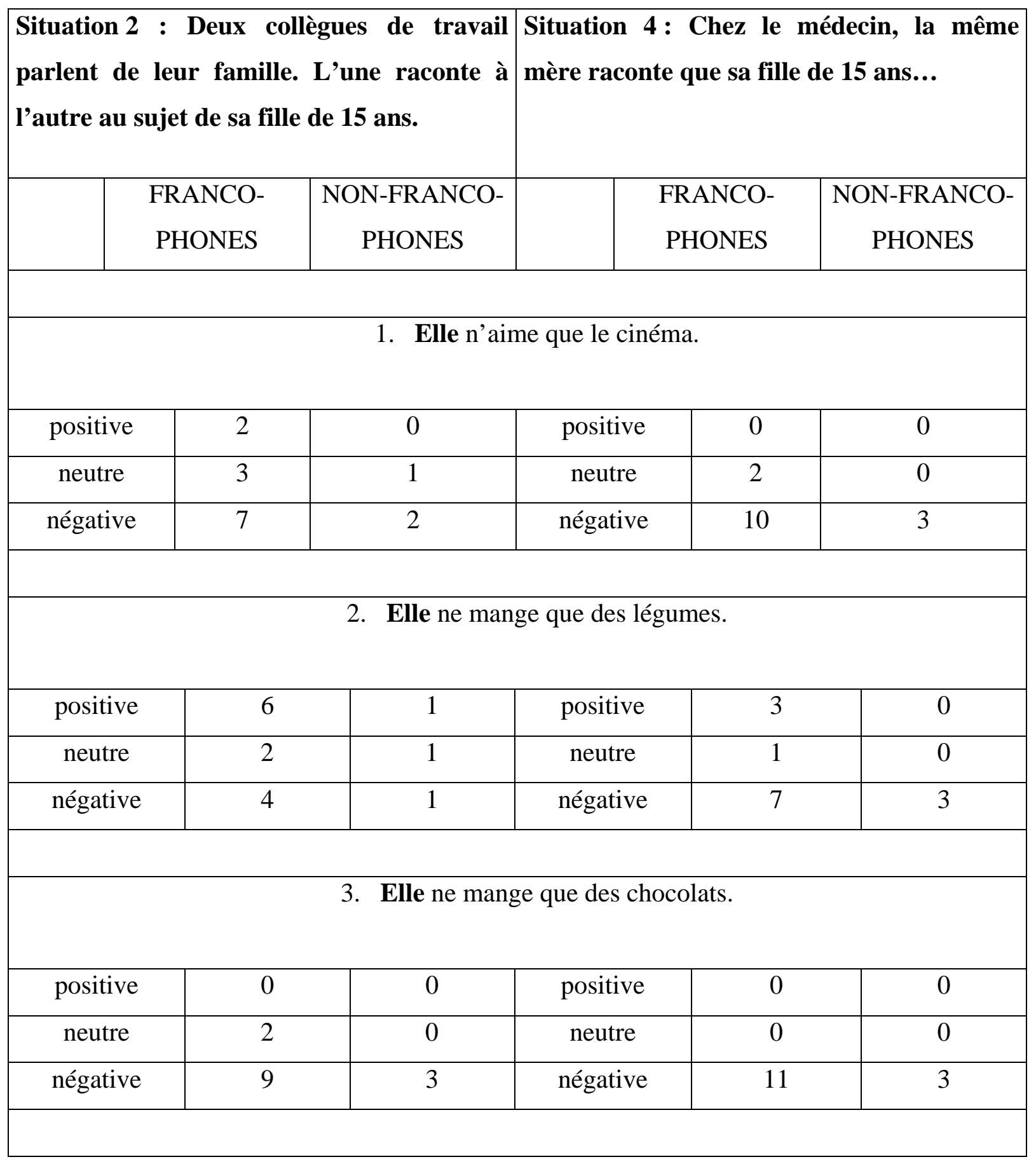




\section{ANEXo B - CoRPUS DO “LE PETIT RoberT"}

\begin{tabular}{|c|c|}
\hline $\mathbf{A}$ & $\mathbf{A}$ \\
\hline $\begin{array}{l}\text { Cette région n'est accessible que par avion. } \\
\text { (verbete accessible, p. 12) }\end{array}$ & $\begin{array}{l}\text { Esta região é acessível somente de avião. } \\
\text { ! Essa região só é acessível de avião. (a região } \\
\text { é outra coisa de carro? A cavalo ?) }\end{array}$ \\
\hline $\begin{array}{l}\text { « Nul ne veut le bien public que quand il } \\
\text { s'accorde avec le sien » (Rouss.). (verbete } \\
\text { accorder, p. 14) }\end{array}$ & $\begin{array}{l}\text { Ninguém quer o bem público, a não ser } \\
\text { quando está de acordo com o seu. } \\
\text { As pessoas só querem o bem público quando } \\
\text { ele está de acordo com o seu próprio. }\end{array}$ \\
\hline $\begin{array}{l}\text { « L’esprit n’accueille une idée qu’en lui } \\
\text { donnant un corps » (J. Renard). (verbete } \\
\text { accueillir, p. 16) }\end{array}$ & $\begin{array}{l}\text { O espírito só acolhe uma idéia dando-lhe um } \\
\text { corpo. }\end{array}$ \\
\hline $\begin{array}{l}\text { Se dit de micro-organismes qui ne peuvent se } \\
\text { développer qu'en présence d’air ou d'oxygène } \\
\text { libre. (verbete aérobie, p. 28) }\end{array}$ & $\begin{array}{l}\text { Diz-se que os microorganismos podem } \\
\text { desenvolver-se somente na presença de ar ou } \\
\text { oxigênio livre. }\end{array}$ \\
\hline $\begin{array}{l}\text { Tendence à ne s’occuper que d’affaires } \\
\text { particulièrement lucratives à base de } \\
\text { spéculation. (verbete affairisme, p. 30) }\end{array}$ & $\begin{array}{l}\text { Tendência a ocupar-se somente de negócios } \\
\text { comerciais paticularmente lucrativas à base de } \\
\text { especulação. }\end{array}$ \\
\hline B & B \\
\hline $\begin{array}{l}\text { «Une baderne qui ne connaissait que sa } \\
\text { consigne » (J. Lemaitre). (verbete baderne, p. } \\
\text { 150) }\end{array}$ & $\begin{array}{l}\text { ?Um veterano burro que conhecia somente sua } \\
\text { caserna. (a única coisa que conhecia) } \\
\text { !Um veterano burro que só conhecia sua } \\
\text { caserna. (só conhecia, não freqüentava?) }\end{array}$ \\
\hline $\begin{array}{l}\text { «L'art n’a que faire des lisières, des menottes, } \\
\text { des bâillons » (Hugo). (verbete bâillon, p. 152) }\end{array}$ & $\begin{array}{l}\text { ?A arte somente tem que fazer bordas, algemas } \\
\text { e mordaças. } \\
\text { A arte só tem que fazer bordas, algemas e } \\
\text { mordaças. }\end{array}$ \\
\hline
\end{tabular}




\begin{tabular}{|c|c|}
\hline $\begin{array}{l}\text { Messe basse (opposé à grand-messe): messe } \\
\text { non chantée, où le prêtre ne fait que réciter les } \\
\text { prières. (verbete bas, basse, p. 164) }\end{array}$ & $\begin{array}{l}\text { ?Missa curta (em oposição a grande missa): } \\
\text { missa não cantada, na qual o padre somente } \\
\text { recita as orações. } \\
\text { !Missa curta (em oposição a grande missa): } \\
\text { missa não cantada, na qual o padre só recita as } \\
\text { orações. (deveria fazer algo mais?) }\end{array}$ \\
\hline $\mathrm{C}$ & $\mathrm{C}$ \\
\hline $\begin{array}{l}\text { «Je n’ai d'amour que pour les caractères d’un } \\
\text { idéalisme absolu, martyrs, héros, utopistes » } \\
\text { (Renan). (verbete caractère, p. 252) }\end{array}$ & $\begin{array}{l}\text { Eu tenho amor somente pelos de caráter } \\
\text { idealista, mártires, heróis e utopistas. } \\
\text { !Só tenho amor pelos de caráter idealista, } \\
\text { mártires, heróis e utopistas. (a restrição é em } \\
\text { relação a que? O amor ou os de caráter } \\
\text { idealista, mártires, heróis e utopistas?) }\end{array}$ \\
\hline $\begin{array}{l}\text { Carbures d’hydrogène (hydrocarbures) : groups } \\
\text { de corps, classés en séries de corps } \\
\text { homologues, dont les molécules ne diffèrent } \\
\text { que par le radical } \mathrm{CH}_{2} \text {. (verbete carbure, p. } \\
\text { 254) }\end{array}$ & $\begin{array}{l}\text { ?Carbonetos de hidrogênio: grupos de cadeias } \\
\text { classificados em séries de cadeias homólogas, } \\
\text { cujas moléculas diferem somente pelo radical } \\
\mathrm{CH}_{2} \text {. (afirmação, todo o resto é igual) } \\
\text { !Carbonetos de hidrogênio: grupos de cadeias } \\
\text { classificados em séries de cadeias homólogas, } \\
\text { cujas moléculas só diferem pelo radical } \mathrm{CH}_{2} \text {. } \\
\text { (espanto?!) }\end{array}$ \\
\hline $\begin{array}{l}\text { «La superstition n’est que la caricature du vrai } \\
\text { sentiment religieux » (Gide). (verbete } \\
\text { caricature, p. 256) }\end{array}$ & $\begin{array}{l}\text { A superstição é somente uma caricatura do } \\
\text { verdadeiro sentimento religioso. }\end{array}$ \\
\hline $\begin{array}{l}\text { Sucre qui n’a été raffiné qu’une fois. (verbete } \\
\text { cassonade, p. 264) }\end{array}$ & $\begin{array}{l}\text { ?Açúcar refinado somente uma vez. } \\
\text { Açúcar refinado uma única vez. }\end{array}$ \\
\hline $\begin{array}{l}\text { L'un des corps de l'armée ne comprenant, à } \\
\text { l'origine, que des troupes à cheval. (verbete } \\
\text { cavalerie, p. 268) }\end{array}$ & $\begin{array}{l}\text { ?Um dos corpos do exército que originalmente } \\
\text { compreendia somente tropas a cavalo. (fato) } \\
\text { !Um dos corpos do exército que originalmente }\end{array}$ \\
\hline
\end{tabular}




\begin{tabular}{|c|c|}
\hline & $\begin{array}{l}\text { só compreendia tropas a cavalo. (aquém do } \\
\text { desejado) }\end{array}$ \\
\hline $\mathbf{D}$ & $\mathbf{D}$ \\
\hline $\begin{array}{l}\text { « Ne pas savoir sur quel pied danser : ne savoir } \\
\text { que faire, hésiter ». (verbete danser, p. 446) }\end{array}$ & $\begin{array}{l}\text { Não saber com qual pé dançar: não saber o que } \\
\text { fazer, hesitar. }\end{array}$ \\
\hline $\begin{array}{l}\text { Il n'y a de beau que le vrai. (verbete 1. de, p. } \\
448 \text { ) }\end{array}$ & Somente a verdade é bela. \\
\hline $\begin{array}{l}\text { « Une discrétion qui n’est que de la décence le } \\
\text { retient » (Gide). (réserve, discrétion) (verbete } \\
\text { décence, p. 456) }\end{array}$ & $\begin{array}{l}\text { Uma discrição que somente a decência o } \\
\text { continha. } \\
\text { ?Uma discrição que é simplesmente decência o } \\
\text { detém. } \\
\text { ?Uma discrição que não é outra coisa senão } \\
\text { decência o detém. }\end{array}$ \\
\hline $\begin{array}{l}\text { « Présentement nul n’est décrié pour ses vices; } \\
\text { on n’est diffamé que par ses vertus » } \\
\text { (Chateaub.). (verbete décrier, p. 466) }\end{array}$ & $\begin{array}{l}\text { Nos dias de hoje, ninguém é caluniado por seus } \\
\text { vícios; somente difamado por suas virtudes. }\end{array}$ \\
\hline $\mathbf{E}$ & $\mathbf{E}$ \\
\hline $\begin{array}{l}\text { Echo simple, qui ne reproduit les sons qu’une } \\
\text { fois. (verbete écho, p. 596) }\end{array}$ & $\begin{array}{l}\text { Eco simples, que reproduz o som somente uma } \\
\text { vez. } \\
\text { !Eco simples, que só reproduz o som uma vez. } \\
\text { (faz outra coisa também?) } \\
\text { Eco simples, que reproduz o som uma única } \\
\text { vez. }\end{array}$ \\
\hline $\begin{array}{l}\text { "Ses paroles n’étaient qu’une réponse } \\
\text { affaiblie, docile, presque un simple écho de } \\
\text { mês paroles » (Proust). (verbete écho, p. 596) }\end{array}$ & $\begin{array}{l}\text { ?Suas palavras eram somente uma resposta } \\
\text { fraca, dócil, quase um simples eco das minhas } \\
\text { palavras. } \\
\text { Suas palavras não eram mais que uma resposta } \\
\text { fraca, dócil, quase um simples eco das minhas } \\
\text { palavras. }\end{array}$ \\
\hline
\end{tabular}




\begin{tabular}{|c|c|}
\hline & $\begin{array}{l}\text { Suas palavras eram só uma resposta fraca, } \\
\text { dócil, quase um simples eco das minhas } \\
\text { palavras. }\end{array}$ \\
\hline $\begin{array}{l}\text { « Les sanglots... qui n’éclatèrent que quand je } \\
\text { me retrouvai seul » (Proust). (verbete éclater, } \\
\text { p. 598) }\end{array}$ & $\begin{array}{l}\text { Os soluços... que apareceram somente quando } \\
\text { me encontrei só. (quando, tempo) } \\
\text { !Os soluços... que só apareceram quando me } \\
\text { encontrei sozinho. (ação, não fizeram outra } \\
\text { coisa senão aparecer, não “explodiram”) }\end{array}$ \\
\hline $\begin{array}{l}\text { « La fonction éducatrice de l'art n’existe que } \\
\text { dans la mesure où l'intention éducatrice est } \\
\text { absente » (Th. Maulnier). (verbete éducateur, } \\
\text { trice, p. 606) }\end{array}$ & $\begin{array}{l}\text { A função educacional da arte existe somente na } \\
\text { medida em que a intenção educacional está } \\
\text { ausente. (condição de existência da função } \\
\text { educacional) } \\
\text { A função educacional da arte só existe na } \\
\text { medida em que a intenção educacional está } \\
\text { ausente. (!(?), porque?) }\end{array}$ \\
\hline $\begin{array}{l}\text { Entamer en n'enlevant que la partie } \\
\text { superficielle. (verbete effleurer, p. 608) }\end{array}$ & Cortar retirando somente a parte superficial. \\
\hline $\begin{array}{l}\text { «Un pas qui ne fait qu’effleurer la terre » } \\
\text { (Barrès). (verbete effleurer, p. 608) }\end{array}$ & $\begin{array}{l}\text { Um passo que somente faz florescer a terra. } \\
\text { (fato positivo) } \\
\text { Um passo que só faz florescer a terra. (deveria } \\
\text { fazer algo mais?) }\end{array}$ \\
\hline $\begin{array}{l}\text { « Des assemblées de village, où le goût du } \\
\text { merveilleux n’a d’égal que le goût de la farce » } \\
\text { (Barrès), n’a rien d’égal que ..., n’est égalé que } \\
\text { par le goût de la farce. (verbete égal, ale, aux, } \\
\text { p. 610) }\end{array}$ & $\begin{array}{l}\text { “Assembléias da cidade, nas quais o gosto pelo } \\
\text { maravilhoso somente é igualado ao gosto pela } \\
\text { farsa” (Barres), não há nada igual a.., somente } \\
\text { é igualado ao gosto pela farsa. (fato) } \\
\text { !“Assembléias da cidade, nas quais o gosto } \\
\text { pelo maravilhoso só é igualado ao gosto pela } \\
\text { farsa” (Barres), não há nada igual a.., somente } \\
\text { é igualado ao gosto pela farsa. (só = nada mais }\end{array}$ \\
\hline
\end{tabular}




\begin{tabular}{|c|c|}
\hline & se iguala a isso) \\
\hline $\begin{array}{l}\text { «Je ne crois que les histoires dont les témoins } \\
\text { se feraient égorger » (Pasc.). (verbete égorger, } \\
\text { p. 612) }\end{array}$ & $\begin{array}{l}\text { Acredito somente em histórias cujas } \\
\text { testemunhas se fariam degolar. (objeto da } \\
\text { minha crença) } \\
\text { !Só acredito em histórias cujas testemunhas se } \\
\text { fariam degolar. (não faço mais nada, nem } \\
\text { tomo nenhuma outra ação) }\end{array}$ \\
\hline $\begin{array}{l}\text { La faveur du Roi « Vous élève en un rang qui } \\
\text { n’était dû qu'à moi » (Corn.). (verbete élever, } \\
\text { p. 618) }\end{array}$ & $\begin{array}{l}\text { ? Foi somente graças a mim que o } \\
\text { favorecimento do Rei o aumentou de posto. } \\
\text { Foi unicamente graças a mim que o } \\
\text { favorecimento do Rei o aumentou de posto. }\end{array}$ \\
\hline $\begin{array}{l}\text { Louis XIV « ne voulait de grandeur que par } \\
\text { émanation de la sienne » (St-Sim.). (verbete } \\
\text { émanation, p. 620) }\end{array}$ & $\begin{array}{l}\text { Luís XIV queria a grandiosidade somente pela } \\
\text { emanação da sua própria. (condição) } \\
\text { Luís XIV só queria a grandiosidade pela } \\
\text { emanação da sua própria. (!(?)) }\end{array}$ \\
\hline $\mathbf{F}$ & $\mathbf{F}$ \\
\hline $\begin{array}{l}\text { N'avoir qu'une façade d'honnêteté. } \\
\text { (apparence) (verbete façade, p. 746) }\end{array}$ & $\begin{array}{l}\text { ?Ter somente uma aparência honesta. } \\
\text { Só ter aparência honesta. (!(?)) }\end{array}$ \\
\hline $\begin{array}{l}\text { Ce n'est qu'une façade. (verbete façade, p. } \\
\text { 746) }\end{array}$ & $\begin{array}{l}\text { É somente aparência. } \\
\text { É só fachada. }\end{array}$ \\
\hline $\begin{array}{l}\text { «Tu me lâcherais à la face les sales preuves } \\
\text { que tu n'es qu'une bourrique » (Mac Orlan). } \\
\text { (verbete face, p. 746) }\end{array}$ & $\begin{array}{l}\text { *Você me jogaria na cara as provas sujas de } \\
\text { que é somente de um burro. } \\
\text { Você me jogaria na cara as provas sujas de que } \\
\text { não passa de um burro. }\end{array}$ \\
\hline $\begin{array}{l}\text { N'avoir qu'une très faible idée de qqch. (faible } \\
\text { indice) (verbete faible, p. 750) }\end{array}$ & Ter somente uma vaga idéia de algo. \\
\hline $\begin{array}{l}\text { «Louis XV, avec toutes sortes de faibles, } \\
\text { n'avait qu'une seule force, celle d'être } \\
\text { inexorable » (Muss.). (faiblesse) (verbete }\end{array}$ & $\begin{array}{l}\text { Luís XIV, com toda sorte de fraquezas, tinha } \\
\text { somente uma qualidade, a de ser inexorável. }\end{array}$ \\
\hline
\end{tabular}




\begin{tabular}{|c|c|}
\hline faible, p. 750) & \\
\hline $\begin{array}{l}\text { « Un fainéant qui n’aimait qu’à boire » (Balz.). } \\
\text { (paresseux) (verbete fainéant, ante, p. 752) }\end{array}$ & $\begin{array}{l}\text { ?Um preguiçoso que gostava somente de } \\
\text { beber. } \\
\text { Um preguiçoso que gostava só de beber. (de } \\
\text { nada mais, não gostava de comer, por } \\
\text { exemplo) } \\
\text { !Um preguiçoso que só gostava de beber. (não } \\
\text { fazia de mais nada) }\end{array}$ \\
\hline $\begin{array}{l}\text { Ne faire qu'un, n'en faire qu'un. (un) (verbete } \\
\text { faire, p. 752) }\end{array}$ & $\begin{array}{l}\text { ?Somente um, é somente um. } \\
\text { Só fazer um, só fazer um. } \\
\text { Fazer só um. }\end{array}$ \\
\hline $\begin{array}{l}\text { «Il ne revient pas, ne donne plus de ses } \\
\text { nouvelles, n’en fait qu’à sa fantaisie » (Loti). } \\
\text { (agir à sa fantasie) (verbete faire, p. } 752 \text { ) }\end{array}$ & $\begin{array}{l}\text { Ele não vem mais, não dá mais notícias, age } \\
\text { somente segundo suas fantasias. } \\
\text { Ele não vem mais, não dá mais notícias, só faz } \\
\text { o que bem entende. }\end{array}$ \\
\hline $\begin{array}{l}\text { Il ne fait que bâiller. (faire seulement) (verbete } \\
\text { faire, p. } 752 \text { ) }\end{array}$ & Não faz outra coisa a não ser bocejar. \\
\hline $\begin{array}{l}\text { Il ne fait que d'arriver, laisser lui le temps de } \\
\text { se reposer. (venir) (verbete faire, p. 752) }\end{array}$ & Acabou de chegar, deixe-o descansar. \\
\hline $\begin{array}{l}\text { « J’avais falsifié mon bulletin de naissance, } \\
\text { l’usage de la poste restante n’étant permis qu'à } \\
\text { partir de dix-hit ans » (Radiguet). (falsifier) } \\
\text { (verbete falsifier, p. 756) }\end{array}$ & $\begin{array}{l}\text { Eu tinha falsificado minha certidão de } \\
\text { nascimento, o uso da caixa postal é permitido } \\
\text { somente a partir dos } 18 \text { anos. } \\
\text { Eu tinha falsificado minha certidão de } \\
\text { nascimento, o uso da caixa postal só é } \\
\text { permitido a partir dos } 18 \text { anos. }\end{array}$ \\
\hline $\mathbf{G}$ & $\mathbf{G}$ \\
\hline $\begin{array}{l}\text { Je ne veux d'autre gage que votre parole. } \\
\text { (verbete gage, p. 842) }\end{array}$ & $\begin{array}{l}\text { Só quero a sua palavra como garantia. } \\
\text { A única garantia que quero é a sua palavra. }\end{array}$ \\
\hline Je n’y ai gagné que des coups. (verbete gagner, & ?Ganhei somente golpes. \\
\hline
\end{tabular}




\begin{tabular}{|c|c|}
\hline p. 842) & Só levei porrada/pancada. \\
\hline $\begin{array}{l}\text { Gant n'ayant qu’un seul doigt separé, le pouce } \\
\text { (V. Moufle), laissant à nu les premières } \\
\text { phalanges (V. Mitaine). (verbete gant, p. 848) }\end{array}$ & $\begin{array}{l}\text { ?Luva com somente um dedo separado, o } \\
\text { polegar, deixando nuas as primeiras falanges. } \\
\text { ?Luva só com um dedo separado, o polegar, } \\
\text { deixando nuas as primeiras falanges. } \\
\text { Luva com só um dedo separado, o polegar, } \\
\text { deixando nuas as primeiras falanges. }\end{array}$ \\
\hline $\begin{array}{l}\text { Il ne pense qu'à la gaudriole. (bagatelle, } \\
\text { débauche) (verbete gaudriole, p. 854) }\end{array}$ & $\begin{array}{l}\text { Ele pensa somente na pechincha. (além de } \\
\text { fazer outras ele pensa e quando pensa, o } \\
\text { único objeto de sua reflexão é a pechincha) } \\
\text { Ele só pensa em pechinchar. (não faz outra } \\
\text { coisa além de pensar em pechinchar) }\end{array}$ \\
\hline $\mathbf{H}$ & $\mathbf{H}$ \\
\hline- & - \\
\hline $\mathbf{I}$ & $\mathbf{I}$ \\
\hline $\begin{array}{l}\text { «Les lois humaines sont fondées sur l’utilité, et } \\
\text { ce n’est peut-être qu'une utilité apparente et } \\
\text { illusoire » (France). (verbete illusoire, p. 960) }\end{array}$ & $\begin{array}{l}\text { ?As leis humanas são fundamentadas na } \\
\text { utilidade, e é somente uma utilidade aparente e } \\
\text { ilusória. } \\
\text { As leis humanas são fundamentadas na } \\
\text { utilidade, e talvez esta não passe de uma } \\
\text { utilidade aparente e ilusória. }\end{array}$ \\
\hline $\begin{array}{l}\text { «L'illustrateur ne doit voir qu'avec les yeux } \\
\text { d'un autre » (Gautier). (verbete illustrateur, p. } \\
960 \text { ) }\end{array}$ & $\begin{array}{l}\text { O desenhista deve ver somente com os olhos } \\
\text { do outro. } \\
\text { O desenhista só deve ver com olhos de outro. }\end{array}$ \\
\hline $\begin{array}{l}\text { Ce n'est qu'un pâle imitateur. (verbete } \\
\text { imitateur, trice, p. 962) }\end{array}$ & $\begin{array}{l}\text { ?É somente um pálido imitador. } \\
\text { É só um pálido imitador. }\end{array}$ \\
\hline $\begin{array}{l}\text { «On ne peut imiter de vos gestes que ce qu’ils } \\
\text { ont de mécaniquement uniforme » (Bergson). } \\
\text { (verbete imiter, p. 962) }\end{array}$ & $\begin{array}{l}\text { Podemos imitar somente aquilo que os seus } \\
\text { gestos tem de mecanicamente uniforme. } \\
\text { (objeto da imitação) }\end{array}$ \\
\hline
\end{tabular}




\begin{tabular}{|c|c|}
\hline & $\begin{array}{l}\text { !Só podemos imitar aquilo que os seus gestos } \\
\text { tem de mecanicamente uniforme. (não } \\
\text { podemos fazer mais nada) }\end{array}$ \\
\hline $\begin{array}{l}\text { Implication d’une proposition B par une } \\
\text { proposition A, proposition qui n’est fausse que } \\
\text { si A est vraie et B est fausse (V. Antécédent, } \\
\text { conséquent). (verbete implication, p. 968) }\end{array}$ & $\begin{array}{l}\text { ?Implicação de uma proposição B por uma A, } \\
\text { proposição que é falsa somente se A for } \\
\text { verdadeira e B, falsa. } \\
\text { Implicação de uma proposição B por uma A, } \\
\text { proposição que só é falsa se A for verdadeira e } \\
\text { B, falsa. }\end{array}$ \\
\hline $\begin{array}{l}\text { « Des choses qui ne paraissent impossibles que } \\
\text { tant qu'on ne les a pas tentées » (Gide). } \\
\text { (verbete impossible, p. 970) }\end{array}$ & $\begin{array}{l}\text { Coisas que parecem impossíveis somente na } \\
\text { medida em que não as tentamos. } \\
\text { Coisas que só parecem impossíveis na medida } \\
\text { se não as tentarmos. }\end{array}$ \\
\hline $\begin{array}{l}\text { Qui, par un vice de nature ou par accident, ne } \\
\text { peut se mouvoir, ou ne se meut qu'avec une } \\
\text { extrême difficulté. (verbete impotent, ente, p. } \\
\text { 970) }\end{array}$ & $\begin{array}{l}\text { ?Quem, por vício de natureza ou acidente, não } \\
\text { pode se movimentar, ou quem se movimenta } \\
\text { somente com extrema dificuldade. } \\
\text { Quem, por vício de natureza ou acidente, não } \\
\text { pode se movimentar, ou quem só se movimenta } \\
\text { com extrema dificuldade. }\end{array}$ \\
\hline $\begin{array}{l}\text { Il ne sait lire que l’imprimé. (verbete imprimé, } \\
\text { ée, p. 972) }\end{array}$ & $\begin{array}{l}\text { Ele sabe ler somente as letras impressas. (e } \\
\text { nenhum outro tipo de letra) } \\
\text { !Ele só sabe ler as letras impressas. (não sabe } \\
\text { escrever) }\end{array}$ \\
\hline $\mathbf{J} / \mathbf{K}$ & $\mathbf{J} / \mathbf{K}$ \\
\hline $\begin{array}{l}\text { Il n’a jamais fait que s’amuser. (autre chose } \\
\text { que ...) (verbete jamais, p. 1040) }\end{array}$ & Ele não fez outra coisa a não ser se divertir. \\
\hline $\begin{array}{l}\text { Ce n'est jamais qu'un enfant, après tout, ce } \\
\text { n'est qu'un enfant. (verbete jamais, p. 1040) }\end{array}$ & $\begin{array}{l}\text { Não é mais que uma criança, apesar de tudo, } \\
\text { somente uma criança. } \\
\text { !É só uma criança, apesar de tudo, só uma }\end{array}$ \\
\hline
\end{tabular}




\begin{tabular}{|c|c|}
\hline & criança. (quantidade? Uma criança só?) \\
\hline $\mathbf{L}$ & $\mathbf{L}$ \\
\hline- & - \\
\hline $\mathbf{M}$ & $\mathbf{M}$ \\
\hline $\begin{array}{l}\text { Objet fabriqué, généralement complexe (V. } \\
\text { Mécanisme), destiné à transformer l'énergie } \\
\text { (V. Moteur) et à utiliser cette transformation } \\
\text { (se distingue en principe de appareil et de outil, } \\
\text { qui ne font qu'utiliser l'énergie). (verbete } \\
\text { machine, p. 1124) }\end{array}$ & $\begin{array}{l}\text { Objeto industrializado, em geral complexo, (v. } \\
\text { mecanismo), destinado a transformar energia } \\
\text { (v. motor) e utilizar essa transformação (em } \\
\text { princípio, distingue-se de aparelhos e } \\
\text { ferramentas que somente utilizam de energia). } \\
\text { Objeto industrializado, em geral complexo, (v. } \\
\text { mecanismo), destinado a transformar energia } \\
\text { (v. motor) e utilizar essa transformação (em } \\
\text { princípio, distingue-se de aparelhos e } \\
\text { ferramentas que só utilizam de energia). }\end{array}$ \\
\hline $\begin{array}{l}\text { Il n'est qu'une machine à fabriquer de l'argent. } \\
\text { (verbete machine, p. 1124) }\end{array}$ & $\begin{array}{l}\text { ?É somente uma máquina para fabricação de } \\
\text { dinheiro. } \\
\text { É só uma máquina para fabricação de dinheiro. }\end{array}$ \\
\hline $\begin{array}{l}\text { Il n'a que la peau et les os*; c'est un sac d'os*. } \\
\text { (verbete maigre, p. } 1130 \text { ) }\end{array}$ & $\begin{array}{l}\text { É apenas pele e osso, um saco de ossos. } \\
\text { Ele é pele e osso. }\end{array}$ \\
\hline $\begin{array}{l}\text { Il n’a obtenu que de bien maigres résultats. } \\
\text { (médiocre) (verbete maigre, p. 1130) }\end{array}$ & $\begin{array}{l}\text { ?Obteve somente resultados medíocres. } \\
\text { Só obteve resultados medíocres. }\end{array}$ \\
\hline $\begin{array}{l}\text { «Un père n’est le maître de ses enfants que } \\
\text { pour leur intérêt » (Senancour). (chef) (verbete } \\
\text { maître, maîtresse, p. 1134) }\end{array}$ & $\begin{array}{l}\text { Um pai é senhor de seus filhos somente em } \\
\text { benefício deles. (única situação possível para } \\
\text { ser senhor dos filhos) } \\
\text { !Um pai só é senhor de seus filhos em benefício } \\
\text { deles. (função de pai? É outra coisa em } \\
\text { outras situações que o benefício deles) }\end{array}$ \\
\hline $\begin{array}{l}\text { Etre maître de soi, Etre son maître (par rapport } \\
\text { aux autres) : être libre et indépendant, n'avoir }\end{array}$ & $\begin{array}{l}\text { Ser mestre de si mesmo, Ser seu mestre (em } \\
\text { relação aos outros): ser livre e independente, ter }\end{array}$ \\
\hline
\end{tabular}




\begin{tabular}{|c|c|}
\hline $\begin{array}{l}\text { d'autre maître que soi-même. (verbete maître, } \\
\text { maîtresse, p. 1134) }\end{array}$ & $\begin{array}{l}\text { como mestre somente a si mesmo. } \\
\text { Ser senhor de si mesmo, Ser seu senhor (em } \\
\text { relação aos outros): ser livre e independente, } \\
\text { não ter outro senhor além de si mesmo. }\end{array}$ \\
\hline $\begin{array}{l}\text { «Son Dieu prétendu n’est qu’un être } \\
\text { malfaisant » (Rouss.). (mauvais, méchant) } \\
\text { (verbete malfaisant, ante, p. 1138) }\end{array}$ & $\begin{array}{l}\text { Seu suposto Deus nada mais é do que um ser } \\
\text { malvado. }\end{array}$ \\
\hline $\begin{array}{l}\text { «Si le peuple (russe) a l’air sale, cette } \\
\text { malpropreté n’est qu'apparente » (Gautier). } \\
\text { (saleté) (verbete malpropreté, p. 1140) }\end{array}$ & $\begin{array}{l}\text { ?Se o povo (russo) tem o aspecto sujo, essa } \\
\text { falta de limpeza é somente aparente. (não é } \\
\text { aprofundada? São de fato sujos.) } \\
\text { Se o povo (russo) tem o aspecto sujo, essa falta } \\
\text { de limpeza é só aparente. (de fato não são } \\
\text { sujos) }\end{array}$ \\
\hline $\mathbf{N}$ & $\mathbf{N}$ \\
\hline $\begin{array}{l}\text { Principe fondamental de tout jugement moral, } \\
\text { ensemble de règles idéales dont les lois } \\
\text { humaines ne sont qu'une imitation imparfaite. } \\
\text { (verbete nature, p. 1258) }\end{array}$ & $\begin{array}{l}\text { Princípio fundamental de todo julgamento } \\
\text { moral, conjunto de regras ideais, cujas leis } \\
\text { humanas são somente uma imitação imperfeita. }\end{array}$ \\
\hline $\begin{array}{l}\text { « Rien n'empêche tant d'être naturel que } \\
\text { l'envie de le paraître » (La Rochef.). (verbete } \\
\text { naturel, elle, p. 1258) }\end{array}$ & $\begin{array}{l}\text { Nada impede alguém tanto de ser natural } \\
\text { quanto de desejar de parecê-lo. }\end{array}$ \\
\hline $\begin{array}{l}\text { Il ne peut faire un pas que sa mère ne } \\
\text { s'inquiète : sans qu'elle s'inquiète. (verbete ne, } \\
\text { p. 1260) }\end{array}$ & $\begin{array}{l}\text { Ele não pode dar um passo sem que sua mãe se } \\
\text { preocupe: sem que ela se preocupe. }\end{array}$ \\
\hline $\begin{array}{l}\text { « M'en parlez pas... - Si c’est pas malheureux } \\
\text { !... - J'avais qu'elle » (Carco). (verbete ne, p. } \\
1260)\end{array}$ & $\begin{array}{l}\text { Não me diga... - Que triste!... - Eu só tinha a } \\
\text { ela. }\end{array}$ \\
\hline $\mathbf{O}$ & $\mathbf{O}$ \\
\hline Chez Descartes, Qui n'est que conceptuel. & Segundo Descartes, o “quem” é somente \\
\hline
\end{tabular}




\begin{tabular}{|c|c|}
\hline (verbete objectif, ive, p. 1292) & conceitual. \\
\hline $\begin{array}{l}\text { "Quant aux incursions diaboliques, on ne les } \\
\text { refoule qu'après de persistantes obsécrations » } \\
\text { (Huysmans). (supplication) (verbete } \\
\text { obsécration, p. 1294) }\end{array}$ & $\begin{array}{l}\text { Quanto às incursões diabólicas, nós a refutamos } \\
\text { somente após persistentes súplicas. (quando, } \\
\text { não antes) } \\
\text { !Quanto às incursões diabólicas, nós só a } \\
\text { refutamos após persistentes súplicas. (fazemos } \\
\text { outras coisas com elas) }\end{array}$ \\
\hline $\begin{array}{l}\text { Instrument du genre du sextant, mais dont le } \\
\text { bâti n'est que de } 45^{\circ} \text {. (verbete octant, p. 1298) }\end{array}$ & $\begin{array}{l}\text { Instrumento do gênero Sextante, mas cujo } \\
\text { ângulo é somente de } 45^{\circ} \text {. (não é maior que) }\end{array}$ \\
\hline $\begin{array}{l}\text { N'avoir d'yeux que pour qqn : ne voir que lui, } \\
\text { et au fig. Ne s'intéresser qu'à lui. (verbete oeil, } \\
\text { yeux, p. 1300) }\end{array}$ & $\begin{array}{l}\text { Ter olhos somente para uma pessoa: ver } \\
\text { somente a ela e, no figurado, interessar-se } \\
\text { somente por ela. }\end{array}$ \\
\hline $\mathbf{P}$ & $\mathbf{P}$ \\
\hline $\begin{array}{l}\text { Ne jouer que des pannes. (rôle insignifiant dans } \\
\text { une pièce) (verbete 2. Panne, p. 1348) }\end{array}$ & Representar somente papéis insignifi \\
\hline $\begin{array}{l}\text { Suivi d'un nom ou nominal pluriel ou collectif, } \\
\text { sauf s’il ne s'agit que de deux choses (V. } \\
\text { Entre). (verbete parmi, p. 1362) }\end{array}$ & $\begin{array}{l}\text { Seguido de um substantivo ou nominal plural } \\
\text { ou coletivo, exceto se se tratar somente de duas } \\
\text { coisas. }\end{array}$ \\
\hline $\begin{array}{l}\text { « Ce qu’on appelle création dans les grands } \\
\text { artistes n'est qu'une manière particulière à } \\
\text { chacun... de rendre la nature » (Delacroix). } \\
\text { (verbete particulier, ière, p. 1366) }\end{array}$ & $\begin{array}{l}\text { ?O que chamamos de criação nos grandes } \\
\text { artistas é somente uma característica } \\
\text { individual... de reproduzir a natureza. } \\
\text { O que chamamos de criação nos grandes } \\
\text { artistas é só uma característica individual... de } \\
\text { reproduzir a natureza. }\end{array}$ \\
\hline $\begin{array}{l}\text { Qui ne concerne qu'un individu (ou un petit } \\
\text { groupe) et lui appartient (opposé à collectif, } \\
\text { commun). (verbete particulier, ière, p. 1366) }\end{array}$ & $\begin{array}{l}\text { O que concerne somente ao indivíduo (ou a um } \\
\text { pequeno grupo) e lhe pertence (em oposição a } \\
\text { coletivo, comum). }\end{array}$ \\
\hline $\begin{array}{l}\text { «Ce n’est que par les beaux sentiments qu'on } \\
\text { parvient à la fortune! »(Baudel.). (verbete }\end{array}$ & $\begin{array}{l}\text { É somente com os bons sentimentos que } \\
\text { alcançamos a felicidade! }\end{array}$ \\
\hline
\end{tabular}




\begin{tabular}{|c|c|}
\hline parvenir, p. 1368) & \\
\hline $\begin{array}{l}\text { «Il n’y a que deux espèces de parvenus : ceux } \\
\text { qui parlent toujours de leurs origines et ceux } \\
\text { qui n’en parlent jamais » (Duham.). (verbete } \\
\text { parvenu, eu, p. 1368) }\end{array}$ & $\begin{array}{l}\text { Há somente duas espécies de recém-chegados: } \\
\text { os que sempre falam de suas origens e aqueles } \\
\text { que nunca falam delas. }\end{array}$ \\
\hline $\begin{array}{l}\text { Se dit d’un un dispositif électrique (filtre) qui } \\
\text { ne laisse passer qu'une bande de fréquence. } \\
\text { (verbete passe-bande, p. 1370) }\end{array}$ & $\begin{array}{l}\text { ?Diz-se de um dispositivo elétrico (filtro) que } \\
\text { deixa passar somente uma banda de freqüência. } \\
\text { Diz-se de um dispositivo elétrico (filtro) que só } \\
\text { deixa passar uma banda de freqüência. }\end{array}$ \\
\hline $\begin{array}{l}\text { «La femme est un être si délicat. Il n’y a qu’à } \\
\text { regarder les mains à côté d'une grosse patte } \\
\text { d’homme » (Romains). (verbete patte, p. 1380) }\end{array}$ & $\begin{array}{l}\text { A mulher é um ser tão delicado. Basta } \\
\text { olharmos suas mãos ao lado da pata grande de } \\
\text { um homem. }\end{array}$ \\
\hline $\mathbf{Q}$ & $\mathbf{Q}$ \\
\hline $\begin{array}{l}\text { « Il n’y a qu’un adjectif pour la qualifier » } \\
\text { (Maupass.). (verbete qualifier, p. 1574) }\end{array}$ & Há somente um adjetivo para qualificá-la. \\
\hline $\mathbf{R}$ & $\mathbf{R}$ \\
\hline $\begin{array}{l}\text { «On ne voyait que des carottes, des navets... } \\
\text { des salsifis, toutes les plantes dont les racines } \\
\text { grasses sont bonnes et savoureuses » } \\
\text { (Maupass.). (verbete racine, p. 1590) }\end{array}$ & $\begin{array}{l}\text { Víamos somente cenouras, nabos... salsifis, } \\
\text { todas plantas cujas raízes grandes são boas e } \\
\text { saborosas. (objeto da ação, o que era visto) } \\
\text { Só víamos cenouras, nabos... salsifis, todas } \\
\text { plantas cujas raízes grandes são boas e } \\
\text { saborosas. (ação, não as colhemos) }\end{array}$ \\
\hline $\begin{array}{l}\text { « Le coup de vent du sud-ouest n’était qu’une } \\
\text { rafale momentanée » (Baudel.). (verbete rafale, } \\
\text { p. 1594) }\end{array}$ & $\begin{array}{l}\text { ?O golpe de vento do sudoeste era somente } \\
\text { uma ventania momentânea. } \\
\text { O golpe de vento do sudoeste era só uma } \\
\text { ventania momentânea. }\end{array}$ \\
\hline $\begin{array}{l}\text { « Cette fausse modestie qui n’est qu'un } \\
\text { raffinement de l'orgueil » (Laclos.). (verbete } \\
\text { raffinement, p. 1594) }\end{array}$ & $\begin{array}{l}\text { Essa falsa modéstia que é somente um } \\
\text { refinamento do orgulho. (nada além disso) } \\
\text { Essa falsa modéstia que não passa de um }\end{array}$ \\
\hline
\end{tabular}




\begin{tabular}{|c|c|}
\hline & refinamento do orgulho. (aquém? Negativo?) \\
\hline $\begin{array}{l}\text { Les nouvelles mesures qu'on a prises ne sont } \\
\text { qu'un rafistolage. (verbete rafistolage, p. 1594) }\end{array}$ & $\begin{array}{l}\text { As novas medidas que adotamos são somente } \\
\text { uma reparação. }\end{array}$ \\
\hline $\begin{array}{l}\text { « Je pense qu'il n’y a pour l’esprit qu’une seule } \\
\text { manière de raisonner, comme il n’y a pour le } \\
\text { corps qu'une seule manière de marcher » (Cl. } \\
\text { Bernard). (verbete raisonner, p. 1598) }\end{array}$ & $\begin{array}{l}\text { Creio que para o espírito haja somente uma } \\
\text { maneira de pensar, como há para o corpo } \\
\text { somente uma maneira de caminhar. }\end{array}$ \\
\hline $\begin{array}{l}\text { «L’homme ne peut que ramper, si la religion } \\
\text { ne le soulève » (Gide). (rastejar-se) (verbete } \\
\text { ramper, p. 1602) }\end{array}$ & $\begin{array}{l}\text { O homem pode somente se rastejar se a } \\
\text { religião não o sustentar. } \\
\text { !O homem só pode rastejar-se se a religião não } \\
\text { o sustentar. }\end{array}$ \\
\hline $\begin{array}{l}\text { «Les filles n’auront qu’à rappliquer chez } \\
\text { nous » (Cocteau). (revenir, venir, arriver) } \\
\text { (verbete rappliquer, p. 1606) }\end{array}$ & $\begin{array}{l}\text { As garotas terão somente que vir à nossa casa. } \\
\text { As garotas só terão que vir à nossa casa. }\end{array}$ \\
\hline $\mathbf{S}$ & S \\
\hline $\begin{array}{l}\text { « Rien n’est si dangereux qu’un ignorant ami. } \\
\text { Mieux vaudrait un sage ennemi » (La Font.). } \\
\text { (verbete sage, p. 1750) }\end{array}$ & $\begin{array}{l}\text { Nada é mais perigoso que um amigo ignorante. } \\
\text { Melhor um inimigo sábio. }\end{array}$ \\
\hline $\begin{array}{l}\text { «Ce n'est que dans le sang qu'on lave un tel } \\
\text { outrage » (Cron.). (verbete sang, p. 1760) }\end{array}$ & $\begin{array}{l}\text { Somente com sangue se limpa tal ultraje. } \\
\text { Só com sangue se limpa tal ultraje. }\end{array}$ \\
\hline $\begin{array}{l}\text { «L’argent n’était pour moi que satisfaction de } \\
\text { fantaisies » (Stendhal). (verbete satisfaction, p. } \\
\text { 1766) }\end{array}$ & $\begin{array}{l}\text { O dinheiro era para mim somente uma maneira } \\
\text { de satisfazer fantasias. }\end{array}$ \\
\hline $\begin{array}{l}\text { « Un art sauvage ne se maintient que dans la } \\
\text { sauvagerie qu'il exprime, et l'intrusion d’un art } \\
\text { civilisé le détruit » (Malraux). (verbete } \\
\text { sauvage, p. 1770) }\end{array}$ & $\begin{array}{l}\text { Uma arte selvagem existe somente na } \\
\text { selvageria que exprime, e a intrusão de uma } \\
\text { arte civilizada a destrói. } \\
\text { Uma arte selvagem só existe na selvageria que } \\
\text { exprime, e a intrusão de uma arte civilizada a } \\
\text { destrói. }\end{array}$ \\
\hline
\end{tabular}




\begin{tabular}{|c|c|}
\hline $\begin{array}{l}\text { "Science sans conscience n’est que ruine de } \\
\text { l’âme » (Rabelais). (verbete science, p. 1778) }\end{array}$ & $\begin{array}{l}\text { Ciência sem consciência é somente a ruína da } \\
\text { alma. } \\
\text { Ciência sem consciência é não passa de a ruína } \\
\text { da alma. }\end{array}$ \\
\hline $\begin{array}{l}\text { « La pensée ne revêt le caractère de la science } \\
\text { que lorsqu’elle a une valeur universelle » } \\
\text { (Goblot). (verbete science, p. 1778) }\end{array}$ & $\begin{array}{l}\text { O pensamento somente revela o caráter da } \\
\text { ciência na medida em que esta tenha valor } \\
\text { universal. } \\
\text { O pensamento só revela o caráter da ciência na } \\
\text { medida em que esta tenha valor universal. }\end{array}$ \\
\hline $\mathbf{T}$ & $\mathbf{T}$ \\
\hline $\begin{array}{l}\text { « Le tableau n'est qu'un amas de taches » } \\
\text { (Dider.). (verbete tache, p. 1914) }\end{array}$ & $\begin{array}{l}\text { ?O quadro é somente um amontoado de } \\
\text { manchas. (concessivo?) } \\
\text { !O quadro é só um amontoado de manchas. } \\
\text { (negativo?) }\end{array}$ \\
\hline $\begin{array}{l}\text { « Insoucieux du relief, il (le Japonais) ne peint } \\
\text { que par le contour et la tache » (Claudel). } \\
\text { (verbete tache, p. 1914) }\end{array}$ & $\begin{array}{l}\text { Despreocupado com o relevo, ele (o japonês) } \\
\text { pinta somente o contorno e a mancha/sombra. }\end{array}$ \\
\hline $\begin{array}{l}\text { Qui ne dure ou ne doit durer qu'un temps } \\
\text { limité. (verbete temporaire, p. 1938) }\end{array}$ & $\begin{array}{l}\text { O que dura ou deve durar somente um período } \\
\text { limitado. }\end{array}$ \\
\hline \begin{tabular}{|l} 
«J’ai forcé à combattre l’ennemi qui ne \\
voulait que temporiser » (Laclos). (attendre) \\
(verbete temporiser, p. 1938)
\end{tabular} & $\begin{array}{l}\text { ?Forcei o combate do inimigo que queria } \\
\text { somente esperar. (nada laém disso, passivo) } \\
\text { !Forcei o combate do inimigo que só queria } \\
\text { esperar. (ativo?) }\end{array}$ \\
\hline $\begin{array}{l}\text { «Ces empoisonnements qui n’agissent qu’au } \\
\text { bout d’un certain temps » (Proust). (verbete } \\
\text { temps, p. 1938) }\end{array}$ & $\begin{array}{l}\text { ?Esses venenos agem somente após algum } \\
\text { tempo. (concessivo?) } \\
\text { !Esses venenos só agem após algum tempo. } \\
\text { (ativo?) }\end{array}$ \\
\hline $\begin{array}{l}\text { N'avoir qu'un temps, être éphémère, } \\
\text { provisoire. (verbete temps, p. 1938) }\end{array}$ & $\begin{array}{l}\text { Ter somente um tempo, ser efêmero, } \\
\text { provisório. }\end{array}$ \\
\hline
\end{tabular}




\begin{tabular}{|c|c|}
\hline $\mathbf{U}$ & $\mathbf{U}$ \\
\hline $\begin{array}{l}\text { « - Ceux qui ne sont pas de la compagnie n’ont } \\
\text { qu'à la boucler et d'une ... » (Dorgelès). } \\
\text { (verbete un, une, p. 2046) }\end{array}$ & $\begin{array}{l}\text { - Os que não são da companhia têm somente } \\
\text { uma serra e uma... (concessivo?) } \\
\text { !- Os que não são da companhia só têm uma } \\
\text { serra e uma... (ativo?) }\end{array}$ \\
\hline $\begin{array}{l}\text { Lui et son frère ne font qu’un; ils n’en font } \\
\text { qu'un : ils sont très unis. (verbete un, une, p. } \\
\text { 2046) }\end{array}$ & $\begin{array}{l}\text { ?Ele e seu irmão são somente um; são somente } \\
\text { um: são muito unidos. } \\
\text { Ele e seu irmão são um só; são um só: são } \\
\text { muito unidos. }\end{array}$ \\
\hline $\begin{array}{l}\text { Qui n'engage qu'une seule partie. (verbete } \\
\text { unilatéral, ale, aux, p. 2048) }\end{array}$ & $\begin{array}{l}\text { O que usa somente uma única parte. } \\
\text { (concessivo?) } \\
\text { !O que só usa uma parte. (ativo?) }\end{array}$ \\
\hline $\begin{array}{l}\text { Se dit d’un mode de filiation ne reconnaissant } \\
\text { qu’une seule ligne, patrilinéaire* ou } \\
\text { matrilinéaire*. (verbete unilinéaire, p. 2048) }\end{array}$ & $\begin{array}{l}\text { Diz-se de um modo de filiação que re- } \\
\text { conhece somente uma linha, paterna ou } \\
\text { materna. }\end{array}$ \\
\hline $\begin{array}{l}\text { Qui ne comprend qu’une seule loge; qui n’est } \\
\text { pas divisé en compartiments. (verbete } \\
\text { uniloculaire, p. 2048) }\end{array}$ & $\begin{array}{l}\text { ?Que compreende somente um lugar; que não é } \\
\text { dividido em compartimentos. } \\
\text { Que compreende um lugar somente; que não é } \\
\text { dividido em compartimentos. } \\
\text { Que compreende um só lugar; que não é } \\
\text { dividido em compartimentos. }\end{array}$ \\
\hline $\begin{array}{l}\text { Qui ne possède qu'un ovule. (verbete uniovulé, } \\
\text { ée, p. 2048) }\end{array}$ & $\begin{array}{l}\text { ?Quem possui somente um ovário. } \\
\text { Quem possui só um ovário. (não possui dois) } \\
\text { !Quem só possui um ovário. (mas esse ovário } \\
\text { não funciona) }\end{array}$ \\
\hline $\begin{array}{l}\text { Se dit de la femme qui n’a eu qu'un seul } \\
\text { enfant. (verbete unipare, p. 2048) }\end{array}$ & $\begin{array}{l}\text { Diz-se da mulher que teve somente um filho. } \\
\text { (concessivo?) } \\
\text { Diz-se da mulher que teve só um filho. } \\
\text { (negativo?) }\end{array}$ \\
\hline
\end{tabular}




\begin{tabular}{|c|c|}
\hline & Diz-se da mulher que só teve um filho. (!(?)) \\
\hline $\begin{array}{l}\text { Se dit des verbes qui ne peuvent être employés } \\
\text { qu'à la } 3^{\mathrm{e}} \text { pers. du sing. (du point de vue } \\
\text { conceptuel, ce sont des verbes impersonnels). } \\
\text { (verbete unipersonnel, elle, p. 2048) }\end{array}$ & $\begin{array}{l}\text { Diz-se dos verbos que podem ser empregados } \\
\text { somente na } 3^{\text {a }} \text { pessoa do sing. (do ponto de } \\
\text { vista conceitual, são verbos impessoais). } \\
\text { Diz-se dos verbos que só podem ser } \\
\text { empregados na } 3^{\text {a }} \text { pessoa do sing. (do ponto de } \\
\text { vista conceitual, são verbos impessoais). (!(?)) }\end{array}$ \\
\hline $\begin{array}{l}\text { Qui ne concerne qu'un des deux pôles (électr., } \\
\text { etc.). (verbete unipolaire, p. 2048) }\end{array}$ & $\begin{array}{l}\text { O que concerne somente a um dos dois pólos } \\
\text { (eletr., etc.) }\end{array}$ \\
\hline $\mathbf{V}$ & $\mathbf{V}$ \\
\hline $\begin{array}{l}\text { «Un mauvais principe qu'il ne désigne que } \\
\text { vaguement » (Gautier). (verbete vaguement, p. } \\
2060)\end{array}$ & $\begin{array}{l}\text { ?Um princípio ruim, designado somente } \\
\text { vagamente. } \\
\text { Um princípio ruim, que ele designa só } \\
\text { vagamente. (modo de designação) } \\
\text { Um princípio ruim, que ele só designa } \\
\text { vagamente. (não utiliza, por exemplo) }\end{array}$ \\
\hline $\begin{array}{l}\text { «Elle ne songe... qu'à varier ses plaisirs » } \\
\text { (Gautier). (verbete varier, p. 2066) }\end{array}$ & Ela só pensa em variar seus prazeres. \\
\hline $\begin{array}{l}\text { « Ne cultiver que deux variétés de pommes » } \\
\text { (Duham.). (verbete variété, p. 2066) }\end{array}$ & Cultivar somente dois tipos de maçãs. \\
\hline $\mathbf{W} / \mathbf{X} / \mathbf{Y} / \mathbf{Z}$ & $\mathbf{W} / \mathbf{X} / \mathbf{Y} / \mathbf{Z}$ \\
\hline- & - \\
\hline
\end{tabular}

Fonte : ROBERT, Paul. Dictionnaire Alphabétique \& Analogique de la Langue Française.

Paris: Le Robert, 1981. 2173p. 


\title{
ANEXO C - CORPUS JORNALÍSTICO
}

\author{
L'art cinétique atteint des records \\ LE MONDE | 01.07.06 | 15h27 • Mis à jour le 01.07.06 | 15h27
}

Révélé en 1955 par l'exposition "Le Mouvement" à la galerie Denise René, l'art cinétique a été salué par le marché avant d'être mis au purgatoire. Depuis deux ans, une réhabilitation est en cours, comme en témoignent les récents records en ventes publiques.

En déroutant les habitudes de regard par des superpositions de trames ou des vibrations lumineuses, l'art cinétique ou optique - autrement appelé op art - voulait changer le monde. Le programme du Groupe de recherche d'art visuel (GRAV), regroupant en 1960 des artistes comme François Morellet, Yvaral ou Julio Le Parc, se présentait comme un projet de société. "Nous voulons sortir le spectateur de sa dépendance apathique qui lui fait accepter, d'une façon passive, non seulement ce qu'on lui impose comme art, mais tout un système de vie", disait leur manifeste.

Les oeuvres cinétiques provoquent chez le spectateur une fascination hypnotique, mêlant plaisir et déplaisir. "L'op ne tiendra pas, parce que les collectionneurs ne peuvent profiter de leurs tableaux; ils sont obligés de tourner les toiles vers le mur pour échapper au mal de mer", aurait déclaré l'artiste Marcel Duchamp.

\section{DOUBLE DATATION}

Figure dominante du cinétisme, Victor Vasarely (1908-1997) suggère le mouvement dans les années 1950 par l'illusion optique de deux formes-couleurs contrastées. Sa production est abondante, mais inégale. Après grandeur et décadence dignes d'un Salvador Dali, les prix de ses œuvres remontent depuis deux ans, grâce notamment aux collectionneurs américains. En mai chez Christie's, Jong, une très grande toile des années 1962-1972, a décroché le record de 296000 dollars (235 600 euros).

Il est néanmoins encore possible d'acheter des pièces de l'artiste datant des années 1950 entre 30000 et 65 000 euros. La galerie Anne Lahumière a ainsi cédé en juin sur la foire Art Basel une petite tempera sur carton de 1956 pour 36000 euros. Il est parfois arrivé à Vasarely d'antidater ses oeuvres. On trouve du coup souvent des pièces portant une double datation, celle de conception et celle d'exécution.

Autre figure consacrée de l'art optique, le Vénézuélien Jesus Rafael Soto (1923-2005) a produit vers 1954 des structures en Plexiglas dans lesquelles il superposait deux surfaces tramées. Les prix de ses œuvres varient de 60000 à 400000 dollars en ventes publiques. Une de ses sculptures a été achetée pour 57600 livres sterling (83 396 euros) par le Museum of Modern Art de New York (MoMA) chez Sotheby's en 2003. 
La spécialiste de Christie's Florence de Botton observe que, en deux ans, la cote de Soto a triplé. "Ses prix sont importants car, hormis la clientèle intéressée par le cinétique, il mobilise aussi les collectionneurs sud-américains", indique Martin Guesnet, spécialiste d'Artcurial.

L'intérêt des Latino-Américains profite aussi aux tarifs de Carlos Cruz-Diez, dont certaines oeuvres se négocient autour de 120000 euros. La palme des records revient toutefois à la Britannique Bridget Riley. Le 21 juin chez Sotheby's, le galeriste new-yorkais Jeffrey Deitch a acquis un panneau de 1966 pour 1,18 million de livres sterling. "On ne connaissait que quatre autres oeuvres de cette série, et en dehors de la nôtre il n'en restait qu'une seule en mains privées.", précise Grégoire Billault, spécialiste de Sotheby's.

Le mouvement cinétique a aussi flirté avec les arts décoratifs. Comme le souligne Florence de Botton, le goût pour le design des années 1970 explique en partie le retour en grâce de l'art cinétique. Cette dimension "décorative" était en verve en mars au Pavillon des antiquaires, à Paris. La galerie Brocéliande y a cédé une pièce de Julio Le Parc pour 15000 euros. Cette sculpture éditée à plusieurs exemplaires prenait la forme d'une lanière métallique horizontale se déhanchant lorsque le moteur était actionné. Une oeuvre séduisante sans être hypnotique.

Galerie Denise René, 196, boulevard Saint-Germain, 75006 Paris. Tél. : 01-42-22-77-57.

Roxana Azimi

Article paru dans l'édition du 02.07.06

http://www.lemonde.fr/web/article/0,1-0,36-790675,0.html 
Foot-business

Vers un Mondial en crypté ?

LE MONDE | 01.07.06 | 14h49 • Mis à jour le 01.07.06 | 14h49

Comment voir les rencontres du Mondial sans payer un abonnement à une chaîne privée ? La question agite les téléspectateurs algériens et marocains, confrontés au monopole d'un bouquet satellite. Ce débat n'a encore jamais eu lieu en France, les chaînes généralistes ayant toujours assuré une large retransmission de la compétition.

Le Mondial allemand 2006 ne déroge pas à cette tradition : les mordus du ballon rond ont pu suivre 55 des 64 rencontres sur des chaînes hertziennes non payantes (TF1 et M6). Pourrait-il en être autrement pour les prochaines éditions?

L'Union européenne a, en théorie, exclu cette hypothèse. Adoptée en 1997, la directive "Télévision sans frontières" permet à chaque Etat membre de dresser une liste d'événements sportifs "d'importance majeure" devant être protégés contre une diffusion réservée aux seuls abonnés à une chaîne payante. Pour cela, chaque pays définit sa propre liste. Une fois inscrit sur la liste nationale, l'événement devient "protégé".

La France a édicté sa liste fin 2004. Dans celle-ci on retrouve, aux côtés de toutes les rencontres de l'équipe de France de football 22 autres événements auxquels le législateur a pensé nécessaire de garantir par avance un libre accès (Tour de France, Tournoi des 6 nations, Grand Prix de France de F1, finales des championnats d'Europe et du monde de handball ou de basket-ball lorsque l'équipe de France y prend part...).

Toutefois, cette protection n'a pas résisté au fonctionnement du marché télévisuel. Le 5 février, la finale du championnat d'Europe de handball opposant la France à la Croatie - un événement pourtant inscrit sur la liste française - n'a été retransmise que sur le canal de la chaîne payante, propriétaire des droits.

L'objectif étant d'empêcher qu'une partie du public soit privée de l'accès à un tel événement, on ne peut que souhaiter que ce raté soit sans lendemain. France-Brésil uniquement en crypté, y pensez vous ?

Chronique réalisée par le Centre de droit et d'économie du sport de Limoges (www.cdes.fr)

J.-B. Boucheron

Article paru dans l'édition du 02.07.06

http://www.lemonde.fr/web/article/0,1-0,36-790821,0.html 
Jen-Pierre Rehm, directeur artistique du festival international de Marseille depuis 2001

Les mille et une vies du documentaire

LE MONDE | 01.07.06 | 12h24 • Mis à jour le 01.07.06 | 14h26

On assiste depuis quelques années à un fort regain du documentaire, dont attestent le nombre croissant et le succès, pour certains, de la sortie de ces films en salles. Confirmez-vous ce constat et comment l'expliquez-vous?

Je serai un peu plus nuancé. Je ne crois pas, d'abord, que le documentaire ait jamais quitté les salles, simplement il y a eu des effets médiatiques qui ont fait que, à un moment donné, sa présence est devenue plus manifeste, et que par un effet boomerang des producteurs et des distributeurs ont réalisé qu'il y avait un marché possible du genre en salles.

Ce n'est donc pas une résurrection, s'agissant d'un genre qui a toujours été vivace, notamment dans sa capacité à résister aux formes majoritaires. Il me semble, ensuite, que le succès récent en salles de certains d'entre eux s'explique par deux facteurs. Le premier est une volonté de compréhension de ce qui nous arrive dans un monde où les pouvoirs fabriquent, de manière très ingénieuse, toujours plus d'opacité.

Le second est que la fiction ne prend plus en charge ces questions comme elle a pu le faire par le passé. La grille de lecture et d'intelligibilité de la fiction, avec des scénarios qui se copient peu ou prou les uns les autres et qui aboutissent à répéter Star Wars à des échelles variables, est devenue beaucoup trop lâche.

Il y aurait donc à l'origine de ce regain documentaire une double crise, celle du politique et celle de la fiction?

C'est exactement la même pour moi, car il n'y a pas de politique sans représentation. C'est pour cela que l'art, et plus particulièrement le cinéma, m'intéresse autant, car je pense qu'il n'y va pas là d'une activité annexe, présentant au mieux un intérêt culturel, mais de nos existences et de notre rapport à l'Histoire. Par sa capacité à sonder longuement, et modestement aussi, j'y insiste, une question qui peut sembler de prime abord locale, le documentaire s'inscrit pleinement dans cette articulation entre l'art et l'Histoire.

Les cinéastes dont je présente des rétrospectives à Marseille entretiennent ce type de rapport, qu'il s'agisse de Jean-Pierre Gorin et de Werner Herzog l'année dernière, ou du cinéaste allemand Hartmut Bitomsky cette année, qui montre par exemple dans un de ses films, contrairement à l'idée répandue, que la construction par Hitler d'un complexe autoroutier en Allemagne correspondait moins à une visée utilitaire qu'à une exigence d'image. Cela est tout à fait fascinant.

Revenons au présent et aux événements qui ont marqué l'histoire récente du documentaire, à commencer par Etre et avoir de Nicolas Philibert, à la fois pour son impressionnante réussite commerciale et pour le procès qui s'est ensuivi à l'initiative de son personnage principal, l'instituteur Georges Lopez, qui s'estimait lésé par ce succès. 
Que pensez-vous, tant du succès, inattendu, du film que de la procédure, tout aussi surprenante, qui l'a suivie?

L'histoire du procès est évidemment très intéressante car elle montre avant tout que dans l'état de grande misère dans lequel nous vivons, la dernière chose dont les gens se sentent propriétaires, c'est leur image. Qu'on puisse vouloir s'approprier quelque chose qui est par essence de l'ordre de la dépossession me paraît étrange. D'un autre côté, ce dont atteste cette procédure, sans que cela doive remettre en cause l'honnêteté de Nicolas Philibert, c'est d'une protestation symptomatique contre la manière dont une certaine forme de documentaire a pu au cours de son histoire naturellement s'emparer du travail des gens, comme s'il s'agissait d'un acquis. Je pense qu'on est là dans ce qu'on pourrait appeler un inquestionné générique.

Quant au succès du film, on peut peut-être l'assimiler à celui de certaines expositions impressionnistes qui éludent la personnalité artistique des peintres au bénéfice du mouvement qui les rassemble : il y a un effet de nostalgie pour la pédagogie heureuse d'un monde perdu, celui d'une France du XIX ${ }^{\mathrm{e}}$ siècle, qui n'a sans doute jamais existé.

Autre événement d'importance, la Palme d'or accordée au Festival de Cannes en 2004 au documentaire anti-Bush de Michael Moore Fahrenheit 9/11... Comment analysez-vous cette récompense?

Dans la mesure où ce succès peut permettre la production et l'existence concomitantes d'aventures plus singulières, on ne peut que s'en réjouir. D'un autre côté, il faut bien dire que cette palme décrète la victoire d'une rhétorique télévisuelle dont la structure non déclarée est celle du procès. Cette forme, devenue largement majoritaire dans le documentaire, distribue les rôles des personnages conformément à un modèle destiné à faire éclater une vérité, à désigner des coupables et à instruire un châtiment.

Le film de Michael Moore, par son cadrage, par son montage, est exemplaire de cette mise en spectacle d'une conception policière des manifestations du sens. Que quelqu'un comme Charlton Heston, par exemple, en fasse les frais m'incommode. Car je n'oublie pas que Charlton Heston a produit, et joué dans La Soif du mal d'Orson Welles, un film d'une tout autre complexité sur les rapports entre la vérité et la justice, et qu'il a également accompagné nombre de manifestations pour les droits civiques aux Etats-Unis. Tout n'est donc pas si simple. Les films les plus passionnants sont, me semble-t-il, ceux qui remettent délibérément le genre à l'épreuve d'une scénographie qui échappe à ce cadre juridique.

Pour moi, le documentaire est un poème sur l'actualité qui appelle à une relecture constante. C'est un outil de compréhension du monde qui utilise des clés parfois étranges, mais surtout pas des passe-partout qui font semblant d'ouvrir des portes pour mieux les verrouiller.

Un dernier succès en date, qui a celui-ci véritablement défrayé la chronique, est celui du Cauchemar de Darwin d'Hubert Sauper qui se veut, à partir d'une situation locale, une métaphore de l'exploitation de l'Afrique par l'Occident. Votre sentiment sur ce qui est devenu une affaire non seulement cinématographique mais aussi politique? 
Ce qui m'a étonné dans cette histoire, c'est, justement à la faveur de l'aspect politique de la polémique, l'aveuglement total au geste cinématographique. Je déplacerai donc la question sur le terrain esthétique en disant que ce film a manifestement choisi la courte focale. Cela signifie que le réalisateur a délibérément décidé d'être très proche de ce qu'il filme, de placer tous les événements sur un seul plan, d'éviter la profondeur de champ.

Etait-ce, sur le plan métaphorique, la meilleure focale ? Etait-ce, en d'autres termes, la distance la plus adéquate, la plus juste, pour évoquer ce sujet ? Je ne sais pas. Mais peut-on autant reprocher à un film, comme on l'a beaucoup fait pour celui-ci, ce qui n'entre visiblement pas dans son champ de vision et donc dans son projet ? Je crois qu'on n'a pas assez vu que le film d'Hubert Sauper reposait aussi sur une sorte de naïveté et de propos métaphorique qui proposaient un type de contrat particulier.

Beaucoup de réalisateurs et de producteurs se plaignent du formatage de plus en plus strict imposé par le principal bailleur de fonds du genre qu'est la télévision. En êtes-vous d'accord, et de quels horizons, dans ce cas, viennent les recherches les plus novatrices?

C'est évidemment une question fondamentale. Même s'il ne faut pas verser dans l'accusation systématique de la télévision, qui permet toujours, même si c'est trop rarement, à certains projets singuliers d'exister, force est de constater, en effet, que les tentatives les plus fructueuses, les films qui font avancer le genre, sont très souvent, aujourd'hui, des oeuvres autoproduites. Cela a été rendu possible grâce aux nouvelles technologies, qui permettent désormais une indépendance presque totale à l'égard des critères classiques de production, depuis le coût de financement jusqu'à la présence d'une équipe en passant par les contraintes de durée ou de sujets.

Tous ces impératifs, qu'il ne faut surtout pas mésestimer au nom du romantisme de l'artiste tout-puissant, tendent malgré tout à produire des oeuvres qui finissent structurellement par toutes se ressembler en dépit de leurs velléités de ne pas entrer dans le moule. Prenez le Français Olivier Zabat avec 1/3 des yeux, prenez le Chinois Wang Bing avec A l'ouest des rails, ce sont des gens qui ont travaillé longtemps seuls, à l'écart des circuits cinématographiques et du confort, même relatif, qu'ils procurent, et qui ont créé des formes qui bouleversent totalement le genre.

L'histoire de l'art, de Franz Kafka employé dans une compagnie d'assurances jusqu'à Francis Ponge qui travaillait à l'EDF, nous montre que la création n'est pas nécessairement l'apanage de gens qui s'y consacrent exclusivement, en vertu du respect et du luxe dévolu en France au statut d'auteur de cinéma, statut dont on sait combien il a été dévoyé, y compris dans le domaine du documentaire, depuis son invention par la Nouvelle Vague.

Jean-Pierre Rehm est directeur artistique du Festival international du documentaire de Marseille depuis 2001. Il travaille à l'Ecole des beaux-arts de Lyon

Propos recueillis par Jacques Mandelbaum Illustration d'Aline Bureau Article paru dans l'édition du 02.07.06

http://www.lemonde.fr/web/article/0,1-0,36-790657,0.html

http://www.lemonde.fr/web/article/0,1-0,36-790657@45-1,0.html 


\section{Les places boursières rebondissent}

LE MONDE | 01.07.06 | 13h23 • Mis à jour le 01.07.06 | 13h23

Les grandes places boursières sont-elles en train de sortir de l'ornière ? Cette semaine, les principaux indices ont fortement progressé des deux côtés de l'Atlantique. Le Dow Jones a gagné 1,47 \%. Le Nasdaq composite, riche en valeurs technologiques, a bondi de 2,39\%.

Dans le sillage de Wall Street, le CAC 40, à Paris, a progressé de 3,08 \% en cinq jours, revenant tout près des 5000 points (à 4 965,96 points). A Londres et à Francfort, les indices Footsie et DAX ont respectivement gagné $2,48 \%$ et $2,78 \%$.

Sur les places asiatiques, les rebonds ont également été significatifs. A Tokyo, l'indice Nikkei a ainsi terminé la semaine en hausse de 2,52 \%.

Le bilan boursier du premier semestre reste mitigé. L'indice Standard \& Poor's 500 ne progresse que d'un peu moins de $2 \%$ depuis le début de l'année, alors que le Nasdaq recule de 1,5\%. A Paris, le CAC 40 gagne $5,32 \%$ depuis le $1^{\mathrm{er}}$ janvier, soit deux fois moins qu'au début du mois de mai.

Cette semaine, la principale raison de la hausse est le bon accueil réservé par les investisseurs à la décision de la Réserve fédérale américaine (Fed), jeudi 29 juin. Cette dernière a relevé ses taux d'intérêt directeurs de 25 points de base (à 5,25 \%).

Certains analystes redoutaient un resserrement monétaire de 50 points de base. Surtout, beaucoup ont voulu voir dans les propos des banquiers centraux des raisons de penser que le cycle de hausse des taux était sur le point de prendre fin.

Mi-mai, les investisseurs avaient été ébranlés dans leurs certitudes quand la Fed avait laissé entendre qu'elle ne négligeait aucune hypothèse, y compris celle d'une poursuite de la hausse de ses taux directeurs.

Les analystes pensaient au contraire qu'elle s'apprêtait à marquer une pause. Les hausses de taux sont a priori pénalisantes pour les marchés boursiers car elles rendent les placements en actions moins attractifs.

La progression plus rapide que prévu des indices de prix aux Etats-Unis ainsi que des déclarations des membres de la Fed ont ensuite renforcé ce scénario, faisant plonger, par à-coups, les grandes Bourses mondiales durant tout le mois de mai.

Les places émergentes, considérées comme plus risquées, ont connu des vagues de désinvestissements encore plus importantes de la part des gérants de fonds occidentaux.

Aujourd'hui, un nouveau scénario de pause dans la hausse des taux de la Fed se redessine-t-il ? 
Les analystes de la société française Global Equities en doutent. Selon eux, " la réaction euphorique et haussière du marché actions américain juste après le communiqué du comité de politique monétaire (de la Réserve fédérale américaine) est surprenante". "L'anticipation d'une croissance qui progresse moins vite, et qui peut générer des craintes déflationnistes et peser sur les marges des entreprises, conjuguée à une éventuelle nouvelle hausse des taux directeurs, n'aurait pas dû provoquer l'optimisme du marché", ajoutent-ils.

Pour François Chevallier, stratège chez VP Finance, à Paris, l'investisseur a le choix entre deux stratégies. "Il peut parier sur le fait que les fins de cycle de hausse des taux s'accompagnent souvent d'un rallye boursier, comme en 1989 et en 1995. D'autant qu'aujourd'hui, les actions américaines et européennes sont sous-évaluées et peuvent encore progresser", explique M. Chevallier.

L'investisseur peut au contraire choisir la prudence, au vu de la nouvelle flambée des prix du pétrole et de l'affaiblissement du dollar face à l'euro, qui pourraient peser, notamment sur les actions européennes. Le baril de pétrole brut coté à New York s'est renchéri de 3 dollars cette semaine, à plus de 73 dollars vendredi 30 juin.

"Les stocks d'essence sont particulièrement surveillés par les opérateurs, et les craintes de possibles pénuries au début de la saison de conduite automobile continuent de soutenir les prix", selon les analystes de la banque Citigroup.

Cécile Ducourtieux

Article paru dans l'édition du 02.07.06

http://www.lemonde.fr/web/article/0,1-0,36-790649,0.html 


\section{Daft Punk, fastueux crescendo électro}

LE MONDE | 01.07.06 | 14h24 • Mis à jour le 01.07.06 | 14h24 BELFORT ENVOYÉ SPÉCIAL

A 2 heures et demie du matin, l'immense pelouse qui s'étend au pied de la grande scène des Eurockéennes est encore noire de 30000 personnes.

Le 30 juin, la journée d'ouverture de la dix-huitième édition du festival belfortain, qui se terminera le 2 juillet, a jusque-là déroulé des concerts d'une excitation assez routinière (Anaïs, Deftones, Arctic Monkeys, The Strokes). Mais on pressent qu'un événement se prépare derrière le grand rideau sombre. Daft Punk vient de lancer sa première tournée mondiale depuis près de dix ans. Et ce concert est leur seule date française.

Le duo formé par les Français Thomas Bangalter et Guy-Manuel de Homem-Christo (Le Monde du 30 juin) a longtemps fait de la surprise un mode de fonctionnement. Dans les deux premiers albums (Homework et Discovery), la découverte de leur musique s'accompagnait nécessairement de l'étonnement de nouveaux sons et images, mettant en scène leur anonymat via la naissance d'alter ego cybernétiques. Cette course à la sensation, doublée d'un don pour les défoulements extatiques, en avait fait des stars internationales de la génération house et techno.

En 2005, un troisième album (Human After All) mettait en sourdine cette quête de spectaculaire et décevait en conséquence. Leur retour sur scène correspond à une remise à niveau de leur capacité de surprendre.

A la tombée du rideau apparaît une pyramide, au sommet soulevé comme un chapeau. Retentissent soudain les cinq notes qui, dans le film Rencontres du troisième type, servaient à dialoguer avec les extra-terrestres. Sanglés de cuir, coiffés de casques intégraux futuristes, les Daft prennent alors les commandes en haut du monument.

\section{TENDUS VERS L'EFFICACITÉ}

Ce ne sont encore que des contre-plongées de lumières blanches et des lignes blafardes, projetées au son du mot "robot" épelé au Vocoder, mais la limpidité de la puissance numérique et la cohérence graphique impressionnent déjà.

Tout n'ira ensuite que crescendo. Certes, on retrouve l'art originel du groupe, né de l'observation des meilleurs DJ. Dans leurs ordinateurs, ils ont stocké toutes leurs musiques mixées dans l'instant, tendues vers l'efficacité de l'impact dynamique et de la danse. Le duo reste statique sur son perchoir, mais les sons et lumières fusionnent et virevoltent avec une époustouflante magie. Dans la première demi-heure, c'est une ruche de néons, de figures dessinées sur des écrans géants. Puis la pyramide elle-même s'anime d'une géométrie en trois dimensions, embarquée dans un voyage sidéral. 
A chaque seconde son ébahissement : un concert inoubliable, que des milliers de spectateurs cherchent à immortaliser sur leur téléphone portable.

Stéphane Davet

Article paru dans l'édition du 02.07.06

http://www.lemonde.fr/web/article/0,1-0,36-790686,0.html 


\title{
Chronique
}

\section{Maigret chez les aristos, par Dominique Dhombres}

\author{
LE MONDE | 01.07.06 | 13h18
}

L'église catholique, apostolique et romaine joue un grand rôle dans ce Maigret-là. Elle inspire la plus grande dévotion à Jacotte, gouvernante depuis près d'un demi-siècle d'un diplomate, le comte de SaintHilaire. Autant ou presque que le comte lui-même, dont elle a jadis été la maîtresse.

Et voilà qu'on retrouve le noble vieillard tué de quatre balles de revolver dans le bureau de son hôtel particulier de la rue Saint-Dominique. Il écrivait ses Mémoires, en prenant garde de n'égratigner personne. Il avait aussi écrit des milliers de lettres passionnées à Isabelle, l'amour de sa jeunesse, qu'il n'avait pu épouser, faute d'argent, et qui était devenue princesse de Wissemberg à la suite d'un mariage de raison. Il avait continué à l'aimer, sans jamais la revoir. Il y a beaucoup d'aristocrates et presque autant de crucifix dans "Maigret et la princesse", diffusé vendredi 30 juin sur France 2. Et toujours la musique, inquiétante, grinçante et prenante de Laurent Petitgirard, qui est la marque de fabrique de cette série. On ne s'en plaindra pas. Voilà quinze ans que Bruno Cremer est le célèbre commissaire divisionnaire à la télévision. Cela avait commencé en 1991 avec "Maigret et la Grande Perche" pour ce qui était alors Antenne 2.

Depuis lors, c'est toujours la même lenteur, une façon d'enfiler son manteau ou de fumer sa pipe qui n'appartient qu'à lui. Un regard lourd aussi, sur les intérieurs et sur les gens. Une manière d'attendre qu'ils se dévoilent eux-mêmes. Cette fois-ci, en outre, Maigret retrouve une atmosphère qu'il a connue dans sa jeunesse, lorsque son père était régisseur d'un château. Il a du mal à brusquer ces gens-là, qui semblent taillés d'une autre étoffe. Plutôt que d'entrer au salon, il préfère rester à l'office, en quelque sorte. Il piétine, tâtonne, fait retourner le jardin de l'hôtel particulier, boit le vin blanc et mange en connaisseur le lapin aux champignons de la gouvernante.

L'affaire est des plus singulières, car le comte de Saint-Hilaire était un vieillard et n'avait pas d'ennemis. On ne vous donnera pas ici le mobile, et encore moins l'explication de ce crime qui n'en est pas un, car ce téléfilm est promis à de nombreuses rediffusions, et ce serait gâcher. Tout au plus faut-il regarder attentivement du côté des prie-Dieu et autres missels qu'affectionne Jacotte.

Colette Renard, en gouvernante dévote, mais qui n'a pas toujours été que cela, forme un duo d'enfer, si on ose, avec Bruno Cremer. Le commissaire a raison de ne pas la bousculer. Entre trois Pater, deux Ave et une visite à Sainte-Clotilde, elle finira bien par se confesser à lui aussi.

DOMINIQUE DHOMBRES

Article paru dans l'édition du 02.07.06

http://www.lemonde.fr/web/article/0,1-0,36-790688,0.html 
Chronique du médiateur

\section{Les vacances d'un ministre, par Robert Solé}

LE MONDE | 01.07.06 | 13h16 • Mis à jour le 01.07.06 | 13h16

Son courriel portait un point d'exclamation rouge. Ce qui veut dire qu'il était "envoyé avec une importance haute", selon le charabia informatique.

"Le sujet me semble infiniment plus important que la plupart des cas dont vous traitez, m'écrivait ClaudeJean Bertrand, du Vésinet (Yvelines). Le 10 juin, à l'émission "Tout le monde en parle", de Thierry Ardisson, le ministre des affaires étrangères, Philippe Douste-Blazy, a démenti toutes les critiques que lui avait adressées Le Monde dans un article exceptionnellement virulent." Et notre lecteur, qui est aussi un universitaire, spécialiste des médias, me sommait de trancher : "De deux choses l'une, soit il a dit la vérité et il convient que Le Monde démente à son tour et s'excuse pour une attaque indécente dans un journal de qualité. Soit il a menti derechef, avec plus d'insolence que jamais, et il mérite d'être à nouveau cloué au pilori."

Le portrait de Philippe Douste-Blazy publié dans Le Monde du 28 avril n'était pas vraiment une hagiographie. "Le ministre des affaires étrangères ne parle pas l'anglais, ni l'espagnol, ni aucune autre langue que le français, écrivait Raphaëlle Bacqué. Il ne pratique pas non plus le langage diplomatique qui oblige à peser la moindre virgule..."

La journaliste du Monde indiquait entre autres que le chef de la diplomatie française aurait confondu en public Taïwan et la Thaïlande. Lors d'une visite au Musée Yad Vashem de la Shoah, à Jérusalem, il se serait inquiété des juifs tués en Angleterre pendant la seconde guerre mondiale, s'attirant une réponse gênée du conservateur : "Mais, M. le ministre, l'Angleterre n'a pas été occupée par les nazis." Sans sourciller, le ministre aurait repris : "Mais il n'y a pas de juifs expulsés d'Angleterre ?"

De manière plus générale, Raphaëlle Bacqué insistait sur la "désinvolture" de Philippe Douste-Blazy "à l'égard de l'argent de l'Etat, de l'amitié, de la fidélité", ajoutant: "La plupart de ses anciens collaborateurs l'ont quitté, exaspérés par sa légèreté et son insatiable ambition. Pire, beaucoup lui reprochent de mentir partout sur tout, à tous."

Le ministre des affaires étrangères n'a pas écrit au Monde pour protester et exercer un droit de réponse. Ce n'est que six semaines plus tard, interrogé à l'antenne par Thierry Ardisson, qu'il a dénoncé "un tissu de mensonges". Oui, il parle anglais ; non, il n'a pas confondu Taïwan et Thaïlande ; non, il n'a pas prononcé les propos qui lui ont été attribués à Jérusalem... Ce n'est "pas vrai", c'est "totalement faux", c'est "ridicule"...

Thierry Ardisson n'a pas insisté. D'ailleurs, le public présent dans le studio, venu goûter des plats plus pimentés, semblait impatient d'applaudir d'autres invités : Dominique Ambiel, Pascal Olmeta, Pauline Ester, DJ Roudoudou... 
Raphälle Bacqué ne retire pas un mot de ce qu'elle a écrit. "En tant que journaliste politique, précise-t-elle, je connais Philippe Douste-Blazy depuis 1992. Tous les faits relatés dans mon papier ont été recoupés quand ils n'ont pas été directement constatés, par moi-même ou par des correspondants du Monde à l'étranger. Dans ses visites, le ministre est toujours accompagné par quantité de journalistes. C'était le cas au Musée de la Shoah à Jérusalem, et l'incident a d'ailleurs été rapporté par la presse israélienne."

Ce n'est pas la première fois que Le Monde consacre une double page à un ministre en exercice. S'intéresser à Philippe Douste-Blazy était d'autant plus justifié qu'il occupe un poste-clé et que des journaux étrangers se sont interrogés sur ses prestations diplomatiques.

Un lecteur internaute, Xavier Barthe, m'écrit : "Le ton perfide de cet article m'a profondément déplu. Je l'ai trouvé humainement blessant et intellectuellement peu convaincant."

Bien que très sévère, le portrait du Monde ne passait pas sous silence les qualités du ministre : habile, séduisant, audacieux, pour ne pas dire culotté, Philippe Douste-Blazy sait prendre des risques. Ce médecin qui a été happé par la politique ne s'illusionne pas sur ses compétences géostratégiques, mais croit dur comme fer à son étoile et n'est pas homme à se frapper la tête contre les murs pour avoir commis un lapsus.

La double page du Monde contenait un article d'accompagnement, également signé de Raphaëlle Bacqué, ayant pour titre : "Que s'est-il passé à la Mamounia ?" On y apprenait que, le 31 décembre 2005, en vacances dans le célèbre hôtel de Marrakech, Philippe Douste-Blazy s'était violemment disputé avec sa compagne, une productrice de télévision. "Un différend peu discret, était-il précisé, puisque des voisins du couple, au troisième étage de l'hôtel, ont pu en suivre les péripéties et voir le ministre et sa compagne, légèrement vêtus, s'invectiver dans le couloir."

Des lecteurs ont été choqués que Le Monde reprenne cette information, révélée par Le Canard enchaîné. Nicole Truffaut (Compiègne), par exemple, dénonce "un article de concierge, fait de ragots de bas étage, sur la vie privée du ministre".

Le Monde a estimé au contraire que cela ne pouvait être réduit à une simple dispute. "La scène a fait l'objet de plusieurs notes au sein du Quai d'Orsay et d'un rappel à l'ordre de l'Elysée", remarque Raphälle Bacqué. Dans son article, elle racontait que sur le passage du ministre, à l'Assemblée nationale, des députés de l'opposition, la mine épanouie, murmuraient : "Mamounia ! Mamounia !"

Au début de 2006, Le Monde n'avait rien dit de l'incident de Marrakech. Etait-il nécessaire d'en faire état de manière aussi détaillée quatre mois plus tard, à l'occasion d'un portrait de Philippe Douste-Blazy ? Je n'en suis pas convaincu. Ce portrait redoutable, illustré par divers épisodes, n'avait pas besoin d'un deuxième article, entièrement consacré à une scène de ménage.

Un débat a eu lieu à ce sujet avant que Raphaëlle Bacqué ne prenne la plume. Il y a vingt ans, la question ne se serait même pas posée : Le Monde faisait totalement silence sur la vie privée des personnages publics. Mais les médias français ont évolué dans ce domaine, encouragés parfois par les intéressés eux-mêmes, qui mettent en scène leur intimité quand cela les arrange. 
Où s'arrête la légitime information des citoyens ? Où commence le voyeurisme ? Un événement privé ne mérite de figurer dans Le Monde que dans deux circonstances : s'il a une incidence sur la vie publique ou s'il est indispensable pour connaître la personnalité d'un dirigeant.

La règle ne s'applique pas mécaniquement. Chaque cas appelle une évaluation. Mais, dans le doute, le silence est d'or.

\section{ROBERT SOLÉ}

Article paru dans l'édition du 02.07.06

http://www.lemonde.fr/web/article/0,1-0,36-790658,0.html 


\section{Les socialistes adoptent leur projet pour 2007}

LE MONDE | 01.07.06 | 13h43 • Mis à jour le 01.07.06 | 17h05

Les principaux dirigeants du PS et 900 délégués se sont retrouvés, samedi $1^{\mathrm{er}}$ juillet, à Paris lors d'une convention nationale exceptionnelle destinée à approuver le projet socialiste pour 2007. Le texte, déjà connu, ne sera plus complété que par quelques amendements. Vendredi soir, la direction du parti examinait, parmi 2000 propositions additionnelles envoyées par les fédérations, celles qui pourraient s'ajouter aux mesures déjà arbitrées. Un amendement de la fédération de Paris sur le "droit à mourir dans la dignité" a ainsi été retenu.

François Hollande compte en profiter pour lancer un appel à tous les socialistes, et en particulier aux présidentiables du parti, les invitant fermement à devenir "les promoteurs du projet". C'est que la compétition entre les prétendants à l'investiture présidentielle a relégué le texte au second plan. Signe de cet intérêt assez relatif : le 22 juin, lors du vote dans les fédérations, à peine la moitié des militants ont approuvé le document.

\section{"CHARTE ÉTHIQUE"}

Mais l'adoption finale du projet doit aussi permettre au premier secrétaire du PS sur lequel les pressions s'accroissent depuis le retour dans le jeu de Lionel Jospin, de faire passer un autre message. M. Hollande entend préciser, s'agissant du choix du candidat, qu'il se prononcera, pas avant septembre, pour "la solution la plus rassembleuse et la plus efficace". Ce, "en dehors de toute considération personnelle, amicale ou familiale", a-t-il confié au Monde.

Afin de contenir les tensions, le PS devrait se doter, pour la première fois, d'une "charte éthique", manuel de bonne conduite à usage des candidats. Un premier projet de douze articles a été préparé. Il stipule que les "candidats reconnaissent l'engagement socialiste de chacun d'entre eux", et qu'"ils veillent à ce que leurs propos et ceux de leurs soutiens ne puissent affaiblir l'image et le combat des socialistes dans l'objectif de gagner en 2007".

Samedi, le PS devait également approuver les candidatures pour les législatives de 2007 avec, pour objectif la parité, et trancher les cas de litige. Ces derniers concernent en particulier les candidats issus de l'immigration. M. Hollande devrait annoncer un accord avec le Parti radical de gauche qui se voit réserver une trentaine de circonscriptions. Les militants de ce parti pourraient être associés, dans un vote à part, à la désignation du candidat socialiste, renonçant ainsi au leur. Un autre accord devrait suivre avec le MRC de Jean-Pierre Chevènement.

Isabelle Mandraud

Article paru dans l'édition du 02.07.06

http://www.lemonde.fr/web/article/0,1-0,36-790632,0.html 


\section{Droits d'auteur : ce qui va changer}

LE MONDE | 01.07.06 | 14h19 • Mis à jour le 01.07.06 | 14h19

Au terme d'une séance houleuse et de débats enflammés, les députés et les sénateurs ont définitivement adopté, vendredi 30 juin, la loi sur les droits d'auteur et les droits voisins sur Internet. Examiné depuis Noël 2005, profondément remanié par les deux chambres, ce texte a mis en ébullition les partis politiques et a fait l'objet de critiques multiples. La loi, qui intègre dans le droit français une directive européenne de 2001, vise à protéger l'auteur sur Internet tout en respectant la liberté de l'internaute. En voici les points principaux.

Les sanctions. Le nombre d'internautes fraudeurs est évalué à près de huit millions en France. Ils encourent des sanctions graduées, en fonction de la gravité de la faute. Le gouvernement pénalise plus fortement les "dealers" que les consommateurs. Des contraventions, de 38 à 150 euros réprimeront les échanges illicites d'oeuvres en ligne, selon qu'il s'agit d'une simple reproduction ou d'une mise à disposition massive d'oeuvres protégées. Ces amendes seront-elles dissuasives ? Des décrets préciseront la façon dont elles seront appliquées.

Le détenteur ou l'utilisateur d'un logiciel de contournement des mesures techniques de protection (MTP) est, lui, passible de 750 euros d'amende. Un "hacker" qui décrypte ces MTP risque 3750 euros d'amende. Les pourvoyeurs de moyens de contournement s'exposent à dix mois d'emprisonnement et 30000 euros d'amendes.

L'exception pédagogique. A compter du $1^{\mathrm{er}}$ janvier 2009, une exception pédagogique s'appliquera aux droits d'auteurs, à des fins d'illustration dans le cadre de l'enseignement et de la recherche. Elle sera compensée par une rémunération négociée sur une base forfaitaire pour les auteurs. La loi prévoit aussi des exceptions au droit d'auteur en faveur des bibliothèques, musées, services d'archives, et des handicapés.

Création d'une autorité administrative indépendante. La loi crée une autorité de régulation des mesures techniques (six membres nommés par décret pour six ans). Dotée de compétences judiciaires et techniques, cette instance tranche les conflits dans les domaines de la copie privée et de l'interopérabilité.

La copie privée. Le nombre de copies d'une oeuvre pour un usage personnel n'est pas fixé par la loi. L'Autorité de régulation le définira pour chaque support (CD, DVD, etc.).

L'interopérabilité. Actuellement, la plate-forme iTunes d'Apple n'est accessible que depuis le baladeur numérique iPod. La loi vise au contraire à permettre au consommateur de lire des fichiers musicaux WMA (Windows de Microsoft) ou iTunes, achetés par l'internaute, sur n'importe quel lecteur MP3 ou ordinateur. Cette interopérabilité a été rognée par rapport au texte voté par les seuls députés. Mais la France est le seul pays à inscrire un tel principe dans une loi et à aller aussi loin. 
En cas de pratiques anticoncurrentielles, les éditeurs de logiciels, fabricants de systèmes techniques et exploitants de service doivent donner accès aux informations essentielles pour l'interopérabilité. S'ils refusent, l'autorité administrative pourra trancher la question dans les deux mois.

Mais les industriels peuvent conserver leur secret s'ils apportent la preuve que la publication de la documentation de leur logiciel "porte atteinte à la sécurité et à l'efficacité de ladite mesure technique". Cette mention fait dire à certains que le gouvernement a "capitulé devant Apple et Microsoft".

\section{Nicole Vulser}

Article paru dans l'édition du 02.07.06

http://www.lemonde.fr/web/article/0,1-0,36-790680,0.html 
Des moyens provisoires pour la psychiatrie à Fresnes

Article publié le 01 Juillet 2006

Par Nathalie Guibert

Source : LE MONDE

Taille de l'article : 277 mots

Extrait : L'ALERTE lancée dans nos colonnes par le médecin-chef psychiatre de la prison de Fresnes (Val-de-Marne), Christiane de Beaurepaire ( Le Monde des 7-8 mai), qui avait annoncé qu'elle cesserait le travail le 30 juin en raison du manque de moyens de son service, a provisoirement payé. Quatre étudiants en médecine vont permettre au service médico-psychologique régional (SMPR) de Fresnes d'assurer les soins dans la maison d'arrêt durant l'été. L'hôpital Paul-Guiraud de Villejuif, dont dépend le SMPR, a recouru à une agence d'intérim. La situation était potentiellement explosive : pour 2000 détenus, le SMPR n'aurait disposé, à partir de juillet, que de moins d'un poste d'infirmier en équivalent temps plein.

http://www.lemonde.fr/cgi-

bin/ACHATS/acheter.cgi?offre=ARCHIVES\&type_item=ART_ARCH_30J\&objet_id=951140

JEAN-MARIE LEBLANC DIRECTEUR DU TOUR DE FRANCE « C'est un geste courageux et un bon exemple pour les autres directeurs sportifs »

Article publié le 01 Juillet 2006

Par Propos recueillis Evelyne Vincent

Source : LE MONDE

Taille de l'article : 655 mots

Extrait : Quelle est votre réaction après la décision de l'équipe allemande T-Mobile d'exclure de son équipe Jan Ullrich ? Je trouve ça normal, dans ce contexte, avec les preuves qui existent. Mais je ne peux pas m'empêcher de constater que c'est un geste courageux et un bon exemple pour les autres directeurs sportifs. Aujourd'hui, on ne peut plus faire que ça : être courageux. Face à une affaire de telle ampleur, où sont impliqués des coureurs du peloton, le Tour de France peut-il, légitimement, toujours partir ? Pourquoi ne partirait-il pas ? Si la justice espagnole nous disait : attention, sur vos 200 partants du Tour, nous en avons 150 sur nos listes, alors là, on pourrait se poser la question.

http://www.lemonde.fr/cgi-

bin/ACHATS/acheter.cgi?offre=ARCHIVES\&type_item=ART_ARCH_30J\&objet_id=951163

Adidas, en force

Article publié le 01 Juillet 2006

Par Gérard Coudert

Source : LE MONDE

Taille de l'article : 378 mots

Extrait : Avantage Adidas. A l'aube des quarts de finale du Mondial, la firme allemande est en position de force avec encore trois équipes sous contrat dans la compétition : l'Allemagne, la France et l'Argentine. L'équipementier, qui avait six « clients » au début de la compétition, devance son principal concurrent, Nike, qui n'en a plus que deux - le Brésil et le Portugal. Viennent ensuite Puma (Italie), Umbro (Angleterre) et Lotto (Ukraine). Adidas aura fatalement une équipe en moins dès le prochain tour - Allemagne et Argentine se rencontrent samedi. Mais, même si le Brésil reste le grand favori, la marque aux trois bandes est assurée de faire de bonnes affaires grâce à ce Mondial.

http://www.lemonde.fr/cgibin/ACHATS/acheter.cgi?offre=ARCHIVES\&type_item=ART_ARCH_30J\&objet_id=951201 


\section{Wimbledon : deux Françaises qualifiées pour les huitièmes de finale}

LEMONDE.FR | 02.07.06 | 08h33 • Mis à jour le 02.07.06 | 08h33

Un duo féminin, Amélie Mauresmo et Séverine Brémond, défendra les chances du tennis français en huitièmes de finale de Wimbledon après la défaite du dernier homme en lice, Sébastien Grosjean.

Mauresmo a vécu une première semaine bien tranquille. Samedi $1^{\mathrm{er}}$ juillet elle a battu samedi l'Australienne Nicole Pratt en deux sets 6-1, 6-2 pour rejoindre Brémond, qui avait créé une belle surprise la veille en gagnant sa place en deuxième semaine pour la première fois de sa carrière.

Mauresmo, tête de série $n^{\circ} 1$ pour la première fois à Wimbledon, s'est promenée samedi de la même manière que lors des deux premiers tours. Pour son entrée dans le tournoi, elle avait balayé la Croate Ivana Abramovic 6-0, 6-0. Au tour suivant, l'Australienne Samantha Stosur ne lui avait guère posé plus de problèmes $(6-4,6-2)$.

Fidèle au service-volée qui lui a toujours bien réussi à Wimbledon, où elle reste sur trois demi-finales lors de ses trois dernières participations (2002, 2004, 2005), la n¹ mondiale n'a fait qu'une bouchée de Pratt, une des anciennes du circuit à 33 ans.

La Française a quand même eu une grosse déception, celle d'avoir vu rejetée la demande de changement d'horaire qu'elle avait formulée auprès des organisateurs afin de pouvoir suivre tranquillement le match de Coupe du monde France-Brésil.

Au contraire, la fin du match entre le Croate Mario Ancic et le Suisse Stanislas Wawrinka, interrompue par la nuit vendredi, a été ajoutée au dernier moment au programme du court $\mathrm{n}^{\circ} 2$, repoussant d'autant le début de sa rencontre. "J'ai fait une Nalbandian, mais ça n'a pas marché", a dit la Française, dans une allusion à l'Argentin qui lui avait obtenu de jouer plus tôt pour voir Argentine-Allemagne.

\section{GROSJEAN ÉCHOUE}

En huitièmes de finale, les choses risquent de se corser face à Ana Ivanovic ( $\left.\mathrm{n}^{\circ} 19\right)$, une joueuse qui ne rappelle pas que des bons souvenirs à Mauresmo. C'est contre la Serbe de 18 ans, un des grands espoirs du tennis mondial, que la $n^{\circ} 1$ tricolore avait échoué au troisième tour de Roland-Garros en 2005 . Mais Mauresmo est nettement moins vulnérable sur l'herbe anglaise que devant le public parisien.

Sébastien Grosjean s'est incliné face au Chypriote de Paris Marcos Baghdatis, l'étonnant finaliste de l'Open d'Australie qui avait eu depuis quelques difficultés à confirmer son parcours à Melbourne.

Battu en quatre sets 4-6, 6-4, 6-4, 6-4, le Marseillais enregistre son plus mauvais résultat à Wimbledon depuis 2001. Il restait sur un quart de finale (2005) et deux demi-finales (2003, 2004) dans le tournoi du Grand Chelem où il a été le plus régulier. 
Grosjean a commis beaucoup trop d'erreurs (45 contre 23) pour inquiéter le Chypriote de Paris, qui n'est pourtant pas connu comme un spécialiste du gazon.

\section{Avec AFP}

http://www.lemonde.fr/web/article/0,1-0,36-790938,0.html 


\section{L'ancien dictateur tchadien Hissène Habré sera jugé au Sénégal}

LEMONDE.FR | 02.07.06 | 17h18 • Mis à jour le 02.07.06 | 17h18

Nous avons pensé que le Sénégal était le pays le mieux placé pour juger [Hissène Habré] et je pense que nous ne devons pas fuir notre responsabilité", a déclaré le président sénégalais, Abdoulaye Wade, lors du sommet de l'Union africaine (UA) à Banjul. "Les Africains doivent être jugés en Afrique, c'est pourquoi j'ai refusé l'extradition de Hissène Habré vers la Belgique", a-t-il ajouté, écartant également l'idée d'une transmission de la procédure belge à la justice sénégalaise.

"Ce n'est pas un problème facile, il concerne l'ensemble du continent africain", a poursuivi M. Wade, qui a demandé l'assistance de l'UA pour l'organisation du procès. "Notre souci est la recherche de la vérité, autant pour Hissène Habré que pour les prétendues victimes", a-t-il conclu.

Réfugié au Sénégal, l'ancien chef de l'Etat tchadien a été inculpé par un tribunal belge pour crimes contre l'humanité, crimes de guerre et actes de torture, sur plainte de trois Belges d'origine tchadienne pour des atrocités commises lorsqu'il était au pouvoir de 1982 à 1990.

\section{HRW SE FÉLICITE DE CETTE DÉCISION}

Après avoir refusé de le juger en 2001, la justice sénégalaise s'est déclarée incompétente en novembre 2005 pour statuer sur une demande belge d'extradition. Le président sénégalais avait alors renvoyé l'affaire devant l'UA afin de trouver une solution.

Les responsables africains réunis à Banjul ont examiné dimanche matin le rapport d'un comité d'experts mandaté par l'UA en janvier lors du sommet de Khartoum, qui a préconisé dans ses conclusions de privilégier une solution africaine à cette affaire, a-t-on appris de source diplomatique africaine. Trois options ont fait l'objet des discussions à huis clos des chefs d'Etat et de gouvernement des pays membres de l'UA réunis à Banjul : un procès devant la justice sénégalaise, le renvoi de l'ancien président tchadien devant un tribunal de son pays et son jugement devant la cour africaine des droits de l'homme. C'est la première option qui a finalement été retenue.

"Si le Sénégal, qui a refusé de juger Hissène Habré il y a sept ans, s'engage maintenant, nous ne pouvons que nous réjouir", a réagi Reed Brody de Human Rights Watch (HRW), chef de file des ONG de défense des droits de l'homme qui assistent les victimes de l'ancien dictateur tchadien. "Il faut que le Sénégal fasse vite", a-t-il ajouté. Avant de souligner que "les victimes ont attendu quinze ans, cela fait sept ans que leur première plainte a été déposée et deux des sept premiers plaignants sont déjà morts".

Avec AFP

http://www.lemonde.fr/web/article/0,1-0,36-790997,0.html 


\section{Cristiano Ronaldo brille en sélection et irrite ses fans de Manchester}

LEMONDE.FR | 03.07.06 | 10h47 • Mis à jour le 03.07.06 | 11h02

Si Cristiano Ronaldo retourne dans son club de Manchester United après la Coupe du monde, l'accueil risque d'être houleux. Pas seulement parce que le milieu offensif portugais a demandé, après trois saisons, de quitter le nord de l'Angleterre pour rejoindre le Real Madrid de ses rêves.

A en croire la presse britannique, l'"autre Ronaldo" aurait été doublement responsable de l'élimination de l'Angleterre en quarts de finale du Mondial, samedi $1^{\text {er }}$ juillet, à Gelsenkirchen. Au passage, il aurait dilapidé son capital de sympathie auprès des supporteurs d'Old Trafford. Ceux-ci ne lui en voudront pas tant d'avoir inscrit le tir au but qui a scellé la victoire du Portugal. Quoique : à l'image du joueur, son geste ne fut pas franc du collier puisqu'il a ralenti son élan pour feinter Paul Robinson, ce qui aurait pu le contraindre à un nouvel essai.

"J'étais très confiant avant de tirer le penalty, fanfaronnait-il après le match. Je l'ai bien frappé et j'ai marqué un grand but." Grâce à lui, les Lusitaniens sont en demi-finales, stade qu'ils n'ont jamais atteint depuis le Mondial anglais de 1966. Ils rencontreront la France, mercredi 5 juillet, à Munich.

Ce que les Anglais n'oublieront pas, c'est cette $62^{\mathrm{e}}$ minute les condamnant à terminer la partie à dix. Lorsque le tempétueux attaquant de Manchester United Wayne Rooney a piétiné l'entrejambe de Ricardo Carvalho. Cristiano Ronaldo est sitôt allé rapporter le méfait à l'arbitre, ce qui a provoqué la fureur de Rooney contre son coéquipier mancunien. Pendant que le pitbull anglais rejoignait les vestiaires en shootant violemment dans une bouteille d'eau, Ronaldo adressait un clin d'œil malicieux au banc de touche portugais.

Le mouchard s'est ensuite absous : "On va dire que l'arbitre a donné un carton rouge parce que je lui ai parlé. Ce n'est pas vrai. Je lui ai parlé pour seulement signaler qu'il y avait une faute, pas un carton rouge." Dribbles inutiles Tous les footballeurs du dimanche ont croisé un jour Cristiano Ronaldo : c'est ce garçon brillantissime, techniquement dix crans au-dessus des autres, auquel on reproche de passer son temps à se plaindre auprès de l'arbitre et d'être trop individualiste. A 21 ans, le surdoué n'a pas encore acquis l'intelligence et la science du jeu de Luis Figo, avec lequel il permute souvent sur les deux flancs de l'attaque portugaise.

Contre l'Angleterre, le feu follet a pourtant effectué un grand match. Il a donné le vertige à son autre partenaire de club, le défenseur Gary Neville, par ses passements de jambe spectaculaires, sa rapidité et sa percussion. Ce ne fut pas toujours le cas au premier tour, où on le vit plus d'une fois s'enferrer dans des dribbles inutiles alors que des camarades étaient démarqués.

Cristiano Ronaldo s'attire facilement des ennemis. Sa présence était incertaine contre l'Angleterre. Il fut victime d'un double attentat au match précédent contre les Pays-Bas. Khalid Bouhlarouz vint s'essuyer les crampons sur la cuisse de l'homme à abattre, suivi de près par Mark Van Bommel. Ronaldo quitta la partie en pleurant et le match dégénéra. Les hooligans, si redoutés en dehors du stade, jouaient en fait sur la pelouse. 
L'ascension foudroyante de Cristiano Ronaldo Santos Alveiro a débuté en 2003. Pour ses 17 ans, le natif de Funchal, dans l'île de Madère, joue sous les couleurs du Sporting Lisbonne, qui l'emporte lors d'une rencontre amicale (3-1) contre Manchester United.

"Après notre match, les gars ne parlaient que de Ronaldo dans le vestiaire, a raconté Alex Ferguson, l'entraîneur du club mancunien. Dans l'avion du retour, ils m'ont prié de le faire signer." Pour 12 millions d'euros, Manchester double le Milan AC et la Juventus, qui le convoitaient également.

Dès sa première saison à Old Trafford, le gamin à houppette conquiert les cœurs, au point de prêter son visage à un jeu vidéo, "FIFA Street 2".

Curieusement, depuis le 1er juillet à Gelsenkirchen, la presse anglaise n'a pas de mots assez durs pour ce simulateur de haut vol. Comme si ses qualités appréciées sous le maillot de Manchester s'étaient transformées en défauts sous celui du Portugal.

Bruno Lesprit (envoyé spécial à Gelsenkirchen)

http://www.lemonde.fr/web/article/0,1-0,36-791113,0.html 


\section{Chronique \\ Le ciel et la Terre à domicile, par Laurent Greilsamer}

LE MONDE | 03.07.06 | 13h16 • Mis à jour le 03.07.06 | 13 h16

Planer. Poser un regard d'aigle sur toutes choses. Planer et voir défiler dans le lointain plaines et coteaux, villes et villages, forêts et prés, rivières et torrents. Planer sur un monde apaisé, plongé dans un silence entier et pur. Planer et dominer...

C'est une vieille histoire et un vieux rêve. Icare, ce jeune dieu grec fougueux, en sait quelque chose. Pour avoir cru possible de voler et s'être trop rapproché du soleil, cet imprévoyant a payé de sa vie son défi. On ne survolait pas impunément l'univers en ces temps immémoriaux. Le poète Pétrarque (1304-1374) n'avaitil pas eu l'impression de franchir une frontière invisible en gravissant le mont Ventoux et de pénétrer un monde inconnu, abandonné des hommes...

Aujourd'hui, des centaines de millions d'êtres humains survolent la terre chaque année. Et découvrent ou redécouvrent le plaisir de surplomber en avion leur Terre, la beauté et la grandeur des paysages du Nord et du Sud. C'est devenu un besoin. S'échapper par le haut. Quel que soit le point de vue. Les uns dorment dans les arbres ; les autres s'aventurent sur le viaduc de Millau ; d'autres encore grimpent sur le Toit du monde dans l'ébriété d'un air quasi inviolé.

Le survol est désormais à la portée de tous. Un vol gratuit, disponible à domicile. Un clic sur Internet, et vous voilà dans les airs. Pionnier en la matière, Google Earth a révolutionné les perspectives. L'irrésistible moteur de recherches américain vous permet de découvrir Bagdad vu du ciel comme si vous y étiez, La Nouvelle-Orléans comme vous ne voudriez pas y être. Cette fois, c'est l'Institut géographique national (IGN) qui propose à chacun de s'envoler au-dessus de la France et de zoomer à volonté sur les lieux qui lui sont le plus chers grâce au site Géoportail.

L'idée est tellement bonne que le site a failli sombrer sous la pression de la demande lors de son inauguration, le 23 juin. Comme si la France tout entière n'attendait que cela : se regarder, se contempler, s'admirer en son beau miroir. Des millions d'internautes se pressaient sur le seuil du tapis volant, et des millions de voyeurs, en quête d'images de leur quartier ou de leur maison de campagne, revenaient frustrés. Problèmes techniques... Le dimanche suivant, l'IGN comptabilisait encore plus d'internautes en mal de baptême de l'air virtuel.

Rassurons-nous : tout sera bientôt en état de marche. Et interrogeons-nous plutôt sur les raisons de ce formidable succès, comme sur le sacre planétaire du photographe Yann Arthus-Bertrand avec ses clichés pris du ciel et cette course au stockage d'impressions neuves. On aime survoler la Terre et la maison de son enfance dans un grand écart savant, on adore planer au-dessus de sa ville, on se surprend à jubiler en passant en rase-mottes au-dessus de sa rue. Une manière de se réapproprier le monde, de se rassurer en visionnant sous un angle inattendu des paysages familiers. Loin de la grande Histoire, on raffole de ces lieux de notre mémoire personnelle. Ce n'est plus une mode, mais un droit ! Un dirigeant de l'IGN cité par l'AFP déclare, sans rire, que cette ruée constitue "un élément très positif pour l'exercice de la citoyenneté". 
Au même moment, le site de l'Institut national de l'audiovisuel (INA) rencontre un engouement identique. Des millions d'internautes piochent dans les 100000 heures d'archives radiophoniques et télévisuelles proposées gratuitement en consultation. Chaque jour, l'INA enregistre près de 800000 pages lues. L'histoire retiendra un jour que les émissions les plus demandées sont actuellement "Les Shadoks", la série des "Rois maudits" et celle des "Cinq Dernières Minutes", après un plébiscite de Serge Gainsbourg à "Apostrophes" en 1986 et du discours d'André Malraux en 1964, à l'occasion de l'entrée au Panthéon de la dépouille mortelle de Jean Moulin. Un pot-pourri détonnant.

\section{Laurent Greilsamer}

Article paru dans l'édition du 04.07.06

http://www.lemonde.fr/web/article/0,1-0,36-791170,0.html 
Point de vue

Une complainte pour "Libé", par Bernard Lallement

LE MONDE | 03.07.06 | 13h22 • Mis à jour le 03.07.06 | 13h22

C'était, dans ces mêmes colonnes, le 23 décembre 1973. En compagnie de Jean-Paul Sartre, Philippe Gavi et Serge July, je signais un appel aux lecteurs du Monde afin qu'ils viennent en aide à Libération, que nous venions de créer sans argent ni publicité, et qui menaçait de s'arrêter faute de moyens. Une souscription populaire avait été lancée. L'émotion était immense. En quelques jours, des milliers de chèques et de billets de banque déferlèrent au siège de notre quotidien, toujours accompagnés d'un mot émouvant d'encouragement.

Dans l'histoire de la presse, il faut remonter à 1929, et à la liquidation de la Banque ouvrière et paysanne, soutien de L'Humanité, pour trouver un tel élan en faveur d'un journal. Plus de 500000 francs d'alors furent ainsi réunis, nous permettant d'éponger nos dettes. "La France d'en bas, celle des grands ensembles, des champs et des usines, celle du métro et des tramways prend la parole", affirmions-nous dans l'éditorial collectif du 22 mai 1973, annonçant notre parution quotidienne.

Cette France-là répondait à notre appel. Car le Libération de cette époque n'était pas n'importe quel journal. C'était notre "Libé". Né dans la mouvance post-soixante-huitarde, il faisait partie de ces aventures extraordinaires que forgent les rencontres fortuites d'improbables destins. Celles, d'abord, d'un ancien journaliste hippique et d'un dirigeant maoïste.

Le premier, Jean-René Huleu, publie à Bruay-en-Artois un bulletin ronéoté pour informer les mineurs. Le second, Jean-Claude Vernier, en rapporte l'idée d'un quotidien qu'il confie à Benny Lévy (alias Pierre Victor), dirigeant de la Gauche prolétarienne (GP). Ensuite, entre ce dernier et Jean-Paul Sartre, qui servait, déjà, de caution intellectuelle à La Cause du peuple. Avant d'être atteint de la maladie qui l'empêchera de s'en occuper activement, pour autant qu'on l'eût laissé faire d'ailleurs, il deviendra, tout naturellement, le premier directeur de publication de Libération.

Enfin viendront s'agréger : Philippe Gavi, ami de Michel Foucault, en provenance du groupuscule Vive la Révolution, moi-même qui, avec mon complice Gérald Bouf, avais fondé les Cahiers d'écologie politique, et toute une équipe, pour la plupart maoïstes, avec à leur tête Serge July, rapatrié pour l'occasion des corons du Nord où il représentait la GP sous le pseudonyme de Marc.

Le journal affichait une détestation ostentatoire de l'argent en général et des banquiers en particulier. Libération se voulait avec et pour le peuple. Son manifeste, publié le 5 février 1973, était sans équivoque sur ses intentions : "La majorité des rédacteurs de la presse quotidienne reçoit servilement des directives fabriquées dans les grands restaurants où se rencontrent les faiseurs de la politique officielle. Le journaliste de Libération s'informe dans les cités ouvrières, les quartiers populaires, les villages, parce qu'il y vit et qu'il y connaît des gens. (...) Pour le journaliste de Libération, plus on monte dans l'échelle sociale, plus on trouve de corruption, ce qui lui donne un critère dans son travail d'information." 
Dès les fonts baptismaux, le "réalisme économique" était forclos, de même que toutes les convenances d'un monde bourgeois. Cela n'eut pas que des effets négatifs, bien au contraire. La liberté de ton du journal, qui lui vaudra de nombreux procès, son impertinence, son humour décalé, l'utilisation, nouvelle à l'époque, du dessin et de la photographie ont renouvelé considérablement le traitement de l'information, l'affranchissant d'un style trop compassé.

Hélas ! La mythologie populaire ne peut suffire en elle-même. La réalité extérieure pointe son nez et s'instille, peu à peu, dans les bureaux de la rédaction. Une première crise éclate en mai 1974, divisant l'équipe sur l'avenir du journal et les moyens de dépasser le seuil de nos 35000 exemplaires quotidiens. Serge July plaide pour une "transformation qualitative et, avec elle, celle de l'outil Libération. (...) Il convient de sortir du gauchisme et d'être du côté de ce qui vit". Une partie de l'équipe, dont l'actuel directeur de la rédaction Antoine de Gaudemar, choisira de partir.

D'autres tumultes scanderont la vie de Libération. D'abord, celui de 1981, où le journal s'ouvre au marché publicitaire, ensuite financier, jusqu'à l'entrée dans le capital du président de France Galop.

Avec toujours le même homme qui, tel un fil rouge, dénoue les intrigues et relie les hommes. De nous tous, Serge July est le seul à s'être maintenu à la tête de l'entreprise, contre vents et marées, tel le capitaine de Baudelaire. Il en est la mémoire mais aussi l'incarnation. Il a toujours eu, avec son journal, un rapport anaclitique. C'est au travers de son regard que "Libé" voyait le monde. Celui-ci a évolué à son insu et a provoqué sa perte.

L'arrivée d'Edouard de Rothschild ne pouvait que conduire au divorce d'avec le directeur de Libération. Ce sera la dernière rencontre improbable de l'histoire du quotidien. Il y a trente ans, le premier aurait été honni par celui-là même à qui, hier, il vient de sauver la mise pour mieux, ensuite, tenter de la lui rafler au nom d'une logique financière trop longtemps ignorée.

Quelle que soit l'issue de cette énième crise, c'est toute une histoire qui se termine irrémédiablement. Celle où écrire était du sens, selon la belle formule de Claude Simon. Celle où il s'agissait d'enquêter puis d'informer, afin de permettre aux lecteurs de se forger une idée et non pas de leur en livrer une ? Prête à l'emploi. Celle des débats, des querelles, des critiques, des oppositions. Celle où la pensée tenait le haut du pavé et où nous n'avions pas, encore, abdiqué notre conscience sur l'autel du libéralisme. Celle de l'engagement dans lequel, pour reprendre une expression sartrienne, l'homme pouvait encore inventer son chemin.

De nos jours, où seuls les cours de la Bourse connaissent l'extase, les ratios de financement tiennent lieu de nouvelle grammaire. Les opinions, lorsqu'elles existent, sont calibrées, évaluées, sondées, expertisées avant que d'être exprimées. Même dans la création, l'originalité est devenue un produit de rebut.

Libération est né de la seule volonté d'une poignée de jeunes gens, armés de leurs seules convictions. Un tel dessein est devenu impensable. La presse, comme d'ailleurs l'édition, se sont constituées en filiales de groupes financiers, avec leurs "stratégies" propres. L'ontologie passe par pertes et profits, et les comptes d'exploitation sont autant de nouvelles chartes pour nos libertés. 
Aussi notre "Libé" tanguera-t-il vers La Nausée : "Il faudrait qu'on devine, derrière les mots imprimés, derrière les pages, quelque chose qui n'existerait pas, qui serait au-dessus de l'existence. Une histoire, par exemple, comme il ne peut pas en arriver, une aventure." Serge July, nouveau Roquentin des temps modernes, est le dernier acteur d'une invraisemblable destinée au terme de laquelle résonnent maintenant, comme un rappel à l'ordre, Les Mains sales de Sartre : "Tous les moyens sont bons quand ils sont efficaces."

Quant à Edouard de Rothschild, il aura tout loisir de méditer cette réplique de Nekrassov : "L'argent n'a pas d'idées."

Bernard Lallement, premier administrateur-gérant de "Libération", est l'auteur de "Libé, l'Euvre impossible de Sartre" (Albin Michel, 2004).

Article paru dans l'édition du 04.07.06

http://www.lemonde.fr/web/article/0,1-0,36-791233,0.html 


\section{Point de vue}

\section{Ensemble, modernisons la France, par Christian Blanc, Jean-Marie Bockel et Alain Lambert}

LE MONDE | 03.07.06 | 13h22 • Mis à jour le 03.07.06 | 13h22

Par manque de lucidité et de courage politique, la puissance publique française a peu à peu perdu contact avec la modernité. La situation est aujourd'hui dégradée à un point tel que l'équipe dirigeante qui sera élue en 2007 sera investie d'une responsabilité historique. Si la France ne renoue pas avec le dynamisme, le processus d'unification de l'Europe sera stoppé et l'ambition européenne d'une société solidaire dans une économie de marché réduite à néant. Rien ne pourra alors contrebalancer l'hégémonie des Etats-Unis et de la Chine, avec des risques pour la paix dans le monde.

La tâche est immense et ne peut plus être repoussée, sauf à prendre le risque de voir la France se désagréger dans des convulsions violentes. Mais la tâche est aussi délicate, elle ne pourra être menée à bien, le moment venu, que si elle a été bien préparée en amont. C'est pourquoi nous estimons que notre responsabilité d'élus est de mettre à profit l'année qui nous sépare des échéances électorales pour créer les conditions d'un sursaut collectif.

Dans ce but, nous avons décidé d'unir nos forces au sein d'un comité d'action pour la modernisation de la France. Cette démarche au-dessus des partis politiques est rendue possible par un diagnostic partagé et des convictions identiques sur la méthode pour réformer.

Le diagnostic peut être résumé en trois points.

Premièrement, l'économie française patine, elle ne profite pas du dynamisme mondial et gâche ses potentiels, ce qui se traduit par une croissance molle.

Deuxièmement, rares sont les domaines d'intervention de la puissance publique qui n'ont pas besoin d'une refonte de leurs modes de fonctionnement. Education, solidarités, recherche... Partout l'organisation est inadaptée. A tel point que même une augmentation des moyens ne permettrait pas de progrès sensibles.

Troisièmement, l'endettement de l'Etat a atteint un niveau insoutenable et fragilise notre édifice national. La dette est une contrainte qui impose que les réformes s'accompagnent d'une baisse globale de la dépense publique de l'ordre de $20 \%$. Et ce au moment où un effort devra être consenti pour la recherche et l'enseignement supérieur. Mais cette contrainte peut aussi être une chance. En effet, résoudre un problème en distribuant des subsides n'est plus une option disponible : quand les caisses sont vides, la démagogie et la lâcheté ne peuvent que s'effacer devant l'intelligence et le courage.

La méthode pour réformer repose sur trois fondamentaux. D'abord, toute réforme doit s'appuyer sur une analyse lucide. Le scénario classique d'une élection présidentielle voit les candidats multiplier les promesses, avant que l'heureux élu ne commande un audit pour voir ce qu'il va être possible de tenir. Il faut inverser cette logique, les propositions des candidats doivent être basées sur un audit préalable. Pour 2007, le rapport Pébereau sur la dette publique constitue un tel audit. 
Ensuite, on ne peut réformer que de façon globale et cohérente. La méthode des petits pas est vouée à l'échec car chaque petit pas se heurte à l'incompréhension - et donc aux résistances - des populations concernées. Tant et si bien que la succession de petits pas se termine par un piétinement inefficace, coûteux et démoralisant.

Enfin, il n'y a pas de réforme possible sans légitimité électorale. Seules les réformes clairement présentées pendant la campagne pourront être menées à bien.

Conséquence de ces trois fondamentaux, c'est en amont de la campagne électorale que se joue la modernisation de la France. Aussi, pour créer les conditions de la transformation sociale du pays, nous souhaitons rencontrer tous les acteurs de la définition d'un nouveau pacte social. Les différents syndicats, bien sûr, mais aussi le monde associatif et plus largement les corps constitués qui souhaitent jouer un rôle dans l'évolution du pays. Au terme de ces échanges, nous présenterons les grandes lignes d'un pacte social en prise avec le monde d'aujourd'hui, ainsi qu'une méthodologie pour le mettre en oeuvre.

Ce "manifeste pour la modernisation" sera rendu public en janvier 2007, peu de temps avant que chacun des candidats à l'élection présidentielle ne dévoile la vision de la France qu'il propose aux Français. Né de discussions avec le mouvement social, le manifeste sera soumis à l'approbation des milliers d'élus locaux qui auront à jouer le rôle crucial de pédagogues pour que la France relève les défis qui l'attendent.

Notre démarche est fondée sur l'optimisme et la confiance dans l'aspiration des Français à une fraternité renouvelée. Selon nous, l'idée d'une France irréformable est non seulement un renoncement coupable, mais aussi un contresens historique. Au cours de notre histoire, il est souvent arrivé que des hommes et des femmes de bonne volonté mettent en commun leurs énergies pour initier les bouleversements qui ont permis à la France de rayonner. Les derniers exemples remontent à 1946 et 1958. C'est d'une impulsion collective de cet ordre que notre pays a aujourd'hui besoin pour que s'expriment tous ses potentiels de créativité et de solidarité. Nous savons que c'est indispensable, nous voulons prouver que c'est possible.

Christian Blanc est député apparenté UDF, président d'Energies 2007.

Jean-Marie Bockel est sénateur PS, ancien ministre.

Alain Lambert est sénateur UMP, ancien ministre.

Article paru dans l'édition du 04.07.06

http://www.lemonde.fr/web/article/0,1-0,36-791239,0.html 


\title{
Louis Gallois, un eurosceptique à la tête d'EADS
}

\author{
LE MONDE | 03.07.06 | 13h38
}

Invariablement, lorsque l'on brosse le portrait du recordman de la longévité à la tête de la SNCF - il aurait soufflé ses dix bougies cet été -, deux locutions s'imposent. La première, "un grand serviteur de l'Etat", le flatte. La deuxième, "proche de Jean-Pierre Chevènement", l'irrite. "Epargnez-moi ce copié-collé", demande-t-il, aussi exigeant à l'égard des journalistes que de ses collaborateurs.

Louis Gallois a beau ne pas cacher ses convictions - jusqu'à assister à une projection d'un film de Ken Loach contre la privatisation du rail, organisée par les syndicats de la SNCF -, tous mettent en avant sa droiture et sa probité. D'ailleurs, c'est la droite qui l'a nommé à la tête de l'entreprise socialement la plus sensible de France.

Son condisciple à l'ENA, Alain Juppé, alors premier ministre, lui annonce la nouvelle le mardi 23 juillet 1996. Le temps presse : le titulaire du poste, Loïk Le Floch-Prigent, rattrapé par l'affaire Elf six mois après sa nomination, est incarcéré depuis le 5 juillet. Alain Juppé n'a réussi à convaincre ni Henri Lachmann (PDG de Strafor-Facom) ni Pierre Bilger (GEC-Alstom). Plus tard, Louis Gallois pourra dire qu'il a été placé là "surtout parce qu'au bout de trois semaines on n'avait trouvé personne d'autre" !

La proposition - l'ordre ? - d'Alain Juppé a sûrement flatté celui qui six mois auparavant estimait que, "pour un homme issu de la fonction publique, la présidence de la SNCF est, avec celle de l'EDF, la plus prestigieuse mission du pays". Mais la tâche a de quoi effrayer : l'entreprise, qui emploie 181000 cheminots, perd 16,6 milliards de francs (chiffres 1995) et sa dette s'élève à plus de 200 milliards de francs. Dix ans plus tard, la SNCF emploie 171500 personnes, réalise des bénéfices, a modernisé son image et son réseau, et sa dette a été transférée à Réseau ferré de France. Louis Gallois s'apprête donc une nouvelle fois à jouer les pompiers, toujours au service de l'Etat.

Une constante pour ce diplômé d'HEC, depuis sa sortie de l'ENA en 1972. Après dix années passées au ministère des finances, il deviendra directeur de cabinet de Jean-Pierre Chevènement, alors ministre de la recherche et de la technologie, dans le sillage de la gauche arrivée au pouvoir en 1981. Proche du Cérès, l'aile gauche du Parti socialiste, Louis Gallois ne quittera pratiquement plus son mentor jusqu'en 1989.

Celui-ci le nommera directeur général de l'industrie, où il sera l'artisan de la restructuration de CreusotLoire, puis en fera son directeur de cabinet civil et militaire lorsqu'il sera ministre de la défense.

Louis Gallois quittera ses fonctions en juillet 1989 - dix-huit mois avant Jean-Pierre Chevènement - pour prendre les rênes de la Snecma. En cavalier émérite, il les conservera pendant trois ans, avant de devenir président de l'Aerospatiale. C'est grâce à cet énarque débarqué chez les $\mathrm{X}$ de l'armement, que les gyrophares des voitures de direction ont été supprimés... De cette période, il conservait dans son bureau, au siège de la SNCF, plusieurs maquettes d'avions et de moteurs qui voisinaient avec les maquettes de TGV et de locomotives - "qui le suivront bien sûr". 
A son arrivée, en 1996, nul ne prédisait un grand avenir à Louis Gallois à la tête de l'entreprise ferroviaire. Ce technocrate était supposé trop aimer les avions. Il est d'ailleurs resté un administrateur pointilleux d'EADS. Mais, au fil du temps, le courant est passé. Avec les syndicats - on a même vu un grand gaillard cégétiste baiser son crâne barthézien lors de la cérémonie des voeux en 1999. Avec son adjoint aussi, Guillaume Pepy, qu'il continue de vouvoyer et avec lequel il a formé un couple improbable, mais redoutable. Même si le contexte diffère, cette capacité à travailler en confiance avec une autre forte personnalité est sans doute un atout dont il aura besoin chez EADS.

Il n'y a pas que le temps passé à la tête de l'entreprise qui fasse de Louis Gallois une exception. Contrairement à la plupart de ses pairs, ce fils d'un assureur de Montauban n'est pas intéressé par l'argent. L'un de ses condisciples de l'ENA, Dominique Perben, son ministre de tutelle lorsqu'il était à la SNCF, s'était étonné : "Quand j'ai appris que Louis Gallois gagnait moins de 15000 euros par mois, je suis tombé sur le cul !" Il s'offre même le luxe de refuser les jetons de présence des différents conseils d'administration (Thales, EADS...) où il siégeait. Administrateur d'Air France, il n'entendait pas être surclassé. Louis Gallois a la fierté des modestes : "Je ne gagne pas beaucoup, mais je dépense peu", aime-t-il répéter.

Il n'aime surtout pas gaspiller et n'entend pas que d'autres le fassent. Pas question que les cadres de la SNCF voyagent en première ou dorment ailleurs que dans un Ibis. S'il se félicite du succès de l'Eurostar, il a toujours du mal à comprendre que les entreprises fassent voyager leurs cadres en "premium" entre Paris et Londres. Louis Gallois, lui, paie ses timbres, habite depuis des années le même pavillon de banlieue et sa voiture de fonction passe le week-end au siège de l'entreprise.

Ce faux coincé n'hésite pas à (bien) danser le rock au cours d'un séminaire de direction. Il en dit peu sur sa vie privée mais, en patron de la SNCF, il avait du mal à protéger son intimité. Parce qu'il voyageait en train, il y avait toujours un cheminot pour avoir vu "Loulou" à Belle-Ile ou à la montagne. Passionné de vélo (ah, le Tour de France !) et de rugby, il serait privé par un départ prématuré de la SNCF d'un événement majeur, pour lequel il s'est particulièrement mobilisé : le train du rugby, une opération menée par la SNCF et la Fédération française de rugby pour promouvoir "France 2007" sur le territoire national. En revanche, ça tombe bien : les matches France-Allemagne semblent n'avoir jamais été sa passion. A la tête de la SNCF, il a toujours su s'entendre avec les Allemands pour réduire les ambitions libérales de Bruxelles. Etre nommé au chevet de l'entreprise qui devrait symboliser l'Europe n'est d'ailleurs pas le moindre des paradoxes pour cet eurosceptique.

François Bostnavaron photo gilles rolle/réa Article paru dans l'édition du 04.07.06

http://www.lemonde.fr/web/article/0,1-0,36-791232,0.html 


\section{Le Brésil célèbre le "genio" de Zidane}

LE MONDE | 03.07.06 | 13h43

Au Brésil, il n'y en a que pour Zinédine Zidane depuis samedi $1^{\mathrm{er}}$ juillet. Avant le match, les journaux affirmaient que le capitaine des Bleus serait mis à la retraite par une victoire du Brésil. Une forte envie de revanche régnait dans un pays où la finale de 1998 et les deux buts de la tête du n ${ }^{\circ} 10$ tricolore ont laissé des bleus à l'âme.

Mais, après un premier quart d'heure illusoire, les Brésiliens ont senti que la vengeance prenait des allures de déroute. Agglutinés autour du bar Adega do Juca, dans le quartier de Flamengo, les supporteurs emmaillotés de jaune et vert ont commencé à huer leurs joueurs.

Principalement Cafu, Kaka, Roberto Carlos, Ronaldinho et Ronaldo... En même temps, montaient des clameurs d'admiration devant l'enchaînement des gestes d'artiste de Zinédine Zidane, que les Brésiliens appelaient soudain, avec gentillesse, "Zizou".

"J'ai cru reconnaître l'habilité de notre Zico de 1982", confiait un supporteur qui ne décolérait pas devant l'apathie de son groupe de stars. "J'aime voir jouer Zidane, c'est un classique, un vrai maître", avouait de son côté Ivan Soter, auteur de trois encyclopédies sur le football brésilien en Coupe du monde.

Dès la fin du match, les médias ont pris le relais pour rendre un hommage appuyé à Zinédine Zidane. "La beauté du jeu était du côté blanc et on a follement envié la France", commentait Télé Globo. "Le bourreau de 1998" s'est alors métamorphosé en "génial Zizou", même s'il a humilié la Seleçao : "Une leçon, une vraie démonstration, un show de Zidane."

Les Brésiliens se consolent en disant qu'ils ont repoussé la sortie d'un joueur "qui glorifie le football". Ils ne veulent soudain plus le voir partir à la retraite, espérant pouvoir admirer l'élégance et l'efficacité de son style, "ses passes millimétrées, ses dribbles déconcertants" pour encore deux matches.

Annie Gasnier (Correspondance, Rio de Janeiro) Article paru dans l'édition du 04.07.06

http://www.lemonde.fr/web/article/0,1-0,36-791270,0.html 


\section{Georges Vigarello : "Tout d'un coup, une explosion positive" \\ LE MONDE | 03.07.06 | 13h47 • Mis à jour le 03.07.06 | 13h47}

Spécialiste des représentations du corps, l'historien Georges Vigarello analyse la ferveur générée par les succès des Bleus.

Des centaines de milliers de personnes ont fêté dans la rue la victoire de l'équipe de France face au Brésil. Comment expliquer ce phénomène?

La première explication est purement sportive : le football provoque une excitation très particulière. Il s'agit d'un sport extraordinairement géométrique et immédiatement perceptible en termes de combat. Comme au rugby, le dispositif "militaire", si je puis dire, y est très visible. On voit se déployer des ensembles collectifs, des stratégies... Le spectateur est saisi par ce spectacle d'équipe, mais aussi par le spectacle des individualités.

A ce titre, la télévision est un outil étonnant. Sur le but français de samedi, on distingue parfaitement une image d'ensemble - le centre de Zidane - et une image individuelle - l'acrobatie remarquable d'Henry. Comme le cyclisme, le football est à la fois un sport d'équipe et un sport individuel, ce qui le rend très séducteur. J'ajouterai que cette discipline qui interdit l'usage de la main génère de la tension chez le spectateur. On est dans l'ordre du retenu et de l'explosif. Tous ces ingrédients expliquent pourquoi on a besoin de faire la fête après un match.

\section{Y a-t-il une spécificité française dans ces manifestations de joie ?}

Tous les sports, mais surtout le football, provoquent un phénomène d'identification. La France n'y échappe pas. Il faut voir dans la ferveur actuelle une forme de revanche par rapport à la situation du pays aujourd'hui. La France a actuellement le sentiment - à tort ou à raison - d'être en stand-by. L'affaire Clearstream, le retour du Clemenceau, le non au référendum, le côté obscur de l'élection présidentielle de 2007, l'impression que rien ne se dessine pour demain... Il y a incontestablement un "phénomène français". Phénomène auquel l'équipe de France n'a d'ailleurs pas échappé elle-même. Les Bleus ont été champions du monde, puis d'Europe, avant de se mettre à décliner et tout perdre. Ils arrivent au Mondial 2006 et poursuivent sur leur lancée, avec des nuls peu convaincants contre la Suisse et la Corée. Et puis, brusquement, cette équipe montre une subtilité, une énergie, de la force collective, de la virtuosité. On a l'impression qu'elle transcende tout : les déclinologues, la crise des banlieues, les centristes...

\section{N'est-ce pas la spontanéité de cette ferveur qui est le plus surprenant ?}

Si. Il y a actuellement une perte de la ferveur collective. On est dans une société individualiste où les gens regardent leur télé, ne sortent que par petits groupes ou par tribus... Les occasions de se fondre dans la masse sont peu nombreuses. La ferveur religieuse est éloignée, les grandes rencontres convergentes du $1^{\text {er }}$ Mai ont disparu... Les seules grandes ferveurs qui existent sont des marches de victimes, comme celles qui 
sont organisées après des agressions d'enfants. Tout d'un coup, le Mondial offre une sorte d'explosion positive.

\section{Que vaut cependant ce phénomène d'identification?}

Toute la question est là. Nous sommes également dans une société de l'éphémère, où les idées changent rapidement... Souvenons de 1998 et de la France "black-blanc-beur". Beaucoup pensaient que nous allions entrer dans une ère nouvelle, qu'on reconnaîtrait enfin les gens différents... On a vu le résultat. Il ne faut donc pas s'illusionner. Je ne crois pas que l'émotion qui se dégage des phénomènes de grandes rencontres soit très profonde. Le Mondial terminé, on reviendra sans doute dans le gris, dans le banal.

\section{Faut-il voir dans cette ferveur un contrepoint à la crise des banlieues ?}

Il est certain que cette équipe de France est d'autant plus plaisante qu'elle est multiculturelle. Pour les gamins de banlieues, c'est encore plus extraordinaire de voir que leurs représentants sont sur le terrain. Des images télévisées en ont montré certains brandir le drapeau bleu-blanc-rouge, samedi soir. On a en effet le sentiment que la crise des banlieues est oubliée. Mais il serait imprudent de tirer des conclusions définitives. Nous avons là un phénomène fragile, éphémère. Quant au sport, s'il peut contribuer au multiculturalisme, il n'est pas le remède à tout. Le partage des valeurs passe d'abord par l'école, par le langage, par la mémoire.

\section{Que retenir alors de cette ferveur?}

Son caractère hédoniste. Nous vivons dans un monde où le plaisir consiste à faire la fête. L'aspect moral du sport, que soutenaient les grands-pères fondateurs du sport comme Pierre de Coubertin, est mis au second plan au bénéfice de l'"être ensemble". Les gens veulent prendre du plaisir. Ils savent également qu'ils seront vus, raison pour laquelle ils se griment et s'habillent aux couleurs de l'équipe de France. L'homme de la fête devient homme de spectacle. On est dans un phénomène de regardant-regardé, largement alimenté par la télévision.

Propos recueillis par Frédéric Potet Article paru dans l'édition du 04.07.06

http://www.lemonde.fr/web/article/0,1-0,36-791271,0.html 


\section{Discovery Channel favorite à sa propre succession}

LE MONDE | 03.07.06 | 14h17 • Mis à jour le 03.07.06 | 14h17 STRASBOURG ENVOYÉ SPÉCIAL

Les premières foudres lancées par le grand tribunal populaire du Tour de France désormais réduites à l'état de braises, après avoir embrasé la Grande Boucle deux jours durant, la course a débuté par deux petites surprises du chef. Le prologue, couru samedi $1^{\mathrm{er}}$ juillet dans les rues de Strasbourg, a été remporté par un sprinter, le Norvégien Thor Hushovd (Crédit agricole), devant les spécialistes du genre, parmi lesquels David Millar ou David Zabriskie. Et la première étape, disputée le lendemain sur une boucle de 184,5 km autour de la capitale alsacienne, a vu la victoire d'un "outsider", le Français Jimmy Casper.

"Gagner devant Mc Ewen, Zabel et Boonen, c'est énorme", déclarait le coureur de Cofidis, étonné de s'emparer du maillot vert. Beaucoup moins étonnante était la prise du maillot jaune par George Hincapie, deuxième du prologue à 73 imperceptibles centièmes de seconde du vainqueur, à la faveur d'un sprint intermédiaire.

L'Américain ne possédait que 2 misérables secondes d'avance au classement général, mais là n'est pas la question.

L'important est que l'équipe Discovery Channel a annoncé clairement la couleur en moins de temps qu'il ne faut pour descendre de vélo. Seuls les suiveurs victimes de daltonisme peuvent encore nourrir quelques maigres doutes. "Nous sommes très motivés car nous avons beaucoup de possibilités, explique sobrement Johan Bruyneel, le directeur sportif de cette équipe qui conduisit Lance Armstrong tout au long de ses sept victoires sur le Tour. Nous partons avec de grandes ambitions."

Eusebio Unzue, directeur sportif de la formation Caisse d'Epargne-Iles Baléares, confirme sans hésitation le bien-fondé d'une telle confiance : "Alors qu'ils étaient dans l'anonymat du temps d'Armstrong, plusieurs coureurs de cette équipe peuvent aujourd'hui s'exprimer librement." Ils ne sont en effet pas moins de quatre, l'Américain George Hincapie, le Portugais José Azevedo, l'Italien Paolo Savoldelli et l'Ukrainien Yaroslav Popovych, à n'avoir plus à servir les intérêts prioritaires du plus grand maître que le monde cycliste ait connu.

Et l'on peut légitimement se demander comment le Tour 2006 pourrait échapper à l'un d'eux. José Azevedo, 32 ans, cinquième du Tour de France en 2004, Paolo Savoldelli, 33 ans, $25^{\mathrm{e}}$ du Tour et vainqueur du Giro en 2005, George Hincapie, 33 ans, $14^{\mathrm{e}}$ du Tour 2005, sont des coureurs que Eusebio Unzue qualifie de "vétérans pleins d'expérience". Quant à Yaroslav Popovych, 26 ans, $12^{\mathrm{e}}$ du Tour 2005 et meilleur jeune, il représente l'avenir de cette formation. Leurs résultats, obtenus pour certains d'entre eux alors qu'ils étaient bridés par leur devoir d'équipier, en dit long sur les possibilités de ces coureurs.

Le plus difficile pour eux sera peut-être de se défaire de la concurrence interne, d'obtenir un durable statut de leader. La situation au sein de l'équipe Discovery Channel n'est pas sans rappeler les épreuves américaines d'athlétisme sur 100 mètres, qualificatives pour les Jeux olympiques, dont on dit qu'elles sont 
plus dures encore à gagner que la finale olympique. Bien qu'il s'en défende, George Hincapie a dans ce sens marqué un point important par rapport à ses coéquipiers.

"Le terme de leader n'a pas d'importance, ce n'est qu'un mot, explique l'Américain. Moi, je connais mes ambitions. Je sais que je suis l'un des meilleurs coureurs du monde et je n'ai pas besoin pour le moment de l'aide de mon équipe. Mais je ne suis pas non plus ici pour remplacer Lance Armstrong", précise-t-il. Hincapie, qui n'a pas peur des mots puisque ce ne sont que des mots, avoue sans peine sa cruelle déception de ne pas avoir remporté le prologue mais ajoute, si l'on avait encore des doutes sur sa touchante assurance, qu'il se sent "en grande forme".

Il y aurait là de quoi refroidir les ardeurs des autres favoris. Mais les deux principaux qui restent en course, les Américains Levi Leipheimer (Gerolsteiner) et Floyd Landis (Phonak) n'ont pas attendu leur compatriote pour prendre les devants. Le premier remportait tranquillement le Dauphiné Libéré, au mois de juin, le second s'était imposé sur Paris-Nice. "Nous sommes ici pour gagner, il n'y a pas le moindre doute là dessus, et le fait qu'Ullrich et Basso ne soient pas là ne change rien à l'affaire", affirme l'un des lieutenants de Landis, l'Espagnol Miguel Angel Martin Perdiguero, qui n'affiche ici d'autre prétention que d'aider son leader à gagner. A y regarder de près comme de loin, il serait étonnant que le Tour de France 2006 échappe à l'emprise américaine.

Jean-Louis Aragon

Article paru dans l'édition du 04.07.06

http://www.lemonde.fr/web/article/0,1-0,36-791222,0.html 


\section{Le succès d'audience de Radio Classique pousse France Musique à revoir sa grille}

LE MONDE | 03.07.06 | 12h45 • Mis à jour le 03.07.06 | 14h57

Longtemps retransmis par France Musique, le Festival d'art lyrique d'Aix-en-Provence, qui se tient du 2 au 22 juillet, est, pour la deuxième année consécutive, diffusé par Radio Classique.

La station privée, propriété du groupe LVMH, a soufflé en 2004 à sa rivale publique les droits de retransmission des principaux concerts.

Le directeur du festival, Stéphane Lissner, aujourd'hui parti diriger la Scala de Milan, avait demandé 170 000 euros de droits de retransmission à France Musique. Soit l'équivalent d'un cinquième du budget annuel de la radio publique, qui ne peut ni ne veut payer. Frédéric Olivennes, le directeur général de Radio Classique, n'hésite pas : "Nous avons la possibilité d'apporter de l'espace publicitaire, contrairement au service public", glisse-t-il, discret sur le contenu et le montant de son offre.

France Musique n'a pas dit son dernier mot. "Nous aimerions retravailler avec Aix, dit Thierry Beauvert, le directeur de la station. Nous rencontrerons très prochainement le nouveau directeur du festival, Bernard Focroulle." Son argument principal pour espérer reprendre le contrat dès l'an prochain : avec France Musique, quasiment l'intégralité du festival était retransmise. Ce n'est pas le cas avec Radio Classique, qui ne diffuse que quatre concerts complets cette année.

Un épisode qui accentue les tensions entre les deux radios dédiées à la musique classique. Les chiffres d'audience, depuis le repositionnement de Radio Classique, sont sans appel : sur la période de janvier à mars 2006, France Musique a accusé une baisse de 16,1 \% par rapport à la même période de 2005, tandis que sa rivale privée enregistrait une hausse de 28,2 \%, selon les chiffres de Médiamétrie.

Les deux radios n'ont pas la même conception de la façon de promouvoir la musique. Quand Radio Classique mise sur des clips télé et la tournée d'un bus dans les villes de province, France Musique se contente d'un affichage succinct sur les taxis parisiens. Les budgets consacrés à la communication par les deux stations sont révélateurs : 2 millions d'euros pour la station de LVMH, et 105000 euros pour celle de Radio France.

Rivales, elles ne sont d'accord que sur un point : jouer la carte de la différenciation. "Il est fondamental de se distinguer", estime M. Olivennes. "Nous ne faisons pas le même métier", déclare M. Beauvert. Les deux stations ont des conceptions divergentes en matière de programmation.

France Musique a bâti sa réputation sur les retransmissions intégrales de concerts et les commentaires musicologiques. L'auditeur pourra ainsi écouter cet été 240 concerts, enregistrés à Salzbourg, Glyndebourne ou La Roque-d'Anthéron. La station compte des producteurs de haut vol et bénéficie, pour la captation des concerts, des moyens techniques de Radio France. "France Musique sert la musique, Radio Classique s'en sert", tranche M. Beauvert. 
"Nous sommes plus sur le registre de l'émotion que de la connaissance", reconnaît volontiers Sébastien Lancrenon, directeur des programmes de Radio Classique. "Entertainment", c'est le mot-clé de la station privée, qui privilégie la diffusion des "tubes" du classique. Le choix de ne pas diffuser les oeuvres en intégralité ? "Aucune radio musicale ne diffuse l'album de Madonna en entier", lance M. Olivennes, volontiers un peu "provoc".

A partir de cette année, Médiamétrie enregistrera les scores des radios en juillet et août. L'impact du Festival d'Aix sera ainsi visible pour les deux stations, qui préparent déjà le choc de la rentrée. Radio Classique va accentuer le caractère grand public de son format, avec davantage de musiques de films à l'antenne, et des personnalités connues, comme Claire Chazal, notamment dans les tranches d'information économique, l'autre spécificité de la radio privée. Objectif affiché : passer de 1,4 \% à $2 \%$ d'audience. Pour cela, la station, qui ne dispose que de 70 fréquences (contre 500 pour France Musique), espère obtenir "entre 15 et 25 fréquences de plus d'ici deux ans", dit M. Olivennes.

La radio publique, sans trop le dire, cherche à se démocratiser. "La grille du week-end changera considérablement sur France Musique", révèle son directeur. Sont ainsi prévus une émission consacrée aux musiciens amateurs, et un nouveau rendez-vous avec Frédéric Lodéon, l'animateur vedette du classique sur France Inter. L'antenne s'ouvrira également à des instrumentistes qui ont un bon contact avec le public comme le violoncelliste Jérôme Pernoo.

\section{Antoine Pecqueur}

Article paru dans l'édition du 04.07.06

http://www.lemonde.fr/web/article/0,1-0,36-791216,0.html 


\section{Les bisons, le cheval et la belette}

LE MONDE | 03.07.06 | 15h31 • Mis à jour le 03.07.06 | 15h32 NIAUX ENVOYÉ SPÉCIAL

La grotte de Niaux (Ariège) est célèbre pour son "Salon noir" aux bisons, chevaux et bouquetins dessinés par les magdaléniens. Elles ont été authentifiées en 1906 par Emile Cartailhac et l'abbé Breuil, en un temps où l'existence d'un art préhistorique pariétal venait à peine d'être admise par les savants eux-mêmes.

Pour fêter ce centenaire, les responsables de la grotte ont eu une idée étonnante : non pas d'ouvrir le Salon noir aux visiteurs - il l'est depuis fort longtemps toute l'année -, mais de les faire pénétrer cet été, de juillet à septembre, dans le mystérieux "réseau Clastres", une longue galerie qui est le plus souvent inaccessible - et n'a été parcourue pour la première fois qu'en 1970.

Pour y parvenir, il faut s'enfoncer dans Niaux. Rien de périlleux d'abord : les voûtes sont hautes, le chemin tracé par les milliers de visiteurs qui ont pénétré ici et qui, au XVII ${ }^{\mathrm{e}}$ comme au XIX ${ }^{\mathrm{e}}$ siècle, ont écrit leurs noms sur les parois. Puis vient une porte, encastrée dans la roche : l'entrée du "réseau Clastres", défendu par quatre lacs. L'eau y monte généralement jusqu'à la voûte, et, des décennies durant, les spéléologues ont échoué à les franchir. En 1970, enfin, ayant pompé le "lac 3", ils se sont avancés dans une galerie, parfois très basse. Ils ont vite repéré des empreintes de pas fossiles, les charbons de bois laissés par des torches et des peintures.

Depuis, à quelques reprises, des préhistoriens sont venus pour étudier ce miracle : une galerie intacte, fermée à une extrémité par les lacs et à l'autre - celle par où sont entrés les préhistoriques - par un éboulement énorme de blocs, aujourd'hui cimentés par des concrétions.

Les empreintes, ce sont celles de trois enfants, âgés entre 8 et 10 ans. Ils marchaient lentement sur la pente sablonneuse. Leurs pas sont demeurés très nets dans le sol, qui, depuis, a durci, recouvert d'une pellicule de calcite. Ces enfants sont passés là, il y a une douzaine ou une quinzaine de millénaires. Seuls ? On ne sait pas. Car il y a d'autres traces, d'adultes celles-ci. Ils ont cassé des concrétions pour s'ouvrir un passage plus large : les dégâts restent visibles. Ce sont eux aussi les auteurs des cinq figures de la salle des peintures : trois bisons, un cheval et une belette. Les quatre premiers ne posent guère de problèmes : on y retrouve la sûreté de geste des artistes du Salon noir, et il est possible de reconstituer la genèse des figures trait après trait. Il en a fallu une quarantaine pour le cheval, qui a été dessiné en commençant par la crinière.

Pour la belette, plus étrange, il n'en a fallu que dix. On dit "belette" parce que l'identification paraît s'imposer au premier coup d'oeil, mais les préhistoriens, prudents, préfèrent parler de mustélidé, sans précision d'espèce. Or ce mustélidé est le seul de tout l'art pariétal - première énigme.

Deuxième : il est dessiné plus grand que nature, alors que la taille des bisons et du cheval est sensiblement réduite - ce qui est le cas de loin le plus fréquent. 
Troisième surprise : le style est différent, plus elliptique, mais tout aussi maîtrisé. Les courbes s'enchaînent impeccablement.

Les cinq peintures eurent-elles le même auteur ? Ou plusieurs ? De quel sexe ? De quel âge ? L'association des animaux a-t-elle un sens ? Magie ou plaisir de dessiner sur une paroi lisse, à la lumière des torches de résineux ? Quand on est assis sur le sol devant les dessins, les questions se multiplient, sans solution pour la plupart. Mais le sentiment qui s'impose d'abord est celui d'une suspension inespérée du temps.

Pour que les visites soient possibles, les lacs ont été pompés. Il y en aura deux par jour, chacune limitée à quatre personnes. Celles-ci ne doivent pas craindre de ramper dans l'eau boueuse sous les concrétions, qu'il ne faut pas effleurer : l'exercice n'est pas de tout repos.

Il est précédé par une épreuve plus difficile encore : pour sélectionner les 450 élus, Pascal Alard, qui dirige le Parc de la préhistoire de Tarascon, a choisi un moyen égalitaire : la lettre de motivation. Il en a déjà reçu des dizaines, argumentées ou poétiques.

\section{Philippe Dagen}

Article paru dans l'édition du 04.07.06

http://www.lemonde.fr/web/article/0,1-0,36-791286,0.html 


\section{L'Anglais John Bickerton remporte l'Open de France}

LE MONDE | 03.07.06 | 15h52 • Mis à jour le 03.07.06 | 15h52

La plupart des cadors du circuit européen qui ont honoré l'Open de France de leur présence pour son centenaire n'étaient pas vraiment désintéressés. Derrière les dunes du Golf national, à Saint-Quentin-enYvelines, où se disputait ce tournoi du 30 juin au 2 juillet, c'est la Ryder Cup qu'ils avaient en ligne de mire, outre les primes : plus de 666000 euros au vainqueur, 444000 euros au deuxième, 250000 euros au troisième, cela valait le déplacement.

La Ryder Cup, cela fait plusieurs semaines que les golfeurs n'ont plus que ça en tête. Hormis l'Ecossais Colin Montgomerie, qui avait déclaré forfait pour raison de surmenage, et l'Anglais David Howell, qui n'a pas passé le cut, aucun des meilleurs joueurs du Vieux Continent n'était encore assuré de participer à la grande fête golfique qui oppose tous les deux ans les meilleurs Européens aux meilleurs Américains. Pour cela, il faut se placer dans les cinq premiers de l'un des deux classements qualificatifs, établis sur l'année précédant la Ryder Cup.

Le premier, basé sur le classement mondial, permet de sélectionner les joueurs qui ont fait le choix de jouer aux Etats-Unis. David Howell en est le leader, devant Colin Montgomerie. La seconde liste est calculée exclusivement sur les tournois européens. A l'issue de l'Open de France, les deux premiers du seul tournoi français d'envergure ont fait la meilleure affaire : l'Anglais John Bickerton, vainqueur, apparaît dorénavant à la cinquième place et l'Irlandais Padraig Harrington, son second, s'installe en tête. Cela ne pouvait pas mieux tomber pour ce dernier car la Ryder Cup 2006 aura lieu dans son propre pays, à quelques kilomètres au sud-ouest de Dublin.

\section{L'OPEN BRITANNIQUE}

Rien n'est encore perdu pour tous les autres, mais presque. Les quatre prochains tournois à leur calendrier, dont l'Open britannique qui se jouera du 20 au 23 juillet, offrent des dotations extrêmement avantageuses.

Cependant, plus le temps passe, plus la concurrence se fera rude, notamment pour les deux Français. Raphaël Jacquelin et Jean Van de Velde sont donc condamnés à des coups d'éclat s'ils veulent représenter leur pays et prendre la suite de Thomas Levet, unique français vainqueur de la Ryder Cup, en 2004.

Deuxième de l'Open de France 2005 derrière Jean-François Remesy, Jean Van de Velde s'est affirmé comme le plus en forme des joueurs hexagonaux, malgré sa $17^{\mathrm{e}}$ place, devant Jean-François Lucquin et le jeune Adrien Mörk, $21^{\mathrm{e}}$ ex aequo.

A Newport, l'US Open féminin, qui se disputait du 30 juin au 2 juillet, sera prolongé d'un cinquième tour, qui se jouera lundi 3 juillet, pour permettre à la Suédoise Annika Sorenstam et à l'Américaine Pat Hurst de se départager. Les deux joueuses ont terminé ex aequo dans le par, avec 284 coups. La Française Patricia Meunier-Lebouc a pris la dixième place de ce tournoi majeur. 


\author{
Jean-Louis Aragon \\ Article paru dans l'édition du 04.07.06 \\ http://www.lemonde.fr/web/article/0,1-0,36-791227,0.html \\ Le champion de France, Florent Brard, n'est pas avide de gloire
}

LE MONDE | 03.07.06 | 14h17 • Mis à jour le 04.07.06 | 12h30

STRASBOURG ENVOYÉ SPÉCIAL

Au bar de l'hôtel qui accueillait son équipe à Strasbourg, Florent Brard se bourre d'amandes au chocolat. Il a pourtant déjà dîné, tôt, il est vrai, mais tout de même. "Je suis très gourmand", se justifie le nouveau champion de France sur route. Ce Tourangeau d'origine, qui "aime bien manger", est aussi amateur de vins. "J'ai une belle petite cave et j'aime de plus en plus les blancs, ceux d'Alsace notamment."

Ce soir-là, il se contentera d'un "déca". "J'ai un grand-père qui faisait de la piquette, un petit vin, quoi, rectifie-t-il. Mais le vin, ce n'est pas que le goût, c'est aussi le partage, ça ne se boit pas seul, c'est toute une culture. Je vais chez les petits producteurs, on va voir les vignes, la terre. Quand on connaît un peu son histoire, le vin est meilleur."

Florent Brard n'a pas un palmarès style grand cru bourgeois : une dizaine de victoires pour une carrière débutée tardivement chez les pros, en 2000. Il avait déjà 24 ans. Tout petit pourtant, il baignait dans le vélo. Son père faisait des compétitions amateurs. Alors forcément, il a "chopé le virus". "J'avais un tempérament à foncer, se souvient Florent Brard. A 13 ans, les courses étaient trop courtes pour moi, mais mon père m'a canalisé. Mon père ?" En trois mots, un double portrait jaillit, limpide : "Mon père, aucun vice, le goût du travail bien fait. Moi aussi, mais pas tout le temps."

Pour Eusebio Unzue, son directeur sportif chez Caisse d'Epargne-Iles Baléares, le titre de champion de France de Florent Brard n'est que "la confirmation de la classe innée" qu'il avait repérée chez lui il y a six ans. "Je suis arrivé au championnat un peu mou du genou. Mais plus les tours passaient, mieux ça allait, j'étais vraiment dans le truc. On est tendu vers l'objectif, on capte tout, on maîtrise son sujet. On sait quels gars sont les plus dangereux, on analyse bien la situation. Je me suis fait tout petit et puis voilà." Du travail bien fait.

Le problème du nouveau champion de France, c'est qu'il a toujours eu "l'envie de brûler les étapes". Mais ce sont certaines étapes de sa vie professionnelle qui l'ont un peu brûlé. Passages d'équipe en équipe, chutes, blessures, accusation de dopage (suspendu 6 mois après un contrôle positif aux corticoïdes en 2002, il a été blanchi par le Conseil d'Etat), maladies, licenciement, procès. Le Tourangeau a tout connu, en garde une certaine amertume, mais ne fuit pas ses responsabilités. "Avant, je faisais un peu n'importe quoi. Maintenant je trouve du plaisir à faire le métier. C'est un peu une vie de moine, mais on finit par se sentir bien. Et puis faire ces efforts, ça paye."

\title{
TENDANCE FIL DE FER
}

Florent Brard, qui vit avec sa compagne et leurs deux petites filles de 3 ans et 6 mois à Serres-Castets (Pyrénées-Atlantiques), tout près de Pau, n'a jamais vraiment été un rêveur. "J'ai du mal à me projeter, je 
suis dans l'instant. Pour moi, la vie est un grand livre qu'on ouvre feuille à feuille, avec quelques pages un peu chiantes. De 14 à 20 ans, c'était le mieux. On est pur, on y croit à bloc."

Aujourd'hui, il relativise. "Je suis super-content d'être champion de France, mais ce n'est que du vélo, du sport, pas un métier. Mes parents bossaient chez Michelin. Pour moi, c'est ça bosser. A la limite, ce titre me fait presque plus plaisir pour eux. Je ne suis pas avide de gloire." Faudra qu'il s'y fasse, Florent ; un maillot tricolore de champion de France ne passe pas inaperçu sur les routes du Tour de France, même s'il est porté par un coureur d'une équipe espagnole, celle d'Alejandro Valverde, l'un des outsiders de l'épreuve.

Avec son 1,86 mètre tendance fil de fer, ses cheveux décolorés - "une connerie" - et sa vieille boucle d'oreille - "toute pourrie" -, Florent Brard, qui participe à son deuxième Tour, se définit comme un rouleur, un passe-partout, qui fonctionne à coups de défis. "Là, j'ai 30 ans, ça me fait chier, ça passe trop vite. A cet âge-là, dans la vie, tu es un minot, mais dans le vélo, tu es un vieux", déplore-t-il avec l'air mutin de ceux que l'envie de faire des conneries démange en permanence.

\section{Jean-Louis Aragon}

Article paru dans l'édition du 04.07.06

http://www.lemonde.fr/web/article/0,1-0,36-791224,0.html 


\section{Le rêve brésilien n'était qu'un mirage}

LE MONDE | 03.07.06 | 13h40 • Mis à jour le 03.07.06 | 15h42

Ils vont rejoindre la cohorte des vaincus. S'aligner, tête basse, dans le rang des maudits, des traîtres, des Brésiliens qui n'ont pas gagné la Coupe du monde de football, ceux que le Brésil insulte, puis que le Brésil oublie, généreux pour les seuls vainqueurs. Ainsi va l'étrange destin d'une Seleçao oublieuse de sa magie, du jeu ensorcelant qui devait assurer au pays un sixième titre mondial. Contre la France, le mirage s'est dissous, et les joueurs de Carlos Alberto Parreira sont apparus tels qu'ils sont : ou trop vieux, tel le capitaine Cafu, âgé de 36 ans, ou trop gros, comme Ronaldo, ou atteints d'une panne subite d'inspiration, voire de la peur des Français, comme Ronaldinho ou Kaka.

Cette assemblée de stars, promise à une facile victoire, comparée aux plus grands millésimes (l'équipe de Pelé en 1970), enregistre le plus mauvais résultat du Brésil depuis 1990. En guise de consolation, elle n'offre qu'une série de records inutiles : avec 15 buts, Ronaldo est devenu le buteur le plus prolifique de l'histoire de la compétition ; Cafu reste le seul joueur à avoir disputé trois finales consécutives en Coupe du monde : avec 386 minutes sans commettre une faute, Lucio a fixé une nouvelle référence en matière de défense propre. Mais, contre la France, Ronaldo n'a pas marqué, Cafu n'a pu assez courir, et Lucio a été sanctionné d'un carton jaune.

Sous le choc de la défaite, chacun a tenté de comprendre, livrant des bribes d'explication. "La France était meilleure tactiquement", a dit Carlos Alberto Parreira, dont le futur s'inscrit déjà en pointillé. Kaka, comme Cafu, a souligné le rôle de Zinédine Zidane. "Il a fait un grand match. C'est un grand joueur", affirme le premier, tandis que le capitaine de la Seleçao ajoute : "Nous l'avons laissé libre pendant toute la partie, et accorder de la liberté à Zidane est très dangereux." Ils sont plus discrets sur leurs propres absences, ou sur le Mondial raté du meilleur d'entre eux.

Du 13 juin, date du premier match du Brésil, jusqu'à la défaite (0-1), samedi $1^{\mathrm{er}}$ juillet, Ronaldinho n'a pas inscrit un seul but. Le Barcelonais flamboyant qui faisait au printemps trembler l'Europe du football s'est soudain mué en garçon perdu, obstinément inefficace. Il est, du coup, la cible des mécontents, avec Parreira. A l'entraîneur, les supporteurs reprochent d'avoir renoncé au style offensif. Pourquoi s'être obstiné dans le conservatisme ? Avoir maintenu sa confiance à des joueurs usés, comme Roberto Carlos et Cafu, alors que piaffaient sur le banc des remplaçants des artistes bien plus en jambes?

\section{TROP INDIVIDUALISTES ?}

Le défenseur français Eric Abidal a suggéré une autre explication. "Nous nous sommes forgé un état d'esprit, a-t-il assuré. C'est tout un groupe qui a joué. Nous n'avons de qualités que par le collectif. Eux sont beaucoup plus individualistes. C'est à celui qui va faire la différence." Au risque de perdre le contact avec la réalité du jeu. "J'ai eu l'impression que nous pensions pouvoir plier le match à n'importe quel moment", a avoué Cafu. 
Pour lui comme pour ses coéquipiers, aucune explication, si subtile soit-elle, ne peut effacer la tristesse. "Je suis malheureux, a confié le milieu de terrain Emerson, car nous avons fait pleurer beaucoup de gens, ma famille y compris." Avait-il en mémoire l'anecdote racontée par Barbosa, gardien de but de la Seleçao en 1950, que les supporteurs avaient jugé coupable de la défaite contre l'Uruguay qui coûta au Brésil sa première Coupe du monde ? Vingt ans après les faits, il avait croisé une femme qui l'avait reconnu, et désigné à son fils en disant : "Tu vois, lui, il a fait pleurer tout le Brésil."

Le président Lula a tenté de ramener la défaite à une juste proportion, exprimant sa "solidarité" avec les vaincus. Mais, pour lui comme pour tous ses compatriotes, il faudra attendre quatre ans pour rêver à nouveau.

Pascal Ceaux (envoyé spécial à Francfort)

Article paru dans l'édition du 04.07.06

http://www.lemonde.fr/web/article/0,1-0,36-791268,0.html 


\section{Libération.fr fait peau neuve et se veut plus "interactif"}

LEMONDE.FR | 03.07.06 | 11h27 • Mis à jour le 04.07.06 | 11h09

Libération change de tête. Doublement. Jeudi 29 juin, Serge July a tiré sa révérence, quittant le journal qu'il a fondé en septembre 1972 avec Jean-Paul Sartre. Dimanche 2 juillet, le site Web du journal fait peau neuve. De là à en tirer de curieuses coïncidences... Il n'y a que de rares contributeurs du site pour faire le raccourci.

"Pour la deuxième fois en moins d'un an, Libération.fr fait peau neuve, indique la rédaction sur le site. Ce nouveau site, qui a évolué en prenant compte des critiques que vous aviez formulées il y a environ huit mois, à l'ergonomie nouvelle, c'est plus d'infos, plus d'articles, plus de photos, plus de vidéos et de reportages sonores. Bref, plus d'actualité, de diversité, de profondeur et d'analyse."

Le cahier des charges du nouveau site a été défini à l'automne dernier et le travail pour le nouveau site a commencé au début de l'année, avec un outil reposant sur le langage Ajax développé par BT. "Nous avons récupéré une partie des articles automatiquement, et nous récupérons d'autres morceaux à la main", explique Denis Delbecq, l'un des deux rédacteurs en chef-ajdoint du site de Libération.

\section{WEB 2.0, COMMENTAIRES ET BLOGS}

Le nouveau Libération.fr propose l'intégralité - gratuitement - du journal en ligne. Surtout, il mise sur l'interactivité, espère surfer sur la vague du Web 2.0 et sur les contributions des "libénautes", les fidèles du site, un phénomène dont a profité le site lors des mouvements anti-CPE et de l'affaire Clearstream. "Il est important que les internautes puissent dire ce qu'ils pensent, il y a une demande", justifie Denis Delbecq. Pourtant, tous les articles ne seront pas ouverts aux commentaires : la modération des réactions coûte cher.

Le site met en avant les blogs, attribués aux personnes choisies par la rédaction. "Pas question de faire du chiffre, d'accumuler les blogs : il s'agit d'experts dans un domaine, comme le blog effet de terre, ou celui consacré aux jeux vidéo ou à la Coupe du monde", explique Denis Delbecq.

\section{ABONNEMENTS PAYANTS À L'AUTOMNE}

Pour l'organisation et le modèle économique, pas de mystère : la rédaction est appelée à contribuer "à l'enrichissement en continu du site". Les journalistes tiennent également des blogs et conçoivent des contenus multimédias. "On s'éloigne du schéma où les rédacteurs pensent que le Web tue le papier. On est passé au bimédia au printemps, la rédaction commence à s'approprier le Web, notamment par l'utilisation du matériel de prise de vue et de prise de son", ajoute Denis Delbecq. Lors de la conférence de rédaction, les chefs de service donnent leur menu Web de la journée et la rédaction du journal assure une permanence auprès du site, au gré de l'actualité, pour le reste de la journée.

Pour son financement, Libération.fr a recours à la publicité, aux bandeaux et autres pop-ups : "Le modèle économique du site est fondé principalement sur les recettes publicitaires, indique la rédaction du journal 
dans un texte de présentation de sa nouvelle formule. C'est la condition pour que Libération.fr reste majoritairement gratuit. Mais la plupart des navigateurs intégrant désormais des fonctions 'anti-pop-up', les annonceurs en proposent de moins en moins. Sur la plupart des pages figurent également des liens sponsorisés."

Enfin, le site compte lancer, à la rentrée, une zone abonnés. "Un espace privilégié dans lequel l'internaute pourra tout à la fois bénéficier d'archives, de contenus à forte valeur ajoutée et d'une relation privilégiée avec les journalistes de Libération et les autres abonnés", avance le journal dans son texte de présentation. Enfin, une zone abonnés devrait voir le jour à l'automne.

Avec tous ces changements, Libération espère bien sûr voir le trafic augmenter sur son site. "L'ancien outil était antédiluvien, très vite les internautes se retrouvaient dans un entonnoir, les visites créaient peu de trafic", constate Denis Delbecq.

Pierre Bouvier

http://www.lemonde.fr/web/article/0,1-0,36-791098,0.html 
Enquête

\section{Vladimir Poutine, tsar du gaz}

LE MONDE | 03.07.06 | 15h04 • Mis à jour le 03.07.06 | 15h04

Vladimir Poutine aime commencer tard sa journée de travail. Le matin, dans sa résidence de NovoOgarevo, dans l'ouest huppé et verdoyant de Moscou, il lui arrive de faire de l'équitation ou des longueurs de piscine. A 53 ans, le président russe est un homme de petite taille, mince, qui cultive son corps. C'est un sportif, amateur de ski et de judo. On ne lui connaît aucun excès d'alcool, aucun geste inconvenant en public. A la télévision, il apparaît parfois une tasse de thé à la main. Ces petites choses sont appréciées des Russes, qui gardent un souvenir consterné des frasques et de la dégradation physique de Boris Eltsine. Une photo des années 1980 montre un tout autre Vladimir Poutine, pourtant. C'était à Dresde, en RDA. On le voit dans un jardin, torse nu, jouant au ping-pong, le ventre gras et flasque. Il était alors agent du KGB, d'un rang subalterne. Sa carrière ne décollait pas. Il buvait de la bière.

En fin de matinée, un cortège toutes sirènes hurlantes conduit le président russe vers son bureau dans l'aile nord-ouest du Kremlin, tout près des anciens appartements de Staline. L'endroit a conservé, d'après les témoins, une atmosphère surannée, avec boiseries, moquettes, et une multitude de téléphones alignés à la façon soviétique. Depuis Lénine, tous les numéros un russes ont dirigé le pays depuis ce bâtiment, un ancien palais du Sénat tsariste qui donne sur la place Rouge. Vladimir Poutine a une forte capacité de travail et enchaîne les entretiens jusqu'à minuit. Il absorbe les dossiers, avale des statistiques.

De caractère froid, il est appliqué. Ce n'est pas un orateur charismatique, capable d'électriser des foules comme son voisin de Biélorussie, le président Loukachenko - qui l'agace. Mais il articule bien, il est clair, et a l'humour grinçant. Longtemps, Vladimir Poutine a manifesté envers ses supérieurs une fiabilité irréprochable. Cette fidélité est la raison principale pour laquelle, alors qu'il était inconnu du grand public, il a été choisi par l'entourage de Boris Eltsine en 1999 pour assurer la relève du pouvoir. Il a hésité avant d'accepter.

C'est que Poutine a connu des périodes difficiles, dont il a su se relever. Notamment en 1990, lorsqu'il s'est retrouvé sans emploi, de retour d'Allemagne de l'Est, pris dans les fissures de l'URSS qui s'effondrait - "la plus grande catastrophe du $X X^{e}$ siècle", selon lui. Il a envisagé un temps de travailler comme chauffeur de taxi pour subvenir aux besoins de sa famille : Lioudmila, son épouse, effacée, ancienne hôtesse de l'air sur Aeroflot, Macha et Katia, ses filles, aujourd'hui étudiantes. Le KGB l'a finalement affecté à la faculté de droit de Leningrad, où il avait étudié. C'est là qu'il a approfondi ses liens avec Anatoli Sobtchak, le futur maire et l'étoile montante des réformateurs ou affairistes de la ville.

Aujourd'hui encore, ceux qui le côtoient sur des questions d'investissements affirment que les notions d'économie du président russe restent fortement marquées par son expérience personnelle. Celle d'un ancien responsable des relations économiques extérieures de Saint-Pétersbourg au début des années 1990, quand tous les coups étaient devenus possibles et que les mafias commençaient à se partager les biens d'Etat. 
Il est arrivé à Vladimir Poutine d'évoquer devant Gerhard Schröder un autre épisode difficile. Il s'agit du blocus de Leningrad pendant la guerre, et de la mort, en bas âge, de ses deux frères. Son père, Vladimir Spiridonovitch, était ouvrier, un homme austère et de peu de mots. Il a combattu les nazis dans un bataillon du NKVD, le prédécesseur du KGB. Désormais fils unique, Vladimir Poutine est né sept ans après le conflit mondial, lorsque sa mère avait 41 ans. Adolescent, il rêvait devant des films soviétiques d'espionnage. Il a décidé de rejoindre le KGB.

Son talent pour gagner la sympathie en évoquant des pans de vie personnelle relève, selon les connaisseurs à Moscou, d'une technique assimilée dans les écoles du KGB. Lors de sa première rencontre avec George Bush en 2001, Vladimir Poutine lui a parlé de religion, et d'une croix qu'aurait miraculeusement retrouvée sa mère après un incendie. Lorsqu'un soir de 1998, alors chef des services secrets, il a invité une jolie journaliste russe blonde à déguster des sushis dans un restaurant de Moscou, Vladimir Poutine a montré qu'il connaissait étonnamment son histoire familiale : il avait apparemment consulté ses fiches.

Sur le dossier de la Tchétchénie, Poutine a opté pour la force brute, sans états d'âme. Sa réputation de dirigeant à poigne vient d'ailleurs entièrement de là. Les morts se comptent par dizaines de milliers depuis 1999, l'année où la guerre l'a porté au pouvoir ; il n'a jamais eu un mot pour les victimes civiles ou pour les soldats russes tués. C'est pour lui une guerre entre "les nôtres" et "les autres", l'ennemi n'est à ses yeux qu'un fanatisme islamique, attisé par des forces extérieures conspirant pour affaiblir la Russie. Il a survolé un jour en hélicoptère Grozny et s'est agacé du paysage de ruines, conscient du problème d'image pour l'extérieur. Il s'est ainsi assuré depuis longtemps que les télévisions étrangères ne puissent travailler librement en Tchétchénie. Un jour au Kremlin, il a répondu à la militante démocratique Svetlana Gannouchkina, qui le prenait à partie sur les crimes perpétrés en Tchétchénie : "On a l'armée qu'on a."

Cela ne l'empêche pas, pendant que les troupes russes pratiquent la technique du fagot - on attache les Tchétchènes entre eux et on les fait sauter à l'explosif -, d'organiser avec un grand naturel, en mai 2003, les fastueuses cérémonies du tricentenaire de Saint-Pétersbourg. Les dignitaires du monde entier ont pu goûter un spectacle de Jet-Ski zigzaguant sur les eaux de la Neva, des bateaux à voile évoquant l'époque de Pierre le Grand le long de belles façades de palais restaurées.

Là, Vladimir Poutine était à son aise. Autant, au même moment, que lors du sommet avec l'Union européenne où il distribuait les tours de parole. Les représentants des pays d'Europe centrale candidats à l'intégration étaient relégués dans les coins de la salle, comme des cancres.

En dépit de sa facile réélection en mars 2004 pour un nouveau mandat de quatre ans, l'année qui a suivi a été pénible pour Poutine. Le démantèlement de la compagnie pétrolière Ioukos a terni son image, des attentats sanglants se sont succédé en Russie, culminant avec la prise d'otages de l'école de Beslan, en septembre 2004. Mais l'événement qui l'a le plus ébranlé a été la "révolution orange" en Ukraine. La perte de l'Ukraine a été pour Vladimir Poutine un important revers de politique étrangère. Capable de grande vulgarité lorsqu'il est contrarié, il a dit un jour à un officiel géorgien que, dans l'ex-URSS, "tous les dirigeants avaient chié dans leur pantalon" après la révolution en Géorgie. 
Ce sont aussi les inconvénients du système de pouvoir très fermé qu'il a mis en place : Vladimir Poutine ne disposerait que d'un nombre limité de cadres fiables. Arrivé dans la grande politique malgré lui, cet homme qui a dit un jour préférer l'ombre à la lumière et ne pas aimer les élections, s'en remet à un groupe étroit de conseillers qu'il a connus pour la plupart à Saint-Pétersbourg ou au KGB.

Il a l'habitude de lire chaque jour en abondance les spravki, les fiches que lui fournit le FSB, les services secrets. Et sur l'Ukraine, ses informateurs l'avaient malheureusement assuré de la victoire du candidat de Moscou. Comme dans toutes les crises, que ce soit le naufrage du sous-marin Koursk en août 2000, les prises d'otages dans le théâtre de la Doubrovka en octobre 2002, ou celles de Beslan, aucun responsable fédéral de haut rang n'a été sanctionné.

Chaque soir, les Russes voient la télévision nationale dresser le portrait d'un président décidé et infaillible. En privé, des membres de son entourage le décrivent comme un président hésitant, susceptible de succomber à des influences diverses. Un "type humain qui fait des erreurs", a confié un jour à des journalistes son ancien chef d'administration, Alexandre Volochine. Notamment dans l'affaire Ioukos, que Vladimir Poutine n'aurait pas maîtrisée de bout en bout.

Des ambassadeurs occidentaux conviennent cependant de la difficulté de la tâche, dans un pays aussi étendu, aussi complexe, rongé par la corruption et la bureaucratie. "N'imaginez pas que Poutine se lève le matin, décide quelque chose, et que ce quelque chose se réalise. Ça ne se passe pas comme ça", indique l'un d'entre eux.

Mais d'autres sources, russes, affirment que Poutine "décide de tout, personnellement". Même du contenu du journal Izvestia, auquel il a ordonné en 2005 d'être "plus patriotique". L'exaltation d'un patriotisme militariste et la promotion d'une vision de la Russie comme forteresse assiégée à la fois par les Occidentaux et par les islamistes, sont des éléments récurrents du discours du Kremlin. Les "révolutions de couleur" dans l'ex-URSS et le drame de Beslan en septembre 2004 ont accentué ce réflexe : il s'agit de souder le pays en brandissant un ennemi extérieur.

Les décisions importantes sont ainsi prises par un groupe très restreint qui se réunit en principe le samedi matin, dans la résidence de Novo-Ogarevo, autour de Vladimir Poutine. Les médias sont tenus à l'écart. Certains, à Moscou, ont parlé de "petit Sovnarkom", l'acronyme du "Soviet des commissaires du peuple", qui désignait le coeur du pouvoir sous Lénine et Staline. Le groupe se compose de deux ou trois ministres, du chef de l'administration présidentielle, des représentants des forces de l'ordre et des services de sécurité. Poutine s'intéresse surtout à la stratégie énergétique de la Russie. Sans la flambée des prix des hydrocarbures dans le monde, la Russie serait un tout autre pays. C'est le coeur de la reprise économique, du remboursement de la dette extérieure, et du retour du pays sur la scène internationale, après l'effacement des années 1990. Mais selon les experts, pour continuer sur cette lancée, le pays a besoin d'énormes investissements, d'ouvrir de nouveaux gisements, de construire de nouveaux pipelines.

Beaucoup de ces questions n'ont pas encore été tranchées. Le président s'est pris d'un grand intérêt pour ce secteur, surtout le gaz, dont la Russie détient les premières réserves mondiales. On prête à Vladimir Poutine 
l'intention, s'il se retire des affaires en 2008, de prendre la tête d'un grand conglomérat énergétique d'Etat. Comme son ami Gerhard Schröder, qu'il a fait nommer à la tête d'une structure de Gazprom.

Le $1^{\mathrm{er}}$ janvier 2006, le monde européen de l'énergie a tremblé lorsque la Russie a coupé ses livraisons de gaz à l'Ukraine, en raison d'une dispute sur le prix. En plein hiver, les approvisionnements de l'Europe étaient menacés. Selon le Spiegel, Gerhard Schröder a dû prendre son téléphone pour dire à Poutine de rouvrir le robinet, ce qu'il a fait trois jours plus tard. Le 31 décembre 2005, le président russe tenait une réunion d'urgence avec les responsables du gaz, et appelait à un accord avec les Ukrainiens. Selon des diplomates, il n'était pas très favorable à une hausse brusque du tarif pour l'Ukraine.

Les responsables des finances du géant gazier auraient insisté. "L'histoire a été très mal gérée par les Russes, et leur a coûté cher en termes d'image, commente un diplomate allemand. Couper le gaz, c'est comme utiliser l'arme atomique. C'est la menace qui est efficace, pas le fait d'appuyer sur le bouton."

Lors du G-8 que présidera pour la première fois la Russie, du 15 au 17 juillet à Saint-Pétersbourg, Vladimir Poutine présentera sa conception de la "sécurité énergétique" aux dirigeants des sept pays les plus industrialisés du monde. Les échanges s'annoncent complexes. Dans les entretiens qu'il a pu avoir ces derniers mois avec des responsables occidentaux, le président russe s'est montré très confiant et offensif. "Il est obsédé par une seule question, l'énergie, dit une source européenne qui l'a côtoyé. Il a un discours nationaliste, l'énergie est le coeur de la puissance russe. Il manifeste par ailleurs un grand mépris pour les Américains, qui n'ont pas compris, selon lui, comment fonctionnent le monde, le terrorisme, l'islam..."

On a dit en 2005 à Moscou que Vladimir Poutine avait laissé le clan des "durs", les nationalistes emmenés par Igor Setchine, le patron de la compagnie Rosneft qui a avalé Ioukos, prendre le dessus. Igor Setchine est un ancien "interprète" du KGB en Afrique qui a longtemps travaillé pour Poutine comme simple assistant. "Il lui apportait des papiers et gérait son agenda, raconte un connaisseur. Mais, comme du temps d'Eltsine, celui qui gère l'accès physique au président occupe une place stratégique. Setchine et ses alliés ont développé d'importants appétits financiers."

Vladimir Poutine cherche en fait à contrebalancer les influences. Il a repris contact avec un personnage-clé des années Eltsine, l'ancien chef de l'administration présidentielle Alexandre Volochine, qui avait démissionné après l'arrestation du patron de Ioukos. Il l'a consulté sur les questions ukrainiennes, après la débâcle de 2004-2005. Le président entretient aussi des liens discrets avec le jeune oligarque Roman Abramovitch, qui l'a aidé à transférer vers l'Etat d'importants actifs pétroliers - renforçant au passage sa considérable fortune personnelle.

Après plus de six années au pouvoir, Vladimir Poutine ne paraît pas enthousiaste à l'idée de briguer un troisième mandat en 2008. Il assure ne pas vouloir modifier la Constitution de 1993, dont il s'est pourtant écarté en centralisant fortement le pouvoir et en réduisant les libertés publiques. Il a mis en piste deux hommes de confiance comme potentiels successeurs, Sergueï Ivanov et Dimitri Medvedev, mais rien n'indique que son choix soit arrêté. 
"A l'instar de l'entourage d'Eltsine, Poutine voudra des garanties de sécurité et d'immunité avant d'envisager de partir", a commenté Alexeï Venediktov, le patron de la radio Echo de Moscou. Ce média très écouté dans la capitale russe jouit d'une certaine liberté de ton, à l'intérieur de bornes fixées par le Kremlin : jamais, par exemple, de reportages sur la Tchétchénie.

Vadimir Poutine laisse ainsi coexister plusieurs tendances au sein de son parti hégémonique "Russie unie", qui a atteint le million de membres (la Russie compte 143 millions d'habitants). Parmi les tenants d'une ligne plus libérale, évolue le banquier mondain Alexandre Lebedev, qui s'est retrouvé dans Paris Match pour avoir financé une soirée en l'honneur de la fondation Raïssa-

Gorbatchev, dans le château de la famille de Lady Di, à Althorp. Ancien agent du KGB à Londres, chose dont il se targue presque, ce milliardaire raconte qu'à l'image de Poutine en 1990-1991, il s'est retrouvé perdu quand l'URSS a disparu.

A deux pas de la Loubianka, le siège des services spéciaux à Moscou, un restaurant entièrement consacré à la glorification du KGB a ouvert il y a quelques années. Il s'appelle "Le Bouclier et l'Epée". On y voit des tableaux représentant Staline, une statue en pied de Felix Dzerjinski, le chef de la première police politique, la Tcheka, et on y écoute des chants militaires soviétiques. C'est là que des responsables du FSB se réunissent, dit-on, pour célébrer l'anniversaire d'Andropov.

Vladimir Poutine a effacé un des legs de l'époque Eltsine en rendant ce genre d'endroit possible, voire populaire. La pierre des Solovki, hommage aux millions de victimes du goulag, gît discrètement près de là. Jamais visitée par ceux qui dirigent aujourd'hui la Russie.

Natalie Nougayrède

Article paru dans l'édition du 04.07.06

http://www.lemonde.fr/web/article/0,1-0,36-791244,0.html

http://www.lemonde.fr/web/article/0,1-0,36-791244@45-1,0.html

http://www.lemonde.fr/web/article/0,1-0,36-791244@45-2,0.html 


\section{Analyse \\ Energie et climat : sortir de la frénésie, par Hervé Kempf}

LE MONDE | 04.07.06 | 12h51 • Mis à jour le 04.07.06 | 12h51

La contradiction entre le discours proclamé et la réalité des actes est devenue une telle constante de la vie politique que l'on finit par ne plus s'en étonner. Il est cependant un domaine où cette contradiction est si lourde de conséquences pour l'avenir qu'il est nécessaire de la souligner : la divergence entre la politique énergétique suivie et l'évolution probable du changement climatique.

La question du changement climatique n'a cessé de grossir en importance dans les dernières années, au point que des parlementaires, dont la prose est généralement marquée par la plus grande modération, n'hésitent pas à parler de "catastrophes climatiques annoncées", comme les députés Jean-Yves Le Déaut (PS) et Nathalie Kosciusko-Morizet (UMP), dans un récent rapport sur l'effet de serre (Le Monde du 14 avril). De même, les sénateurs Pierre Laffitte (RDSE) et Claude Saunier (PS) affirment dans un rapport publié prochainement que les "conséquences du changement climatique sont très sous-estimées". Ces textes ne sont que les productions les plus récentes d'une liste devenue impressionnante de cris d'alarme lancés par experts et scientifiques.

Et, officiellement, la France se fixe pour objectif de réduire de $80 \%$ ses émissions de gaz à effet de serre en 2050. Cela implique une réduction de l'ordre de $3 \%$ par an des émissions de gaz à effet de serre dès aujourd'hui.

Or qu'observe-t-on en matière de production énergétique ? Que la France s'apprête à mettre en service plus de 10000 mégawatts (MW) de capacité de production électrique à combustible fossile d'ici à 2012, soit l'équivalent de près de dix réacteurs nucléaires. EDF planifie ainsi la mise en service de $3100 \mathrm{MW}$, Poweo de 2800 MW, SNET de 2000 MW, Gaz de France de 1430 MW, Suez de 840 MW. Aucun des opérateurs n'indique avoir calculé les émissions de gaz carbonique produites par ces nouvelles capacités. Et pour cause : même si une partie - environ $2000 \mathrm{MW}$ - correspond au remplacement de centrales à charbon très émissives par des centrales à gaz qui le sont beaucoup moins, le bilan global n'en sera pas moins inévitablement défavorable.

Une centrale à cycle combiné à gaz, d'une puissance de 400 MW, fonctionnant 6000 heures par an (soit 68 $\%$ du temps), rejette ainsi environ 960000 tonnes de gaz carbonique par an.

A ces capacités nouvelles, s'ajouteraient de surcroît au moins un réacteur nucléaire, dit EPR, de 1600 MW et un parc éolien approchant $2000 \mathrm{MW}$. Si ces énergies n'émettent pas de gaz à effet de serre, elles ont un impact écologique important : déchets nucléaires et lignes à haute tension liées à l'EPR, comme dans la Manche et le parc naturel du Verdon, rupture et banalisation des paysages ruraux par la multiplication des éoliennes.

Comment s'explique cette frénésie de construction de capacités électriques de toutes sortes, si contraire à la nécessité proclamée de prendre en compte le changement climatique et l'environnement ? Par le dogme intangible qu'il est inéluctable d'augmenter la consommation électrique : selon RTE (Réseau de transport 
d'électricité), elle devrait croître en France de 1,7 \% par an jusqu'en 2010 - soit un taux à peine inférieur à la croissance économique -, puis de 1,2 \% par an. Cette prévision découle d'une prolongation des tendances actuelles, de l'apparition de nouvelles sources de consommation - comme la climatisation en été -, et d'un report sur l'électricité de divers usages, surtout industriels, du pétrole. Mais elle est surtout l'effet de l'absence de politique sérieuse de plafonnement de la consommation d'électricité.

En Europe, la logique est la même : augmentation de la consommation d'électricité et des capacités de production. Du fait de l'augmentation du prix du gaz - peu ou prou aligné sur celui du pétrole -, certains analystes prévoient même un retour du charbon, moins cher mais plus émetteur en gaz carbonique.

\section{ALIBI ÉCOLOGIQUE}

Dans la logique dominante, ce n'est donc pas, au mieux, avant le milieu de la décennie prochaine que le secteur électrique pourrait commencer à réduire ses émissions de gaz à effet de serre. Dans cette optique, le développement des énergies renouvelables ne sert que d'alibi écologique à une politique sur le fond inchangée. Elles ne transformeront pas la donne. Ainsi, l'Espagne, qui est un des champions mondiaux de l'éolien avec plus de 10000 MW d'aérogénérateurs installés, est pourtant un très mauvais élève de la classe climatique : ses émissions de gaz à effet de serre dépassent de plus de $40 \%$ son niveau de 1990 alors que, en application du protocole de Kyoto, elle ne devrait pas dépasser +16 \% en 2010.

Pourquoi les gouvernements prennent-ils pour acquise l'augmentation de la consommation d'électricité ? D'abord parce que, dans la foulée de la libéralisation promue par l'Europe dans les années 1990, ils se sont privés des moyens d'orienter la politique énergétique. "Tout est laissé à l'initiative du marché, juge Pierre Radanne, consultant indépendant, alors que les opérateurs visent essentiellement à rémunérer leurs actionnaires." Le critère dominant la politique publique est ainsi la mise en place d'acteurs nationaux puissants dans le cadre d'un marché ouvert. Or les producteurs sont dans une logique d'offre. Ils font ce qu'ils savent faire : produire plus. A l'inverse, comme le remarque Benjamin Dessus, du groupe de réflexion Global Chance, "il n'y a pas de lobby de l'économie d'énergie", alors même qu'il y a là un important gisement d'efficacité économique et d'emplois.

La réduction des consommations d'énergie est en effet le meilleur moyen pour atteindre l'objectif de réduction drastique des émissions de gaz à effet de serre. Une étude que vient de publier Global Chance montre que, même si l'on poursuivait au maximum de leurs possibilités dans le monde les programmes nucléaires et d'énergies renouvelables, on ne parviendrait en 2030 qu'à stabiliser les émissions de gaz à effet de serre, dès lors que la croissance de la consommation d'électricité se poursuivrait. Inversement, "le scénario fondé sur un programme de maîtrise de la demande d'énergie permettrait à lui seul la stabilisation des émissions beaucoup plus tôt, vers 2025".

Il serait utile que les responsables politiques qui disent se préoccuper du changement climatique interrogent sérieusement le dogme de l'augmentation inévitable de la consommation. Peut-être pourraient-ils s'appuyer sur l'analyse économique, en se demandant ce qu'il vaut mieux pour la collectivité : accroître la rente des vendeurs de gaz et des producteurs d'électricité, ou augmenter les emplois et diminuer la facture énergétique du pays en promouvant l'efficacité énergétique? 
Hervé Kempf

Article paru dans l'édition du 05.07.06

http://www.lemonde.fr/web/article/0,1-0,36-791622,0.html 
Point de vue

Le véritable apport de Mme Royal, par Zaki Laïdi

LE MONDE | 04.07.06 | 12h59 • Mis à jour le 04.07.06 | 12h59

Il y a deux mois, il était encore possible de réduire le phénomène Ségolène Royal à une bulle médiatique que la confrontation avec le monde réel ferait éclater. Depuis le $1^{\mathrm{er}}$ juin, cette interprétation se trouve non pas totalement démentie mais sévèrement infléchie par un fait majeur : l'augmentation considérable du nombre d'adhérents au PS, leur détermination à participer à la désignation du futur candidat socialiste à la présidentielle.

Certes, il est encore trop tôt pour affirmer que tous ou même la majorité de ces nouveaux militants voteront mécaniquement pour $\mathrm{M}^{\mathrm{me}}$ Royal. Mais au regard de leur sociologie très marquée (jeunes, diplômés, urbains) et de leur mobilisation en masse, on peut imaginer que leur intervention dans la désignation du candidat répond à une volonté de renouvellement, peut-être surfaite mais en tout cas réelle.

Il faut donc prendre le "ségolisme" au sérieux. Il exprime la transformation profonde du sens du politique, qui n'est plus cette réalité qui transcende les hommes pour les projeter dans un monde ou une société différente, mais pour les aider à se réaliser dans leur vécu. Le "ségolisme" n'est ni plus ni moins que l'incarnation de cette révolution où les individus pris en société ne peuvent vivre, s'exprimer et se situer que par rapport à des "mondes vécus", c'est-à-dire par rapport à des contextes professionnels, identitaires, culturels qui organisent leur vie. La révolution des "mondes vécus" n'abolit pas le collectif, mais elle prend son sens premier dans l'individu pour qui un projet de société ne peut plus ressembler à un modèle clés en main renvoyant à un "autre monde". Cela ne signifie pas que l'individu n'ait plus besoin de politique, bien au contraire : ses demandes vis-à-vis du politique s'accroissent et touchent tous les domaines de sa vie. Le politique n'est plus tout mais il est dans tout. Voilà la réalité de notre temps et voilà ce que le "ségolisme" tente de capter.

La forme légitime du politique devient ce que les Anglais ont appelé la life politics, la politique de la vie. La life politics part du bas, des problèmes du quotidien. Elle politise même des sujets qui ne l'étaient pas forcément, comme la scolarisation précoce, le bizutage, etc. Elle détruit ainsi la distinction aristocratique entre haute politique et problèmes de la vie quotidienne. Mais du même coup, déclasse l'expertise, brise symboliquement la distance entre celui qui sait et celui qui doit savoir, précisément parce qu'elle préjuge que chaque citoyen est porteur d'une vérité, d'un fragment d'expérience et de savoir. Et si Ségolène Royal est la seule personnalité politique qui suscite la sympathie des blogueurs, c'est parce que la philosophie des blogs repose sur l'idée que chacun peut apporter son savoir, son expérience en la communiquant aux autres.

Il y a naturellement dans toute cette réalité une part d'illusion, de confusion des genres et de démagogie potentielle. D'autant que l'exemple de $\mathrm{M}$. Blair est là pour nous montrer combien une philosophie fondée précisément sur la life politics a débouché sur une concentration sans précédent du pouvoir politique en Grande-Bretagne. Et il n'y a a priori aucune raison que la France échappe par enchantement à un tel détournement. Mais le fait est là, ce lien au réel du quotidien est bien installé en France. Et le fait que la démocratie d'opinion soit en train de dynamiter la sociologie des militants du PS en est l'expression. Elle 
bouleverse la hiérarchie des problèmes en survalorisant les enjeux de vie en société par rapport à des questions plus classiques comme la renationalisation de l'électricité par exemple. Elle bouscule les clivages traditionnels, précisément parce qu'elle part de problèmes que les individus n'appréhendent pas sur la base de clivages partisans.

Le "ségolisme" renvoie aussi à une technique politique fondée sur ce que le sondeur américain Dick Morris avait appelé la triangulation politique. Elle a été mise en oeuvre par Bill Clinton avant d'être reprise par Tony Blair. Elle part de l'idée que la droite est politiquement et sociologiquement plus forte que la gauche sur certains sujets, et que les chances de celle-ci seront obérées si elle ignore ou si elle attaque frontalement les valeurs de cette droite.

D'où l'idée de s'approprier certaines thématiques de droite, quitte à en faire un usage politique différent de celui de la droite. Ainsi la gauche peut faire d'une pierre deux coups : conquérir un espace à droite tout en donnant à cette conquête un contenu de gauche. C'est ce qu'a fait Bill Clinton par exemple sur la question de l'équilibre budgétaire. Il a cassé l'image de démocrates impécunieux, y compris en coupant sur les budgets sociaux, mais a réorienté aussi les dépenses publiques dans un sens plus redistributif.

Dans la triangulation, il y a donc deux dimensions : une première qui reflète l'emprise de la life politics dans les représentations du politique, c'est-à-dire qui atténue l'écart traditionnel entre la gauche et la droite. Une seconde qui traduit la volonté de la gauche de conquérir le pouvoir en tentant d'asphyxier la droite. C'est ce que fait Ségolène Royal en évoquant le sujet de l'insécurité et en allant jusqu'à parler d'encadrement militaire pour les délinquants. La référence symbolique à "l'encadrement militaire" la rend populaire à droite, sans pour autant la couper totalement de la gauche puisqu'il lui est tout à fait possible de démontrer qu'un encadrement militaire est socialement préférable à un emprisonnement. La mise sous tutelle des allocations familiales répond au même souci et produit les mêmes effets. Le positionnement paraît spectaculairement autoritaire et coercitif alors que, dans les faits, il s'inscrit dans une logique de rééducation et de responsabilisation.

L'avantage de la triangulation ne s'arrête pas là. Car il donne l'impression de dynamiter les clivages politiques en proposant des solutions nouvelles, qui en réalité ne le sont pas toujours. L'encadrement militaire des jeunes délinquants a déjà été essayé et a été abandonné. Et la mise sous tutelle - qui n'est d'ailleurs pas la suspension - est déjà mise en oeuvre par les juges.

La question, maintenant, est de savoir comment ce double mouvement d'identification à la life politics et de triangulation peut s'étendre et se développer. A l'évidence, le deuxième chapitre de son livre en ligne sur le site Désirs d'avenir paraît insuffisamment mûri. Les observateurs n'ont retenu que la critique des 35 heures qui, elle aussi, a fait l'objet d'une triangulation parfaite : critique des limites de cette loi honnie par la droite, mais insistance sur les dégâts réels ou supposés causés sur les couches populaires. Le reste du document s'inspire de la même démarche mais sans convaincre. Le développement consacré aux délocalisations est d'une très grande confusion. Ségolène Royal cherche, à juste titre, à mettre fin à la diabolisation caricaturale par la gauche de la mondialisation sans sous-estimer les déséquilibres engendrés par cette même mondialisation. Mais elle est loin d'avoir trouvé sur ce registre une expression appropriée. 
Il faut prendre le "ségolisme" au sérieux en se déprenant de deux travers qui brouillent son appréciation sereine : la "peopolisation" du jugement politique qui conduit à une adhésion paresseuse à ce qui est à la mode, et son envers, sa disqualification automatique au prétexte qu'elle enfreindrait les règles du jeu politique classique.

Zaki Laïdi est politologue au Centre d'études et de recherches internationales (CERI). Article paru dans l'édition du 05.07.06

http://www.lemonde.fr/web/article/0,1-0,36-791686,0.html 
Entretien

"Des guerriers, pas des techniciens"

LE MONDE | 05.07.06 | 09h36 • Mis à jour le 05.07.06 | 10h00

Bernard Lama suit le Mondial comme consultant pour Canal+. Ancien gardien de but du Paris-SaintGermain, il a été champion du monde en 1998 et champion d'Europe en 2000. Entre février 1993 et septembre 2000, il a joué à 44 reprises sous le maillot de l'équipe de France. Il nous livre ses observations sur le tournoi et plus particulièrement sur le parcours des Bleus.

Quelle appréciation portez-vous sur cette Coupe du monde ?

Nous avons assisté à des rencontres de bon niveau tant sur le plan physique que technique. Lors du premier tour, l'Argentine et l'Espagne ont livré des rencontres intéressantes. L'Equateur et le Ghana ont marqué les esprits. Je regrette simplement que les arbitres aient perdu la maîtrise d'un certain nombre de matches. Le spectacle en a souffert.

Quels sont les joueurs qui vous ont impressionné ?

Sur la durée du tournoi, personne n'a vraiment brillé. Il n'y a pas eu de révélation. En revanche, j'ai été déçu par les Brésiliens, en particulier par Kaka et Ronaldinho. D'une manière générale, j'attendais davantage des Pays-Bas, qui n'ont pas manifesté un bon état d'esprit. Je n'ai pas aimé l'agressivité de leurs joueurs devant le Portugal.

\section{A l'exception du Ghana, le premier tour a été fatal aux pays africains et asiatiques. Comment interprétez-vous leurs échecs?}

La Corée du Sud et le Japon, qui ne sont tout de même plus des néophytes, n'ont pas répondu aux espoirs placés en eux. Quant aux représentants de l'Afrique, n'oublions pas qu'ils ont été volés par l'arbitrage. Cela n'explique pas tout. Les joueurs de ce continent ont tout pour réussir, mais ils souffrent d'un environnement défaillant. Regardez ce qui s'est passé avec le Togo, qui a été miné par cette histoire de primes. Les équipes africaines ne progresseront que lorsqu'elles seront libérées de leurs problèmes d'infrastructures. S'y ajoutent des problèmes d'encadrement technique. Il y a trop de mercenaires autour des sélections alors qu'il faudrait entreprendre un travail à long terme pour développer les qualités naturelles des footballeurs africains.

Les performances de l'équipe de France lors du premier tour ont fait l'objet de critiques de la part de plusieurs champions du monde de 1998 . Avez-vous partagé leur déception?

Je faisais partie des déçus du premier match devant la Suisse. Ensuite, j'ai noté une amélioration face à la Corée du Sud, même si le résultat n'était pas celui que nous attendions. Globalement, le jeu pratiqué par l'équipe de France n'était pas satisfaisant. Quand on n'est pas bon, il faut savoir accepter les critiques. J'ai constaté qu'il n'y avait pas de progrès par rapport au niveau de jeu présenté durant les éliminatoires. Au niveau de l'ambiance, de l'état d'esprit et de la qualité du football, il était légitime de s'interroger. 


\section{Que voulez-vous dire quand vous parlez de l'ambiance?}

Il y avait des tensions entre le sélectionneur et certains joueurs. La qualification pour les huitièmes de finale a ensuite libéré les esprits et installé l'indispensable climat de solidarité.

Croyez-vous qu'il faille nécessairement une relation d'amitié entre le sélectionneur et ses joueurs pour obtenir des résultats?

Ce n'est pas ce que je dis, mais il faut du respect et de la camaraderie pour aller au bout d'une Coupe du monde, qui dure tout de même un mois. Je crois que le parcours de l'équipe de France depuis la fin de la phase des poules a permis un rapprochement. Cette équipe avait besoin d'oublier le souvenir du Mondial raté de 2002 et d'écrire sa propre histoire. C'est ainsi que l'on cimente un groupe.

\section{Que pensez-vous des performances de Zinédine Zidane ?}

Il a réalisé un bon tournoi. Devant le Brésil, il a atteint le sommet. C'est extraordinaire pour lui de terminer sa carrière sur une Coupe du monde réussie.

\section{Le football français va-t-il profiter del'élan généré par cette Coupe du monde ?}

Je n'en suis pas sûr du tout. Le triomphe du Mondial 1998 a suscité un mouvement qui n'a pas perduré. La France a du mal à considérer le sport comme une activité économique à part entière. Prenez l'exemple de nos stades. A l'inverse de l'Allemagne, nous n'avons pas profité de notre Coupe du monde pour en créer, à l'exception du Stade de France, ou les mettre aux normes de la modernité.

Les résultats de la France n'ont pas pleinement convaincu les observateurs étrangers, qui regrettent un jeu trop frileux à leur goût. Qu'en pensez-vous?

Nous ne pouvons pas jouer comme l'Argentine ou le Brésil. Comme beaucoup de pays européens, nous privilégions la rigueur en positionnant neuf joueurs derrière le ballon.

Partagez-vous les réserves émises sur la qualité technique des joueurs français?

Oui. Ces dernières années nous avons davantage formé des athlètes, des guerriers, plutôt que des techniciens. Aujourd'hui, nous avons des joueurs qui courent vite et qui sautent haut. Dès lors, il ne faut pas s'étonner des difficultés rencontrées pour créer le jeu ou réaliser des attaques placées. Au niveau de la formation des jeunes, nous avons été moins vigilants sur le volet technique. Dans la tête des entraîneurs, le football français est naturellement doué techniquement, mais c'est un leurre. Au bout de la chaîne, on retrouve une équipe de France faite uniquement pour pratiquer la contre-attaque. Si nous voulons rester au sommet de la hiérarchie, il va falloir remettre en cause des certitudes surannées.

Pour terminer, avez-vous compris les états d'âme de Grégory Coupet, qui a quitté un moment l'équipe de France lors du stage de Tignes avant de revenir? 
Je les ai parfaitement compris pour avoir vécu une situation analogue lors du Mondial 1998 quand Aimé Jacquet m'a annoncé au stage de Casablanca que je serais le no2 dans la hiérarchie des gardiens de but. Pendant toute la durée de la compétition, il faut prendre sur soi. Cela s'est bien passé pour moi, car nous sommes devenus champions du monde. J'ai eu l'occasion de parler avec Grégory. Je lui ai dit que ça ira mieux dans quelque temps. Il a encore de belles années devant lui. Au Mondial 2010, il aura l'âge de Jens Lehmann, le gardien de l'Allemagne.

Elie Barth

http://www.lemonde.fr/web/article/0,1-0,36-792014,0.html 
Point de vue

\section{Laissez de Gaulle en paix !, par Edouard Balladur}

LE MONDE | 05.07.06 | 13h33 • Mis à jour le 05.07.06 | 13 h33

Voici que renaît le débat sur la politique économique nécessaire à notre pays. Il n'est pas nouveau. Il y a déjà des années, certains avaient fait l'apologie du déficit budgétaire, remède miracle pour relancer notre économie, de la faiblesse de la monnaie, indispensable au soutien de nos exportations, de la baisse des taux d'intérêt, garantie d'un investissement accru et d'une productivité meilleure.

On a vu ce qu'il en est advenu. Le déficit des finances publiques est demeuré l'un des plus importants en proportion de la richesse nationale, les taux d'intérêt de la Banque centrale européenne sont parmi les plus bas au monde. Pour autant, les problèmes de la France ont-ils été résolus ? En aucune manière : la croissance est insuffisante comparée au reste du monde, le commerce extérieur en déficit, le chômage l'un des plus importants au monde en proportion de la population active, l'endettement public a progressé de façon massive, quant à la fracture sociale, quel que soit le critère qui permette de la qualifier, elle n'a pas été réduite, tout au contraire. Apparemment, tout cela ne sert pas de leçon aux propagandistes de "l'autre politique", et à leurs thèses.

Mais il y a plus grave. Ces thèses, finalement fondées sur une politique de facilité et de laisser-aller, se réclament de De Gaulle alors que rien n'est plus contraire à sa pensée et à son action. Rappellerai-je que le redressement français, tel qu'il le voulut en 1958, était fondé sur la force de la monnaie et sur la bonne santé des finances publiques et sociales ? Chacun a le souvenir de la prospérité qui en est résultée. Rappellerai-je aussi que rien n'est plus opposé à l'état d'esprit et à l'attitude morale de De Gaulle que de s'en prendre aux autres des déceptions, des épreuves de la nation ? En 1940, il n'a pas imputé aux Anglais et aux Américains l'effondrement de la France, mais à nos faiblesses intérieures et aux erreurs de nos chefs militaires ; en 1958, il n'a pas attribué au rôle de l'étranger nos difficultés coloniales et algériennes, mais à notre absence de lucidité et de volonté ; et quand il a décidé notre entrée dans le Marché commun, il a entendu ouvrir notre pays à la compétition et à la liberté et l'a forcé à s'adapter au monde. Pour de Gaulle, les problèmes de la France devaient être résolus par les Français, par leur volonté, par la politique qu'ils choisissaient, ils devaient s'en sentir responsables, et eux seuls.

Pour ceux qui prônent un prétendu renouveau de la politique économique, de quoi s'agit-il aujourd'hui ? Contre toute vérité, d'attribuer à la Banque centrale européenne l'atonie de notre économie, de faire baisser artificiellement l'euro afin de nous dispenser de tout effort national, de réclamer davantage encore de déficits publics, alors qu'ils sont parmi les plus élevés du monde. C'est véritablement confondre les conséquences et les causes et s'empêtrer dans des contradictions intellectuelles. Les baptiser "gaullisme social" ne suffit pas à les légitimer. Pour de Gaulle seul l'effort collectif national permettait le progrès et la juste participation de tous à ses fruits.

Laissons donc "l'autre politique" au vestiaire des idées mortes! Soyons cohérents, soyons lucides et volontaires : le redressement de la France ne dépend pas des autres, ni de la levée des contraintes que les autres lui imposeraient, il dépend d'elle-même. Soyons capables, enfin, de réformer l'Etat, de diminuer les 
dépenses collectives et les excès de la redistribution, de récompenser le mérite, ce qui suppose d'abaisser les prélèvements publics et de pousser à l'augmentation des revenus directs, de réformer le marché du travail pour le rendre plus souple, de développer la rapidité de nos capacités de réaction dans la compétition mondiale, de réformer notre système de santé, d'améliorer les résultats de nos universités en leur donnant l'autonomie. Tout cela, nous pouvons l'atteindre avec une monnaie stable et des taux d'intérêt faibles, comme aujourd'hui.

Voilà les réformes qui nous rendront la croissance et l'emploi et qui amélioreront la justice sociale et la force du pays. Elles ne dépendent que de nous-mêmes.

Edouard Balladur, ancien premier ministre (1993-1995), est député UMP de Paris.

Article paru dans l'édition du 06.07.06

http://www.lemonde.fr/web/article/0,1-0,36-792173,0.html 
Portrait

\section{Willy Sagnol fait parler son autorité}

LE MONDE | 06.07.06 | 10h12 • Mis à jour le 06.07.06 | 10 h12

(envoyé spécial à Munich)

Stade de Munich, mercredi 5juillet, peu avant minuit. Plusieurs centaines de journalistes agglutinés derrière des barrières attendent la sortie des joueurs. Willy Sagnol, 29ans, passe au travers de cette forêt de micros et de stylos sans un mot, juste quelques signes lointains de reconnaissance. Les Bleus viennent de battre le Portugal (1-0), sont qualifiés pour la finale de la Coupe du monde, cela lui suffit, il n'a rien à ajouter. La preuve est faite, il est sûrement heureux.

Pendant l'échauffement d'avant-match, il a envoyé des baisers à sa femme et à sa petite fille qui le regardaient des tribunes. Après la victoire, dans les escaliers qui mènent aux vestiaires, il s'est assis pour pleurer, un drapeau tricolore autour du cou.

Il est chez lui dans ce stade et dans cette ville. Willy Sagnol joue sous les couleurs du Bayern Munich depuis 2001. En Bavière, il a accumulé les trophées et le soutien inconditionnel des supporteurs munichois qui scandent son prénom à chaque match. C'est pourquoi, ce Mondial, il voulait le réussir, ne pas revivre le désastre de 2002, en Corée du Sud, où, remplaçant, il s'était senti "inutile". C'est pourquoi encore, il y a quinze jours, quand les Bleus balbutiaient leur football, il avait parlé, et pas pour ne rien dire.

Extraits. Willy Sagnol n'a pas regardé le Mondial à la télé : "On dort foot, on mange foot, on pense foot, alors si en plus..." Willy Sagnol n'a pas supporté ceux qui ont critiqué l'équipe de France. Aux anciens champions du monde passés commentateurs qui avaient émis des réserves sur le jeu des Bleus de 2006, il a lancé un "ferme ta gueule" définitif. L'invective va sûrement lui être souvent rappelée, Willy Sagnol s'en moque. De toute manière, il n'apprécie guère les journalistes qui "ont raconté des choses absurdes" sur le stage de Tignes et qui se plaisent à lancer des "polémiques". Il leur a dit en face.

Willy Sagnol a détesté les sifflets du Stade de France, fin mai, lors du match de préparation contre le Mexique (1-0) : "Le public parisien, on a l'impression qu'il vient à un spectacle." Un seul public lui va, celui de Saint-Etienne, sa ville de cœur. Willy Sagnol est certes connu, mais il "n'a pas demandé à être un dieu vivant". Il plaint Zinédine Zidane de ce qu'il "endure". Willy Sagnol veut continuer à faire tranquillement son marché le samedi matin.

Pour un peu, à l'entendre, il serait mauvais coucheur, atrabilaire, têtu obstiné, râleur perpétuel. Ses coéquipiers racontent qu'il lui arrive parfois de piquer des colères, c'est sa manière de sonner l'alarme quand il sent que les choses vont de travers. Il peut le faire dans l'intimité du groupe, ou choisir l'extérieur (via la presse, donc). En septembre 2005, après la victoire des Français contre les îles Féroé (3-0), il avait tancé ses camarades qui se croyaient déjà en Allemagne : "Nous avons oublié les fondamentaux. A un moment on s'est vu trop beaux, chacun a essayé de faire son petit numéro." La leçon a été entendue et diversement appréciée. Mais, avec désormais 44sélections, Willy Sagnol appartient aux cadres de l'équipe de France. C'est lui qui, au nom de tous, a négocié les primes pour cette Coupe du monde : 240000 euros chacun en 
cas de victoire finale. Sa proximité avec Zinédine Zidane lui donne encore plus de poids. Et ses performances sur le terrain avec le maillot du Bayern ajoutent à son autorité; cette année, il a été élu meilleur arrière droit du championnat allemand.

En équipe de France, il assure et rassure. Il garde fermement son territoire, aime les longues échappées dans le couloir pour balancer des centres tendus devant la cage adverse et n'hésite pas à frapper de loin, une qualité rare dans cette sélection.

Certes, dans les premiers matches du Mondial, il a semblé moins à l'aise que d'habitude, mais l'équipe ne tournait pas bien rond non plus. Il le savait, et cela l'a énervé. N'empêche que, dimanche 9 juillet, elle jouera la finale, contre l'Italie. Alors Willy Sagnol n'a qu'un message : que les grincheux se le tiennent pour dit.

Bruno Caussé

http://www.lemonde.fr/web/article/0,1-0,36-792521,0.html 


\section{Revue de presse}

\section{Le baiser de Zidane}

LEMONDE.FR | 06.07.06 | 11h52 • Mis à jour le 06.07.06 | 11h52

Mercredi soir à Munich, les Bleus ont battu les Portugais un à zéro en demi-finale de la Coupe du monde. Tandis que la presse portugaise s'en prend à l'arbitrage et au mauvais sort, les autres titres saluent la prestation de Zidane et de la défense française.

\section{PRESSE PORTUGAISE : L'ADIEU AUX "CONQUISTADORS"}

Avant le match, les quotidiens sportifs portugais croyaient, dur comme fer, en la destinée glorieuse de l'équipe nationale. $\underline{O \text { Jogo }}$, mercredi, avait même publié en "une" un coq gaulois, avec ces mots : "Nous allons les plumer !" De son côté, A Bola se lançait "à la conquête de Berlin" et suggérait de donner aux joueurs le doux nom de "conquistadors". Jeudi matin, force leur est de déchanter. "Encore et toujours les penalties !" peste le gratuit 24 Horas. Déjà en 2000, en demi-finale de l'Euro, le Portugal avait été éliminé sur un penalty en or de Zidane. "Zidane écarte encore une fois les Portugais de la finale", soupire le Diario de Noticias de Lisbonne. Pour le Jornal de Noticias, c'est tout simplement "un rêve" qui s'achève.

La frustration est souvent perceptible. "Cela s'est joué à un cheveu", titre 24 Horas. Et A Bola de commenter : "Au foot, il n'y a pas de victoire morale, encore moins en phase finale d'une Coupe du monde. Le Portugal a perdu un match qu'il aurait pu gagner." Le quotidien sportif n'en démord pas : "La France a rarement autant souffert. Les Portugais ont possédé la balle pendant presque $60 \%$ du temps, ils ont tenté douze tirs contre cinq aux Bleus, ont obtenu huit corners contre cinq. Nous avons attaqué beaucoup plus que les Français, mais le résultat est là."

Et alors, à quoi s'est jouée la rencontre ? Dans un autre article intitulé "Ne pleure pas, Portugal", $\underline{A \text { Bola }}$ estime que la Selecçao n'a rien à se reprocher : "La France a été calculatrice. Elle s'est à peine livrée en contre-attaque, et a gagné grâce à son organisation défensive." 24 Horas, pour sa part, rapporte les propos de Cristiano Ronaldo : "Quiconque a vu le match a pu se rendre compte que l'arbitrage était injuste (...). Nous avons bien joué et nous avons été les meilleurs sur le terrain, mais nous n'avons pas reçu un bon traitement de la part de l'arbitre." L'arbitrage est aussi pris pour cible par $\underline{O}$ Jogo, qui se plaint en "une" que n'ait pas été sifflé un penalty sur le joueur de Manchester United. Le quotidien dénonce "une injustice" flagrante.

En tout cas, rendez-vous a été pris pour la suite. Tandis qu'A Bola salue en "une" la prestation de ses

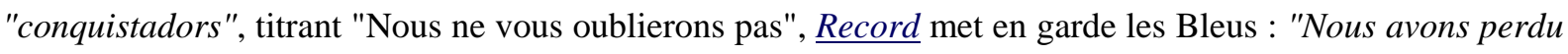
une bataille, mais c'est bien d'une guerre qu'il s'agit et, tôt ou tard, elle sera gagnée par le Portugal."

\section{PRESSE EUROPÉENNE : LE DIEU ZIDANE}

S'il y en a certains que la défaite du Portugal ravit, ce sont bien les tabloïds londoniens. The Daily Mirror et $\underline{T h e}$ Sun ont choisi le même titre, au-dessus d'une photo de Cristiano Ronaldo : "Tu ne fais plus de clin d'œil 
!" Une référence au quart de finale contre l'Angleterre : après avoir obtenu l'expulsion de Wayne Rooney, le joueur de 21 ans avait adressé un clin d'œil malicieux à son banc. Mercredi soir, "l'odieux ailier pleurait comme un veau, après que lui et ses collègues adeptes du plongeon" ont été éliminés de la Coupe du monde : le spectacle a visiblement réjoui The Sun. "Le simulateur de plongeons avait perdu le sourire", renchérit The Daily Mirror. L'envoyé spécial du Guardian (Londres) à Munich, s'il reconnaît que Ronaldo a joué dans des conditions difficiles - hué par le stade à chaque fois qu'il touchait la balle -, critique lui aussi le manque de fair-play des Portugais : entendre Scolari et le joueur de Manchester United, après le match, s'en prendre à l'arbitre urugayen de la rencontre, est selon lui inadmissible.

"Et ils voulaient les mettre à la retraite !" s'écrie, de son côté, Sport. Le quotidien catalan se régale de voir les Bleus, cette "équipe de retraités", "ressusciter" de l'autre côté du Rhin. "La défense française est un mur." Mercredi sur le terrain, "Gallas et Thuram ressemblaient à deux colosses. Vieira et Makelele étaient l'image vivante de deux robots programmés pour boucher tous les trous", raconte-t-il. Pour The Scotsman, les Bleus n'avaient qu'un seul point faible : leur gardien de but. "Le plus grand allié des Portugais, hier, était Fabien Barthez, clown sans doute incurable dont les excentricités inexplicables peuvent transformer un haussement d'épaules en attaque cardiaque" : cela a failli être le cas en fin de match.

Le reste de la presse européenne, pour l'essentiel, n'a d'yeux que pour Zidane. Sans attendre la finale contre l'Italie, dimanche, le tabloïd Bild de Hambourg l'érige en "dieu du football". Le quotidien sportif $\underline{A S}$ (Espagne) s'en étonne encore : mercredi soir, "le grand Zidane semblait aussi jeune qu'un cadet", "il se retirera après la finale, avec l'admiration de tout le monde du football". Le Times (Londres) est du même avis : "Si rien n'en dit aussi long sur un homme que la manière dont il quitte la scène, ce n'est que justice que le dernier match de Zidane soit la finale de la Coupe du monde."

\section{ET DIMANCHE, L'ITALIE...}

Le quotidien sportif romain, le Corriere dello sport, joue les fiers-à-bras : "Zidane, tu ne nous fais pas peur !" titre-t-il en "une". Le Corriere della Sera est plus réservé : "Comme en 1998, deux hymnes vont s'affronter, 'frères d'Italie' contre 'enfants de la patrie'. Cannavaro, le capitaine italien, s'inquiète, et il a raison... si l'on pense au regard sage et implacable du vieux faucon Zizou : mercredi encore, on a vu combien il compte. Ou aux coups de patte de Thierry Henry, qui, s'il n'est pas un génie de la stratégie, reste l'attaquant le plus rapide du monde. Pour toutes ces raisons, et aussi à cause de la malice de Raymond Domenech, on doit avoir de la peur et du respect pour cette France qui, face au Portugal, a confirmé qu'elle était une machine assez bien huilée." Et La Repubblica, de son côté, rappelle que la Squadra Azzurra n'a jamais réussi, depuis 1978, à battre les Bleus en sélection officielle...

Le tabloïd allemand $\underline{B i l d}$, en tout cas, met en garde les Italiens. Zidane, avant les précédents matches, avait embrassé Raul, le capitaine espagnol. Il avait embrassé Ronaldo, la star de la sélection brésilienne. Mercredi soir, il a embrassé Luis Figo, le capitaine de la sélection lusitanienne : "A chaque fois, il s'agissait d'une ambrassade 'mortelle'", assure le quotidien. Fabio Cannavaro est prévenu... 
Marie Béloeil, avec Luc Vinogradoff

http://www.lemonde.fr/web/article/0,1-0,36-792491,0.html

http://www.lemonde.fr/web/article/0,1-0,36-792491@45-1,0.html 


\section{Mexique : le conservateur Felipe Calderon a remporté l'élection présidentielle sur le fil}

LEMONDE.FR | 07.07.06 | 07h08 • Mis à jour le 07.07.06 | 11h15

Les voix ont été comptées et recomptées. Selon les résultats définitifs rendus publics jeudi 6 juillet, le candidat du Parti d'action nationale (PAN), Felipe Calderon, a été élu avec près de 15 millions de voix (35,89 \%), devant celui du Parti de la révolution démocratique (PRD) qui en totalise 14,7 millions (35,31 $\%)$. Au terme d'une élection à suspense, Andres Obrador et Felipe Calderon ne sont départagés que par 236 000 voix $(0,57$ point $)$.

Le Mexique était suspendu depuis le scrutin de dimanche au décompte officiel, qui a débuté mercredi, car les résultats préliminaires de l'Institut fédéral électoral (IFE) ne donnaient pas une tendance suffisamment claire pour annoncer dès dimanche soir le vainqueur.

Cette élection présidentielle, "la plus serrée de l'histoire du Mexique", a été "propre et transparente", a commenté le président de l'IFE. Mais le candidat de la gauche conteste ces résultats et dénonce de "nombreuses irrégularités". Il demande un troisième décompte des 41,7 millions de bulletins de l'élection présidentielle. Il a appelé ses partisans à une manifestation samedi dans le centre de Mexico.

Le Tribunal fédéral électoral qui doit officiellement proclamer le nom du nouveau président d'ici au 6 septembre après avoir examiné les plaintes du parti du PRD, devra trancher sur la demande d'un nouveau décompte voix par voix.

Sans majorité absolue, ni à la Chambre des députés, ni au Sénat, la droite devra faire des alliances pour gouverner. "Si les autorités électorales le confirment, je serai un dirigeant non seulement pour mon parti, mais pour tous les Mexicains", a déclaré le candidat de la droite, Felipe Calderon. "L'heure de la conciliation est venue", a-t-il déclaré devant des centaines de ses partisans réunis pour fêter la victoire. Et d'ajouter : "A partir d'aujourd'hui j'appelle tout le monde à participer avec générosité et patriotisme à un gouvernement d'union nationale." "Le message que nous ont donné les Mexicains est clair : travaillez ensemble, laissez de côté la politique des factions, des petits groupes et mettez-vous d'accord pour le bien du Mexique : je le ferai", a-t-il ajouté. Avec AFP

http://www.lemonde.fr/web/article/0,1-0,36-792972,0.html 


\section{Point de vue}

\section{Le foot, industrie sans frontières, par Branko Milanovic}

LE MONDE | 07.07.06 | 14h04 • Mis à jour le 07.07.06 | 14h04

Avec le Mondial 2006 on constate à nouveau que le football est le sport le plus populaire de la planète ; c'est aussi la profession la plus mondialisée. Il serait inconcevable que des médecins, des informaticiens, des "cols bleus" ou des employés de banque brésiliens, camerounais ou japonais passent d'un pays à un autre comme le font les joueurs de foot.

Le club londonien Arsenal est intégralement composé d'étrangers. Même les rôles de capitaine ne sont plus réservés aux joueurs nationaux : Thierry Henry est capitaine d'Arsenal, Andreï Chevtchenko, ukrainien, a souvent été le capitaine du Milan AC et jouera l'année prochaine avec le club champion d'Angleterre Chelsea. Des dizaines de Sud-Américains et d'Africains jouent dans des clubs russes, turcs, polonais...

Le football donne un aperçu de la manière dont la vraie mondialisation du travail pourrait fonctionner. Longtemps, dans le foot, une réglementation interdisait aux clubs de faire jouer plus de deux joueurs étrangers à chaque match. L'arrêt Bosman, du nom d'un joueur belge qui a défié avec succès cette réglementation, a tout changé à partir de 1996. Les clubs les plus riches d'Europe ont conquis la liberté de recruter les meilleurs joueurs, quelle que soit leur origine.

Quand l'offre et la demande jouent à l'échelle mondiale, on assiste à une concentration des talents et à des succès. Considérons le nombre de clubs qui se sont qualifiés parmi les huit meilleurs de la Ligue des champions européenne. Entre 1967 et 1986, le nombre d'équipes différentes qui se qualifiaient pour les quarts de finale variait entre 28 et 30 . Au cours des dix ans qui ont suivi, ce chiffre tombe à 26, et lors de la période la plus récente (2000-2004), il n'y en a eu que 21. La conclusion est simple : de moins en moins de clubs accèdent à l'élite européenne.

Il en va de même pour les championnats nationaux. Depuis le lancement de la Premier League anglaise en 1992, tous les titres à l'exception d'un seul ont été remportés par Manchester United, Arsenal ou Chelsea. En Italie, depuis 1991, tous les trophées de première division, sauf deux, ont été remportés soit par la Juventus soit par le Milan AC. En Espagne, depuis 1985 trois championnats seulement n'ont pas été gagnés soit par le Real Madrid, soit par Barcelone.

La raison de cette concentration au sommet est évidente : les clubs les plus riches sont désormais capables d'attirer les meilleurs joueurs du monde. Et cela s'est accompagné d'une amélioration de la qualité de jeu, due à ce que les économistes appellent un "rendement d'échelle croissant". Lorsque les meilleurs joueurs évoluent ensemble, la qualité de chacun, et de toute l'équipe, augmente de façon exponentielle. Lorsque Ronaldinho et Messi, ou Kaka et Chevtchenko jouent ensemble, leur "production" globale (le nombre de buts) est supérieure à la somme des buts que chacun marquerait s'il jouait dans un club différent avec des joueurs moins talentueux. 
La libre circulation des travailleurs dans d'autres secteurs produirait sans doute le même résultat. Si des médecins, des informaticiens ou des ingénieurs (sans parler des légendaires plombiers polonais !) étaient autorisés à se déplacer librement, la concentration de talents dans les pays les plus riches serait susceptible d'augmenter. L'inégalité dans la distribution des talents entre pays serait plus grande, mais la production totale des biens et des services dans le monde, ainsi que leur qualité moyenne, augmenterait, comme dans le cas du football aujourd'hui. Les pays plus pauvres ou plus petits ne peuvent plus imaginer remporter un championnat européen, comme ce fut autrefois le cas pour Steaua (Roumanie), Red Star (Serbie) ou Nottingham Forest (aujourd'hui en train de languir en troisième division anglaise).

Mais alors que les inégalités se creusent entre clubs, l'inverse se vérifie quand ce sont des équipes nationales qui s'affrontent. La marge moyenne de victoire parmi les huit meilleures équipes nationales de la Coupe du monde n'a fait que décroître, passant de plus de 2 buts dans les années 1950 à environ 1,5 but dans les années 1960, 1970 et 1980, et à seulement 0,88 but pour la Coupe du monde de 2002.

C'est vrai aussi pour tous les matches de finale, et pas seulement ceux entre les huit meilleures équipes nationales. La diminution des marges de victoire est d'autant plus impressionnante que la Coupe du monde est passée de 16 à 32 équipes nationales, dont beaucoup sont nouvelles et plutôt inexpérimentées. Curieusement, elles ne se font pas écraser par les équipes vedettes. Au contraire, les huit meilleures équipes des quatre dernières Coupes du monde comprenaient des "nouvelles venues" qui ne s'étaient jamais qualifiées en quarts de finale auparavant, comme la Turquie et la Corée du Sud en 2002.

Cela s'explique. Tout d'abord, la libre circulation signifie que les bons joueurs issus d'équipes nationales de second plan s'améliorent bien plus qu'ils ne l'auraient fait s'ils étaient restés chez eux. Un bon joueur danois ou bulgare s'améliore bien plus vite s'il rejoint Manchester United ou Barcelone. Ensuite, cette amélioration de la qualité est "captée" par les équipes nationales grâce à la règle de la FIFA, qui demande que les joueurs ne jouent que pour leur équipe nationale. Eto'o peut jouer pour n'importe quel club espagnol, italien ou anglais, mais dans le cadre de compétitions entre nations, il ne peut jouer que pour le Cameroun. En d'autres termes, la FIFA a introduit une règle institutionnelle qui permet aux petits pays (dans le sens footballistique) de capter certains des bénéfices du jeu de haute qualité d'aujourd'hui, inversant en partie le processus de "fuite des jambes."

La même règle pourrait s'appliquer à d'autres activités. La libre circulation des travailleurs qualifiés pourrait s'accompagner de conditions internationales qui exigeraient, par exemple, que les émigrants des pays pauvres travaillent au moins un an sur cinq dans leur pays d'origine. Le monde devrait tirer des leçons de la Coupe du monde. Traduit de l'anglais par Bérengère Vienno

(c) Project Syndicate, 2006.

Branko Milanovic est économiste à la Fondation Carnegie pour la paix internationale.

Article paru dans l'édition du 08.07.06

http://www.lemonde.fr/web/article/0,1-0,36-793211,0.html 


\section{ÉCONOMIE CHRONIQUE}

\section{Penalty contre le capitalisme}

LE MONDE | 08.07.06 | 14h06 • Mis à jour le 08.07.06 | 14h06

Si le Portugal a perdu la joie, mercredi soir quand son équipe a encaissé le penalty de Zizou, Nuno Gonçalvez a perdu, lui, des dizaines de milliers d'euros. Il possède une part des contrats de Ricardo Costa, $n^{\circ} 4$ dans l'équipe nationale, arrière, 25 ans, joueur du FC Porto. La "valeur" de Costa aurait grimpé en cas d'accession à la finale et plus encore en cas de victoire à la Coupe.

M. Gonçalvez, comme le racontait The Wall Street Journal cette semaine, est à la tête d'un hedge fund de 14 millions de dollars qui investit dans le foot. Concrètement, il cofinance l'acquisition par les grands clubs de jeunes joueurs portugais ou brésiliens en espérant que leurs performances permettront, trois ans plus tard, de les revendre à des prix de star. Cet hiver, le fonds a réalisé une très jolie plus-value en cédant la vedette Cristiano Ronaldo à Manchester United pour 19,2 millions de dollars. M. Gonçalvez l'avait repéré à 16 ans dans l'école de formation du Sporting Lisbonne, et il avait pris 35 \% du joueur, dont la "valeur" était estimée alors à 640000 dollars.

Les hedge funds investissent tout. Le foot comme le vin, les timbres comme la Bourse. Repérer les valeurs montantes avant les autres et les acheter, ou les valeurs descendantes avant les autres et les vendre, voilà la philosophie. Avec une méthode : les fonds ne détiennent pas les titres, ils les empruntent. Ils ne réalisent l'achat qu'à la fin, lorsqu'ils dénouent l'opération. L'effet de levier est maximal, et ils ne supportent pas l'intégralité du risque.

Leurs bons résultats ont fait leur succès. Les hedge funds, en français "fonds spéculatifs" ou "fonds de gestion alternative", sont nés à la marge. Mais ils occupent aujourd'hui une place considérable dans le monde financier. Ils gèrent environ 1200 milliards de dollars, le double d'il y a cinq ans. On compterait 8 500 fonds dans le monde. Cette industrie influence les banques, qui s'y mettent, et grandit vite. Elle commence à gérer les actifs des particuliers et plus seulement ceux des autres acteurs financiers (banques, fonds de retraite...). "Certains jours, les hedge funds représentent jusqu'à un tiers des transactions boursières à Londres ou à New York", note le professeur Olivier Pastré ("Les enjeux économiques et sociaux de l'industrie bancaire", rapport au Comité consultatif du secteur financier, avril 2006).

La puissance les a changés. Ils étaient, jusqu'à ces derniers temps, des acteurs passifs, se contentant de placer leur argent. Leur poids leur permet aujourd'hui de prendre des participations significatives dans les entreprises cotées pour contester les gestionnaires. Ils réclament un rôle actif chez Time Warner, General Motors, Arcelor-Mittal, ou Deutsche Börse.

En 1999, un hedge fund, Long Terme Capital Management, s'écroule. La Federal Reserve (Fed) qui craint des faillites en cascade se rue à son secours. On découvre subitement le "risque systémique" que ces jeunes créations font courir, par leurs emprunts gigantesques, à l'ensemble des places financières. La Fed recommande aux banques de ne rien prêter sans solide contrepartie. 
Un autre risque apparaît : la faible transparence de ces fonds. Des délits d'initiés font scandale. Le système de rémunération, proportionnel aux gains, pousse au crime. La SEC (Securities and Exchange Commission) intervient pour mettre un peu d'ordre et exige, à compter de février, la publication d'un minimum d'informations.

Troisième reproche : le risque extrême. Comme le succès a attiré du monde et comme les emprunts sont devenus plus chers avec la hausse des taux, les marges des hedge funds ont fondu depuis deux ans. D'où une prise de risque de plus en plus grande et une extension à des domaines hasardeux, comme le foot ou le vin.

Les chutes des cours de Bourse en mai et en juin ont fait naître une dernière critique : ces pertes seraient en partie imputables aux hedge funds dont les algorithmes corrélés accentuent fortement les tendances. Plutôt que d'être des moutons noirs iconoclastes et de corriger le grégarisme des marchés financiers, ils sont devenus le gros du troupeau et vont dans le même sens.

Il y a dix jours, sous forte pression des lobbies, un tribunal fédéral américain a bloqué les demandes d'informations de la SEC. En réponse, le procureur général du Connecticut, où nombre de ces fonds sont domiciliés, a répliqué que les hedge funds sont "dans un trou noir juridique". Il demande aux autorités fédérales de fixer des règles au plus vite.

Faut-il siffler un penalty contre les avant-centres du capitalisme que sont les hedge funds et les réguler ? Le débat est relancé. Leurs défenseurs mettent, non sans raison, leur utilité en avant. Ils ne font, après tout, qu'un travail de financier prenant des risques. Réguler serait coûteux, complexe et, en définitive, guère possible. Mais, dans l'autre sens, les pressions contre ces monstres du capitalisme moderne grandissent.

Depuis vingt-cinq ans et le début de la libéralisation des marchés financiers, les Etats n'ont eu de cesse que de lever une à une les restrictions à l'innovation financière. L'adoption de lois destinées à limiter les hedge funds marquerait un tournant radical. Il y a peu de chances. Mais il faudrait, quoi qu'il en soit, exiger plus de transparence.

\section{ÉRIC LE BOUCHER}

Article paru dans l'édition du 09.07.06

http://www.lemonde.fr/web/article/0,1-0,36-793496,0.html 


\section{CHRONIQUE DU MÉDIATEUR \\ Mots en guerre, par ROBERT SOLÉ}

LE MONDE | 08.07.06 | 14h17 • Mis à jour le 08.07.06 | 14h17

Dans le courrier des lecteurs, le plus significatif est parfois... l'absence de courrier. Il y a quelques années encore, le fait de consacrer plusieurs pages par jour à un grand événement sportif valait au Monde une pluie de protestations. Cela s'est estompé progressivement. Le football en particulier a acquis droit de cité. Pour le Mondial 2006, les lettres rageuses, sur le thème "ras le foot", se comptent sur les doigts de la main.

La qualité et la diversité des articles consacrés au ballon rond y contribuent sans doute. En parcourant ces quatre pages quotidiennes, avec leurs différents éclairages, leurs multiples entrées, on se dit que des sujets plus importants et plus graves mériteraient de bénéficier de la même inventivité...

"Depuis le début du Mondial, il y a presque autant de buts marqués en Allemagne que de morts chez les Palestiniens, nous écrit amèrement Mourad Akalay (courriel). Tandis que les premiers sont accueillis par des hourras et retransmis en direct par toutes les télés du monde, les seconds n'intéressent personne. (...) Sur le terrain, les juges de touche ne voient que les hors-jeu palestiniens, tandis qu'aucun attaquant israélien n'est sanctionné, même pour faute grave commise dans la surface de "destruction" du camp adverse. L'arbitre américain se refuse à siffler la fin de la partie tant que la Palestine ne déclarera pas forfait. Elle subira, comme toujours et sans fin, les tirs au but israéliens..."

L'incessant courrier des lecteurs à propos du Proche-Orient ne se limite pas à des jeux de mots. Mais, à chaque nouvel épisode de cette guerre de soixante ans, la polémique se focalise sur le vocabulaire. Ainsi, $L e$ Monde, régulièrement accusé de parti pris, dans un sens ou dans l'autre, serait trahi par le sien.

"Je m'étonne qu'un journal de cette qualité puisse employer des termes impropres, écrit Jean Delemer, de Saint-Cyr-sur-Mer (Var). Depuis des années, il nous parle de guerre israélo-palestinienne. Peut-on parler de guerre quand un occupant dispose d'un armement mille fois supérieur à celui du pays occupé ?"

A l'inverse, Pierre Aknine (courriel) réagit à un article du 15 juin relatant des combats dans le nord de Gaza : "Je note la différence "éclatante" des termes utilisés : les roquettes (palestiniennes) sont qualifiées d'"artisanales" tandis que les raids (israéliens) le sont de "sanglants". Il y a des morts des deux côtés, mais la manière différente de qualifier ces actions mortelles ne laisse aucun doute sur la partialité de l'auteur de l'article."

Marc Lacombe (Toulouse) félicite ironiquement Le Monde pour son "sens de la mesure ou plutôt des euphémismes", à propos de l'intervention israélienne. "Vous qualifiez de "vaste coup de filet" l'enlèvement de ministres et de députés palestiniens démocratiquement élus, et d'"avertissement" le survol du palais de Bachar Al-Assad par un chasseur israélien. Imaginez qu'un avion militaire syrien survole la Knesset. N'appelleriez-vous pas cela un acte de guerre?" 
Deux poids, deux mesures, estime aussi Armand Veilleux, abbé de Scourmont, en Belgique : "Bien sûr, on peut et on doit demander aux Palestiniens de ne pas attaquer les civils en Israël ; mais pourquoi ne pas demander en même temps à Israël de cesser ses assassinats systématiques en Palestine, tuant chaque fois des civils ? (...) Il est normal qu'on s'émeuve de l'enlèvement d'un jeune soldat juif ; mais personne ne s'émeut devant l'enlèvement fréquent de centaines de Palestiniens, parmi lesquels se trouvent de nombreux enfants, qui pourrissent dans les prisons d'Israël. (...) Pourquoi l'explosion de bombes humaines en Israël serait-elle un acte de terrorisme, mais pas le lancement de bombes inhumaines sur la Palestine du haut des airs ?"

Le Monde du 30 juin annonçait que "le corps d'un colon de 18 ans", enlevé en Cisjordanie, avait été retrouvé près de Ramallah. Aussitôt, des protestations ont fusé. Robert Botbol (courriel) ne comprend pas que l'on désigne ainsi "un jeune juif abattu par des terroristes".

Jusqu'aux années 1950, le mot "colon", identifié à "pionnier", avait une connotation héroïque chez les partisans du sionisme. Aujourd'hui, il peut paraître péjoratif à certains. Mais si Le Monde parlait d'"habitants des localités" et d'"implantations" dans les territoires conquis en 1967, comme on le fait en Israël, ne cacherait-il pas à ses lecteurs une partie de la réalité ?

Des défenseurs des Palestiniens nous reprochent l'emploi du mot Tsahal pour désigner l'armée israélienne. C'est le cas de Marwan Zeineddine, qui écrit du Royaume-Uni : "Je n'arrive pas à comprendre pourquoi Le Monde s'obstine à employer ce mot. C'est ridicule. Faut-il y voir un soutien implicite à Israël ?"

En hébreu, Tsahal est l'acronyme d"'Armée de défense d'Israël". C'est le terme consacré, comme peut l'être la Wehrmacht ou l'Armée rouge. On a tendance à l'utiliser en français par commodité, pour éviter des répétitions de mots, sans rapport avec l'admiration que des Israéliens peuvent éprouver pour leurs forces militaires.

"Après des mois d'affrontements, les activistes des factions rivales palestiniennes collaborent pour organiser la résistance à l'opération d'Israël à Gaza", était-il écrit dans Le Monde du 29 juin. Hector Chemla (courriel) dénonce "la désinformation permanente" du journal : "Des assassins qualifiés d'activistes... Il ne manque plus que l'adjectif "héroïque" pour donner plus de poids au mot résistance."

Entre les "martyrs" célébrés par des foules arabes et les "terroristes" dénoncés en Israël, les journalistes cherchent leurs mots. "Le vocabulaire évolue en fonction de la situation, souligne Gilles Paris, qui vient de passer cinq ans à Jérusalem comme correspondant du Monde. J'ai quasiment cessé d'écrire "activistes", lui préférant "miliciens", qui correspond mieux à une militarisation de la société palestinienne et à l'émiettement de ses groupes armés."

Rémy Ourdan, chef du service International, a mis en garde récemment les correspondants du Monde contre l'usage des mots "terrorisme" et "terroriste". Il préfère par exemple que l'on qualifie Al-Qaida de "mouvement djihadiste" (ou "islamiste"), car son objectif est le djihad, le terrorisme n'étant pour les disciples de Ben Laden qu'un moyen parmi d'autres. "Les mouvements utilisant le terrorisme, estime-t-il, sont "séparatistes", "islamistes", "maoïstes", etc., mais le terrorisme n'est jamais, ou rarement, l'objectif ni 
une fin en soi. Leurs membres commettent éventuellement un "attentat terroriste", mais on ne peut pas les qualifier de "terroristes par nature"."

Le vocabulaire n'est pas innocent, les mots ne sont jamais neutres. Au début de la guerre civile au Liban, en 1975, Le Monde appelait les forces antagonistes "islamo-progressistes" et "chrétiens conservateurs". Ce qui, pour son lectorat, suffisait à disqualifier les seconds...

\section{Robert Solé}

Article paru dans l'édition du 09.07.06

http://www.lemonde.fr/web/article/0,1-0,36-793545,0.html 


\section{Joseph Nadj ensorcelle Avignon}

LE MONDE | 09.07.06 | 08h14 • Mis à jour le 09.07.06 | 09h14 AVIGNON ENVOYÉE SPÉCIALE

Des sons de clochettes se dissipent dans le vent léger qui court sur le plateau de la Cour d'honneur du Palais des papes. Il gonfle le pantalon du mannequin au visage bandé assis à une table en train d'attendre. Le dîneur solitaire fait une tête d'enterrement. Les motifs de prédilection du chorégraphe et plasticien d'origine hongroise Josef Nadj sont à leur poste : la table, le pantin défiguré, la réversibilité vie-mort. Sans compter les palissades en bois qui bordent un côté de la scène tandis qu'une petite estrade carrée se dresse à l'opposé. Que la sarabande commence !

Vendredi 7 juillet, Asobu ("jeu" en japonais), de Josef Nadj, artiste associé de l'édition 2006 du Festival, a ramassé dans un mouvement ample, une respiration dilatée, les fragments d'un rêve surréaliste tissé des textes d'Henri Michaux (1899-1984), auquel la pièce rend hommage. Dans une montée gestuelle et sonore, seize interprètes et quatre musiciens, tous habillés en noir et gris, ont donné au mot "sortilège" une saveur inédite où l'obscurité et la beauté de l'humain s'équilibrent dans un furieux tiraillement.

Pourquoi le Japon ? Pour Michaux, d'abord. Après Raymond Roussel, Bruno Schultz ou Georg Büchner, c'est le voyageur-écrivain auquel s'arrime Josef Nadj dans Asobu. Pour le soutenir au cours de son périple spectaculaire, dans ce qui ressemble toujours peu ou prou à une plongée introspective, Nadj a élu Michaux, partenaire mental de longue date dont la proximité fait ici fructifier ses fantasmes.

Michaux a traversé l'Europe et l'Asie pour se poser au Japon avant la seconde guerre mondiale. Nadj travaille régulièrement au Japon et a choisi six danseurs nippons pour participer à Asobu. Mais l'emprise de Michaux ne s'arrête pas là. Il peignait et dessinait. Nadj aussi. Le chorégraphe aime visiter les galeristes parisiens possédant des oeuvres du poète. Le trait fourmillant de l'un n'est pas sans rappeler le coup de plume minutieux et dense de l'autre.

Sur un plateau dégagé dans sa quasi-totalité, Josef Nadj donne libre cours à sa fureur de danser, traçant des déplacements de groupe ou des échappées en duo savamment articulés. La femme pelotonnée dans les bras de l'homme ou celle le surplombant telle une vigie s'inscrivent d'ores et déjà parmi les vignettes rares de l'album d'images de Josef Nadj.

Idem les solos féminins, qui n'ont besoin de rien pour griffer l'air en rêvant de le caresser. Sculptural, le geste chorégraphique recycle les corps pour faire advenir des créatures imaginaires qu'un jeu d'ombres sublime en monstres de parade.

\section{SEUIL APRÈS SEUIL}

Josef Nadj est un être partagé, morcelé. Sa danse part en éclats, cassant l'interprète sans le démantibuler. Son théâtre d'images aussi. Sa structure en abyme, imbriquant des scènes les unes dans les autres comme des poupées gigognes dont l'air de famille n'empêche pas d'infimes différences, entrechoque les 
associations poétiques que seul un rêveur effréné doublé d'un insomniaque peut imaginer. Seuil après seuil, les personnages s'enfoncent, s'ingénient d'un coup de tête à repousser le cauchemar qui pointe derrière le leurre de la réalité. Il y a toujours chez Nadj le revers de la vie qui s'exprime dans un sursaut de lucidité.

La question du visage, cher à Michaux, se concentre chez Nadj dans la figure du pantin. Enveloppé façon momie prête à être enterrée ou entièrement dissimulé par un foulard pour un rituel nippon revu et corrigé, le visage, ce messager ouvert de la personne, avance voilé, brouillé. Le solo autoportrait de Nadj, créée en 2002, ne s'intitulait pas par hasard Journal d'un inconnu, soulevant le point d'interrogation de l'identité ou de celle que l'on s'imagine posséder.

Battant au rythme martelé de la musique signée par Akosh Szelevenyi et Szilard Mezeï (deux semaines avant la création, le complice-musicien Vladimir Tarasov, perle rare dans l'accompagnement-live du chorégraphe, a été débarqué du spectacle), Asobu se déchiffre pas à pas comme une énigme sans solution. Sur des percussions fines ou épaisses, avec contrebasses, flûte et violon, le "jeu" se maintient pendant plus d'une heure quinze, intense, fertile (presque trop vers la fin), comme si Nadj se prenait lui-même en otage. Les accents jazzy barrissants de cette complainte tendue hurlent le prix à payer pour rester bien vivant.

"J'écris pour me parcourir, disait Michaux. Peindre, composer, écrire : me parcourir. Là est l'aventure d'être en vie." Depuis la création de sa compagnie en 1986, six ans après avoir quitté sa Yougoslavie natale pour la France, Josef Nadj, nommé directeur du Centre chorégraphique d'Orléans en 1995, poursuit une oeuvre hantée par la connaissance de soi et l'irréductibilité du destin. Cyclique, Asobu perpétue avec une rare amplitude une boucle de naissance et de mort à l'horizon sans cesse repoussé. Pièce paradoxalement épurée, truffée pourtant de références, elle se lit comme le manifeste d'une conscience qui ne trouve de paix momentanée que dans l'action spectaculaire.

Pour sa première expérience dans la Cour d'honneur, Nadj a eu la veine d'une insolente distribution. Auprès des six Japonais nouveaux venus dans la troupe et parfaits agents déstabilisateurs, la présence résolue et puissante d'anciens a fait pencher la bascule. Les Hongrois Istvan Bickei, Peter Gemza, Gyork Szakonyi, ainsi que Kathleen Reynolds, Mathilde Lapostolle, Cécile Loyer et Nasser Martin-Gousset donnent un relief majeur à Asobu. Cette pléiade, qui tient tout simplement l'histoire de Nadj dans sa main, a offert une floraison superbement inattendue.

Asobu, de Josef Nadj. Cour d'honneur du Palais des papes. Tél. : 04-90-14-14-14. Jusqu'au 13 juillet, relâche le 10, à 22 heures. De 13 à 36 a euros. Reprise au Théâtre de la Ville, Paris-4e, du 3 au 8 octobre.

Prochaine création : Paso Doble, avec Miquel Barcelo. Eglise des Célestins. Du 16 au 27 juillet, à 18 heures. De 13 a à $25 \propto$.

Rosita Boisseau

Article paru dans l'édition du 09.07.06

http://www.lemonde.fr/web/article/0,1-0,36-793560,0.html 


\section{Raymond Domenech : "L'homme du match, c'est Materazzi"}

LEMONDE.FR | 10.07.06 | 00h35 • Mis à jour le 10.07.06 | 15h49

Raymond Domenech (France, sélectionneur) : C'est une grosse déception, je n'ai pas d'autres mots, une grosse déception." "On ne peut être que déçu, profondément déçu. Sur la qualité du jeu, on le méritait. Seule la victoire est belle. Il manquera un petit quelque chose. Se satisfaire d'à peu près, ce n'était pas l'objectif".

Au sujet de l'expulsion de Zidane : "Il faut être arbitre pour faire un truc pareil. Le faire finir de cette manière là, c'est triste. On n'excuse pas mais on comprend, quand on prend (des coups) pendant une heure vingt."

"On peut dire que l'exclusion de [Zinédine Zidane] est un élément du match parce que sur la deuxième mitemps et la prolongation, les Italiens n'attendaient qu'une chose, c'était d'arriver aux tirs au but, c'était leur seul espoir. Mais il y a déjà eu la sortie de Patrick Vieira qui a aussi eu une influence. Après il y a la sortie de Zinédine, on se retrouve à dix. Il y a eu deux faits marquants avant les tirs au but."

"Materazzi a fait beaucoup de cinéma quand il est tombé de si haut. Il est grand, il est costaud, et un coup de vent l'a fait tomber. L'homme du match, ce n'est pas Pirlo, c'est Materazzi, il marque et il fait exclure Zidane... Mais après, sur le geste, je le regrette, et nous le regrettons aussi, et Zidane aussi. Mais Materazzi ne doit pas y être pour rien. Je n'imagine pas que Zidane avait envie d'être exclu. Il s'est passé quelque chose. C'est évident. (...) C'est triste quand un grand joueur termine sa carrière comme ça, exclu, alors qu'il a fait une grande compétition. J'aurais préféré le sortir, moi, à cinq minutes de la fin, pour qu'il ait une vraie ovation. Je ne m'attendais pas à une ovation comme celle-là..."

Willy Sagnol à propos de l'incident Zidane-Materazzi : "Je n'ai rien vu, je ne sais pas ce qu'il s'est passé mais ça n'a rien changé au match. J'espère que ce qu'on a fait jusqu'à la finale va nous servir de base pour les qualifications à l'Euro-2008. Si on garde le même état d'esprit, on devrait y arriver. Arriver en finale et perdre aux tirs au but, c'est difficile de retenir quelque chose au niveau sportif, mais on retiendra notre merveilleuse aventure humaine et cela, ça n'a pas de prix. Jedis merci à Zidane, Thuram et Makelele pour ce qu'ils ont fait mais maintenant on va essayer de se débrouiller sans eux."

David Trezeguet : "C'est vrai que je connais bien Buffon, mais je n'ai pas specialement changé ma façon de tirer pour ça. Je ne pense pas avoir mal tiré, il est important de prendre ses responsabilités et je garde la tête haute. J'ai dit à Buffon qu'on allait se retrouver pour les vacances. il faut accepter la défaite, ça fait partie du football, nous avons dominé et malheureusement on s'est retrouvé aux tirs au but."

William Gallas (au micro de Canal+) : "Après l'expulsion de Zidane, on savait qu'on pouvait les mettre encore en danger. Même si Zizou est sorti, on voulait absolument gagner, et ne pas repartir sur une défaite. C'est le football. Malheureusement on ne le maîtrise pas! C'est dommage, peut-être qu'on fera mieux la prochaine fois. Tout le monde a vu que dans le jeu on a été meilleurs qu'eux. On n'a été mis en danger que sur les coups francs et les corners. Je pense qu'on a vu une grande équipe de France". 
Marcello Lippi, sélectionneur de l'équipe d'Italie : "Nous avons mal commencé en concédant le penalty, mais mes joueurs ont bien réagi et ils se sont créés des occasions. Je suis fier de mes joueurs pendant cette Coupe du monde. Les tirs au but, c'est toujours une loterie, je le sais, j'en ai gagné et perdu en Ligue des champions. Mais mes joueurs étaient prêts, ils avaient les idées claires."

Fabio Cannavaro : "Nous voulions le trophée et nous nous sommes battus de toutes nos forces. L'Allemagne a gagné chez nous (en 1990) et nous gagnons en Allemagne. C'est très bien. Je suis vraiment très heureux car personne n'y croyait au début du Mondial. Mais nous l'avons mérité".

Gennaro Gattuso (milieu de terrain de l'Italie) : "C'est la victoire d'une équipe peut-être pas belle à voir jouer mais avec un coeur gros comme ça. Le succès d'un groupe authentique, mais je ne réalise pas encore".

Avec AFP

http://www.lemonde.fr/web/article/0,1-0,36-793802,0.html 
Revue de presse

\section{L'Italie a gagné, mais à quel prix ?}

LEMONDE.FR | 10.07.06 | 11h59 • Mis à jour le 11.07.06 | 08h16

L'Italie a gagné, mais à quel prix ? Interrogée par le Guardian, une jeune femme précise ainsi que "le meilleur n'est pas tant d'avoir gagné que d'avoir gagné contre la France". Pour le quotidien britannique, le Circus Maximus de Rome, où 200000 tifosis s'étaient réunis pour assister au match, n'avait probablement pas connu une telle liesse depuis les courses de chars qu'il accueillait il y a 2000 ans ! $\underline{\text { Il Tempo }}$ - pour qui le patriotisme est préférable à Coubertin, parce que "l'important est de gagner, pas de participer" - écrit "notre revanche contre Zidane est consommée, l'Italie le méritait, six ans et sept jours après" la défaite de l'Italie en Coupe d'Europe. $\underline{\text { Libero, }}$, ironiquement, affiche en "une" : "Garçon, champagne". La Stampa, résumant bien l'état d'esprit transalpin, affiche un non moins sobre "Campioni del mondo" suivi de cinq points d'exclamation. Dans La Repubblica, le président de la République se félicite quant à lui de cette victoire "qui redonne du sens de l'honneur et de l'identité nationale à notre pays, qui a tant de problèmes et en avait bien besoin". Ce qu'Il Tempo résume en rappelant que si le footbal italien, à cause du scandale des matches truqués, a les pieds dans la boue, il a aussi désormais la Coupe du monde dans les bras, et donc lavé l'honneur du pays.

Le Telegraph parle pour sa part d'"une nuit de drame, d'intrigue et de virtuosité" digne d'un opéra de Verdi, mais dont le scénario aurait peut-être été considéré comme abusif par la Scala. Et la beauté et la "sublime grâce" de Zinédine Zidane ne résistent pas à son coup de tête. Le Times se refuse néanmoins à plomber définitivement sa réputation, dans l'attente d'un complément d'enquête sur la provocation dont il aurait fait l'objet. Si les journaux italiens n'évoquent guère l'attitude du capitaine des Bleus, et encore moins ce que

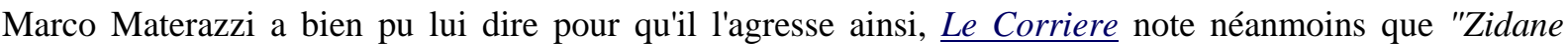
aurait pu être célébré comme un héros, mais qu'il est parti la tête basse, à cause d'un coup de tête".

L'émotion est d'autant plus forte que les footballeurs sont des modèles, et le Mondial leur célébration. Le Gleaner jamaïcain notait ainsi dimanche matin que Zidane, du haut de ses 34 ans, avait plus contribué à unifier l'humanité que n'importe lequel des traités politiques, de même que Diego Maradona, "tout drogué, imbécile et incontrôlable qu'il soit, a plus réuni de monde autour de lui que Platon, Kant, Einstein, Gandhi et Mandela". Kofi Annan clamait pour sa part, en ouverture du Mondial, à quel point il en était envieux : alors que la FIFA compte 207 membres, les Nations Unis n'en dénombrent que 191. Pour le secrétaire général de l'ONU, le monde se porterait bien mieux si le concert des nations adoptait ce type de compétition où chaque pays a ses chances et où les citoyens sont fiers de lui appartenir, où les fils d'immigrés deviennent des héros nationaux et où tout le monde respecte les règles du jeu.

Mais pour le Times, impossible de ne pas voir dans ce match ("en noir et blanc") une conséquence de ce qui s'est passé, en Italie, ces dernières années. Ou, plus précisément, à la Juventus de Turin : six des vingt-deux joueurs qui se sont affrontés hier soir font partie de l'équipe - qui risque fort d'être reléguée en troisième division - sans oublier le fait que Thierry Henri et Zinédine Zidane en firent eux aussi partie, et que Trezeguet en est le buteur attitré. Et beaucoup avaient quelque chose à prouver. Or, si la Squadra azzurra a contribué cette nuit à réhabiliter la réputation des joueurs de la Juve, celle de Zidane s'en trouve du coup entachée. D'où cette question : "pourquoi tricher ?" 
Jean-Marc Manach

http://www.lemonde.fr/web/article/0,1-0,36-793818,0.html 


\section{Nucléaire : nouvelle rencontre entre Européens et Iraniens à Bruxelles}

LEMONDE.FR | 11.07.06 | 08h41 • Mis à jour le 11.07.06 | 09h21

Iraniens et Européens se réunissent à nouveau mardi 11 juillet à Bruxelles autour du dossier nucléaire. Les Européens voudraient obtenir une réponse rapide de Téhéran à l'offre, formulée le 6 juin par six pays (France, Grande-Bretagne, Allemagne, Etats-Unis, Russie, Chine), d'une coopération économique et technique en échange du gel du programme d'enrichissement d'uranium mené par l'Iran.

Mais Téhéran continue de souffler le chaud et le froid sur cette question, et garde notamment le flou quant à ses intentions. Ari Larijani, le négociateur iranien, rencontrera Javier Solana, haut représentant de l'Union européenne pour la politique extérieure, accompagné de diplomates des quatre pays européens (dont la Russie) du "groupe des six".

\section{IMPATIENCE}

Le 10 juillet, à Washington, Condoleezza Rice, la secrétaire d'Etat américaine, et Margaret Beckett, son homologue britannique, ont exprimé à nouveau leur impatience, signalant que le retour du dossier au Conseil de sécurité de l'ONU - qui prendrait alors des sanctions contre l'Iran - serait la conséquence d'un refus iranien d'accepter l'offre des Six. Ceux-ci doivent se réunir dès mercredi 12 juillet à Paris pour arrêter une position commune en fonction des résultats de la réunion d'aujourd'hui à Bruxelles.

Téhéran affiche pourtant toujours sa réticence à céder à l'impatience occidentale. Selon un haut responsable iranien, la réunion de Bruxelles est surtout destinée à éclaircir des points de la proposition occidentale jugés obscurs, tandis que le ministre des affaires étrangères iranien, Manouchehr Mottaki, a dit le 9 juillet que l'Iran n'y répondrait que dans la semaine du 14 au 22 août.

\section{Avec AFP}

http://www.lemonde.fr/web/article/0,1-0,36-794225,0.html 


\section{Procès des Français de Guantanamo : nouvelle journée d'explications}

LEMONDE.FR | 11.07.06 | 09h51 • Mis à jour le 11.07.06 | 10h02

Le procès des "Français de Guantanamo" se poursuit mardi 11 juillet devant la $16^{\mathrm{e}}$ chambre du tribunal correctionnel à Paris. Les anciens détenus de la base américaine sont poursuivis pour "association de malfaiteurs en relation avec une entreprise terroriste", et ont jusqu'au 12 juillet pour expliquer aux juges leur passage par les camps d'entraînement islamistes en Afghanistan.

Deux d'entre eux, Nizar Sassi et Mourad Benchellali, ont essayé hier de convaincre les juges que leur parcours n'est pas celui d'apprentis terroristes, mais plutôt celui de jeunes naïfs passionnés par les armes et l'Afghanistan. Arrivés fin juin 2001 à Kaboul, ils séjournent plus de deux mois au camp d'Al-Farouk, où Ben Laden était venu prêcher le combat contre les "mécréants".

Pour Mourad Benchellali, les choses sont claires : s'il s'est retrouvé, en juillet 2001, dans le camp Farouk, c'est à cause de son frère Menad :"Quand je suis arrivé au camp, très vite j'en ai beaucoup voulu à mon frère : je me suis retrouvé dans un monde qu'il ne m'avait pas décrit, a assuré le jeune homme, qui comparaît libre. J'ai rencontré des gens très dangereux, j'ai fait des choses très graves! Il m'a fait entrer dans un monde qui n'est pas le mien."

Les deux prévenus mettent en avant des motivations qui n'ont rien à voir avec le djihad : envie de voir du pays, de manipuler des armes... Mais certainement pas de participer à des actions terroristes, qu'ils rejettent. "Ça nous a pas plu, on était déçus tout de suite... On a demandé à repartir, raconte Mourad Benchellali. Mais la règle, c'était que quand tu rentres dans le camp, tu ne peux en sortir que si tu tombes malade... Pour ça, Nizar a eu de la chance."

\section{"CELUI QUI A UNE ARME, IL EST RESPECTÉ"}

Nizar Sassi, venu avec lui de la banlieue lyonnaise, affirme depuis le début du procès, il y a une semaine, n'avoir été motivé que par la "passion des armes" et avoir été, lui aussi, terriblement déçu par cette université du djihad.

"Monsieur le président, explique-t-il au juge Jean-Claude Kross, j'avais vendu ma voiture, apporté beaucoup d'argent pour acheter des balles... Mais on pouvait pas en acheter. En tout, je n'ai tiré que quinze balles! C'est vrai, j'aime les armes... C'est culturel. Dans ma cité, à Vénissieux, celui qui a une arme, il est respecté. Et l'Afghanistan faisait peur : si tu peux dire que tu as été en Afghanistan, tout le monde te respecte." "Moi aussi, enchaîne Mourad Benchellali, je n'ai tiré que quinze coups. Et j'ai détesté ça. Le reste, c'était des cours en arabe. Je comprenais rien, et c'est tant mieux. J'éprouvais un sentiment de culpabilité à être là..."

Entre novembre et décembre 2001, six Français suspectés de liens avec Al-Qaida ont été interpellés en Afghanistan, à la frontière avec le Pakistan. Ils ont été transférés peu après vers la base américaine de l'île 
de Cuba, où ils resteront entre deux et trois ans. Les autorités américaines avertissent leurs homologues français en février 2002 de la présence de sept Français au camp Delta.

Imad Kanouni, 29 ans, Nizar Sassi, 25 ans, Mourad Benchellali, 24 ans, et Brahim Yadel, 35 ans, seront expulsés vers la France en juillet 2004. Les deux autres, Ridouane Khalid, 38 ans, et Khaled Ben Mustafa, 34 ans le seront en mars 2005. Le septième, le Franco-Indien Mustaq Ali Patel, 44 ans, sera libéré dès son retour sans être mis en examen.

Les avocats des détenus français avaient contesté la légitimité de l'instruction ouverte à Paris sur le parcours des sept hommes, en raison de l'exploitation par la justice de renseignements obtenus à Guantanamo hors de tout cadre légal. Au début du mois d'octobre 2005, la chambre de l'instruction de la cour d'appel de Paris a validé l'enquête.

Avec AFP

http://www.lemonde.fr/web/article/0,1-0,36-794228,0.html 
Trois questions à Jean-Pierre Dubois, président de la Ligue des droits de l'homme

"Le Panthéon est le culte des grands hommes, pas des victimes"

LEMONDE.FR | 12.07.06 | 11h14 • Mis à jour le 12.07.06 | 12h35

\section{Comment réagissez-vous à la décision de Jacques Chirac de ne pas transférer les cendres du capitaine Dreyfus au Panthéon?}

Je trouve qu'il n'y a rien de choquant dans cette décision, Dreyfus a été très courageux mais il a surtout été une victime. Le Panthéon est le culte des grands hommes, pas des victimes. Une cérémonie pour le centenaire de sa réhabilitation me semble tout a fait approprié. Il faut se méfier du culte de la victime, c'est dangereux.

La Ligue des droits de l'homme a été créée en 1898, à l'occasion de l'affaire Dreyfus. Avez-vous prévu des manifestations spéciales pour célébrer le centenaire de la réhabilitation?

Nous préparons actuellement un colloque, pour l'automne, sur le thème "Qu'est-ce qu'être dreyfusard aujourd'hui ?". Il réunira des historiens, des militants des droits de l'homme, des membres de la famille de Dreyfus... Nous souhaitons, au cours de débats, réfléchir sur l'antisémitisme actuel et proposer des solutions. Pour répondre à l'antisémitisme, on entend de plus en plus souvent des discours dits "républicains" ; les personnes qui tiennent des propos antisémites sont montrées du doigt et stigmatisées. Or, la plupart du temps, il ne s'agit que de provocations, pour trouver une écoute. Notre travail consiste donc à rappeler l'affaire Dreyfus et montrer que l'antisémitisme contre les juifs est aussi inacceptable que le racisme envers les immigrés.

\section{Quelles formes prend l'antisémitisme aujourd'hui ?}

L'antisémitisme d'extrême droite reste bien présent, et il ne faut pas le sous-estimer. Mais à côté de ce "vieil" antisémitisme, on trouve aussi des réactions extrêmes par rapport à la situation au Proche-orient. Le juif reste le bouc émissaire de ce qui ne va pas. Ces réactions montrent que les connaissances de l'affaire Dreyfus ne sont pas suffisantes. Le travail de mémoire a été mal fait, et il est temps de le réparer.

Propos recueillis par Anne Laudin

http://www.lemonde.fr/web/article/0,1-0,36-793437,0.html 
Document

\section{L'hommage de Jacques Chirac au capitaine Dreyfus}

LE MONDE | 12.07.06 | 13h30 • Mis à jour le 12.07.06 | 13h37

Entouré du premier ministre et de plusieurs membres du gouvernement, Jacques Chirac a rendu hommage, mercredi 12 juillet, au capitaine Alfred Dreyfus, injustement accusé de trahison, dégradé, déporté pendant près de cinq ans à l'île au Diable en Guyane, avant d'être réhabilité, il y a un siècle. Cette cérémonie a été organisée à l'Ecole militaire, lieu symbolique où Alfred Dreyfus fut dégradé en 1895, puis décoré le 21 juillet 1906, au terme d'une "affaire" qui divisa profondément la France. Nous publions l'intégralité du discours prononcé par le président de la République.

"Le 5 janvier 1895, le capitaine Dreyfus est dégradé pour avoir trahi la France. Le pire des crimes pour un officier. Mais ce crime, Dreyfus ne l'a pas commis.

Au matin, dans la cour d'honneur de l'École militaire, un adjudant s'approche de lui. Il lui arrache boutons, bandes de pantalon, insignes de grade. Il brise le sabre de l'officier. Devant lui, Dreyfus reste droit et digne.

Un photographe a saisi l'instant. Cent ans plus tard, on en ressent encore toute la violence. Le capitaine Dreyfus a vu tomber à ses pieds les lambeaux de son honneur. Il a dû affronter les invectives de la foule. Moment terrible pour cet Alsacien qui a choisi en 1872, après l'annexion par l'Allemagne, de rester français. Lui qui, à l'âge de l'adolescence, a juré de devenir soldat pour défendre sa patrie.

Le voilà relégué sur l'île du Diable, au large de la Guyane. Pendant près de cinq ans, Dreyfus est enfermé dans quelques mètres carrés. A partir de 1896, il est mis aux fers chaque nuit. On dresse autour de lui une double palissade : il ne peut même plus apercevoir la mer, sa grande consolatrice. De Dreyfus, on ne devait plus entendre parler.

On en a parlé, pourtant. Pendant des années, on n'a même parlé que de cela : car Dreyfus était innocent.

Il n'y aurait jamais dû y avoir d'affaire Dreyfus : cette médiocre machination aurait pu être dévoilée dès le départ. Mais, parce que la haute hiérarchie ne pouvait s'être trompée, le capitaine devait à tout prix rester coupable. On invoquait l'intérêt supérieur de la nation. Il ne s'agissait que de dissimuler les défaillances de quelques responsables.

Mais d'autres ont refusé la conspiration de l'injustice. Face à l'adversité, ils ont livré le combat de l'honneur et de la vérité. Et d'abord, bien sûr, Dreyfus lui-même. Issu d'une famille juive profondément ancrée dans la République, polytechnicien, brillamment sorti de l'Ecole de guerre, admis au sein de l'état-major, il accomplit, par son travail et sa compétence, une carrière exemplaire d'officier d'élite de l'armée nouvelle.

Soudain, cet homme est pris dans l'engrenage d'une effroyable erreur judiciaire. Mais il ne se résigne pas : il veut sauver son honneur et l'honneur des siens. Plus que tout, il croit en la France et en la République. 
S'il accepte en 1899 la grâce présidentielle, c'est à la condition de continuer à lutter pour faire reconnaître son innocence. Il se bat pour que son procès soit révisé. Réhabilité, il se rengage pendant la première guerre mondiale et combat vaillamment pour son pays.

La fermeté d'âme, la droiture, le courage d'Alfred Dreyfus forcent l'admiration. Un officier exemplaire qui, dans les plus terribles épreuves, a toujours agi en soldat. Un patriote qui aimait passionnément la France et qui n'a jamais douté d'elle. Un homme aussi, sachons le reconnaître, à qui justice n'a pas été complètement rendue : la mort dans l'âme, faute d'avoir bénéficié de la reconstitution de carrière à laquelle il avait pourtant droit, l'officier a dû quitter l'armée.

C'est pourquoi la nation se devait (...) de lui rendre un hommage solennel. Et puis il y a le lieutenantcolonel Picquart : nommé chef des renseignements militaires, il comprend que Dreyfus n'est pas coupable. Officier loyal, il s'en ouvre à ses chefs. "Si vous ne dites rien, personne ne saura" : voilà la réponse qu'il reçoit. On l'écarte de son poste, on l'envoie en mission dangereuse. Il pourrait se taire. Il choisit de parler. Sa carrière, sa vie même ont failli en être brisées. Mais lui aussi aime l'armée. Il croit en elle : il veut qu'elle soit juste. Ses chefs se refusent à comprendre à quel point le déni de justice fait à Dreyfus est préjudiciable aux intérêts de l'armée, aux intérêts de la France. Picquart remplit son devoir d'honnête homme : son devoir patriotique.

Ces hommes ont créé les conditions du sursaut républicain. Déjà, l'innocence de Dreyfus ne fait plus guère de doute. L'erreur judiciaire qui l'a frappé prend une nouvelle dimension. Commence véritablement l'Affaire : une crise majeure, mais aussi un moment fondateur pour l'enracinement de la République.

Chacun doit choisir son camp. Deux conceptions de l'individu et de la nation s'affrontent. D'un côté, il y a ceux pour qui la raison d'Etat, l'honneur de l'armée doivent prévaloir sur toute autre considération (...). Pour eux, même innocent, Dreyfus doit rester coupable. Tout est bon pour l'abattre et, à travers lui, atteindre une République encore fragile. De l'autre côté, il y a ceux qui combattent au nom du droit fondamental de chaque personne à la justice. Ils considèrent qu'en reconnaissant l'erreur commise (...), la France se grandit. Ces hommes ont des parcours, des croyances, des opinions très différents : Clemenceau, Emile Zola, l'écrivain engagé, et Anatole France, l'académicien au faîte de sa gloire. Léon Blum, le socialiste, et Charles Péguy, le poète catholique. Bernard Lazare, l'anarchiste, et le vice-président du Sénat, Auguste ScheurerKestner. Jaurès, l'éloquence faite homme, et le pur et ardent Lucien Herr, bibliothécaire de l'Ecole normale supérieure. Ce qui les rassemble tous, c'est leur engagement dans l'Affaire. (...) Avec eux, le combat pour Dreyfus devient un combat pour tant de Français. Un combat universel. Un combat pour tous les hommes. Clemenceau l'écrit dans L'Aurore : la République, fondée sur la liberté et la justice, est incompatible avec l'arbitraire et la raison d'État.

La violence des antagonismes nés dans l'Affaire est extrême. Dans un pays où les juifs ont obtenu l'égalité des droits civiques dès 1791, l'antisémitisme se déchaîne, dans les rangs nationalistes, avec une violence inouïe. Pour ou contre Dreyfus, on se bat en duel. (...)

Mais, grâce à la mobilisation des dreyfusards, la voie est enfin ouverte pour la révision. Le 12 juillet 1906, il y a cent ans jour pour jour, la Cour de cassation rend son arrêt. Après avoir conclu, comme vous venez de 
l'entendre, "que de l'accusation portée contre Dreyfus rien ne reste debout", elle annule la décision du conseil de guerre de Rennes. Réhabilitant Dreyfus, elle se place sur le terrain des principes : la Déclaration des droits de l'homme et du citoyen, les règles fondamentales du droit naturel, le primat des droits individuels sur la raison d'Etat.

L'erreur judiciaire (...) a pris une dimension universelle. L'Affaire aurait pu porter un coup fatal à la République : au lieu de cela, non seulement elle a surmonté la crise, mais elle en est sortie plus forte. Plus assurée de sa légitimité et de ses valeurs. Ses piliers y ont trouvé une solidité nouvelle : l'armée, à qui l'on allait demander tant de sacrifices en 1914, s'est ancrée définitivement dans la République.

La justice, avec la Cour de cassation, a démontré son impartialité et son attachement aux droits de l'homme. La presse a su endosser le rôle de contre-pouvoir, si indispensable en démocratie. L'élite de la République, professeurs, savants, écrivains, ceux que depuis lors on appelle les "intellectuels" ont, pour la première fois, exercé ce magistère moral qui marquera le siècle.

La tragédie du capitaine Dreyfus fut un moment de la conscience humaine. Elle continue à résonner fortement dans nos coeurs. Après avoir divisé le pays, elle a contribué à fortifier la République. Elle fut le creuset où finirent de s'élaborer les valeurs humanistes de respect et de tolérance. Des valeurs qui, aujourd'hui encore, constituent notre ciment. La réhabilitation de Dreyfus, c'est la victoire de la République. C'est la victoire de l'unité de la France.

Le refus du racisme et de l'antisémitisme, la défense des droits de l'homme, la primauté de la justice : toutes ces valeurs font (...) partie de notre héritage. Elles peuvent nous sembler acquises. Mais il nous faut être toujours vigilants : le combat contre les forces obscures, l'injustice, l'intolérance et la haine n'est jamais (...) gagné.

Mesdames et Messieurs,

Le 21 juillet 1906, à l'Ecole militaire, Alfred Dreyfus est fait chevalier de la Légion d'honneur. Là encore, une photographie témoigne pour l'histoire : l'officier réhabilité converse avec ses pairs. Sur le visage de ces hommes, il y a de la fierté : on a rendu son honneur volé à un soldat de la République. Aux cris enthousiastes de "Vive Dreyfus !", le capitaine répond avec noblesse : "Non, Messieurs, je vous en prie. Vive la France !" Aujourd'hui, en honorant Dreyfus, Picquart et tant d'hommes d'exception, c'est à la République, et aux valeurs sur lesquelles la France s'est construite, que nous rendons hommage.

Vive la République ! Vive la France !"

Article paru dans l'édition du 13.07.06

http://www.lemonde.fr/web/article/0,1-0,36-794609@45-1,0.html 
Les nouveaux impôts

Article publié le 13 Juillet 2006

Par Marcel Tardy

Source : LE MONDE

Taille de l'article : 223 mots

Extrait : LES IMPÔTS sur les revenus ont déjà été majorés de 10 \% pour le Fonds national de solidarité. Le conseil des ministres, pour couvrir les dépenses d'Algérie, a décidé hier de demander au Parlement un nouveau décime. Ce procédé a l'avantage de la simplicité, mais il ne pouvait manquer de soulever de vives protestations. L'impôt sur les revenus des personnes physiques est celui qui paraît le plus injuste, sinon dans son principe, du moins dans son application. Il n'est payé que par un petit nombre de contribuables honnêtes ou qui n'ont pas la possibilité d'échapper à la vigilance du fisc : notamment gros et moyens salariés, travailleurs intellectuels indépendants, dont les revenus sont déclarés, etc.

http://www.lemonde.fr/cgi-

bin/ACHATS/acheter.cgi?offre=ARCHIVES\&type_item=ART_ARCH_30J\&objet_id=952586 


\title{
Le plus ancien prisonnier de France
}

\author{
LE MONDE | 13.07.06 | 16h00
}

Longtemps, Lucien Léger est resté dans les annales judiciaires pour l'affaire de l'Etrangleur. Puis, au fil des années et de ses treize et vaines demandes de libération conditionnelle formulées depuis 1979, il est devenu "le plus vieux prisonnier de France", emblème du débat et, pour certains, du combat autour des longues peines.

Emprisonné depuis le 5 juillet 1964, condamné à la réclusion criminelle à perpétuité le 7 mai 1966, Lucien Léger était libérable à partir de 1979. Plusieurs arguments ont été avancés pour expliquer le rejet de ses demandes de libération ou de grâce. D'abord le souvenir d'un meurtre d'enfant, et de la terreur qu'ont fait naître les messages signés de l'Etrangleur, dont certains accusaient les parents de Luc Taron, et notamment son père, d'être responsables de la mort de l'enfant.

Le duel entre Lucien Léger et Yves Taron, qui avait commencé dès le début de l'affaire, s'est poursuivi au procès. L'accusé avait affirmé que $\mathrm{M}$. Taron connaissait l'assassin de son fils et le père de la victime avait dû se justifier sur tout : le retard avec lequel il avait signalé la disparition de Luc, la sévérité de son éducation. Yves Taron, lui, était venu aux assises pour réclamer la tête de Léger. Quelques mois après un verdict qui l'avait déçu, il fondait une association de défense de la peine de mort. Puis, après son abolition en 1981, un comité pour son rétablissement. Surtout, il a promis de tuer Léger si celui-ci était libéré.

En 2001, avec la mort d'Yves Taron, cette menace disparaît, mais Lucien Léger, désormais incarcéré à Bapaume (Pas-de-Calais), ne sort pas de prison pour autant. La même année, la cour d'appel de Douai rejette sa treizième demande de libération. La justice lui reproche aussi de continuer à nier le meurtre de Luc Taron, depuis la rétractation de ses aveux, en 1965. Les magistrats de Douai estiment que cette attitude "exclut tout travail psychothérapeutique et empêche de considérer qu'il manifeste des efforts sérieux de réadaptation sociale" (Le Monde du 26 octobre 2001).

Et puis, au bout de vingt, trente, puis quarante années de détention, experts et magistrats s'interrogent chaque fois davantage sur sa capacité, voire sur sa réelle volonté de se réinsérer. Pourtant Lucien Léger a fait des études en prison (droit, philosophie) et, depuis 1984, il a rencontré un boulanger, Lucien Bernhard, prêt à l'accueillir chez lui, à l'aider à retrouver une place dans la société notamment à travers du bénévolat pour la Croix-Rouge. Il est aussi soutenu par des journalistes, des avocats qui assimilent les longues peines à une "peine de mort lente" et par le président d'honneur de la Ligue des droits de l'homme, Michel Tubiana, pour qui "il y a un plafond au-delà duquel la détention n'est plus qu'une vengeance".

Alors, le 31 août 2005, lorsqu'il apprend que sa quatorzième demande de libération a été acceptée mais qu'elle ne sera effective que le 3 octobre suivant, Lucien Léger lance à son avocat : "Je ne suis plus à huit jours près." Il a 68 ans.

Isabelle Talès

Article paru dans l'édition du 14.07.06

http://www.lemonde.fr/web/article/0,1-0,36-795048,0.html 


\section{La "citadelle" sarkozyste s'ouvre aux nouveaux convertis}

LE MONDE | 14.07.06 | 14h36 • Mis à jour le 14.07.06 | 14h36

Un de plus... Le dernier à être tombé dans l'escarcelle de Nicolas Sarkozy est Renaud Donnedieu de Vabres. Le ministre de la culture a fait allégeance au président de l'UMP en le recevant, jeudi 6 juillet, sur ses terres d'Indre-et-Loire : "Cher Nicolas, tu peux compter sur mon énergie, mon enthousiasme et mon engagement dans les batailles qui s'annoncent", a-t-il déclaré.

Le porte-parole du gouvernement avait donné le ton quatre jours plus tôt. Interrogé sur Radio-J, le 2 juillet, Jean-François Copé a laissé entendre qu'il soutiendrait le président de l'UMP dans la perspective de 2007. "Je m'engagerai sans ambiguité pour le candidat soutenu par notre famille politique", a d'abord indiqué le ministre délégué au budget. Avant de dévoiler prudemment ses nouveaux penchants : "A l'heure où je vous parle, le moins qu'on puisse dire est qu'il y a de grandes chances pour que ce soit Nicolas Sarkozy", a relevé M. Copé, en rappelant que Dominique de Villepin avait lui-même déclaré qu'il n'avait "pas d'ambition présidentielle".

Lorsque la composition du gouvernement Villepin fut annoncée, en juin 2005, les rapports de force étaient clairement affichés : placés sous l'autorité du premier ministre, dauphin présumé de Jacques Chirac pour 2007, une pléiade de fidèles du chef de l'Etat étaient invités à encercler la "citadelle" sarkozyste de la place Beauvau. M. Sarkozy, qui n'avait pu "sauver" Patrick Devedjian ni François Fillon lors de la composition du gouvernement, n'avait obtenu que la nomination à ses côtés de deux de ses proches : Brice Hortefeux (collectivités territoriales) et Christian Estrosi (aménagement du territoire). Jalonnant l'effondrement de la popularité de M. de Villepin, l'embrasement des banlieues, la crise du contrat première embauche (CPE), puis l'affaire Clearstream, ont modifié la donne. Au point que la citadelle sarkozyste ne semble plus assiégée que par ceux qui envisagent d'y prendre leur tour de garde.

\section{"M. SARKOZY SERA NOTRE CANDIDAT"}

L'ingratitude n'est pas de mise. Oubliées, les attaques de Jean-Louis Borloo qui, à l'automne 2004, en appelait à une "contre-offensive de la République" face aux "bushistes, adeptes des communautés, du libéralisme et de la religion", et qui estimait que les propositions de M. Sarkozy sur l'immigration n'étaient que "littérature". Le président de l'UMP a volontiers accepté de mettre en scène une souriante réconciliation, devant les caméras de télévision, au plus fort de la crise du CPE. La popularité de M. Sarkozy est le principal paramètre susceptible de faire pencher la balance. Y compris dans les esprits les plus prudents. "Si Nicolas Sarkozy se trouve dans la même situation en janvier 2007, il sera notre candidat", a souligné Michèle Alliot-Marie, le 18 juin sur RTL. La ministre de la défense a toutefois pris soin de rappeler, ultérieurement, qu'elle "n'exclut rien" pour elle-même.

Dans cet inventaire non exhaustif, il convient de ne pas oublier ceux qui briguent une investiture aux élections municipales et qui se doivent de ménager le président de leur parti. C'est le cas de Dominique Perben. Candidat à la mairie de Lyon, le ministre des transports a chaleureusement accueilli M. Sarkozy pour un meeting dans cette ville, le 23 février. "Dans une famille politique comme la nôtre, on peut avoir 
des préférences, on n'a pas le droit d'avoir des adversaires", a, alors, souligné le président de l'UMP. Qui espère bien que cette formule resservira. A son intention, cette fois.

Jean-Baptiste de Montvalon

Article paru dans l'édition du 15.07.06

http://www.lemonde.fr/web/article/0,1-0,36-795538,0.html 


\section{ANEXO D - DEFINIÇÕES DE “APENAS” E “SOMENTE”}

\section{DicionáRios de Português-LAtim}

a) “apenas, 1. adv. somente: solum, tantum, dumtaxat, Cic., tantummodo, Caes., modo, Sal. || apenas discordam num ponto, de re una solum dissident, Cic., || isto requer arte apenas para..., hæc artem dumtaxat requirunt ut (conj.), Cic. \|| pensa apenas em fugir, nihil nisi fugam agitat, Cic. || apenas uma vez, semel, Cic. || apenas por palavras, verbo tenus, Cic. 2. conj. logo que: ubi, ut, simul ac, simul atque, simul ac primum, statim ut, Cic. || apenas me viu, empalideceu, ut me conspexit, deriguit, Cic. || apenas tinha dito isto, quando... hæc dicta dederat, cum... Liv.” (FERREIRA, António Gomes. Dicionário de Português-Latim. Porto: Porto Editora Ltda., 1976, p.98.)

b) “apenas, $a d v$. 1. Dificilmente, com dificuldade, ùnicamente: vix, Cic.; vixdum, Liv.; aegre, Cic.; difficiliter ou difficulter, Cic. 2. Conj. Mal, logo que: simul ac, simul atque, ut, Cic.; vix ou vixdum... cum, Cic.; vix... et ou -que. \| a. me viu, ficou sem pinta de sangue: ut me conspexit, deriguit, Cic. \| a. tinha proferido estas palavras, quando... : hæe dicta dederat cum..., ou sub hæe dicta..., Liv.” (TORRINHA. Dicionário Português-Latino. s.l., 1939, p.97.)

c) "somente, $a d v$. solum, tantum, modo, demum, tantummodo, Cic. \|| governar somente nove meses, solos novem menses praeesse, Cic.” (FERREIRA, António Gomes. Dicionário de Português-Latim. Porto: Porto Editora Ltda., 1976, p.645.)

d) "somente, adv.: solum, modo, tantum, dumtaxat, tantummodo, demum, Cic.; (traduzir pelo adj. solus), Cic. || durante nove meses s.: solos novem menses, Cic. || êste ano s.: hoc demum anno, Liv. (cf. ùnicamente).” (TORRINHA. Dicionário PortuguêsLatino. s.l., 1939, p. ) 


\section{Dicionários MonolíngüEs de Português}

a) “Apenas - Apenasmente não é português; o sufixo mente - o único sufixo adverbial que em português existe - só se acrescenta, para formação de advérbios, aos adjetivos flexionados na forma feminina: bondos(o)a - mente, caprichos(o)a - mente (Gram. Metódica, §527, obs.). Apenas, por ser advérbio, não é possível de acréscimo desse sufixo adverbial.

b) “Apenas - Dizer apenasmente é o mesmo que dizer derrepentemente, ou seja, é dizer tudo menos português.” (ALMEIDA, Napoleão Mendes de. Dicionário de Questões Vernáculas. $3^{\text {a }}$ ed. São Paulo: Ed. Ática S.A., 1996, p.46.)

c) Apenas - não consta (AMARAL, Vasco Botelho de. Dicionário de Dificuldades da Língua Portuguesa. Pôrto: Ed. Educação Nacional, 1938, 2v.)

d) “Apenas - adv. penosamente, com dificuldade: Estava com tanto sono que apenas podia abrir os olhos. | Apenas tem havido púrpura antiga nem moderna que por leves suspeitas neste gênero se não tingisse em sangue. (Vieira, Sermões, II, 37). || Escassamente, levemente; somente: O vento era tão fraco que apenas enrugava a superfície das águas. Apenas levava na algibeira o dinheiro necessário para a jornada. \| (...)” (AULETE, Caldas.

Dicionário Contemporâneo da Língua Portuguesa. $4^{\mathrm{a}}$ ed. Rio de Janeiro: Ed. Delta S.A., 1958, v. 1, p.396.)

e) “APENAS, a custo; adur, aduro; ainda bem não; assim que; com dificuldade; dificilmente, dificultosamente, escassamente, logo; logo que; mal, malavez, misèravelmente, penosamente; pouco mais; quando, quase, simplesmente, só, sòmente; tanto que; ùnicamente. (COSTA, Agenor. Dicionário Geral de Sinônimos e Locuções da Língua Portuguesa. $2^{a}$ ed. Rio de Janeiro: Biblioteca Luso-Brasileira Ltda., 1960, 2v., v.1, p.214.)

f) “Apenas - sin. Ùnicamente, só, sòmente. Mal, penosamente, dificilmente, dificultosamente: Apenas podia mover um braço. Escassamente, levemente.” (FERNANDES, Francisco. Dicionário de Sinônimos e Antônimos da Língua Portuguesa. $10^{\mathrm{a}}$ ed. Porto Alegre: Editora Globo, 1955, p.79.) 
g) “Apenas - De a e penas; esp. apenas, it. appena, fr. à peine. Pena, dificuldade, trabalho (Pacheco e Lameira, Gram. Port., 459). Para João Ribeiro representa uma forma elíptica que o espanhol possui plena: a malas penas, a duras penas aparecem em Cervantes (Gram. Port. 202).” (NASCENTES, Antenor. Dicionário Etimológico da Língua Portuguêsa. $1^{\text {a }}$ ed., $2^{\text {a }}$ tiragem. Rio de Janeiro: 1955, 2 v., v.1, p.37.)

h) “Apenas - adur, dificuldade, dificultosamente, escassamente, logo, mal, malavez, miseravelmente, quando, quase, simplesmente, só, sòmente, ùnicamente.” (Tertúlia Edípica - Sociedade Literária Charadística. Dicionário de Sinónimos da Língua Portuguesa. $3^{\mathrm{a} e d . ~ L i s b o a: ~ E d i t o r a ~ J o a ̃ o ~ F r a n c i s c o ~ L o p e s, ~ s . d ., ~ p .79 .) ~}$

i) “'Somente’ - Não é português, senão francês, o emprego de somente por mas; não devemos construir: 'Você pode ir, somente quero que volte cedo.' Troque-se esse advérbio por mas ou, conforme o caso, por outra legítima conjunção adversativa.” (ALMEIDA, Napoleão Mendes de. Dicionário de Questões Vernáculas. $3^{\mathrm{a}}$ ed. São Paulo: Ed. Ática S.A., 1996, p.531.)

j) “Sòmente, com sentido adversativo, constitue galicismo. Diga-se: mas, porém, todavia, contudo, não obstante, o que é é que, etc.. Em Eça topa-se o uso afrancesado. Os clássicos têm sòmente por excepto.” (AMARAL, Vasco Botelho de. Dicionário de Dificuldades da Língua Portuguesa. Pôrto: Ed. Educação Nacional, 1938, 2v., v.1, p.332.)

k) "Somente - adv. unicamente, exclusivamente, só, apenas; quando muito, tão só (...)" (AUlete, Caldas. Dicionário Contemporâneo da Língua Portuguesa. $4^{\mathrm{a}}$ ed. Rio de Janeiro: Ed. Delta S.A., 1958, v. 5, p.4748.)

l) "sòmente, afora; ainda agora; apenas, exceto, exclusivamente, fora, meramente; não mais; puramente; quando muito; senão; senão quando; só, sol, solamente; tão só; ùnicamente; Tão - : salvante.: (COSTA, Agenor. Dicionário Geral de Sinônimos e Locuções da Língua Portuguesa. $2^{\mathrm{a}}$ ed. Rio de Janeiro: Biblioteca Luso-Brasileira Ltda., 1960, 2v., v.2, p.2135.)

m) “Sòmente - sin. Ùnicamente, exclusivamente; só, apenas.” (FERNANDES, Francisco. Dicionário de Sinônimos e Antônimos da Língua Portuguesa. $10^{\mathrm{a}}$ ed. Porto Alegre: Editora Globo, 1955, p.829.) 
n) Somente - não consta (NASCENTES, Antenor. Dicionário Etimológico da Língua Portuguêsa. $1^{\mathrm{a}}$ ed., $2^{\mathrm{a}}$ tiragem. Rio de Janeiro, s/e, 1955, 2 v.)

o) “Sòmente - afora, apenas, excepto, exclusivamente, meramente, senão, só, sol, solamente, sòmentes.” (Tertúlia Edípica - Sociedade Literária Charadística. Dicionário de Sinónimos da Língua Portuguesa. $3^{\mathrm{a}}$ ed. Lisboa: Editora João Francisco Lopes, s.d., p.910.) 